\title{
EVIDENCE-BASED DESIGN OF WORKPLACE LEARNING
}

Franck T.L. Blokhuis 


\section{Doctoral committee}

$\begin{array}{lll}\text { Chair } & \text { Prof. dr. H.W.A.M. Coonen } & \text { University of Twente } \\ \text { Supervisor } & \text { Prof. dr. W.J. Nijhof } & \text { University of Twente } \\ \text { Referent } & \text { Dr. B.P. Veldkamp } & \text { University of Twente } \\ & & \\ \text { Members } & \text { Prof. dr. J.F.M. Claessen } & \text { Open University } \\ & \begin{array}{l}\text { Prof. dr. A.F.M. Nieuwenhuis } \\ \text { Prof. dr. J. Scheerens }\end{array} & \text { University of Twente } \\ & \text { Prof. dr. P.R.J. Simons } & \text { University of Twente } \\ & \end{array}$

Title

Evidence-based design of workplace learning

University of Twente, Enschede

Print: PrintPartnes Ipskamp - Enschede

Cover design: Evert van de Biezen / Ralf de Bruin

(C) 2006, Franck T.L. Blokhuis \& Leerstoel Curriculumtechnologie voor Beroep en Bedrijf

Universiteit Twente

Faculteit Gedragswetenschappen

Postbus 217

7500 AE Enschede

Telefoon: 0534892262

Dit onderzoek is mogelijk gemaakt met een subsidie van NWO (411-21-306).

No part of this work may be reproduced in any form without the permission in writing of the author

ISBN 90-365-2366-4 


\title{
EVIDENCE-BASED DESIGN OF WORKPLACE LEARNING
}

\author{
PROEFSCHRIFT
}

ter verkrijging van

de graad van doctor aan de Universiteit Twente,

op gezag van de rector magnificus, prof. dr. W.H.M. Zijm,

volgens besluit van het College voor Promoties

in het openbaar te verdedigen

op vrijdag 30 juni 2006 om 15.00 uur

door

Franciscus Thimothimus Lambertus Blokhuis

geboren op 29 april 1963

te Oldenzaal 
Dit proefschrift is goedgekeurd door de promotor prof. dr. W.J. Nijhof 
Voor Saskia, Teun en Veerle 



\section{Voorwoord}

"Durf te dromen", zei iemand die me heel dierbaar is. "Zolang ik jou ken, wil je dit al. Doe het." Het vroeg volharding om die droom in vervulling te laten gaan. $\mathrm{Nu}$ ligt het proefschrift er. Het is de weerslag van ruim vier jaar denken, zoeken, ontwikkelen, ontwerpen en reflecteren.

Als ik op deze plaats in het proefschrift gevoel aan inhoud koppel, overheerst dankbaarheid. Mensen en organisaties boden mij de mogelijkheid om dit onderzoek te doen. Saskia, Teun en Veerle gaven mij de tijd die ik nodig had. Familie en vrienden accepteerden dat ik een tijd minder in 'samen' heb geïnvesteerd. Wim Nijhof en CINOP boden mij de kans te participeren in het onderzoeksprogramma 'Het leerpotentieel van de werkplek' van NWO. Ellen, Nelleke, Willemien en Patricia hebben me veel werk uit hadden genomen. Zij hebben meetinstrumenten ontwikkeld en gegevens verzameld. Peter, Jeroen, Johan, Guido, Appie, Dick en hun roc's hebben me bij de voorbereiding en uitvoering van de pilot geholpen. Hilbrand, Dorothé, Nancy, Debora, Arie en Peter waren mijn contactpersonen binnen de bedrijven die meededen aan het hoofdonderzoek. Mijn (oud) CBB-collega's Derk-Jan, Cindy, Marloes, Bert, Rolinda en Monique hebben meegelezen en meegeleefd. Gay heeft van mijn Engels echt Engels gemaakt. Anouk en Evert hebben de opmaak en vormgeving voor hun rekening genomen. Tom en Rob hebben me in de aanloop naar de afronding terzijde gestaan. De collega's in het onderzoeksprogramma hebben op verschillende momenten hun reactie gegeven op ideeën. Met betrokkenheid en deskundigheid hebben Wim, Bernard en Loek me begeleid op weg naar dit eindresultaat. Aan ieder van jullie: een zeer gemeend dank je wel.

Noodgedwongen blijven de deelnemende studenten, begeleiders en bedrijven op deze plek naamloos. Dat wil niet zeggen dat ze voor mij zonder naam zijn. Aan de meeste van hen heb ik mijn eigen herinneringen. Belangeloos hebben zij deelgenomen. In openheid leverden zij de informatie die nodig was. Ik wil mijn dank aan hen vertalen in zinvolle bijdragen aan leren en werken.

Kijkend naar mijn situatie was leren de afgelopen jaren een van de doelen van werken. Ik heb veel kunnen lezen en mijn deskundigheid op het gebied van werkplekleren kunnen opbouwen. Het uitwerken van een onderzoeksdesign, het 
ontwikkelen van meetinstrumenten, het verzamelen en analyseren van data hebben bijgedragen aan mijn groei als onderzoeker. Niet iedereen heeft de kans om leren en werken zo te combineren. Hoewel het hard werken was, gaf het door zijn continuiteit ook een soort rust die ik zal gaan missen. Het was een bevoorrechte positie.

Uit de vele ervaringen licht ik op deze plek graag nog het opzetten en uitvoeren van de quasi-experimenten die deel uit maakten van dit onderzoek. Dat was uitdagend en boeiend. Het is een design dat weinig gebruikt wordt voor het beroepsonderwijs. En het krijgt niet de kans die het verdient. Gelet op de maatschappelijke waarde van het beroepsonderwijs vragen keuzes en ontwikkelingen om stevige onderbouwingen. De uitkomsten van quasi-experimenten kunnen daarbij helpen.

Gedurende het traject vond ik het zoeken naar de juiste balans een grote opgave. De vraag om te beantwoorden was: hoe doe ik recht aan de verwachtingen en belangen van alle belanghebbenden en betrokkenen? Of ik daarin geslaagd ben, moeten anderen beoordelen. Voor zover nog niet gedaan, geef me bij gelegenheid eens terug of dat is gelukt.

Opleveren van dit proefschrift ervaar ik als een heugelijk moment. Dat deel ik graag met anderen als opmaat voor meer gezellige momenten in de toekomst. Ik prijs me gelukkig het te kunnen vieren met de mensen om mij heen. Degenen die er niet bij kunnen zijn, zal ik missen.

De laatste letter van dit verhaal is geschreven, het laatste woord is er niet over gezegd. Voor nu zet ik er een komma achter. Werkplekleren is een wezenlijk onderdeel van mijn werk geworden. Het bijdragen aan de ontwikkeling van deelnemers in het beroepsonderwijs is de drijfveer in mijn werk gebleven. Mijn gezin is de drijfveer in mijn leven. Sas, Teun en Veerle, dit verhaal draag ik vol liefde op aan jullie.

Franck Blokhuis

's-Hertogenbosch, mei 2006. 


\section{Contents}

Chapter 1 Towards effective workplace learning ..............................1

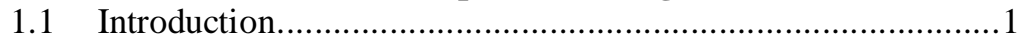

1.2 The Dutch setting .................................................................. 1

1.3 Towards dimensions of workplace learning .............................. 4

1.3.1 Parties involved in workplace learning and their roles .5

1.3.2 Reasons and motives for workplace learning ................6

1.3.3 Sites of workplace learning .......................................

1.3.4 Activities of workplace learning...............................

1.3.5 Outcomes and results of workplace learning............... 9

1.3.6 Dimensions and a definition of workplace learning ... 12

1.4 The necessity of searching for evidence ................................. 13

Chapter 2 A review of workplace learning …..................................15

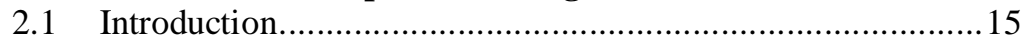

2.2 Selection and analysis of literature ....................................... 15

2.3 Variables influencing workplace learning .............................16

2.3.1 Variables related to student characteristics ................17

2.3.2 Variables related to workplace characteristics ............20

2.3.3 Variables related to vocational education and training

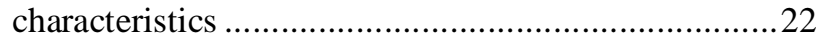

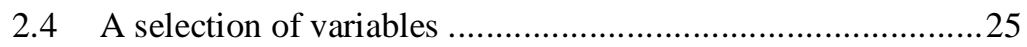

Chapter 3 Designing effective workplace learning …........................35

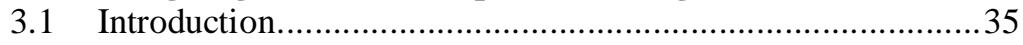

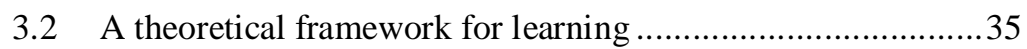

3.3 A theoretical framework for workplace learning .................... 41

3.4 Designing interaction....................................................... 44

3.4.1 An analysis of the context and needs ....................... 45

3.4.2 Specifications for effective, efficient and relevant materials .....................................................................4 47

3.4.3 Development and construction of guidelines for interaction............................................................ 51 
3.4.4 Anticipation of the implementation of the product and processes

3.4.5 Formative and summative evaluation of the product and processes

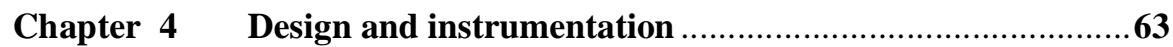

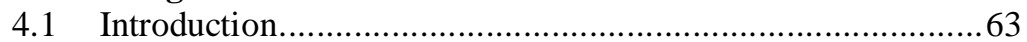

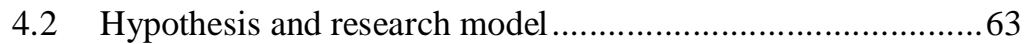

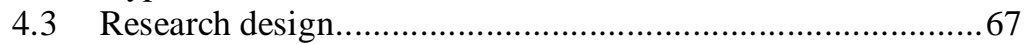

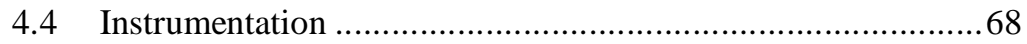

4.4.1 Measurement model for implementation ...................68

4.4.2 Measurement model for effectiveness ........................71

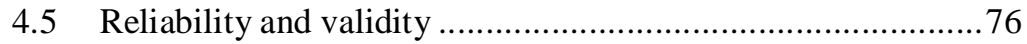

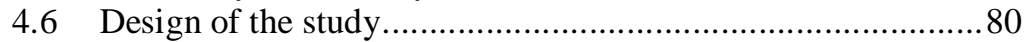

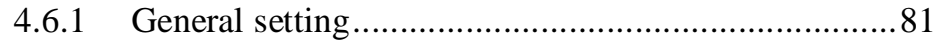

4.6.2 Design of the pilot study ........................................ 82

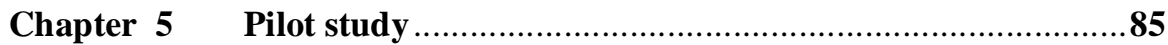

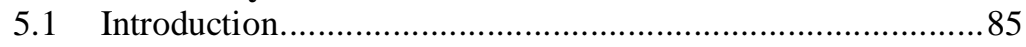

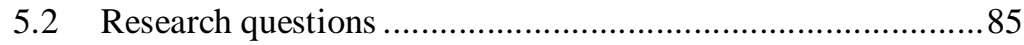

5.3 Student characteristics and workplace characteristics ............87

5.3.1 Results with regard to student characteristics.............87

5.3.2 Results with regard to workplace characteristics........90

5.4 Guidelines for interaction ...............................................93

5.4.1 Results with regard to clarity, usefulness and completeness

5.4.2 Results with regard to the application of the

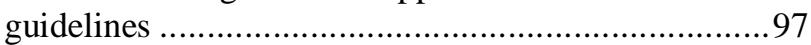

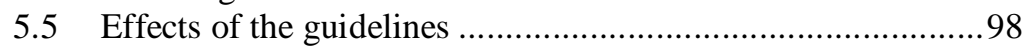

5.6 Conclusions and consequences ........................................100

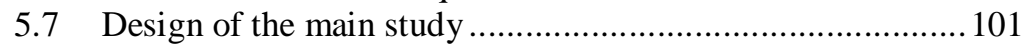

Chapter 6 Workplace learning at a hospital ..................................103

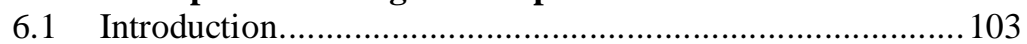

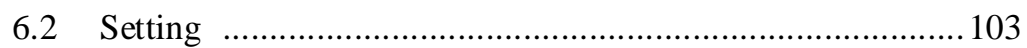

6.3 Method and instrumentation ............................................ 105

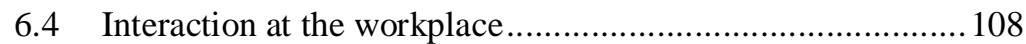

6.5 Use and implementation of the guidelines for interaction ......112

6.6 Mastery of job-relevant competencies............................... 120

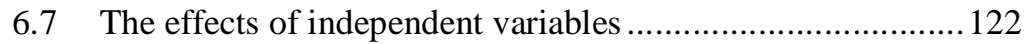

6.7.1 The effect of workplace characteristics.................... 122

6.7.2 The effect of mentor characteristics........................ 124

6.7.3 The effect of student characteristics........................ 126 
6.7.4 The effect of the guidelines for interaction

6.8 Summary and conclusions ................................................ 131

Chapter 7 Workplace learning at a bank...................................133

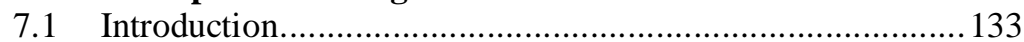

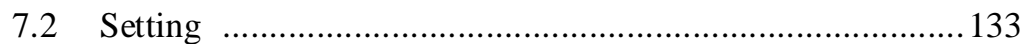

7.3 Method and instrumentation ............................................. 134

7.4 Interaction at the workplace............................................. 138

7.5 Use and implementation of the guidelines for interaction ..... 140

7.6 Mastery of job-relevant competencies.................................. 146

7.7 The effects of independent variables .................................... 147

7.7.1 The effect of workplace characteristics.................... 148

7.7.2 The effect of personal characteristics....................... 149

7.7.3 The effects of interaction processes ......................... 152

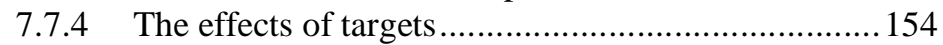

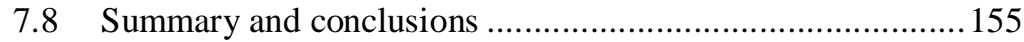

Chapter 8 Workplace learning at an ICT company .......................159

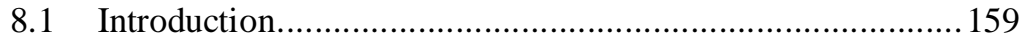

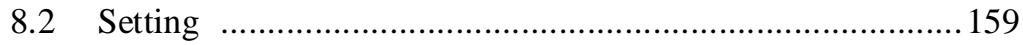

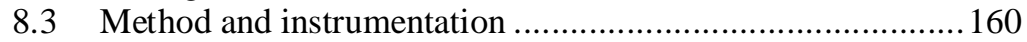

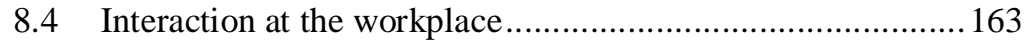

8.5 Use and implementation of the guidelines for interaction ..... 167

8.6 Mastery of job-relevant competencies................................. 173

8.7 The effects of independent variables .................................. 175

8.7.1 The effect of workplace characteristics....................175

8.7.2 The effect of mentor characteristics ........................177

8.7.3 The effect of student characteristics..........................178

8.7.4 The effect of the guidelines for interaction .................180

8.8 Summary and conclusions .............................................. 181

Chapter 9 Conclusions and discussion ….................................183

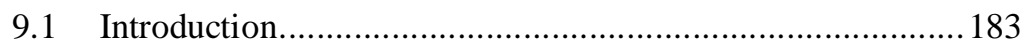

9.2 Findings of the experiments ........................................... 184

9.3 Methodological issues ..................................................... 193

9.4 Implications of the study .................................................. 196

9.4.1 Theoretical implications ...........................................196

9.4.2 Research implications ..........................................196

9.4.3 Practical implications .............................................198

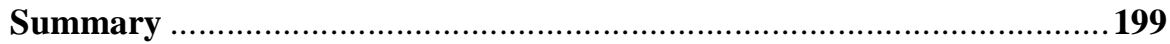

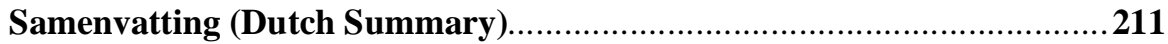




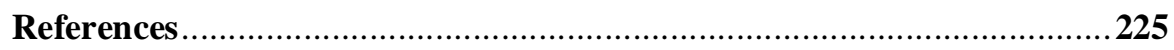

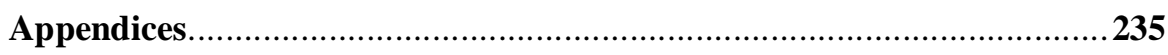

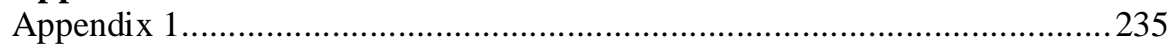

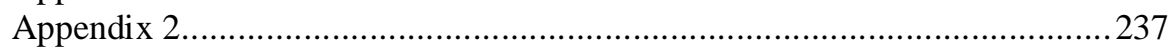

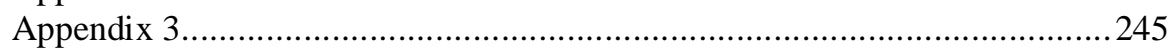

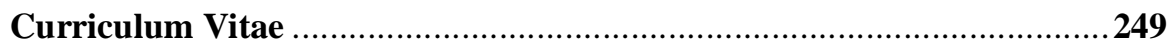




\section{Chapter 1}

\section{Towards effective workplace learning}

\subsection{Introduction}

This study focuses on the effectiveness of workplace learning. Workplace learning is an essential part of every vocational education and training programme in the Netherlands. As in other countries, the workplace is regarded as an environment with great learning potential (Bailey, Hughes, \& Moore, 2004; Billett, 1999), and learning in such an environment is considered indispensable for the development of job-relevant competencies. As a consequence, a substantial amount of training time is spent on workplace learning and its importance is stressed by an act passed by the Dutch government, which states that a diploma is to be awarded to a student only when he has satisfactorily completed the period of workplace learning. Nevertheless, important as it is, workplace learning is also problematic. Studies point to insufficient preparation, interaction and organisation. Improving the quality of workplace learning is considered necessary by all the parties involved. The interesting question is how.

This chapter starts with a short description of workplace learning in the Dutch vocational education and training setting. Next, dimensions of workplace learning are identified, to answer the question of what characteristics workplace learning has. Then, the need for a rational, evidence-based approach to the design of workplace learning is outlined.

\subsection{The Dutch setting}

In 2001, when this study started, the Dutch vocational education and training system numbered some 447,000 students from the age of 16 (Bve-Raad, 2002). Each of them had chosen one of 700 vocational education programmes that were offered by the vocational education and training centres. Both then and now, the programmes are spread over four training levels and two routes. The levels differ in complexity, varying from assistant's training to middle 
management training and specialist education. They also differ in duration, varying from six months to four years. The routes differ in the amount of time spent on workplace learning and the status of the student. In a full-time collegebased route students spend $20 \%-60 \%$ of the training time on workplace learning; in a part-time work-based route at least $60 \%$ of the training time has to be spent on workplace learning. These percentages are laid down in the Adult \& Vocational Education Act of 1995 (Ministerie van Onderwijs, Cultuur en Wetenschappen, 1996). Students in the full-time college-based route carry out their internship in a number of companies. In the part-time work-based route the students are employees who combine part-time education with an apprenticeship in a company.

This means that workplace learning is an essential part of every vocational education and training programme, irrespective of level or route.

The Act not only lays down the amount of time to be spent on workplace learning, it also prescribes the drawing up and signing of a training-employment contract between the student, the vocational education and training centre and the company where workplace learning will take place. This contract specifies a) the period of workplace learning, b) the coaching of the student by the company during that period, and c) the learning aims for that period. The Act also mentions the roles and responsibilities of the parties involved:

- the vocational education and training centres are responsible for drawing up the contract; they also assess whether the learning aims have been achieved;

- the companies have to coach the student;

- the national bodies for vocational training have to ensure a sufficient number of certified companies.

Workplace learning has thus been formalised by an act of parliament. Although the Act mentions four parties, three are directly involved in the learning process: the student, the company and the vocational education and training centre. The fourth party, the national body, contributes indirectly to that learning process and therefore has an indirect responsibility.

The importance of workplace learning is expressed by the statement that a diploma is to be awarded to a student only when he has satisfactorily completed the period of workplace learning. But what do we really know about the effects of workplace learning? 


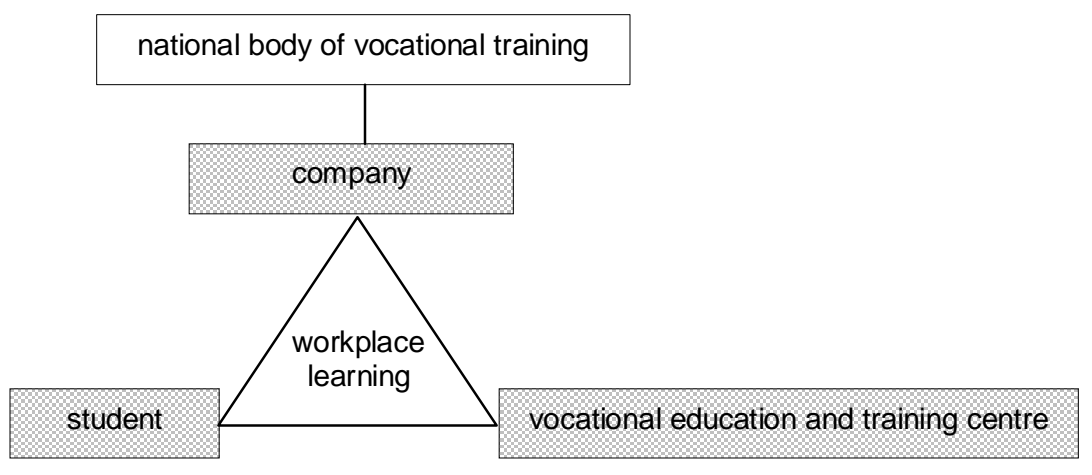

Figure 1.1 Parties involved in workplace learning.

Although important, workplace learning in Dutch vocational education and training is still problematic, as can be seen from several studies that have been conducted (Blokhuis, Jellema \& Nijhof, 2002; JOB, 2001; Stuurgroep Evaluatie WEB, 2001). In general, these studies focus on the satisfaction of the different parties involved regarding workplace learning. One of the studies is a large survey of 57,296 students commissioned by the Association of Young People in Vocational Education (JOB, 2001). This study revealed that, although students in the full-time college-based route believe they learn a great deal at the workplace, the preparation for internships, the assignments that are used and the guidance at school all require improvement. Students in the part-time workbased route, however, are more satisfied regarding workplace learning.

Another study, conducted by an evaluation committee, was commissioned by the Minister of Education, Culture, and Sciences (OC\&W) and the Minister of Agriculture, the Environment, and Fisheries (LNV). This study evaluated the Act; its findings show that workplace learning is problematic (Stuurgroep Evaluatie WEB, 2001). The problems relate to a lack of co-operation between the parties involved, a lack of control and regularisation of workplace learning on the part of the vocational education and training centres, and the inadequate facilities provided by companies for high quality learning opportunities and high quality coaching. In order to solve these problems, the evaluation committee advised focusing attention on communication, the harmonisation of theory and practice, the competencies of practical work supervisors in school and practical instructors in companies.

A third study was conducted, which was commissioned by one of the vocational education and training centres. Blokhuis, Jellema and Nijhof (2002) identified eight problem areas regarding workplace learning. Some important 
problems here concern the lack of co-operation and interaction between the parties involved, the unsatisfactory organisation of the learning process itself (relevance of learning assignments, the programming and harmonising of theory and practice) and a lack of information. In contrast to the findings of the JOB study, the problems are greater for the part-time work-based route.

To improve the quality of workplace learning, it is necessary to solve the problems mentioned. In the Netherlands this aim is endorsed and supported nationwide by all the parties involved: ministries, vocational education and training centres, national bodies for vocational training, organisations of employers and unions, and several umbrella organisations. This implies that they have no doubts about the relevance of workplace learning as part of vocational education and training. Students too subscribe to its relevance, when considering their recognition of the fact that they learn a great deal at the workplace. The question is, however, whether it is possible to improve that quality, in view of the characteristics of the parties participating and possible interventions. At the same time, it is necessary to choose a measure of quality that will enable improvements to be assessed. Because workplace learning is related to realising certain valued learning aims, the quality measure chosen here is effectiveness. The first question to be answered to improve the effectiveness of workplace learning is: What are the characteristics of the concept of workplace learning?

\subsection{Towards dimensions of workplace learning}

There are several theories of learning: behaviourism, cognitivism, action theory, constructivism, meta-cognitive theories, andragogy, ... These theories with different perspectives have proven their value and all have contributed to our knowledge of and insights into learning and instruction (Boekaerts \& Simons, 1993; Reigeluth \& Moore, 1999; Salomon \& Perkins, 1998). At the same time, it seems that there is no complete and consistent theory regarding workplace learning (Billett, 2002; Cheetham \& Chivers, 2001; Cullen, Hadjivassiliou, Hamilton, Kelleher, Sommerlad, \& Stern, 2002; De Jong, 1995; Van der Klink, 1999). For this reason the findings of more general and influential learning theories have been drawn on and applied to workplace learning.

An analysis of literature on workplace learning is necessary to be able to identify theoretical notions of workplace learning, and a decision had to be made on what kind of literature is relevant. Since the focus of this study is related to the Dutch vocational education and training system, Dutch dissertations on that subject seem the most relevant and they also provide international theoretical backgrounds. In view of the status of the parties in the part-time work-based route, dissertations on corporate training would also seem 
to be relevant. In both cases the focus is on employees who combine learning and working. At the same time, this expansion increases the scientific basis of this study. International reviews of workplace learning provide a state-of-the-art overview of the subject. Literature suggested by others studying workplace learning could also provide relevant information. The last category of potentially relevant literature is reviews of learning in general: after all, workplace learning is learning. These reviews can provide additional overall insights to complete the expertise on workplace learning.

This theoretical information has been analysed using questions to track down dimensions of workplace learning and to define workplace learning. The questions are:

- who is involved in workplace learning?

- why is someone learning at the workplace?

- where is workplace learning taking place?

- what is someone doing during workplace learning?

- what is someone learning at the workplace?

- what is workplace learning?

\subsubsection{Parties involved in workplace learning and their roles}

Workplace learning in Dutch vocational education and training involves three parties: the student, the company, and the vocational education and training centre. Each has its own roles and responsibilities, but their common aim is to prepare the student for a career through participating in work processes, for citizenship and for personal development.

In the company the student is trained and coached by a practical instructor. Other employees are involved in the learning process when the student asks them for help or observes them. A manager facilitates that process by assigning a practical instructor to the student and offering the opportunity to practise and to participate in work processes (Holton III, 1996). In the vocational education and training centres teachers help the student to acquire prerequisite knowledge and skills. The practical work supervisor evaluates work experiences with the student and the progress he has made. Exchanging work and learning experiences with peers also takes place at the centre.

In the situation described, the student is the learner. Learning is, however, by definition social (Salomon \& Perkins, 1998), not only an individual matter, and the student is not necessarily the only one who is learning (Bandura, 1986; Gerber, 2001; Marsick \& Watkins, 1990; Poell, 1998; Salomon \& Perkins, 1998). The student is part of a social environment and a social entity (a team, a division, a company). That entity has the possibility to learn. A concept closely related to social learning is communities of practice (Wenger, 1998). This concept stresses the influence of the environment and the 
importance of interaction. Learning is viewed as a process of enculturation and participation in a community of practice, whose members share actions and responsibilities (Wenger, 1998).

Although the student is always involved in learning, this does not necessarily mean that he is in control of the learning process. In instruction, most of the time it is the practical instructor, the practical work supervisor or the teacher who is in control. They select what to do, and when and how to do it. However, it is also possible that the student is in control. In that case learning is labelled as self-directed or self-regulated (Boekaerts, 1997; Knowles, 1975; Noss, 2000; Straka, 2000). Becoming a self-directed learner takes time and requires the help and support of others (Boekaerts, 1997). One concept related to self-directed learning is meta-cognition, meaning knowledge about one's own learning and how to control and improve that learning (Boekaerts \& Simons, 1993; Sternberg, 2001).

All the parties involved are part of the student's learning environment. Such an environment should provide appropriate combinations of challenge and guidance, empowerment and support, self-direction and structure (Reigeluth, 1999). The challenge is to find the ideal combination and to harmonise the activities of all the parties involved.

\subsubsection{Reasons and motives for workplace learning}

Learning is a psychological process, consisting of a beginning, an end and learning activities to perform in between. Regardless of the kind of learning process, a trigger is needed to start it (Bolhuis \& Simons, 1999). Sometimes a student is eager to learn, because he or she wants to acquire new knowledge, new skills, new attitudes or new competencies needed for participating in work processes, for an occupation or career, or the student wants to solve a problem or to improve his or her own actions. In such cases the student is motivated to learn and needs no encouragement to start, although there might be an external cause. In other words, learning is a matter of the student's own choice and free will. It is also possible that the motive to learn at the workplace is quite different. One reason might be to obtain a diploma in order to be able to attend another programme. At least a quarter (29\%) of the students choose another programme (Bve-Raad, 2002). It is also possible that the environment is changing (or intends to change), for instance by introducing new equipment, new labour or learning concepts, or new organisational structures; or the environment wants the student to change. In these cases workplace learning is enforced, which will influence the will to learn.

Not only students have motives for participating in workplace learning, so do companies. Their motives can be roughly divided into three categories: philanthropic motives, individual self-interest and collective interest (Bailey et 
al., 2004). The philanthropic ones are related to the commitment employers feel to the community and their wish to contribute to the general wellbeing. Participation to generate political or economic benefits, to test and recruit potential employees, or to strengthen the relationship with schools are motives that relate to the individual self-interest of companies. Their main collective interest is to overcome the lack of a skilled labour force. The most important motives, however, are the recruitment of entry-level workers and philanthropic goals. If companies do not wish to participate in workplace learning, their main motives are loss of productivity for trainers or mentors, and the students' lack of reliability and maturity. The possibility that students will leave after their period of workplace learning is also considered important.

The challenge with regard to workplace learning is to harmonise the expectations and motives of student, company and school (Kessels, 1996) to prevent disappointment and loss of motivation.

\subsubsection{Sites of workplace learning}

This part might be seen as irrelevant, because posing the question of where workplace learning takes place also provides the answer: at the workplace, of course. However, in vocational education and training, learning not only occurs at the workplace, but also at the vocational education and training centre. These learning processes are supposed to be supplementary. A major problem, however, is how to integrate the student's learning processes at those two learning environments (see Section 1).

One commonly made distinction related to the environment where learning is taking place is learning on the job and learning off the job (Cullen et al., 2002; Frietman, 1990; Jacobs \& Jones, 1995; Van der Klink, 1999). Learning on the job refers to learning that takes place while participating in a work process; learning off the job takes place at a site other than where the work is actually done (Jacobs \& Jones, 1995), for instance at the vocational education and training centre. Learning on the job and learning off the job can be programmed and combined in several ways (Frietman, 1990; Nieuwenhuis, 1991). There are also several models for learning on the job. In traditional apprenticeship the student learns by observing and imitating an expert during his work. In cultural apprenticeship, learning takes place in a community of practice (Wenger, 1998), for instance a team or a company, while sharing experiences with each other. On learning bays and learn stations (Dehnborstel, 1996) intentional learning, experiential learning and working are interwoven. Students from various vocational education and training programmes are responsible for making products and running machines as part of the total work processes within a company. 
With regard to off-the-job learning, there are a number of models possible, depending on their resemblance to and distance from the real workplace. Learning in a classroom is a model of off-the-job learning. It is seen as particularly useful for acquiring the theoretical knowledge necessary for participating in a work process (Boreham, 2002; Fischer \& Rauner, 2002). In simulated work situations the tasks and activities the student has to perform resemble those of a real work situation. It is, however, possible to control the pace of the activities and it allows mistakes to be made here that might otherwise cause serious damage. The interaction between colleagues that takes place at a workplace can be simulated when there are several students working together. Off-the-job models help to alleviate the pressures of the immediate work setting (Jacobs \& Jones, 1995), which enhances the opportunity to reflect on work and learning. On the other hand, there is a need for transferring what has been learned to the real work processes and work situations. This proves to be problematic if not properly guided and supported by the three parties involved (see Section 1).

Although workplace learning is a potentially powerful way of learning (Boekaerts \& Simons, 1993), it is sometimes necessary to combine on-the-job learning with off-the-job learning, for the reasons mentioned. Dehnborstel (1996) carried out several experiments with combinations of on-the-job and offthe-job learning. These combinations aim at using the strengths of learning in different locations and at different periods in a vocational educational and training programme.

\subsubsection{Activities of workplace learning}

Learning is a process that consists of a number of interacting activities. A complete learning process (Simons, Bolhuis, \& Onstenk, 2000) consists of: a) formulating one's aims, b) orientating to the learning possibilities and mobilising prerequisite knowledge, c) performing learning activities, which can be divided into gaining experience, interacting with others, processing abstract information such as language and symbols, and reflecting, d) evaluating whether aims have been reached, and e) regulating the process. Judging by the learning activities described by others (Kolb, 1984; Onstenk, Moerkamp, Voncken \& Van den Dool, 1990), regulating the learning process, preparing for learning, conducting the activities and processing what has been learned seem to be common and relevant activities in learning processes.

The notion of a complete learning process might suggest a kind of universal process, independent of the characteristics and preferences of the student. Studies of learning styles (Hermanussen, De Jong, Wierstra \& Thijssen, 2000; Kolb, 1984; Slaats, 1999; Vermunt, 1992) have, however, shown that individuals differ in the way they learn. A learning style is a composition of 
learning activities, orientation towards learning and the mental model of learning that an individual possesses (Vermunt, 1992), and is a relatively stable preference, independent of learning aims (Boekaerts \& Simons, 1993).

Although research has shown the existence of different learning styles among students in vocational education and training (Hermanussen et al., 2000; Slaats, 1999), the greatest merit of that research is that it indicates that students learn in different ways (Cheetham \& Chivers, 2001). It has proven, however, to be difficult to realise effective learning by harmonising instructional strategies and specific aptitudes. These so-called aptitude-treatment interactions, ATI (Cronbach \& Snow, 1977), are common in education, but they are complex and difficult to demonstrate clearly (Snow, 1989); they are influenced by task and situation. No particular ATI effect is sufficiently understood to form the basis for instructional practice. One exception is the finding that highly structured treatments (high level of external control, well-defined sequences/components) seem to help students with low ability, but hinder those with high abilities. ATI research has also failed to pay attention to the social aspects of learning, which is considered a serious deficiency.

The challenge is to find a way to settle differences in learning in situations where the focus is in the first place on producing and on delivering services according to the requirements of the company, not on learning. Perhaps matching styles and workplace characteristics will provide a suitable solution.

\subsubsection{Outcomes and results of workplace learning}

Workplace learning as part of vocational education and training is aimed at realising certain learning aims specified in the training-employment contract. These aims direct the activities conducted by the student, the practical instructor and the practical work supervisor. A lot happens, however, during participation in work situations. The student tries to fit into a team, which means that socialising takes place, although this is not always an explicit aim. At the same time, the student has to adjust his knowledge, skills and attitudes to conduct tasks the way the company is used to. It is also possible that the student is asked to assist colleagues in performing unknown activities, because of the pressure of work and an extra pair of extra hands is needed at that moment, or something unexpected happens during work.

This means that what someone is learning, and when, is not always predictable or guided by explicit learning aims. It expresses the difference between planned learning (formal, non-formal, intentional) and non-planned learning (informal, incidental) (Boekaerts \& Simons, 1993; Bolhuis \& Simons, 1999; Eraut, 2000; Garrick, 1998; Gerber, 2001; Harris \& Simons, 2001; Marsick \& Volpe, 1999; Marsick \& Watkins, 1990; Straka, 2001; Teurlings \& Van der Sanden, 1999). These kinds of learning are seen as valuable and 
potentially powerful. The outcomes of non-planned learning are varied. From their perspective of informal learning, Eraut, Maillardet, Miller, Steadman, Ali, Blackman, et al (2004) argue that what is required for informal workplace learning to take place is a broad and flexible approach to representing the outcomes of learning. They developed a typology for workplace learning that consists of several categories: task performance, role performance, awareness and understanding, personal development, teamwork, academic knowledge and skills, decision-making and problem-solving, and judgement (Eraut et al., 2004). According to Straka (2004), informal learning is "a metaphor with a serious problem, namely the lack of systematically and empirically grounded valid evidence on why, where, when, how and what is learned under "informal conditions'." (Straka, 2004).

Whether planned or non-planned, learning is not always a process someone is aware of (Bolhuis \& Simons, 1999; Eraut, 2000). Implicit learning is a concept that refers to less conscious or unconscious learning and is therefore not planned. In the case of implicit learning, the student is not guided by learning aims; it occurs during acting and participating. Because the student is not aware of the learning process taking place, it is hard to express its results. These results are often labelled as tacit knowledge and tacit skills and are seen as valuable, because they account for differences in performance and flexibility.

The challenge is to make what someone is learning as visible as possible, to reveal the true potential of the workplace as a learning environment.

Over the years several classifications of learning outcomes have been developed (Bloom, 1956; De Block, 1975; Reigeluth, 1999; Toolsema, 2003; Van Merriënboer \& Van Dijk, 1998). These tools are used to describe and arrange what learning outcomes are being pursued related to different domains and different mastery levels, and they have a different range (Van Merriënboer, Van der Klink \& Hendriks, 2002). It is also possible to use classifications to identify what learning has actually occurred. This is particularly useful when someone is initially unaware of the learning that has taken place and develops tacit knowledge or tacit skills (Eraut, 2000). Although helpful, these classifications are sometimes criticised for the pragmatic and non-excluding nature of the categories involved.

Looking at Dutch national curricula for vocational education and training, the aims were expressed in terms of acquiring and/or applying/using knowledge, skills and/or attitudes. These aims were derived from occupational profiles that were validated and accepted by organisations of employers and unions. What the student has to learn at the workplace is laid down in the training-employment contract. These aims are drawn from the national curriculum the student is following. The vocational education and training 
centre assesses whether the student has reached the learning aims, possibly in consultation with the practical instructor.

In 2002 an innovation in the Dutch vocational education and training system started that has as its aim the development and implementation of competency-based education and training. Learning aims have to be stated as competencies that focus on handling situations at the workplace. The concept of competency consists of six characteristics (Van Merriënboer et al., 2002):

- competencies are related to specific contexts;

- competencies are a cluster of skills, knowledge, attitudes, personality characteristics and insights;

- competencies can change over time;

- competencies are related to activities/tasks;

- learning and development are necessary for acquiring competencies;

- competencies relate to each other.

One of the sources used for identifying these characteristics is the conceptual clarification of the concept of competence, as described by Weinert (2001). In view of the enormous number of existing definitions, Weinert talks about conceptual inflation. Theory does not supply sufficient empirical-based insight to reach a valid, all-comprising definition. He therefore provides five building blocks relevant to a pragmatic definition:

- competence indicates prerequisites for the successful performance of complex tasks;

- the concept of competence should be used when the prerequisites contain cognitive, motivational, ethical and social components;

- the concept of competence implies complexity;

- learning processes are a necessary condition for the acquisition of the prerequisites;

- key competences and meta-competences should be conceptually divided: key competences refer to learning to master various tasks; metacompetences refer to declarative or procedural knowledge about one's own competences.

It is questionable whether the innovation of competency-based education and training will bridge the gap between the two metaphors of learning (Sfard, 1998): the acquisition metaphor and the participation metaphor. Considering the past and current situation in vocational education and training, the focus is on acquiring knowledge, skills and attitudes. Looking at the other metaphor, it is also important to learn to be a part of a community of practice and to develop one's own identity. At the same time, the aim of developing an identity provides an opportunity to learn how to deal with uncertainty (Den Boer \& Nieuwenhuis, 2002). This aim requires the student to play a more active role in choosing or formulating learning aims. It is possible to formulate these aims in terms of 
certain kinds of learning, such as adaptive, mastery, adjusting, creative or developmental learning (Ellström, 2002; Svensson \& Kjellberg, 2001). Nonetheless, in vocational education and training, learning aims will guide learning, irrespective of type.

The challenge is to choose the right learning aims that are realisable at the workplace.

\subsubsection{Dimensions and a definition of workplace learning}

When looking at the answers to the questions posed at the beginning of this section, several dimensions of workplace learning can be distinguished.

The answer to the question of who is involved in learning provides two dimensions. The first dimension refers to the entity that is learning. Although there is always an individual who is learning, it is also possible that the group, the team or some other social entity that the student is part of is able to learn. The second dimension refers to control. In the case of self-regulated learning, the student is in control. In other cases, someone else (a practical instructor, a practical work supervisor and/or a teacher) selects learning aims, provides instruction, and/or assesses the results. These two opposite kinds of control are labelled as internal and external control.

The answer to the question of why someone is learning provides another dimension. A trigger or motive is needed to start a learning process. This motive is internal if the student has found or formulated his own valuable learning aims; it is external if the environment generates the learning aims.

The answer to the question of where someone is learning provides the dimension of the learning environment. Although learning environments are sometimes associated with locations (for instance on the job and off the job) instead of social systems (Koper, 2000), this dimension is intended to reveal whether a learning environment is designed for learning or not. A designed learning environment is expected to be more powerful than an environment that is not deliberately so designed, although learning occurs irrespective of environment.

The answer to the question of what someone is doing during learning refers to the dimension of the learning process. The existence of different learning styles emphasises the necessity to view learning as a process that differs between students, considering the way they learn or prefer to learn, making it a unique process. However, the description of a complete learning process reveals some kind of universal character that is applicable to every student.

The answer to the question of when someone is learning provides another two dimensions. Sometimes learning is a process that is planned; at other times it is not. These two opposites can be referred to as the status of the 
learning process. Whether planned or non-planned, learning is not always a process of which someone is aware. Awareness is thus another dimension.

The final question of what someone is learning provides the dimension of the learning aim. Two metaphors (Sfard, 1998) have been mentioned that can be used to express the different paradigms of learning, including learning aims. The focus of the acquisition metaphor is on individual enrichment and acquiring knowledge, skills, attitudes, competencies, ... The focus of the participation metaphor is on community building and becoming a student.

Thus, in total, eight dimensions are identified. These should be used to characterise different kinds of workplace learning and to design this process.

\begin{tabular}{llr}
\hline Dimension & \\
\hline Entity: & Individual & Social \\
Control: & Internal & External \\
Motive: & Internal & External \\
Learning environment: & Not designed & Designed \\
Learning process: & Generic & Unique \\
Status: & Not planned & Planned \\
Awareness: & Unaware & Aware \\
Aim: & Acquisition & Participation \\
& & \\
\hline
\end{tabular}

Figure 1.2 Dimensions of workplace learning.

The answers can also be used to define the concept of workplace learning. In general, workplace learning can be defined as a multiform, influenceable, individual and social process of development, which occurs by means of participation in work processes and has as its aim understanding, handling and influencing work situations.

\subsection{The necessity of searching for evidence}

This chapter started with a description of the Dutch setting with regard to workplace learning in vocational education and training. It was concluded that this kind of learning is an essential part of every programme. Existing problems show the necessity of improving its quality and effectiveness. This aim is endorsed by all the parties involved in vocational education and training. The assumption and expectation is that workplace learning is powerful and contributes substantially to the student's development of competencies needed to handle situations at the workplace adequately. It is questionable whether this 
optimistic view is realistic. Opponents of the debate on workplace learning stress its orientation to the productivity of the workplace: learning is only a side effect of work activities. They are critical of the actual learning potential of the workplace in the current situation.

The review of theoretical notions of workplace learning, which was the next part of this chapter, showed the diversity of dimensions that are part of the concept of workplace learning. Within this diversity, authors sometimes even have contradictory or conflicting ideas about one aspect of workplace learning, as was the case, for instance with informal learning. To be able to discuss the relevance of this kind of learning and to contribute to further insights, it is necessary to make more explicit both one's point of view and the position one is taking. The dimensions can be used for this purpose. The theoretical notions might foster expectations about workplace learning. They do not, however, provide the convincing evidence needed to justify the importance workplace learning has gained in current vocational education and training. The evidence must come from empirical studies that focus on the processes and outcomes of workplace learning. Unfortunately, these studies have been rather scarce - at least until the end of the previous century (Cullen et al, 2002; De Jong, 1995; Van der Klink, 1999). Empirical data available, however, provide a suitable starting point for answering the question of what variables have actually been shown to influence workplace learning. These variables should be used for further improvement of the effectiveness of workplace learning. The next chapter therefore presents a review that aims at answering this question. 


\section{Chapter 2}

\section{A review of workplace learning}

\subsection{Introduction}

The previous chapter dealt with theoretical notions of workplace learning. Dimensions were identified to answer the question of what characteristics workplace learning has. It ended with the need for a rational, evidence-based approach to the design of workplace learning and the conclusion that there is a need to improve the quality of workplace learning. This chapter focuses on the question of what variables influence workplace learning, starting with a description of the method used for searching and analysing relevant literature. Next, empirical studies were analysed and variables mentioned and described that have been shown to influence the effectiveness of workplace learning. The chapter ends with an overview of the variables that must be taken into account for designing effective workplace learning.

\subsection{Selection and analysis of literature}

Several decisions and steps were necessary to be able to answer the question of what variables influence workplace learning. One decision to be made was what kind of literature is relevant. Since the main focus of this study is on workplace learning in Dutch vocational education and training, Dutch dissertations on that subject are relevant. Most of these studies provide not only theoretical backgrounds but also empirical evidence. In view of the existence of the parttime work-based route, dissertations on corporate training also seem to be relevant. In both cases, the focus is on employees who combine learning and working. At the same time, this expansion increases the scientific basis for the model to be developed and the design principles to be chosen. International reviews of workplace learning provide a state-of-the-art overview of the subject. A related category of potential relevant literature is reviews of learning in general. After all, workplace learning is learning of a special kind. These reviews can provide additional overall insights to complete the expertise on 
workplace learning. Finally, articles about workplace learning that describe empirical studies were considered relevant.

The next decision to be made was how to analyse the literature. The empirical information was analysed in two steps; the first being to characterise the information of each study, using a standardised framework. Each study was characterised on the basis of eight categories:

- the name of the author(s) and year of publication;

- the research design used;

- the sample, including the kinds and numbers of respondents (students or employees) or cases;

- the data-gathering instruments;

- the sources of information;

- the learning environments;

- the dependent variables;

- the independent variables.

The second step was to provide an overview of independent variables and their relation to learning outcomes. In view of the parties directly involved in workplace learning, the variables were linked to students, companies and vocational education and training institutes, including the characteristics of the programmes. The results of the first step were reorganised into a more sober framework that was expected to facilitate the first selection of potentially relevant variables. This framework consisted of four categories:

- the party involved: student, company or institute;

- the independent variable involved;

- the dependent variable that is influenced;

- the studies that mention the relation between the independent and dependent variable.

The third and final step was to use studies that provide strong evidence of influence. These studies had to contain the findings of statistical analyses, such as path, regression or correlation analyses.

\subsection{Variables influencing workplace learning}

In total, 42 studies, consisting of international reviews, Dutch dissertations and articles, were selected and analysed (see appendix 1). The studies analysed revealed a great number of variables, which were grouped on the basis of familiarity to provide a better overview. The variables that were found are presented and described according to the three parties that are directly involved in workplace learning in Dutch vocational education and training. This classification of variables has also been used in other studies that have 
contributed to the understanding of the effectiveness of training programmes (Baldwin \& Ford, 1988; Van der Klink, 1999).

As the focus of this study is on effectiveness, the variables needed to be related to certain kinds of learning aims. The dependent variables were classified according to an adapted model of learning outcomes of training (Kirkpatrick, 1987). The original model, consisting of four categories, has been criticised over the years (Alliger \& Janak, 1989; Alliger, Tannenbaum, Bennet, Traver \& Shotland, 1997). One of Kirkpatrick's four categories - reaction - has therefore been omitted, on the basis of these criticisms. The other three categories (learning, behaviour and results) were used, because they have been shown still to be relevant (Alliger et al., 1997; Van der Klink, 1999). Learning refers to acquiring knowledge, skills, attitudes or competencies that the student needs for handling situations at the workplace. Behaviour refers to applying acquired knowledge, skills, attitudes or competencies while handling situations at the workplace. Results refer to realising organisational aims and improving the functioning of the company or one's own functioning as an experienced employee. Although this last category is irrelevant, in view of the current aims of vocational education and training, it could be relevant, judging from studies of corporate training. The three categories can be seen as three related stages in a long-term learning process and they cover the great diversity of specific learning aims that are mentioned in the studies analysed. None of the studies, however, includes all three categories.

\subsubsection{Variables related to student characteristics}

The studies analysed revealed 38 variables that relate to student characteristics. These variables were divided into six groups.

The first group consists of variables referring to the student's attitudes. Attitudes are seen as 'positive, neutral, or negative response to or evaluations about of a referent, usually represented as position (pro or con) and intensity (strong to weak), and they may or may not result in action' (Martin \& Reigeluth, 1999). The attitudes found in the studies refer to the motive for students to learn and to their motivation. Variables referring to motive are the students' intention, ambition and needs. Dedication can be seen as a kind of motivation, whereas perception of relevance is a precondition for motivation. Although the individual variables referring to motive are not often mentioned in the studies analysed, if combined they become a more influential variable, considering the number of studies and, more importantly, their influence on the learning aims. Motivation has also been shown to influence both learning aims, and it seems to be a variable that cannot be omitted in a model to explain and predict the effectiveness of workplace learning. 
Table 2.1 Student characteristics influencing workplace learning

\begin{tabular}{|c|c|c|c|c|}
\hline Group & Variables & $\begin{array}{l}\text { Influences } \\
\text { acquisition }\end{array}$ & $\begin{array}{l}\text { Influences } \\
\text { application }\end{array}$ & $\begin{array}{l}\text { Studies } \\
\text { (see appendix 1) }\end{array}$ \\
\hline \multirow[t]{7}{*}{ Attitudes } & Learning attitude & $\mathrm{X}$ & - & $2-15$ \\
\hline & Intention & - & $X$ & $11-15-22$ \\
\hline & Ambitions & $X$ & $X$ & 36 \\
\hline & Needs & - & $x$ & 15 \\
\hline & Dedication & $X$ & - & 2 \\
\hline & Perception of relevance & $X$ & $X$ & $13-24-40$ \\
\hline & Motivation & $X$ & $X$ & $\begin{array}{l}1-3-6-13-15-17-19-21-24-25- \\
32-33-36-37-38-39-41\end{array}$ \\
\hline \multirow[t]{10}{*}{ Skills } & Ability/capacity/competencies & $X$ & - & $1-3-15-20-24-33$ \\
\hline & $\begin{array}{l}\text { Kinds of learning/learning } \\
\text { strategies }\end{array}$ & $X$ & - & $1-13-29-31$ \\
\hline & Meta-cognitive learning & $x$ & $\mathrm{X}$ & $8-15-14-23-34-41$ \\
\hline & Learning by doing & - & $\mathrm{X}$ & 23 \\
\hline & Transformative learning & $X$ & - & 8 \\
\hline & Reflection & $X$ & $\mathrm{X}$ & $5-6-14-23-34-42$ \\
\hline & Self-assessment & - & $X$ & 34 \\
\hline & Self-regulation & $\mathrm{X}$ & $X$ & $8-19-23-24-25-30-27-31-35-36$ \\
\hline & Goal-setting & $X$ & $X$ & 40 \\
\hline & Control & - & $x$ & 41 \\
\hline \multirow[t]{3}{*}{ Knowledge } & Knowledge of training & $X$ & - & $2-15$ \\
\hline & Prior knowledge & $X$ & $X$ & $19-21-27$ \\
\hline & Understanding & - & $X$ & $27-40$ \\
\hline \multirow[t]{10}{*}{ Personality } & Self-efficacy & $X$ & $x$ & $13-15-22-33-42$ \\
\hline & Self-confidence & $X$ & $\mathrm{X}$ & $24-36-39$ \\
\hline & Locus of control & $X$ & $\mathrm{X}$ & $11-33$ \\
\hline & Independence & $X$ & - & $2-10$ \\
\hline & Anxiety & $X$ & - & $21-33$ \\
\hline & Persistence & - & $x$ & 32 \\
\hline & Conscientiousness & $X$ & - & 33 \\
\hline & Valence & $X$ & - & 33 \\
\hline & Initiative & $X$ & $x$ & 36 \\
\hline & Learning style & $X$ & - & $15-19-24-25-28$ \\
\hline \multirow{3}{*}{$\begin{array}{l}\text { Part of a } \\
\text { social } \\
\text { entity }\end{array}$} & (Job) involvement & $X$ & $X$ & 13-15-24-33 \\
\hline & Co-operation & $X$ & $X$ & $6-20-24-36$ \\
\hline & Communication & $X$ & $X$ & 39 \\
\hline \multirow[t]{5}{*}{ Input } & $\begin{array}{l}\text { Previous education and } \\
\text { behaviour }\end{array}$ & $X$ & $X$ & $7-11-13-21-24-25-40$ \\
\hline & Experience & $X$ & $\mathrm{X}$ & $10-13-16-21-24-27$ \\
\hline & Age & $X$ & - & $21-24-33$ \\
\hline & Gender & $X$ & $\mathrm{X}$ & $21-24-25$ \\
\hline & Intelligence & $X$ & - & $21-25$ \\
\hline
\end{tabular}

$\mathrm{X} \quad$ variable influences the outcome

variable is not mentioned in the study with regard to the outcome measures or does not influence them 
The second group consists of variables referring to the student's meta-cognitive skills. Skills are seen as 'abilities that are based on aptitudes, relevant knowledge and practice for competent performance' (Martin \& Reigeluth, 1999). The first two variables refer to skills in general. These variables do not reveal the kinds of skills that influence learning and are therefore less useful. The other variables found in the studies refer to elements of the learning process. It seems that being in control is important with regard to workplace learning, in view of the number of studies that have shown its influence. Variables such as self-regulation, self-assessment, control, goal-setting and meta-cognitive learning refer to or are related to the process of self-regulation. Reflection is another variable that has been shown to influence the realisation of the two learning aims.

The third group consists of variables referring to the student's knowledge. Knowledge is seen as 'understanding and information related to a dimension' (Martin \& Reigeluth, 1999). The kinds of knowledge mentioned refer to knowledge of the programme itself and the prior knowledge and understanding that the student brings to the programme. A solid knowledge base has been shown to influence the aim of acquisition, whereas understanding influences the aim of application positively. Knowledge of training might be seen as a variable that influences workplace learning indirectly, because it is expected to influence the expectations and therefore the motivation of the student.

The fourth group consists of variables that refer to the student's traits as part of his or her personality. Most of these traits influence the learning aim of acquiring knowledge, skills, attitudes or competencies. Some of them also influence the learning aim of applying these. Self-efficacy and self-confidence are two closely related variables that are mentioned in several studies; they refer to the confidence that students have in their own ability. The opposite of confidence is anxiety, which influences learning results. Other variables are mentioned in just one or two studies. Although not combined or related in the studies analysed, some of these variables might be influencing variables in other groups. For instance, locus of control, independence and initiative might influence self-regulation.

Although several studies focus on the existence and validation of the different learning styles that the student has, only one study proved that learning styles have an effect on the learning aim of acquiring knowledge, skills, attitudes or competencies (Slaats, 1999).

The fifth group refers to the student as part of a social entity and consists of three variables. Job involvement, co-operation with and communication between the members of that entity influence both learning aims positively. 
This underlines the relevance of these variables and therefore the relevance of participation.

The sixth and last group consists of variables that are used as control variables in the studies that were reviewed. They refer to previous education, experience, age, gender and intelligence. The influence of these variables is ambiguous.

Table 2.1 provides an overview of the studies that mention the influence of a variable on the acquisition and/or application of knowledge, skills, attitudes or competencies. The number of studies that mention this influence is a first indicator of the potential relevance of that variable for the design of effective workplace learning. In the case of student characteristics, this concerns motivation, reflection, self-regulation, prior knowledge and experience, selfefficacy, learning style and participation. These variables influence acquisition as well as application, and are mentioned in at least four studies.

\subsubsection{Variables related to workplace characteristics}

The studies that were analysed revealed 26 variables that relate to the workplace characteristics of the companies. These variables were divided into five groups.

The first group consists of variables referring to the attitudes of practical instructors, colleagues and/or managers. The variables refer to the social norms of the persons mentioned, their perception of relevance regarding learning and what is learned, and their support of the student in learning and applying what is learned. Although not studied in combination, it is possible that relevance and support are related variables, assuming that there is support for something that is seen as relevant.

The second group consists of variables referring to the skills of the practical instructor (although these variables might also be seen as relevant if someone else contributes to the student's learning process). Most of these skills somehow refer to the communication between the practical instructor and the student: coaching, guiding/steering, providing feedback and advising. These variables have been shown to influence the learning aim of acquiring knowledge, skills, attitudes or competencies. Providing feedback and advising also have effects on the learning aim of applying these. 
Table 2.2 Workplace characteristics influencing workplace learning

\begin{tabular}{|c|c|c|c|c|}
\hline Group & Variables & $\begin{array}{l}\text { Influences } \\
\text { acquisition }\end{array}$ & $\begin{array}{l}\text { Influences } \\
\text { application }\end{array}$ & $\begin{array}{l}\text { Studies } \\
\text { (see appendix 1) }\end{array}$ \\
\hline Attitudes & $\begin{array}{l}\text { Social norms } \\
\text { Relevance } \\
\text { Support }\end{array}$ & $\begin{array}{l}- \\
X \\
X\end{array}$ & $\begin{array}{l}X \\
X \\
X\end{array}$ & $\begin{array}{l}11-22 \\
13-15-40 \\
3-11-13-20-22-24-29- \\
32-36-40-41\end{array}$ \\
\hline Skills & $\begin{array}{l}\text { Coaching } \\
\text { Guidance } \\
\text { Feedback } \\
\text { Advising } \\
\text { Regulation }\end{array}$ & $\begin{array}{l}X \\
X \\
X \\
X \\
X\end{array}$ & $\begin{array}{l}- \\
- \\
X \\
X \\
-\end{array}$ & $\begin{array}{l}1-2-3 \\
10 \\
4-9-13-15-24-36-40 \\
36 \\
8\end{array}$ \\
\hline $\begin{array}{l}\text { Workplace } \\
\text { conditions }\end{array}$ & $\begin{array}{l}\text { Situations/conditions } \\
\text { Learning potential of } \\
\text { tasks } \\
\text { Task level } \\
\text { Autonomy } \\
\text { Variation } \\
\text { Opportunity to } \\
\text { learn/use } \\
\text { Pressure of work } \\
\text { Time available } \\
\text { Productivity }\end{array}$ & $\begin{array}{l}- \\
- \\
X \\
X\end{array}$ & $\begin{array}{l}X \\
X \\
X \\
- \\
- \\
X \\
X \\
X \\
-\end{array}$ & $\begin{array}{l}30-31 \\
30 \\
30 \\
20 \\
2-5 \\
3-9-13-22-24-30-32-38- \\
40-41 \\
24 \\
1-9-10-13-22-23 \\
10\end{array}$ \\
\hline $\begin{array}{l}\text { Part of a } \\
\text { social entity }\end{array}$ & $\begin{array}{l}\text { Involvement } \\
\text { Co-operation } \\
\text { Participation } \\
\text { Communication } \\
\text { Behaviour }\end{array}$ & $\begin{array}{l}X \\
X \\
X \\
- \\
X\end{array}$ & $\begin{array}{l}X \\
X \\
X \\
X \\
X\end{array}$ & $\begin{array}{l}13-15-16-20-40 \\
6-20 \\
5-20-42 \\
30-35 \\
24-30-39\end{array}$ \\
\hline Input & $\begin{array}{l}\text { Size and structure } \\
\text { Climate/culture } \\
\text { Level of innovation } \\
\text { Policy }\end{array}$ & $\begin{array}{l}- \\
X \\
- \\
-\end{array}$ & $\begin{array}{l}- \\
X \\
-\end{array}$ & $\begin{array}{l}26 \\
26-33-36-40 \\
26 \\
24\end{array}$ \\
\hline $\mathrm{va}$ & ces the outcom & & & $\mathrm{m}$ \\
\hline
\end{tabular}

The third and largest group consists of variables referring to workplace conditions. Some of these variables are related to the learning potential of the tasks and activities that have to be performed (level of the tasks, autonomy and variation). Autonomy, however, does not seem to have a direct effect on the learning aims. An important variable seems to be the opportunity to learn and to use what is learned, in view of the number of studies that refer to this variable. Other variables, such as pressure of work, time available, and productivity, all somehow refer to that same opportunity. 
The fourth group refers to the possibilities that are offered by the company to participate. Job involvement, co-operation, participation and communication influence the learning aims of acquiring and applying knowledge, skills, attitudes or competencies positively. This underlines the relevance of these variables and therefore the relevance of participation.

The last group refers to some characteristics of the organisation, and consists of variables that are seen as given or used for control. Only the climate or culture of the organisation, however, influences both learning aims. The other variables (size and structure, level of innovation and policy) have not been shown to influence these aims, although policy might affect the opportunity to learn and to use what is learned.

Table 2.2 provides an overview of the studies that mention the influence of a variable on the acquisition and/or application of knowledge, skills, attitudes or competencies. The number of studies that mention this influence is a first indicator of the potential relevance of that variable for the design of effective workplace learning. In the case of workplace characteristics, this concerns support, feedback, opportunity to learn or to use, time available, involvement, and climate or culture. These variables influence acquisition as well as application, and are mentioned in at least four studies.

\subsubsection{Variables related to vocational education and training characteristics}

The studies that were analysed revealed 32 variables that relate to the vocational education and training institute and the vocational education and training programmes. These variables were divided into nine groups, some of which were derived from a pedagogical model for learning and instruction (De Corte, Geerligs, Lagerweij, Peters \& Vandenberghe, 1981): preparation, content, instructional methods, grouping and assessment/evaluation.

The first group consists of just one variable that refers to the attitudes of mentors or teachers: their perception of relevance of workplace learning and what is to be learned. This attitude influences both learning aims.

The second group consists of variables that refer to the mentor's skills. Most of these skills refer to the communication between the mentor or the teacher and the student, in the form of cognitive apprenticeship tools like coaching, guiding/steering, providing feedback, modelling, scaffolding, articulation and explanation. These variables have been shown to influence the learning aim of acquiring knowledge, skills, attitudes or competencies. Coaching, feedback, modelling and scaffolding have effects on the learning aim of applying these. 
The most important variables seem to be coaching and feedback as part of it, considering the number of studies.

The third group consists of variables that refer to preparing students for workplace learning. It seems relevant to prepare the students well by providing a preview and clear goals. It might be expected that these variables would influence the students' expectations and therefore their motivation. The relevance of these variables is obvious for acquiring knowledge, skills and attitudes, or for becoming competent.

The fourth group consists of variables that refer to the content and the way the content is organised. In some studies the relevance of content is mentioned. However, it is not clear what kind of content is meant. Other studies reveal the influence of "real" content, which resembles work and work situations. This kind of content has an effect on both learning aims. The sequence of the content is also relevant. Although the kind of sequence is not mentioned explicitly, it seems that increasing complexity is intended.

The fifth group consists of variables that refer to instructional methods. Allowing the student to practise and the amount of time available for learning are closely related and seem to be influential, in view of the number of studies referring to these variables. Providing variation is another one that seems to be of relevance. These three variables influence the learning aims of acquiring and applying knowledge, skill, attitudes or competencies.

The sixth group consists of three variables that refer to characteristics within groups of students. Co-operation and competition within groups seem to be relevant learning activities. At the same time, allowance should be made for differentiation between and within groups. Being part of a group is also related to participation.

As with the first group, the seventh group consists of just one variable. It seems, however, to be an important one. Ongoing assessment of progress using multiple sources is recommended. At the same time, persons involved in workplace learning should be aware of the influence assessments and evaluations have on learning itself. 
Table 2.3 Vocational education and training characteristics influencing workplace learning

\begin{tabular}{|c|c|c|c|c|}
\hline Group & Variables & $\begin{array}{l}\text { Influences } \\
\text { acquisition }\end{array}$ & $\begin{array}{l}\text { Influences } \\
\text { application }\end{array}$ & $\begin{array}{l}\text { Studies } \\
\text { (see appendix 1) }\end{array}$ \\
\hline Attitudes & Perception of relevance & $x$ & $\mathrm{X}$ & $15-26-40$ \\
\hline Skills & $\begin{array}{l}\text { Coaching } \\
\text { Feedback } \\
\text { External regulation } \\
\text { Guidance/steering } \\
\text { Modelling } \\
\text { Scaffolding } \\
\text { Articulation } \\
\text { Explanation }\end{array}$ & $\begin{array}{l}X \\
X \\
X \\
X \\
X \\
X \\
X \\
X\end{array}$ & $\begin{array}{l}X \\
X \\
- \\
- \\
X \\
X \\
- \\
-\end{array}$ & $\begin{array}{l}1-2-5-6-19-24-29-36-41 \\
4-9-13-15-24-27-41 \\
8 \\
10 \\
6-29 \\
6-19-41 \\
6-24 \\
9\end{array}$ \\
\hline Preparation & $\begin{array}{l}\text { Preparation/preview } \\
\text { Orientation } \\
\text { Clear goals }\end{array}$ & $\begin{array}{l}X \\
X \\
X\end{array}$ & $\begin{array}{l}X \\
- \\
-\end{array}$ & $\begin{array}{l}2-41 \\
10 \\
9-16\end{array}$ \\
\hline $\begin{array}{l}\text { Learning } \\
\text { content }\end{array}$ & $\begin{array}{l}\text { Content } \\
\text { Reality of content } \\
\text { Situated learning } \\
\text { Sequencing }\end{array}$ & $\begin{array}{l}X \\
X \\
X \\
X\end{array}$ & $\begin{array}{l}X \\
X \\
- \\
x\end{array}$ & $\begin{array}{l}3-6-24 \\
1-2-10-16-30-40 \\
6 \\
3-6-9-21-29\end{array}$ \\
\hline $\begin{array}{l}\text { Instructional } \\
\text { method }\end{array}$ & $\begin{array}{l}\text { Principles of learning } \\
\text { Advance organisers } \\
\text { Examples } \\
\text { Practice } \\
\text { Time / duration } \\
\text { Variation }\end{array}$ & $\begin{array}{l}- \\
- \\
- \\
X \\
X \\
X\end{array}$ & $\begin{array}{l}X \\
X \\
X \\
X \\
X \\
X\end{array}$ & $\begin{array}{l}3 \\
41 \\
27 \\
19-32-41 \\
1-9-10-13-22-24-25-27 \\
2-5-16-32-40\end{array}$ \\
\hline Grouping & $\begin{array}{l}\text { Grouping } \\
\text { Co-operation } \\
\text { Competition }\end{array}$ & $\begin{array}{l}X \\
X \\
X\end{array}$ & $\begin{array}{l}- \\
X \\
-\end{array}$ & $\begin{array}{l}9-11 \\
9-20-24 \\
9\end{array}$ \\
\hline $\begin{array}{l}\text { Assessment } \\
\text { / evaluation }\end{array}$ & Assessment / evaluation & $x$ & $\mathrm{X}$ & $9-24-26-27-34-36$ \\
\hline Tools & Guidelines for teachers & $X$ & - & 16 \\
\hline Input & $\begin{array}{l}\text { Practical experience } \\
\text { Sector } \\
\text { Innovation } \\
\text { Policy and expectations }\end{array}$ & $\begin{array}{l}X \\
X \\
- \\
X\end{array}$ & $\begin{array}{l}- \\
- \\
-\end{array}$ & $\begin{array}{l}16 \\
25 \\
29 \\
9\end{array}$ \\
\hline $\begin{array}{l}\text { var } \\
\text { var } \\
\text { infl }\end{array}$ & $\begin{array}{l}\text { influences the outcome } \\
\text { is not mentioned in the } \\
\text { them }\end{array}$ & $w i$ & $\mathrm{t}$ & neas \\
\hline
\end{tabular}


The eighth group also consists of one variable: the availability of guidelines for the teachers. This variable influences the learning aim of acquiring the knowledge, skills, attitudes and competencies needed for handling situations at the workplace.

The last group consists of four different variables. These are used for control, and refer to the characteristics of the teacher or mentor, the programme and the vocational education and education centre. The studies show that a) teachers in successful programmes have practical experience, judging by the content of that programme, b) realising learning aims differs per sector of vocational education and training institutes, and c) the kind of innovation in a vocational education and training institute has an effect on the learning aims, as do the policy and expectations of a centre.

Table 2.3 provides an overview of the studies that mention the influence of a variable on the acquisition and/or application of knowledge, skills, attitudes or competencies. The number of studies that mention this influence is a first indicator of the potential relevance of that variable for the design of effective workplace learning. In the case of vocational education and training characteristics, this concerns coaching/feedback, reality of content, sequencing, time/duration, variation and assessment. These variables influence acquisition as well as application, and are mentioned in at least four studies.

\subsection{A selection of variables}

It is clear that studies of the effectiveness of workplace learning, although not impressive in number when compared to conceptual and theoretical publications (Cullen et al., 2002; De Jong, 1995; Van der Klink, 1999), do expose a great number of variables that influence learning. This conclusion seems to support the scepticism of some that it is not possible to designate variables, because of their multitude and diversity (O'Connor, 1998), or because everything correlates with everything else (Sternberg, 2001). Others conclude that one universal model for workplace learning does not exist (Boud \& Garrick, 1999; Moerkamp, De Bruijn, Van der Kuip, Onstenk \& Voncken, 2000; Mulder, 1997). The analysis conducted showed, however, the relevance of three major categories of variables: student characteristics, the workplace characteristics of the companies, and the characteristics of the vocational education and training institutes and programmes. Empirical studies show that the characteristics of the institutes and programmes are less influential with regard to the effectiveness of learning than are the other two categories (Bosker \& Scheerens, 1989; De Vries, 1988; De Vries \& Meijer, 1983; Meijer \& Lucassen, 1986; Van der Klink, 1999). Collins, Brown and Newman (1989) try to explain this conclusion. 
According to them, transferring the elements of one context or culture (education) to another (workplace) is difficult and problematic, on account of their distinctive characteristics. This does not mean, however, that these educational variables do not influence learning (Bransford, Brown \& Cocking, 2000; Collins et al., 1989; Creemers, 1992). At the same time, the number of variables shows the complexity of workplace learning. To design a manageable model for enhancing the effectiveness of workplace learning, the most influential variables have to be selected. The relevance of this choice and the dilemma involved is illustrated by a statement by Paul Valery (see Weinert, 2001): everything simple is theoretically false; everything complicated is pragmatically useless.

The analysis of the previous section revealed a number of variables that are potentially interesting for designing effective workplace learning. All these variables have been shown to be influential with regard to both acquisition and application in at least four studies. Although relevant, an even more important criterion for selection is empirical evidence of the power of the variables. For that reason, studies were selected that provide data about the power of variables on the basis of path, regression and correlation analyses. Appendix 2 presents an overview of the empirical findings of several studies that were also included in the first phase of the selection process. Four studies were chosen to provide a starting point for selection. These studies sought to demonstrate convincingly the influence of variables by using path or regression analyses. They do, however, partly overlap with regard to the variables that were included, which means that the findings of these studies might provide stronger evidence.

A highly relevant study is that by Colquitt, LePine and Noe (2000), who conducted a meta-analytic path analysis based on more than one hundred studies. The aim of this analysis was to develop a theory of training motivation, and it convincingly revealed the influences of student characteristics such as locus of control, conscientiousness and anxiety on job performance. Motivation and self-efficacy were also designated as influential and therefore relevant variables.

An explorative study of individual and organisational learning conducted by Van Woerkom (2003) convincingly showed the reciprocal relation between critically reflective work behaviour, participation and selfefficacy of employees. The study also showed the influence of several other workplace characteristics.

The results of the case study conducted by Gielen (1995) showed the causal relation between participation (although she labels this as job involvement) and opportunity to perform on the one hand and job performance on the other. The case study also revealed causal relations between self-efficacy on the one hand and opportunity to perform and participation on the other. The 
study by Van der Klink (1999) built on the study by Gielen and is relevant to see whether Gielen's findings were also obtained and confirmed. That study was therefore also examined more closely.

Table 2.4, 2.5 and 2.6 provide an overview of the variables that are considered relevant for designing effective workplace learning. To show the relevance of variables, it was decided to include not only studies that provided convincing empirical data but also supporting studies that mentioned their relevance without presenting such data. The intention here being to underline the importance of the selected variables as much as possible. Most of the variables were included in at least one of the four studies mentioned.

Table 2.4 Influential variables: student characteristics

\begin{tabular}{|c|c|c|}
\hline \multicolumn{3}{|c|}{ Student characteristics } \\
\hline Variable & Empirical evidence & Supporting sources \\
\hline Motivation & $\begin{array}{l}\text { Kulik \& Kulik, 1988; Colquitt et } \\
\text { al., 2000; Van der Waals, } \\
\text { 2001; Geertshuis et al., } 2002 .\end{array}$ & $\begin{array}{l}\text { Baldwin \& Ford, 1988; Collins et } \\
\text { al., 1989; Tannenbaum \& Yukl, } \\
\text { 1992. }\end{array}$ \\
\hline Experience & $\begin{array}{l}\text { Nieuwenhuis, 1991; Gielen, } \\
\text { 1995; Mulder 1997; Van der } \\
\text { Klink, 1999; Van Woerkom, } \\
\text { 2003. }\end{array}$ & $\begin{array}{l}\text { Kessels, 1996; Bransford et al, } \\
2000 .\end{array}$ \\
\hline Self-efficacy & $\begin{array}{l}\text { Van der Klink, 1999; Colquitt } \\
\text { et al, 2000; Geertshuis et al., } \\
2002 .\end{array}$ & Tannenbaum \& Yukl, 1992; \\
\hline Locus of control & $\begin{array}{l}\text { Van der Klink, 1999; Colquitt } \\
\text { et al., } 2000 .\end{array}$ & \\
\hline Prior knowledge & Mulder, 1997 & $\begin{array}{l}\text { Boekaerts, 1997; Bransford et al., } \\
\text { 2000; Fischer \& Rauner, 2002; } \\
\text { Janssen-Noordman \& Van } \\
\text { Merriënboer, } 2002 .\end{array}$ \\
\hline Anxiety & $\begin{array}{l}\text { Mulder, 1997; Colquitt et al., } \\
2000 .\end{array}$ & \\
\hline Conscientiousness & Colquitt et al., 2000. & \\
\hline Learning style & $\begin{array}{l}\text { Slaats, 1999; Hermanussen et } \\
\text { al., 2000; Geertshuis et al., } \\
2002 .\end{array}$ & Boekaerts, 1997. \\
\hline
\end{tabular}


Table 2.5 Influential variables: workplace characteristics

\begin{tabular}{|c|c|c|}
\hline \multicolumn{3}{|c|}{ Workplace characteristics } \\
\hline Variable & Empirical evidence & Supporting sources \\
\hline Participation & $\begin{array}{l}\text { Gielen,1995; Van Woerkom, } \\
2003\end{array}$ & $\begin{array}{l}\text { De Vries \& Meijer, 1983; } \\
\text { Onstenk et al., 1990; Billettt, } \\
2002 .\end{array}$ \\
\hline Opportunity to use & $\begin{array}{l}\text { Gielen, 1995; Hoekstra, 1998; } \\
\text { Van der Klink, } 1999 .\end{array}$ & $\begin{array}{l}\text { Baldwin \& Ford, 1988; } \\
\text { Creemers, 1991; Noss, 2000; } \\
\text { Cheetham \& Chivers, 2001; } \\
\text { Cullen et al., 2002; Limm \& } \\
\text { Johnson, 2002; Russ-Eft, } 2002 .\end{array}$ \\
\hline Communication & $\begin{array}{l}\text { Meijer \& Lucassen, 1986; Gielen, } \\
\text { 1995; Mulder, 1997; Van der } \\
\text { Klink, 1999; Geertshuis et al., } \\
\text { 2002; Van Woerkom, 2003. }\end{array}$ & $\begin{array}{l}\text { De Vries \& Meijer, 1983; } \\
\text { Baldwin \& Ford, } 1988 \text {; Collins } \\
\text { et al., 1989; Creemers, 1991; } \\
\text { Tannenbaum \& Yukl, 1992; } \\
\text { Bransford et al., 2000, Billettt, } \\
\text { 2002; Russ-Eft, 2002. }\end{array}$ \\
\hline Support & $\begin{array}{l}\text { Den Ouden, 1992; Gielen, 1995; } \\
\text { Mulder, 1997; Hoekstra, 1998; } \\
\text { Van der Klink, 1999; Van der } \\
\text { Waals, 2001. }\end{array}$ & $\begin{array}{l}\text { Billettt, 2002; Janssen- } \\
\text { Noordman \& Van Merriënboer, } \\
\text { 2002; Limm \& Johnson, 2002; } \\
\text { Russ-Eft, } 2002 .\end{array}$ \\
\hline Variation & $\begin{array}{l}\text { Meijer \& Lucassen, 1986; Van } \\
\text { Woerkom, } 2003 .\end{array}$ & $\begin{array}{l}\text { De Vries \& Meijer, 1983; } \\
\text { Baldwin \& Ford, 1988; Collins et } \\
\text { al., 1989; Janssen-Noordman \& } \\
\text { Van Merriënboer, } 2002 .\end{array}$ \\
\hline $\begin{array}{l}\text { Pressure of work/ } \\
\text { work load }\end{array}$ & $\begin{array}{l}\text { Van der Klink, 1999; Limm \& } \\
\text { Johnson, 2002; Van Woerkom, } \\
2003 .\end{array}$ & $\begin{array}{l}\text { De Vries \& Meijer, 1983; } \\
\text { Creemers, 1991; Bransford et } \\
\text { al., 2000, Billettt, 2002; Russ- } \\
\text { Eft, } 2002\end{array}$ \\
\hline Task obscurity & Van Woerkom, 2003. & \\
\hline Task autonomy & Van Woerkom, 2003. & \\
\hline Task information & Van Woerkom, 2003. & \\
\hline
\end{tabular}


Table 2.6 Influential variables: vocational education and training characteristics

\begin{tabular}{|c|c|c|}
\hline \multirow[b]{2}{*}{ Variable } & \multicolumn{2}{|c|}{ Vocational education and training characteristics } \\
\hline & Empirical evidence & Supporting sources \\
\hline Relevance & $\begin{array}{l}\text { Meijer \& Lucassen, 1986; Gielen, } \\
\text { 1995; Van der Klink, } 1999 .\end{array}$ & $\begin{array}{l}\text { De Vries \& Meijer, 1983; Noss, } \\
2000 .\end{array}$ \\
\hline Sequence & $\begin{array}{l}\text { Mulder, 1997; Geertshuis et al., } \\
2002 .\end{array}$ & $\begin{array}{l}\text { Lodewijks, 1981; Collins et al., } \\
\text { 1989; Creemers, 1991; } \\
\text { Janssen-Noordman \& Van } \\
\text { Merriënboer, } 2002 .\end{array}$ \\
\hline Preparation & Meijer \& Lucassen, 1986. & $\begin{array}{l}\text { Russ-Eft, 2002, Boshuizen, } \\
2003 .\end{array}$ \\
\hline Consistency & Kessels, 1996 & Tannenbaum \& Yukl, 1992. \\
\hline
\end{tabular}

In the case of student characteristics, motivation to learn, self-efficacy, previous experience and prior knowledge all influence the acquiring and applying of competencies. Intrinsically and highly motivated students are expected to acquire and apply competencies more effectively than do students who are less motivated or more extrinsically motivated. The intrinsically and highly motivated students strive towards aims that they consider relevant and worthwhile. However, if necessary, strategies based on raising interest, demonstrating relevance, developing confidence and providing reinforcement offer strategies for motivating students to learn (Keller, 1983). Motivation, in turn, influences self-efficacy: the belief a student has in his or her own abilities to achieve a desired result or aim (Bandura, 1997; Van Woerkom, 2003). This belief is considered to have a strong impact on behaviour related to change. Previous experience and prior knowledge influence effectiveness, seeing that they provide a reference for learning and acting. However, it should be taken into account that experience and prior knowledge can also be counterproductive, if they provide an inappropriate framework. At the same time, the kind and amount of experience and prior knowledge determines the strategy to develop the mental models necessary to acquire and apply competencies (Janssen-Noordman \& Van Merriënboer, 2002).

More stable personal characteristics that refer to the student's personality, like locus of control, anxiety and conscientiousness, as well as the learning style a student prefers, have also proven their influence, although this seems to be restricted to the process of acquiring competencies. Of the personality characteristics mentioned, only anxiety has a negative effect on motivation and on acquiring competencies. Conscientiousness and internal 
locus of control contribute to effectiveness, because these influence confidence in one's own ability to learn (Colquitt et al., 2000). A learning style is a combination of preferred learning modes (Kolb, 1985). Studies have revealed the existence of several learning styles. How these different styles influence effectiveness is hard to discern, since the kinds of learning styles differ in studies, or this is not mentioned explicitly.

When it comes to the dimensions of workplace learning, the student's motive to learn should be considered a relevant student characteristic, although this was not taken into account in the empirical studies analysed. It might be expected to influence motivation and learning results, depending on the consistency between the motives and the prescribed learning aims. This should not be confused with motivation. Students can be more or less motivated; motives do not fluctuate, they change.

In the case of workplace characteristics, participation, the opportunity to perform and to use what is learned, communication, support, variation and pressure of work all influence the acquiring and applying of competencies. Participation, however, is the only one that also contributes to improving one's own functioning and that of the company. The priority given to learning is expected to influence only the acquiring of competencies. From the perspective of workplace learning, most of these characteristics are considered relatively stable, since they refer to the organisational climate (Van Woerkom, 2003).

Participation is expected to influence effectiveness, since it provides the opportunity to perform and to really experience what is required to carry out the activities at the workplace well. At the same time, it is expected to enhance motivation, as it makes a student feel a valued member of the labour organisation and because the activities conducted are real and relevant and therefore truly matter. There is, however, only an indirect causal relation between motivation and participation. Perhaps this relationship should be considered reciprocal, just as the findings of Van Woerkom (2003) showed some interactive relations, meaning that the variables influenced each other. Participation too provides the opportunity for communication between student and employees. For a student, participation is a gradual process that shifts from peripheral to full participation, which includes taking part in planning, decisionmaking and policy-making.

It is clear that the opportunity to perform influences effectiveness, especially with regard to applying what is learned. The explanation is as short as it is simple: without opportunity there can be no applying.

Communication is a crucial element of the learning processes: there can be no learning without interaction between a student and his or her environment. This variable cannot therefore be omitted because the environment for acquiring and applying competencies is the workplace. This includes explaining why and how activities are conducted and providing feedback on performance, 
preferably as soon as possible. However, if there is enough time to communicate and the activities to be conducted are non-routine, asking questions is preferred to providing explanations (Janssen-Noordman \& Van Merriënboer, 2002). Communication also includes exchanging experiences, which indicates the dual character of communication. At the same time, explaining by the student and providing feedback to employees is expected to be valuable as well, since it helps the student to verbalise his or her own knowledge, skills and experience. It therefore provides learning opportunities for employees, if they are willing to accept this from the student. Communication should preferably therefore be interactive.

Learning is a process which includes the development and change of mental models and behaviour. Support has been shown to reinforce this process and it thus influences effectiveness in a positive way. At the workplace support can be provided in different ways and by different persons. First, the approval of the managers and employees for a student to participate in a work process as part of a learning process. This approval implies making mistakes, and working at his or her own pace. Second, providing help while a student is conducting activities or solving problems. This does not necessarily mean explaining or demonstrating how to do something, but asking questions, providing information or showing trust. Depending on the student's progress, support will be more or less frequent or intense. Because the student's learning process has autonomous performance as its aim, support should decline with time. In instructional theories this process of providing decreasing support is labelled as scaffolding and fading, and has also proven its positive influence on learning.

Variation in work situations contributes to the effectiveness of workplace learning, if it is not overdone. It supports the development of both mental models and the repertoire for handling situations. Whether job rotation, a well-known way of providing variation, is suitable depends on the competencies a students has to acquire and apply. If a job provides the opportunity to learn all the required competencies, it is not necessary to rotate. Broad jobs in general provide more variation than do narrow ones. In view of the kinds of activities, variation is considered necessary only if these are non-routine activities. These kinds of activities require a rich acting repertoire. Routines are performed in just one way, thus making alternatives unnecessary.

If work process knowledge is regarded as a relevant learning aim, participating in other parts of the labour organisation is considered necessary. It gives a student a clear view of how work in different sections is linked.

Learning takes time. Where there is a heavy workload or the pressure of work is great, time for learning at the workplace is considered limited. The consequence is stress if an employee or a student has limited possibilities to control his or her own work (Oeij, Dhondt \& Wiezer, 2003), and stress is considered counterproductive to learning. Moreover, if time is limited, another 
kind of learning process is expected to occur: adapted learning, instead of innovative or creative learning (Ellström, 2001).

Task obscurity, task autonomy and task information are variables that explicitly refer to the characteristics of the task and the task environment. These variables are expected to influence the stage of applying competencies. Task obscurity refers to the extent to which it is clear what is expected from the employees or student. This has several effects on other variables: if expectations are not clear, this provides an employee or a student with the opportunity to discover his or her own way of conducting activities. It seems, however, to have a negative impact on self-efficacy. Task autonomy refers to the control someone has. From the model of Karasek and Theorell (1990) it emerges that a high level of control, combined with a high level of task demands, provides strong learning possibilities. Task information refers to the extent to which information is provided on results and performance. In accordance with instructional theories, clear expectations of goals and criteria contribute positively to learning results (Creemers, 1991).

The last category of independent variables concerns the vocational education and training characteristics. Five variables are expected to influence the effectiveness of workplace learning. The relevance of the learning tasks in the programme is expected to be high if they are realistic and in accordance with what is needed and carried out at the workplace. This contributes to the student's motivation and to transfer, and thus to acquiring and applying competencies. The sequence of the learning tasks, the preparation of the student for what is expected of him or her, the ongoing assessment of progress, the consistency between content and didactics but, most of all, the consistency in expectations of the parties directly involved in the learning process, all contribute to the acquiring of competencies. Looking at the sequence, it is important that the tasks to be conducted gradually become more and more complex. A student should, however, have some autonomy in choosing his or her sequence, hence the sequence should not be totally fixed. The preparation is aimed at providing a student with realistic and clear expectations. It also contributes to the activation of the right mental models needed for conducting the learning tasks. Assessment is the only chosen variable that is not supported by empirical evidence in the studies analysed. However, it might be expected to influence the effectiveness of the learning process if it functions as a basis for selecting new and suitable learning activities, depending on the phase of development. Consistency, finally, has proven to be a highly relevant variable, especially in the case of what is called external consistency. This refers to the extent to which student, teacher and practical instructor share the same expectations about what should be done and where and how this should be done. 
Figure 2.7 presents a model that shows the variables that have been shown to influence workplace learning. The next question that needs to be answered is how to use the findings of the review presented in this chapter for increasing the effectiveness of workplace learning. The next chapter focuses on the design of an intervention that aims at increasing effectiveness through realising high quality interaction. This intervention is in part based on the variables selected in this chapter.

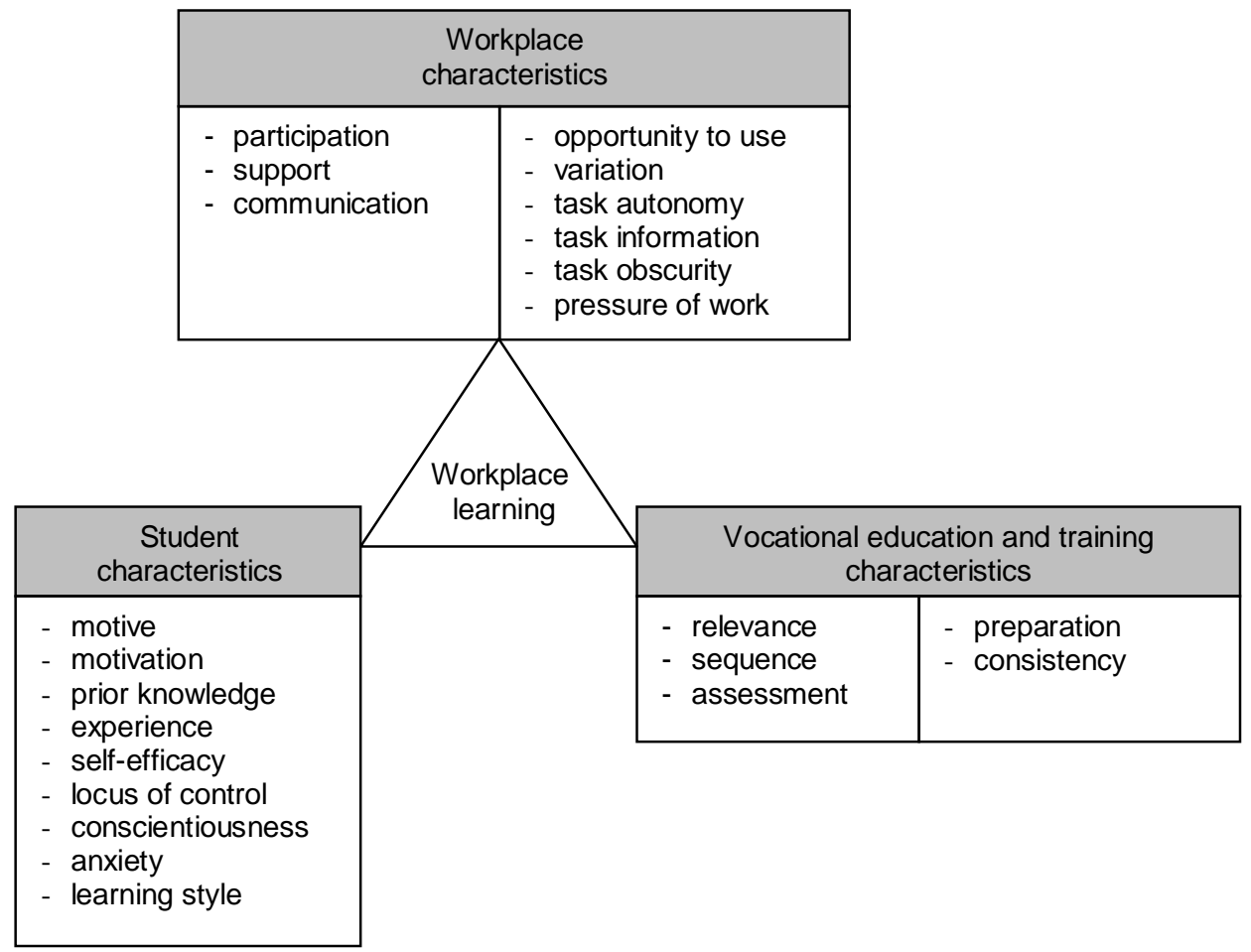

Figure 2.7 Selected variables that have been shown to influence workplace learning. 


\section{Chapter 3}

\section{Designing effective workplace learning}

\subsection{Introduction}

The previous chapter presented the results of a review of workplace learning. Empirical studies were analysed to identify variables that really influence the quality of workplace learning. This chapter presents the design of an intervention aimed at increasing the effectiveness of workplace learning. A theoretical framework for workplace learning was built up step by step, using the learning theory of Illeris. The variables found in the previous chapter were connected to this model, on the basis of which a point of departure for the intervention was chosen. The intervention consists of guidelines for interaction to support workplace learning.

\subsection{A theoretical framework for learning}

During the past few decades ideas and theories of learning have become more comprehensive. It started with a black box approach (behaviourism), which focuses on the input of learning processes and on behaviour as its output, the process itself was omitted. This theory has proven the importance of practice, reinforcement and feedback for learning routines and motor skills. Well-known representatives of this movement are Pavlov (classical conditioning), Skinner (operant conditioning) and Mager (goal analysis). Theories of information processing focus on the process itself from a cognitive perspective. Cognitivism, which focuses on information processing while learning complex cognitive skills, such as solving problems, has proven the importance of storing, retrieving and applying knowledge. Well-known representatives of this movement are Bruner (discovery learning and guided discovery), Ausubel (advance organiser) and Gagné (learning hierarchy). Constructivism underlines the active role of the individual in acquiring and constructing knowledge. It has proven the importance of reflection. In this theory the workplace is seen as a potentially powerful natural learning environment, because of the continuous 
possibility to interact. One well-known representative of this movement is Jonassen (constructivist learning environment). Independent of the kind of theory, learning can be characterised in terms of input - process - output. More consistently defined in terms of learning, these three elements concern the learning conditions, the learning process and the learning results.

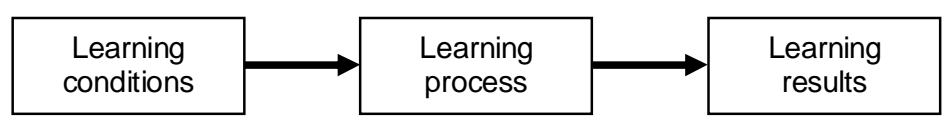

Figure 3.1 The basic structure of learning.

Due to the influence of constructivism, the learning paradigm seems to have shifted towards learning as an active and interactive process that takes place in and is influenced by context (Hoeve \& Nieuwenhuis, 2002). The theories mentioned, however, have different perspectives with their own strengths and weaknesses (Mergel, 1998; Schuman, 1996) and they have contributed in their own way to our knowledge.

\begin{tabular}{|c|c|c|}
\hline $\begin{array}{l}\text { Learning } \\
\text { theory }\end{array}$ & Strengths & Weaknesses \\
\hline Behaviourism: & $\begin{array}{l}\text { The learner is focused on a } \\
\text { clear goal and can respond } \\
\text { automatically to the cues from } \\
\text { that goal }\end{array}$ & $\begin{array}{l}\text { The learner may find himself in a } \\
\text { situation where the stimulus for the } \\
\text { correct response does not occur, and } \\
\text { so the learner cannot respond }\end{array}$ \\
\hline Cognitivism: & $\begin{array}{l}\text { The goal is to train learners to } \\
\text { do a task the same way to } \\
\text { ensure consistency }\end{array}$ & $\begin{array}{l}\text { The learner learns a way to } \\
\text { accomplish a task, but it may not be } \\
\text { the best way, or suited to the learner } \\
\text { or the situation }\end{array}$ \\
\hline Constructivism: & $\begin{array}{l}\text { Because the learner is able to } \\
\text { interpret multiple realities, the } \\
\text { learner is better able to deal with } \\
\text { real-life situations }\end{array}$ & $\begin{array}{l}\text { in a situation where conformity is } \\
\text { essential, divergent thinking and } \\
\text { action may cause problems }\end{array}$ \\
\hline
\end{tabular}

Figure 3.2 Strengths and weaknesses of different main learning theories (Mergel, 1998).

These theories seem to be supplementary rather than competing. They should therefore be combined, and research should be conducted to study the kind of 
combination needed in specific learning situations (see also a recent discussion on 'the new learning' between Wubbels, Van der Werf, Simons, Stevens and De Jong, 2006). Engagement is presented as a potentially powerful concept that combines cognition, motivation and emotion. Although this concept is not included as such, the learning theory of Illeris (2002) seems to provide an answer to the question of how to combine and integrate influential learning theories. The theory also pays attention to cognition, motivation and emotion.

The new learning theory of Illeris (2002) comprises three different dimensions that occur in two processes. These dimensions are the cognitive, the emotional and the social. The cognitive dimension refers to the acquisition of content controlled by the central nervous system. The emotional dimension involves the transmission of psychological energy by feelings, emotions, attitudes and motivations. The social dimension refers to the interaction between the individual and his surroundings. The two processes involved are the internal acquisition process and the external interaction process between learner and his material and social environment. Learning is defined as 'any process that leads to psychological changes of a relatively lasting nature and which are not due to genetic-biological conditions such as maturation or ageing' (p.24). According to Illeris, none of the earlier learning theories recognises or deals with this complexity in its entirety.

According to Illeris, the interaction processes between the individual and his environment provide the input of the learning processes. $\mathrm{He}$ distinguishes six main categories of interaction processes: perception, transmission, experience, imitation, activity and participation. Interaction begins with perception, where the world comes to the individual as a totally unmediated sense impression. The individual is passive. Transmission involves someone from outside having an interest to some degree in passing on something to others or in influencing someone. Experience includes perception and transmission. It also refers to acting in order to benefit from interaction. When someone attempts to do something in the same way as another person, he or she is imitating. Activity refers to goal-directed endeavour, where the individual actively seeks influences that can be used in a particular context. Participation is the most extensive form of interaction. The individual is in a common goal-directed activity, in which the person concerned has a recognised position and thus also an influence. Although distinct, these categories should not be regarded as separate; each of them is more or less present in a specific situation (p.227).

The motivation and motives of the individual are seen as internal psychological prerequisites for learning. These evolve through the individual's unique life process in interaction with social conditions and the individual's own interpretation of the interaction (p.226). 


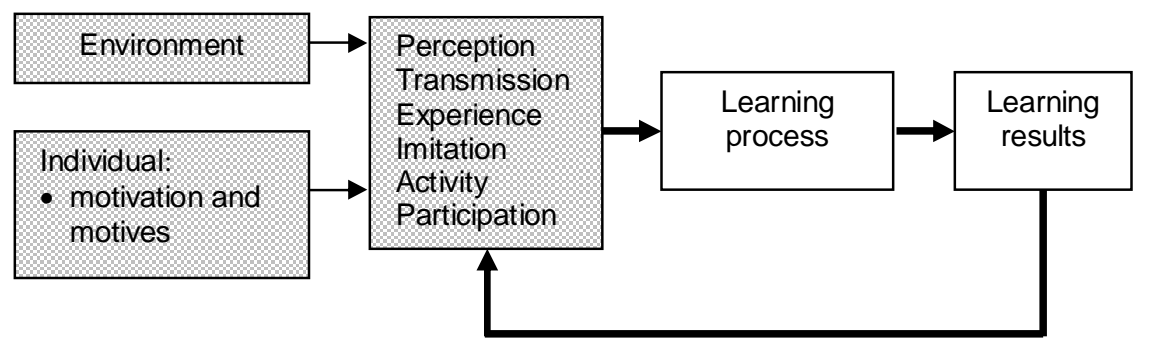

Figure 3.3 Input of the learning process.

The internal psychological aspect of learning consists of the individual's development of psychological structures or schemes through a continuing process of construction and reconstruction (p.43). The cognitive structures of knowledge and ability and the relatively stable psychodynamic patterns of emotions, motivations and attitudes are developed in an integrated way. The internal psychological adjustment processes can be described as an active adaptation of a predominantly cumulative, assimilative or accommodative character (p.43 and p.228):

- cumulative learning: takes place when impressions from the environment cannot be related to previously established structures; the learning products can only be recalled in situations that are almost identical to the learning situation.

- assimilative learning: consists of the adaptation and incorporation of new impressions into previously established structures; the learning products can be activated in a broad spectrum of situations that the individual perceives as related to the learning situation; a distinction can be made between constructive assimilations that predominantly promote development and restrictive assimilations that predominantly assist consolidation.

- accommodative learning: consists of the restructuring of established structures through dissociation, liberation and reorganisation (it implies that part of the structure must be broken up or disintegrated); the learning products can be activated regardless of the nature of the situation; it presupposes the existence of relevant structures that can be reconstructed, individual motivation to undertake such a demanding reconstruction, and a perception of safety and permissiveness in the situation; a distinction can be made between offensive accommodations that predominantly concern forward-looking reconstruction, and defensive accommodations that are predominantly used for the defence 
and protection of existing structures; transformative learning occurs in crisis-like situations that can only be solved by transcending the premises of a problem or situation. It is an extreme kind of accommodative learning for it changes the learner's self.

Development is seen as the interaction process between assimilative and accommodative learning (p.85). It can be seen as a sequence of learning events. The learning processes mentioned differ not only in the way psychological schemes are structured but also in the amount of energy a learner has to expend (Poortman, Nijhof \& Nieuwenhuis, 2003). Cumulative learning processes require a relatively low amount of energy; accommodative and especially transformative learning processes are very demanding. Learner characteristics and environmental characteristics influence the kinds of learning processes that will occur (which underlines the findings of the review). These connections should not be considered as definite or mechanical. The total balance between internal and external conditions and influences is decisive for the type of learning an individual will employ. In general, motivation and a stimulating, confident or safe environment will further the more demanding types of learning. However, it is also possible that the intended learning does not take place. In the case of non-learning or mislearning, there may be resistance or defence on the learner's part. Resistance is something with which one reacts when one encounters influences or situations that seem objectionable or threatening, or which in some other way are so unacceptable that one neither can nor is willing to put up with them. It may lead to making irritated and irritating remarks and creating a disturbance (Illeris, 2002, p.114). Defence can manifest itself in various ways (rejection, blocking or distortion) and is caused by the great number of influences that we encounter every day.

Although Illeris has distinguished kinds of learning processes, he does not describe how these processes evolve. Learning activities such as analysing, selecting, repeating, practising and applying are part of these learning processes (Bolhuis \& Simons, 1999; Pieters \& Verschaffel, 2003). Ten Dam and Vermunt (2003) provide an overview of three different categories of learning activities:

- cognitive learning activities: relating, structuring, analysing, making concrete, applying, memorising, critical processing and selecting.

- affective learning activities: attributing, motivating, concentrating, assessing oneself, valuing, exerting, arousing emotions and expecting.

- regulative learning activities: orienting, planning, guarding the process, checking, diagnosing, steering, evaluating and reflecting.

The learning activities determine the way the learning process is conducted and influence the learning results (Pieters \& Verschaffel, 2003, Ten Dam and Vermunt, 2003), which is in accordance with the theory of Illeris. These activities are influenced by the learning conceptions and learning orientations of 
the learner (Ten Dam and Vermunt, 2003). It is also possible that someone in the environment conducts these activities. In that case the activities are considered instructional. The learning process is then steered by others to some extent. It is important that the instructional activities and learning activities match the extent of steering that is needed and given (Pieters \& Verschaffel, 2003).

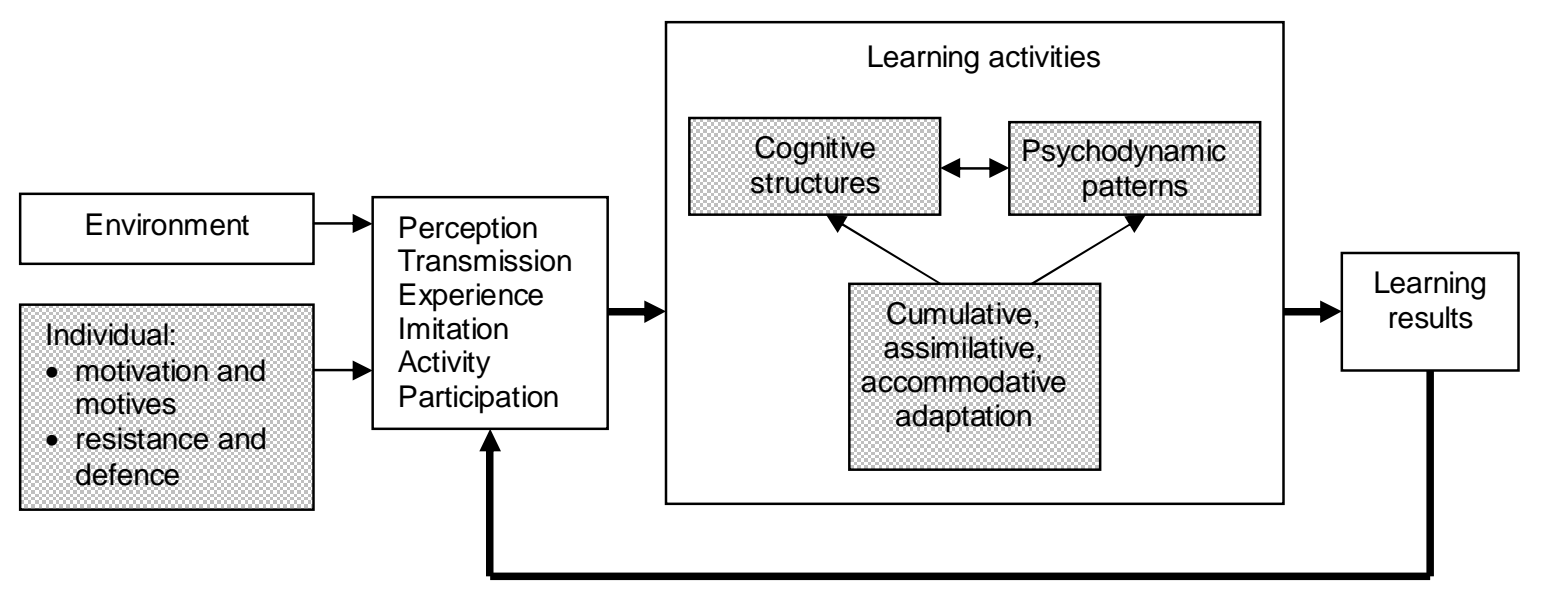

Figure 3.4 Adaptation of structures and schemes.

According to Illeris, the learning result has the character of an individual phenomenon that is always socially and societally marked. The totality of the interaction processes and internal processes of acquisition and elaboration form a lifelong process of experience. Experience embraces the cognitive, emotional and social-societal dimensions of learning, the internal psychological acquisition processes and the social interaction processes. Learning is, however, only the formation of experience when a number of criteria are fulfilled (p.157):

- the subjective must be part of a coherent process involving earlier experiences and future experiential opportunities;

- the learner must be actively present and be self-aware in his or her interactions with the social and/or material environment;

- it must be rooted in a subjectively relevant social context;

- it must reflect or exemplify important social material and/or social structures;

- it typically concerns the important subjectively perceived problems of the participants, which are worked through in a continuing experiential 
process on the basis of previously established patterns of experience and governed by a forward-pointing action perspective.

Because the learning processes are internal they cannot be observed; it is the learner who has to conduct and regulate them. It makes these processes nonobservable; it is the learner's behaviour that enables one to infer that a particular learning result has been reached (Aronson \& Briggs, 1983; (Pieters \& Verschaffel, 2003).

The learning result is not necessarily viewed as positive, considered from the perspective of mislearning (Illeris, 2002). What we remember or learn does not have to be correct or objective. Frequently people acquire the influences they receive in a form that fits in with their own presumptions or interest (Illeris \& Andersen, 2004). Van Woerkom (2003) also concludes that people learn things that are considered negative.

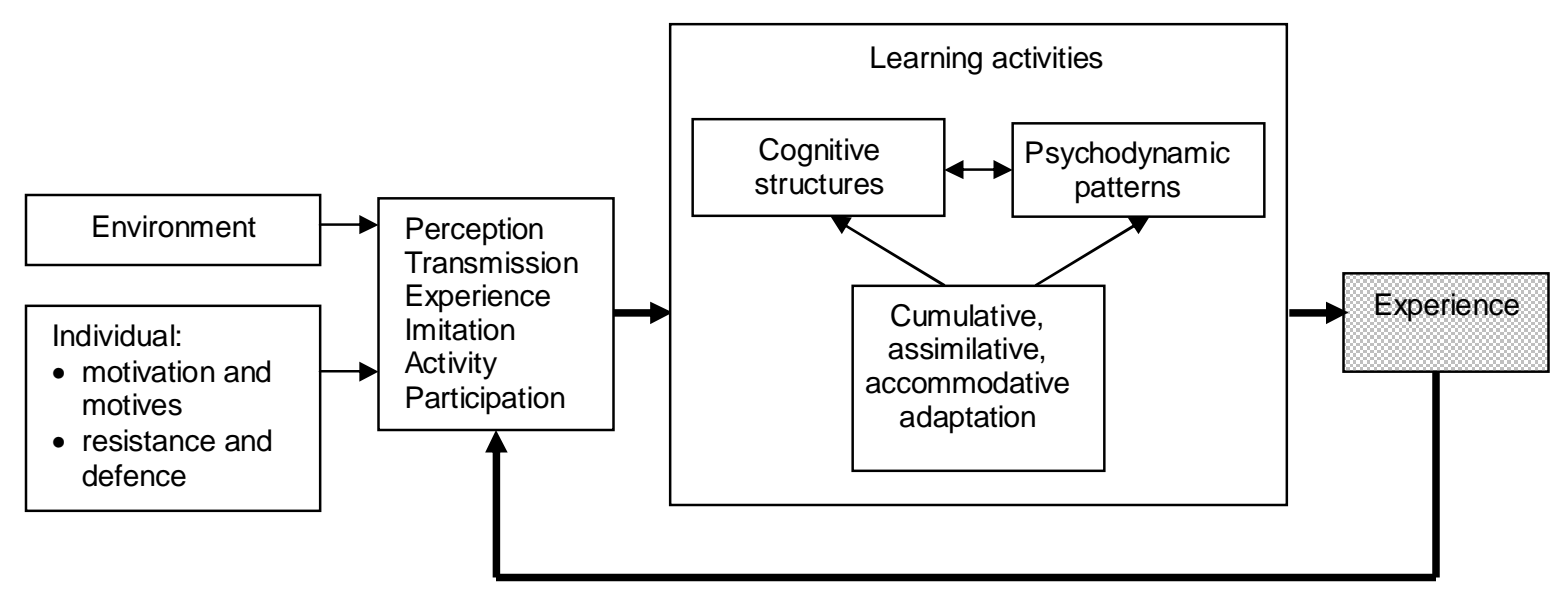

Figure 3.5 Experience as output and input of learning.

\subsection{A theoretical framework for workplace learning}

The framework developed so far is based on learning in general. It needs some adaptations with regard to the effective workplace learning of students in Dutch vocational education and training. According to Illeris, the workplace is a specific space or learning situation that will always influence the learning result. All learning is therefore 'situated learning'. Learning that takes place at work will as a rule be immediately applicable to work, but will also take place on work terms, i.e. those of the employers, and can therefore easily lack a broad 
view and a subjective perspective (Illeris, 2002, p.202). This learning situation is also influenced by, and will itself influence, learning in other spaces or spheres, such as school. These two situations are considered here the two most important spaces in vocational education and training with respect to the roles and responsibilities they have and the time a student spends there.

The student characteristics that have been found to be influential with regard to workplace learning are internal learning conditions that primarily influence the internal psychological acquisition process. Some of the characteristics refer to the relatively stable psychodynamic patterns as part of the emotional dimension of learning, others to the cognitive structures as part of the cognitive dimension. The characteristics involved are prior knowledge, experience, motivation, selfefficacy, locus of control, anxiety, conscientiousness and learning style.

The characteristics of the workplace that influence learning are all part of the social dimension (Illeris, 2002). These characteristics are regarded as input or external learning conditions and are expected to influence learning indirectly. There are two main categories of characteristics. The first one is the organisational climate, which includes descriptive aspects of the organisation, including actual processes and procedures, but excludes values and norms that are part of the organisation's culture (Van Muijen, 1994; Van Woerkom, 2003). This category consists of participation, opportunity to use, communication, support and pressure of work. The second category refers to job and task characteristics, such as variation, task autonomy and task information. The characteristics mentioned have also been found to be important learning conditions for informal learning (Skule, 2003), which stresses their relevance. Although in vocational education and training a student learns in at least two different spaces (in school and at the workplace), school is left out of the design, because the focus is on learning at the workplace. Moreover, according to the theory of Illeris, the influence of school on the learning results is limited, since it merely has an indirect effect.

Interaction concerns the interaction of the student at the workplace. According to the theory, all six kinds of interaction distinguished are present to some extent. For students in the full-time college-based route, however, it seems difficult to really participate as intended in the theory. Although they have a recognised position as "students", who are expected and allowed to learn, it is questionable whether they truly have an influence on work. They are allowed to express what they want to learn, but it is mainly their environment that decides what they have to do. For students in the part-time work-based route the situation is different. As employees, they have a different position. However, there seems to be no weighty reason to exclude one of the six kinds of interaction mentioned, especially because participation as a workplace characteristic influences workplace learning. 
As regards the learning processes, their central feature is constructing and reconstructing psychological structures and schemes. A profitable development process involves the interaction between assimilative and accommodative processes, balanced in relation to the context. As mentioned earlier, this presupposes the existence of relevant structures that can be reconstructed, individual motivation to undertake such a demanding reconstruction, and a perception of safety and permissiveness in the situation (Illeris, 2002, p.44). Cumulative learning is most frequent during the first few years of life. Later it only occurs in special situations where one must learn something with no context of meaning, for example a telephone or pin code number (Illeris, 2003). For that reason it is considered irrelevant as part of the students' learning processes. For Dutch vocational education and training, reflection can be considered an important learning activity, because it allows time-displaced accommodative learning that is not directly connected with new impulses from the environment, for instance at school.

Illeris emphasised the importance of experience relating to developmental processes. In Dutch vocational education and training, however, experience and the identity process are not stated explicitly as intended learning results. In the early 1990s, three kinds of learning results at the workplace were mentioned: practising vocational skills, socialising with regard to one's future vocational role, and working reflectively (Commissie Dualisering, 1993). The focus nowadays is on the development of competencies. According to Bransford et al. (2000), in order to develop competencies students must: (a) have a deep foundation of factual knowledge, (b) understand facts and ideas in the contexts of a conceptual framework, and (c) organise knowledge in ways that facilitate retrieval and application (p.16). It is assumed that competencies provide a solid and necessary basis to handle situations at the workplace (see also Illeris, 2003). More relevant and consistent with the framework is the fact that competencies are considered personal attributes. Performance is considered a measure for competency (Toolsema, 2003). Because competencies are inextricably related to acting in various situations, it is expected that both assimilative and accommodative learning processes will be involved in developing competencies. It depends on the experience and prior or preliminary knowledge of the learner whether assimilative or accommodative learning processes take place.

Figure 3.6 presents a theoretical framework for effective workplace learning, based on the learning theory of Illeris, combined with variables that have been shown to influence workplace learning. This framework postulates that characteristics of the environment (workplace) and characteristics of the student influence the interaction that takes place at the workplace while participating in work processes. Interaction consists of six different but connected categories, and it, in turn, influences the learning process, which consists of the execution of learning activities and the adaptation of 
psychological structures and patterns. The result of the learning process is the acquisition of those competencies required to handle situations at the workplace adequately. To complete the learning cycle, the competencies, in turn, influence the interaction process.

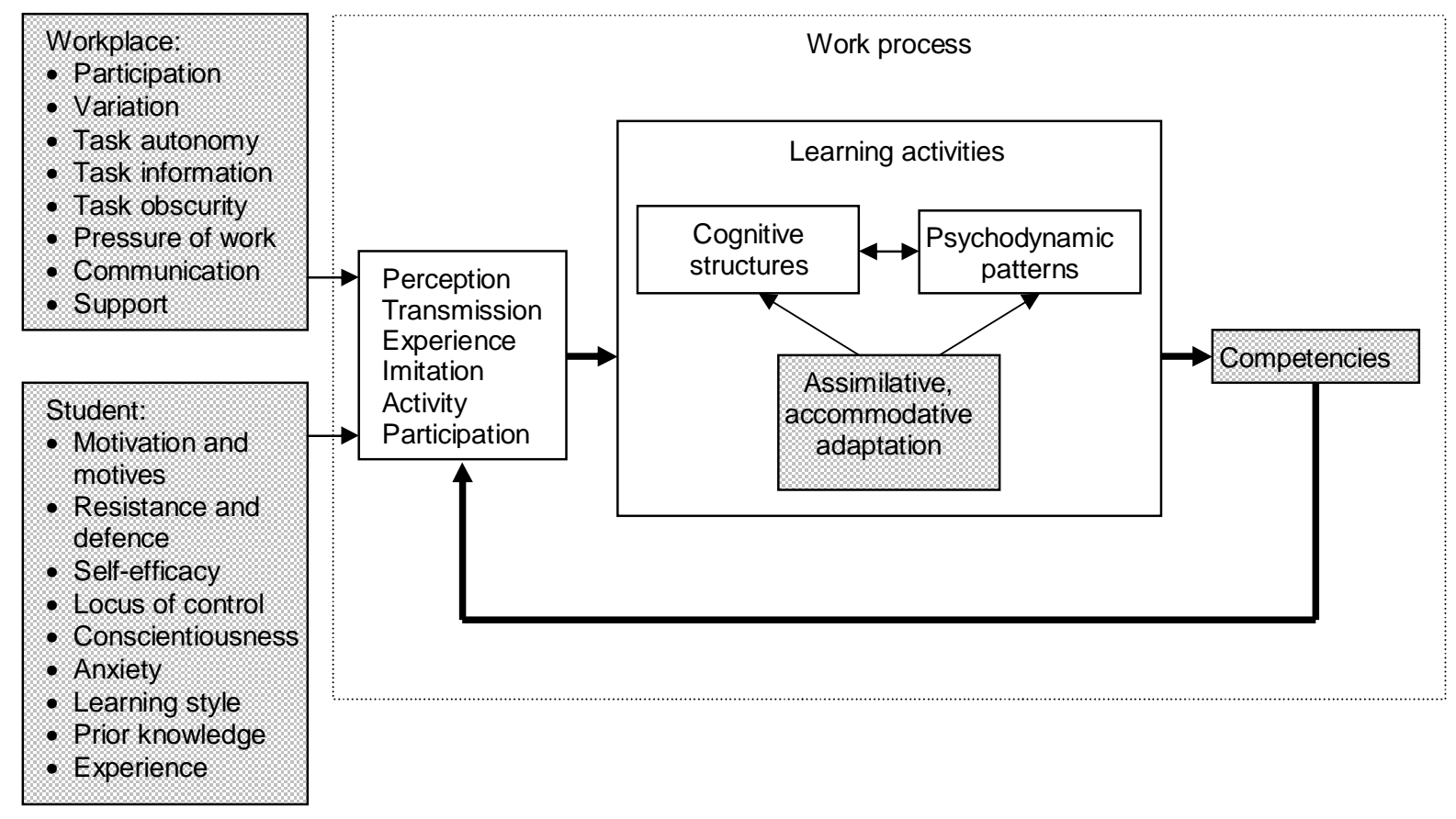

Figure 3.6 A theoretical framework for effective workplace learning.

\subsection{Designing interaction}

From a theoretical point of view, the framework provides four reference points to influence students' acquisition of competencies at the workplace: through workplace characteristics, student characteristics, interaction, and psychological structures and patterns. For a design that aims at increasing students' acquisition of competencies, interaction is considered crucial, because it provides direct input for the learning processes. A design based on workplace characteristics or student characteristics is expected to be less powerful, since their influence on the acquisition of competencies is merely indirect. 
A design process consists of at least five major activities (Gustafson \& Branch, 1997; Visscher-Voerman, 1999). The first one is an analysis of the context and needs, and the second is the design of a set of specifications for effective, efficient and relevant materials. The third one is the development and construction of all materials and supporting processes. The fourth one is the implementation of the product and processes, or anticipation of the implementation, while the fifth and last one is a formative and summative evaluation of the product and processes. Although these activities are often intertwined, here they are described separately in the next subsections.

\subsubsection{An analysis of the context and needs}

In vocational education and training a common and accepted way of interaction at the workplace is that between a student and the practical instructor of the company. Each company that provides students with the opportunity for workplace learning must appoint a practical instructor, whose task it is to coach the student. It is not always the practical instructor, however, who interacts frequently with the student. If the practical instructor is the owner of the company or is from the personnel department, interaction is sometimes very limited. It is not unusual for it to occur only at the beginning of the period of workplace learning, when the student is introduced into the company and at the end, when the period is evaluated. In between, interaction is sometimes considered necessary only if there are serious problems or to inquire about the student's functioning and progress in general. If the practical instructor has more time to spend on coaching, because the company has created a fulltime function for it, this does not necessarily mean that the frequency and intensity of interaction with the student increases. In most cases the practical instructor then has to coach several students and to maintain contact with the national body and the vocational education and training centre. In the situations mentioned the practical instructor often does not participate in the daily work processes, which limits opportunities for coaching while the student is executing tasks.

For the student, however, interaction at the workplace is not limited to coaching by the practical instructor. Most of the time the student participates in daily work processes, executing the tasks that are part of it. This provides the opportunity to experience and gain membership of a community of practice. Such a group consists of a number of employees who a) share a domain of work or interest, and b) engage in joint activities, help each other and share experiences. They share 'a concern or a passion for something they do, and learn how to do it better as they interact regularly' (Wenger, 1998). When learning does take place (which is, of course, the student's aim) in communities of practice, it does not always have to be planned or conscious. It may be the outcome of interaction between employees, aimed at solving problems, asking 
for information, seeking experience or performing certain tasks. Since the student still has to learn how to execute these tasks according to the requirements and routines of the company, an employee is appointed as mentor. As this mentor often executes the tasks the student has to learn, the two of them can work together, which provides a natural basis for interaction. Sometimes employees are chosen on account of their social competencies or their work experience; at other times the tasks the student will be executing determine which employee is appointed. Unlike the practical instructor, however, the mentor is not trained by a national body or a vocational education and training centre to coach students. For the company, training employees to become competent mentors occurs at the expense of work and production. If there is no single mentor, because the student also works with other employees, training would involve a considerable investment for the company. This means that employees who frequently interact with a student are neither trained as a professional nor equipped with supporting tools for interaction. Their way of interaction is probably based on their own experiences as a student, on previous experiences as a mentor and on their own natural way of instructing and communicating with others while working. To use the possibilities of interaction aimed at stimulating learning and the student's acquisition of competencies to their fullest extent, however, employees who frequently work with students are a very interesting group to focus on for the design. Providing them with a supportive tool that helps them to achieve high quality interaction focused on effective learning is considered meaningful. The necessity of such a tool is underlined by the finding that practical instructors, although trained, are in need of instruments and guidelines for supporting the learning of students (Onstenk, Oudejans \& Tamerus, in press). This finding will also hold for mentors who are not trained.

Another possibility not yet mentioned is that of interaction with a fellow student. At school such kind of interaction is far easier to realise than at the workplace. In most small and medium-sized companies, the company provides the opportunity for workplace learning to just one student at a time. And even in large companies, students will not have much opportunity to interact with each other, since they are spread over different teams or departments. From the perspective of becoming part of a community of practice, this is probably beneficial, because students then have to interact with employees. This prevents students forming their own group with their own shared interests.

All in all, appointing mentors and providing them with a supportive tool they do not currently have available seems the best option for realising frequent and valuable interaction that stimulates planned learning. 


\subsubsection{Specifications for effective, efficient and relevant materials}

For the development of a supportive tool for interaction, design specifications have been derived from the theoretical framework for effective workplace learning and the context in which the tool will be used.

According to the theory, workplace learning consists of three different but linked dimensions. The tool for interaction has to focus on all three dimensions to contribute to effective learning; ignoring one or two dimensions reduces its effectiveness. The tool therefore has to provide guidelines for activating cognitive learning activities that contribute to the acquisition of content. It also has to provide guidelines for activating affective learning activities to include the emotional dimension of learning. The learning activities as described by Ten Dam and Vermunt (2003) are considered relevant and useful (see Section 3.2). This means that activities such as relating, analysing, motivating and valuing are to be included in the tool. The social dimension is the interaction itself.

The theoretical framework shows that there are six main categories of interaction, varying from passive (perception) to active (participation). Each of them is present to a greater or lesser degree in a specific situation. The tool has to mirror that variety, since all kinds of interaction are considered relevant with regard to learning. It should pay special attention to activity and participation, because the student is not expected to have much influence at the workplace. Although the student will not be able to influence work processes or the planning of the work, just asking a student what task he wants to learn to execute, or how he wants to learn is a way to include these kinds of interaction. Stimulating students to observe at the workplace is a way to include the category of perception in the tool.

Assimilative and accommodative adaptation of structures and patterns is necessary for true development. Assimilation is, however, the kind of learning that students prefer because it is less demanding and requires less effort (Billett, 1999; Illeris, 2002). To include attention to accommodation in the tool, it must provide guidelines that invite students to reflect on the way they perform and learn. Another possibility is to ask students about other possible ways of performing tasks or handling situations. Although the intention is to realise planned learning, it is possible that this will not occur, due to resistance or defence on the part of the student. The tool must point out clues that indicate that the student might be having trouble learning something, a clear signal of which is when the student shows signs of irritation, frustration, confusion or refusal. The tool must point out the relevance of observing the student's behaviour for these signs, which may also indicate that the balance between the student's self-regulation and the mentor's steering is disturbed. Asking a student how he would like to learn to perform a task provides the opportunity to harmonise the degree of steering and the student's preference. It is also 
necessary for the tool to help to inventory prior knowledge and experience, in order to decide what the student can handle.

On theoretical and empirical grounds, learning is expected to become more effective if interaction takes into account the selected influential workplace characteristics and student characteristics. The tool must therefore offer guidelines on being alert to, for instance, variation and anxiety. It is not realistic, however, to expect the tool to affect the external and internal learning conditions at short notice if these are not already present to some extent. The workplace characteristics and student characteristics are both relatively stable.

The context in which the tool will be used is the workplace. Anticipating the conditions at the workplace is expected to increase the likelihood of successful implementation. One of the important specifications of the tool is related to time. As mentioned above, the time that is available to become used to the tool is probably limited, and it is not realistic to expect mentors to have the opportunity to attend extensive training in its use. In order to limit the necessary training time, the tool itself must indicate how it is to be used as much as possible. In other words, the tool must be clear and simple. To provide mentors with information about the ideas underlying the tool, which is expected to contribute to understanding and to using the tool as intended, the basic principles of the tool must be presented.

Another specification is related to its usability in different kinds of situations. Students attend their period of workplace learning in all kinds of companies, which differ in size, products or services. In addition, the mentors with whom the students interact differ, as do the educational programmes in which the students are participating. The challenge is to develop a generic tool that is useful in many situations: to increase its usability, it has to avoid reference to highly specific situations. The dilemma between generic and specific, however, requires some kind of control of usability just before implementing it, to ensure that the tool will be used.

Finally, the mentor's willingness to use a tool that focuses on learning will increase if it fits into his daily work. Size probably also matters: an extensive tool is considered less suitable, as it will not only probably discourage mentors from using it but may also reduce the likelihood of mentors taking it with them when they have to execute work at different places. As a consequence, they will not have the tool available when they need it. The tool must therefore be as brief as possible and be convenient for taking with them.

Attempts are therefore being made to develop a tool that takes account of the possibilities at the workplace. It has to fit the actual daily situation as much as possible. A supportive tool that aims at changing the organisational climate, the organisational structure or the work processes is considered inadequate. Even if the focus were to be on improvement of the quality of work, as in sociotechnical 
design, and not on learning, such changes are time-consuming and not easy to realise (Van Kollenburg, 2003).

The tool to be developed focuses on the interaction at the workplace between mentor and student. It has to trigger, support and maintain learning processes to attain the desired learning results, which means that it has to create a learning environment (Lowyck \& Terwel, 2003), which is a part of participating in daily work processes. Such an environment should provide appropriate combinations of challenge and guidance, empowerment and support, selfdirection and structure (Reigeluth, 1999).

According to Collins et al. (1989) a model for designing learning environments consists of four dimensions: the content taught, the pedagogical methods employed, the sequence of learning activities and the sociology of learning. Their model is embedded in a theory of learning through cognitive apprenticeship, which aims at the development of concepts through continuing authentic activity (Brown, Collins \& Duguid, 1989). The term points to the contextdependent, situated and enculturating nature of learning (apprenticeship) on the one hand and the acquisition of cognitive skills beyond physical skills on the other. Cognitive apprenticeship seems to be useful with regard to the design of the learning environment, not only at school but also at the workplace. At the workplace, learning is situated and context-dependent in nature. It also seems to fit the presented framework for effective workplace learning, because cognitive apprenticeship also stresses the importance of interaction. Another advantage of the model is that it pays attention to important contributions from behaviourism (for instance modelling and feedback), cognitivism (for instance articulation and increasing complexity and diversity) and constructivism (for instance reflection and context-depended learning). Because the design model was initially developed and used for learning at school, it must be used carefully to prevent it being transferred too easily to workplace learning. The model also lacks explicit attention to the emotional dimension of learning (with the exception of motivation).

Another design approach is presented by Jonassen (undated). According to him, purposeful knowledge construction may be facilitated by learning environments which:

- provide multiple representations of reality, avoid oversimplification of instruction by representing the natural complexity of the world;

- present authentic tasks, contextualise;

- provide real-world, case-based learning environments rather than predetermined instructional sequences;

- foster reflective practice;

- enable context and content-dependent knowledge construction; 
- support collaborative construction of knowledge through social negotiation, not competition among learners for recognition.

With regard to workplace learning as part of vocational education and training, Jonassen points to an important difference between constructivist design and behavioural or cognitive instructional design (or objective design, as he calls it). Objective design has a predetermined outcome. It aims at mapping a predetermined concept of reality into the learner's mind, while constructivism maintains that instruction should foster learning, not control it, because learning outcomes are not always predictable. Because Dutch vocational education and training is aimed at realising pre-determined learning aims, a constructivist design approach is considered less suitable and useful in the current situation. Additionally, constructivism is considered as descriptive rather than prescripttive, which makes it more difficult to use as a design framework.

Figure 3.7 provides an overview of the specifications that will be taken into account for the development of the tool for interaction.

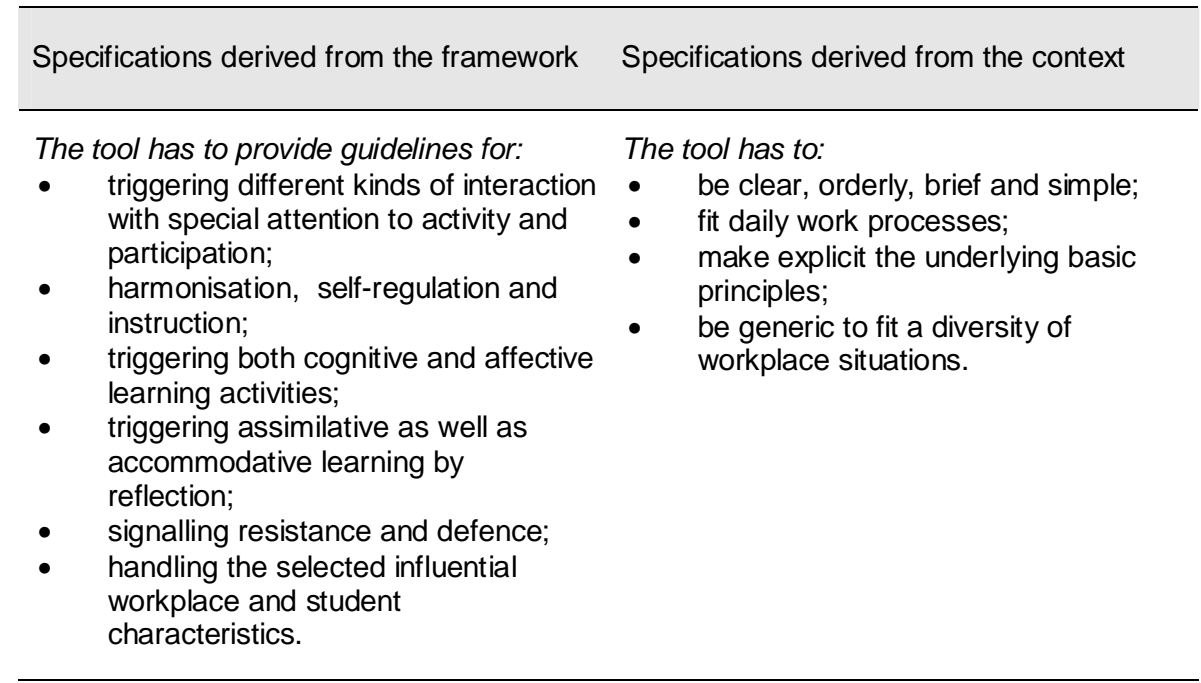

Figure 3.7 Specifications for a supportive tool for interaction. 


\subsubsection{Development and construction of guidelines for interaction}

The previous chapters and sections provided step by step input for the supportive tool for mentors. Chapter 2 resulted in the selection of variables that have been shown to influence workplace learning. The most important categories of variables were those related to student characteristics and workplace characteristics. The variables related to vocational education and training characteristics are less influential, and were omitted from the framework for effective workplace learning as presented in this chapter. The theory of Illeris showed that their influence is indirect at most. Transferring elements from one context or culture (education) to another (workplace) is difficult and problematic, owing to their distinctive characteristics (Collins et al., 1989). To include the remaining influential variables in the tool, each variable was worked out in a set of items as a first step. To ensure the validity of the items, these were derived from existing scales with an acceptable Cronbach's $\alpha$-coefficient. The items were then reformulated in terms of actions for the mentor. For instance as variation; the mentor has to make sure there is variation in locations/people/materials/time/ ... Or as task autonomy; the mentor has to allow the student to execute the task as he wishes. It turned out that several of the student characteristics matched the specifications derived from the theoretical framework, for instance motivation as a prerequisite for accommodative learning, or locus of control, which shows a resemblance to self-regulation.

The next step was to translate the other specifications derived from the theoretical framework for effective workplace learning as mentioned in this chapter into guidelines for interaction. The specifications were dealt with in the order of the learning process, which means that they started with the input for learning, followed by the process itself. The first specification mentioned was triggering different kinds of interaction. Perception, as the most passive form of interaction, is included in the guidelines that instruct the mentor to stimulate the student to observe actively what is happening at the workplace. As the student's workplace learning is planned and directed at the acquisition of competencies, this observation has to focus on the execution of tasks that the student wants to learn to execute. Passing on something to someone or influencing someone (transmission) is realised by formulating guidelines that focus on a dialogue between mentor and student. This kind of interaction also stimulates learning (Vygotsky, 1978). The guidelines have been formulated as much as possible in terms of questions and providing feedback on answers, to realise this dialogue. Because experience includes perception and transmission, this element of interaction has already been achieved and does not need supplementary guidelines. Stimulating imitation is omitted from the guidelines, because at the workplace the student will frequently work with the mentor. At the same time, he is surrounded by other employees who are all potential role models that the 
student can and probably will imitate as a consequence of working with them and observing them. Activity and participation are included explicitly. By adding guidelines that focus on asking a student what he wants to learn or what his preference is as regards support and coaching by the mentor, he is given the position and influence needed for this kind of interaction. Clearly, this influence is related to the process of learning, not to the process of working.

A second specification was harmonising self-regulation and instruction. Because the tool has to be generic and brief, it was impossible to translate all kinds of variations of harmonisation into guidelines. The essence of harmonisation is to strike a balance that matches the wishes of the students with regard to support and the need for support according to the mentor. The inclusion of guidelines that focus on asking the student what kind of support he wants, as well as on asking what the student is already capable of provides the necessary basis for harmonisation. Again, this way of interaction provides the student with some kind of influence. At the same time, it pays attention to and allows for existing individual preferences. To ensure that all relevant elements of self-regulation and instruction (orienting, planning, guarding the process, checking, diagnosing, steering, evaluating and reflecting) were included in the guidelines, a structure of the tool was chosen that reflects these elements. To keep the tool orderly, four phases were distinguished, each with its own focus and each allowing for its own harmonisation of self-regulation and instruction. For instance, when a student is insecure about his ability to plan, and needs external control and support on this part. The phases chosen focus on orienting, preparing, executing and evaluating, and improving. All of these phases included guidelines that focus on guarding the process, checking and diagnosing. An advantage of these phases is that they match the elements of a complete action (Blum, Hensgen, Kloft \& Maichle, 1995), which is considered important for the acquisition of competencies.

The third specification was triggering both cognitive and affective learning activities to meet the dimensions of the learning theory of Illeris. To develop guidelines, the learning activities as distinguished by Ten Dam and Vermunt (2003) were translated into guidelines. The cognitive learning activities that were included are making concrete, selecting, relating, analysing, structuring, memorising, critical processing and applying. The affective learning activities that were included are motivating, appreciating, arousing emotions, concentrating, expecting, attributing, harnessing and assessing. To ensure that both dimensions occur as much as possible simultaneously, each phase was checked for guidelines on both kinds of learning activities.

The fourth specification was triggering both assimilative and accommodative learning to realise the acquisition of competencies and true development. 
Learning requires the activation of psychological structures that can be adapted and reconstructed, individual motivation to undertake adaptation and reconstructtion, and a perception of safety and permissiveness. To meet this specification, guidelines were developed that aim at a) expressing the motives for learning to execute a particular task, b) increasing the student's motivation by discussing the relevance of the task, his confidence in its execution and

providing reinforcement, and c) activating existing structures by asking the student what he already knows and is capable of. Guidelines that invite the student to reflect on his preparation, execution and the learning results should trigger accommodative learning. For each phase of the supportive tool, guidelines that motivate and stimulate activation and reflection were included.

The fifth specification was realised by developing guidelines that focus on the motives of the student in the orientation phase, his confidence in the execution of the preparation phase, and frustrations and irritations in the execution phase.

The translation of the specifications derived from the theoretical framework resulted in a set of guidelines that was not yet structured. The next step required was to decide how to group the guidelines. As mentioned, four phases had already been considered relevant. All the guidelines developed were divided over these phases. The number of guidelines in each phase was too large to realise a structured tool that is brief and easy to handle. For this reason the guidelines were grouped into steps within each phase. A step had to be an entity with its own focus. In addition, the number of guidelines within each step had to be limited, to increase the likelihood that all the guidelines in that step could be used in the time available for interaction. In total, 12 steps were distinguished:

After grouping the guidelines, there proved to be some overlap, for instance in the case of the guidelines that aim at motivating the student, or between task autonomy, locus of control and self-regulation. This overlap was resolved by choosing the guideline that best matched the step. After assigning the guidelines to the steps and choosing to limit overlap, the result was checked to ensure that it matched the specifications derived from the theoretical framework. This means that every phase and every step had to consist of guidelines that stimulate the use of both cognitive and affective learning activities as much as possible. Moreover, each phase had to consist of guidelines aimed at triggering both assimilative and accommodative learning. And guidelines that help to point out potential frustrations and irritations had to be part of every phase, to prevent threats to learning being discovered too late. 
Phases and steps of the tool

Phase 1: Orienting to the task

Step 1: Select together a task the student wants to learn to execute.

Step 2: Talk through together the task the student wants to learn to execute.

Step 3: Determine together what the student already knows and is capable of.

Step 4: Discuss together how the student wants to learn to execute the task.

Step 5: Instruct the student to observe the performance of the task at least once.

Phase 2: Preparing for the execution of the task

Step 6: Discuss together the observation of the task.

Step 7: Prepare together for the execution of the task.

Step 8: Make sure all the student needs to execute the task is available.

Phase 3: Supervising the execution of the task and discussing performance

Step 9: Supervise the execution of the task.

Step 10: Discuss performance with the student immediately after execution.

Step 11: Determine together the next steps necessary to learn to execute the task.

Phase 4: Improving ability

Step 12: Instruct the student to execute the task a couple of times more.

Figure 3.8 Phases and steps of the supportive tool for interaction.

Before shaping the tool, the cognitive apprenticeship model for designing learning environments by Collins et al. (1989) was used to decide whether any adaptations of the guidelines were necessary. As mentioned in the previous subsection, this model fits the aims of the supportive tool for interaction. It therefore functioned as a kind of quality check on the guidelines.

The model consists of four dimensions: content, methods, sequence and sociology. With regard to the dimension of content, elements such as domain knowledge, heuristic strategies, control strategies and learning strategies are considered relevant. Because the supportive tool has to be generic and therefore fit all kinds of authentic situations at the workplace as well as the student's educational programmes, it was impossible to include specific content. However, the supportive tool consisted of guidelines that instruct mentor and student to express what knowledge, skills and attitudes are relevant to the execution of a chosen task that is part of the daily work process. Guidelines were also developed that focus on the execution of the task itself: how it is to be carried out according to the student and how it is actually carried out. The guidelines also invite the mentor to express his preferred way of execution and to provide tips that come in handy while executing the task. Control strategies and learning strategies also received attention. Control strategies were included 
explicitly in one of the guidelines that focuses on the planning of the execution. Here the mentor has to ask the student to prepare for the execution. The student also has to mention what parts of the execution he will give special attention to. In turn, the mentor has to provide feedback on this plan and to offer hints. With regard to the element of learning strategies, regulative learning activities were included.

In respect of the dimension of methods, elements, such as modelling, coaching, scaffolding, articulation, reflection and exploration, must be taken into account. Modelling was included in the guidelines by asking the student to observe his mentor or one of his colleagues executing a chosen task at least once. Coaching is not only included in the guidelines where the mentor is instructed to provide feedback on the student's answers and on his performance. To guarantee the observation necessary for providing feedback, the mentor and student have to form fixed couples who work together as much as possible. Scaffolding was worked out in a set of guidelines that instruct the mentor to ensure that all the student needs to execute the chosen task is available: tools, materials, information, time and support. Scaffolding and fading is explicitly mentioned in the tool as one of the basic principles: the student must have someone who supports him and on whom he can rely. The guidelines also instruct the mentor to explore the type of support the student needs and wants. Guidelines that were developed that invite the student to provide information on his prior knowledge and experience help the mentor to determine the extent of steering and support needed. Articulation is also included. This is a central feature of the guidelines, since it is considered a crucial element for interaction between mentor and student. Most of the guidelines therefore instruct the mentor to ask questions that the student has to answer. Guidelines that instruct the mentor to compare the student's knowledge and approach with his own meet the element of reflection, as defined in the cognitive apprenticeship model: compare problem-solving processes. At the same time, guidelines are included that invite the student to reflect on his own way of acting: what went right, what did not and what must be improved. Exploration is an element that is more difficult to realise in workplace learning, because company quality standards or potential risks limit the student's possibilities to solve problems on his own. One of the guidelines, however, invites the student to articulate his preferred way of handling a situation or solving a problem. In addition, the mentor is instructed by one of the guidelines to allow the student to execute a task in his own way, after the mentor and student have discussed the planning of its execution. In this way risks are limited as far as possible.

The dimension of sequence consists of the elements of increasing complexity, increasing diversity and global before local skills. This dimension is probably the most difficult to realise at the workplace, on account of the existing area of tension between working and learning. Work processes will not be adapted to meet the learning needs of a student, and it is not always possible 
to predict when specific tasks can be executed. To meet the elements of sequence to some extent, what is considered helpful is a list of tasks that are part of daily work processes and are relevant to the competencies the student must acquire to obtain a diploma. This list can be used to select tasks and to discuss the possibilities to learn to execute them. Such a list should be added separately. Formulated guidelines that focus on articulating prior knowledge and experience are helpful in determining what kind of tasks the student is able and allowed to learn to execute. At the same time, guidelines that focus on evaluating the execution of the task must help to determine which developmental step is possible next. Increasing diversity matches the workplace characteristic of variation. Guidelines are included that instruct the mentor to provide the student with variation in tasks and in the way a task can be executed. The element of global before local skills is covered by including guidelines that invite the student to observe the execution of a task, that provide discussion about the planning or preparation of its execution by the student and that provide feedback on specific parts of the planning and execution.

The dimension of sociology consists of the elements of situated learning, culture of expert practice, intrinsic motivation, exploiting co-operation and exploiting competition. The first element does not need any specific guidelines: workplace learning is by nature situated learning. The culture of expert practice is realised by the interaction process between mentor and student and the guidelines that explicitly focus on communication and the exchange of information. Intrinsic motivation matches one of the student characteristics (motivation). The first phase of the tool invites the student to choose a task he wants to learn to execute. If it is not possible to execute the chosen task at short notice, the guidelines instruct the mentor to explore the possibilities and to explain to the student why it is not possible and when there will be an opportunity. The elements of exploiting co-operation and competition are difficult to realise at the workplace; in many cases there is only one student. Joint periods of workplace learning at the same company and with the same mentor are often rare. To meet these elements to some extent, working with the mentor is advised, which provides the opportunity to compare. Guidelines were also included that focus on observing as a way of comparing, and discussing the planning and execution of the task.

In all the elements of the cognitive apprenticeship model for designing learning, the environments matched the guidelines to a large extent.

Finally, a suitable layout and shape was designed. The tool consists of three levels of information: the phases, the steps and the guidelines. With each level the tool becomes more detailed. These levels provide a structure that helps the mentor to determine quickly what is needed during interaction. The ideal order is suggested by presenting the steps as a kind of flow chart. The tool reflects to some extent a "Leittext", which helps the mentor to use the tool without 
extensive training. To increase its attractiveness on the one hand and its manageability on the other, the tool was printed in colour on a solid, plasticised card in A4 format that is easy to take with one and that can withstand hard wear.

The first version of the tool was worked out by ourselves, to ensure that it would match the specifications beforehand as much as possible. This version was discussed and formatively evaluated in separate meetings with an educational science expert, a communication expert, practical instructors and mentors of companies, practical work supervisors and teachers from vocational education and training institutes, and a student. The educational science expert was asked to react to the consistency of the tool with regard to the theoretical framework. The communication expert was asked to comment on the language and layout. Practical instructors and mentors were asked to give their opinion of the clarity, usability and usefulness of the tool. Practical work supervisors and teachers from vocational education and training were asked whether interaction based on the tool would be clear to the students, practical instructors and mentors they knew. Finally, a student was asked to comment on the clarity of the tool and whether this kind of interaction would be experienced as pleasant. Their reactions were used to adapt and improve the first version and to develop a second one that would be used in a pilot study.

Figure 3.9 presents the basic structure and design of the tool. Figure 3.10 and 3.11 provide an overview of the numbers of guidelines per step and, as an example, the guidelines of step 10 (the entire set of guidelines is included in appendix 3). 
Phase 1: Orienting to a new task

\begin{tabular}{|c|c|c|}
\hline Step 1: ....... & Guideline 1.1: ...... & \\
\hline & Guideline ....... & Go to step 2 \\
\hline Step 2: ....... & Guideline $2.1: \ldots \ldots$ & \\
\hline & Guideline ............. & Go to step 3 \\
\hline & paring for the new & \\
\hline
\end{tabular}

\begin{tabular}{|c|c|c|}
\hline Step ... ....... & Guideline ...... & \\
\hline & Guideline ......... & Go to step .. \\
\hline Step ... ....... & Guideline ....... & \\
\hline & Guideline ........ & Go to step .. \\
\hline
\end{tabular}

Phase 3: Supervising the execution of the task and discussing performance

\begin{tabular}{|c|c|c|}
\hline \multirow[t]{2}{*}{ Step ...: } & \multirow{2}{*}{$\begin{array}{l}\text { Guideline ...... } \\
\text { Guideline ...... } \\
\text { Guideline ...... }\end{array}$} & \multirow[b]{2}{*}{ Go to step .. } \\
\hline & & \\
\hline \multirow[t]{2}{*}{ Step $\ldots . . \ldots \ldots$} & Guideline ....... & \\
\hline & Guideline ......... & Go to step .. \\
\hline \multicolumn{3}{|c|}{ Phase 4 : Improving ability } \\
\hline
\end{tabular}

Step 12: ......

Guideline .......

Guideline .......

Guideline 12.6: ... Go back to step ..

Principle 1: ...

Basic principles for interaction:

Principle 2: ...

Principle .... ...

Figure 3.9 Basic structure of the supportive tool for interaction. 
Phase 1: Orienting to a new task

1. Select together a task the student wants to learn to execute.

2. Talk through together the task the student wants to learn to execute.

3. Determine together what the student already knows and is capable of.

4. Discuss together how the student wants to learn to execute the task.

5 . Instruct the student to observe the performance of the task at least once.

Phase 2: Preparing for the execution of the new task

6. Talk through together the observation of the task.

7. Prepare together for the execution of the task.

8. Make sure all the student needs to execute the task is available.

Phase 3: Supervising the execution of the task and discussing performance

9. Supervise the execution of the task.

10. Discuss performance with the student immediately after execution.

11. Determine together the next steps necessary to learn to execute the task.

Phase 4: Improving ability

12. Instruct the student to execute the task a couple of times more.

Figure 3.10 Steps of the supportive tool for interaction.

Step 10. Discuss performance with the student immediately after execution.

Guidelines:

1. Ask what he did while executing the task.

2. Ask whether the execution went as expected/planned, and if not, why not.

3. Ask what went well and what did not. Ask about the reasons.

4. Ask what surprised him.

5. Ask what he thinks of the product/service he delivered.

6. Tell him what you saw during the execution.

7. Express your opinion about his execution of the task.

8. Express appreciation for of the positive aspects of the execution.

9. Tell him what you would have done differently and why.

10. Ask what others could learn from him.

Figure 3.11 Guidelines of step 10. 


\subsubsection{Anticipation of the implementation of the product and processes}

A common way of influencing workplace learning in vocational education and training is via the vocational education and training institutes. Students and practical instructors are informed by the institutes what is expected of them and the institutes distribute the materials needed for workplace learning, and sometimes develop it. At the same time, the institutes have the final responsibility when the education of students is concerned. The institutes have several ways of informing and instructing practical instructors about the period of workplace learning. One way is the organisation of frequent meetings for practical instructors at school. An alternative is the visits by the school's practical work supervisors, who visit the companies with some regularity. During these visits they talk to the practical instructor and exchange information about the possibilities of workplace learning and the students' progress. The route via the schools was therefore considered appropriate to introduce the tool to companies. The tool, however, is intended for mentors, who probably but not necessarily have to be the practical instructors. The question is therefore how to provide mentors with the tool and the necessary information and instructions. One way is to ask the practical instructor of the company to distribute the tool among mentors. Organising a meeting to provide them with information and to instruct them seemed to be an efficient way. It is also questionable whether it is already known who the mentor is before students start their period of workplace learning. Another way is to distribute the tool via students when they know who their mentor is. This way is, however, considered less suitable. Students cannot be expected to be able or in a position to inform and instruct their mentor about the tool. In such a case the mentors must be provided with additional information in writing, to ensure that the appropriate information is available to them. All in all, it seems that organising a meeting is the best starting point for implementing the tool. During this meeting the practical instructors have to be informed of the aim, basic principles and structure of the tool. They also have to be instructed in how to distribute the tool and how to instruct mentors. As mentioned above, time available for training is expected to be limited, so that the instruction for practical instructors and mentors necessarily has to be brief.

Although the aim was to develop a tool that itself indicates how it is to be used, it is quite possible that mentors will develop questions on the basis of actual use. To provide them with the opportunity to ask questions, they must know who they can turn to. At this stage of implementation a kind of help desk, which is easy to call and accessible most of the time, seems necessary to ensure that mentors do not stop using the tool simply because they have no one to turn to. Since the tool is in a developmental stage, the help desk is best manned by the developer of the tool. He is the best informed about the tool and is interested in any questions that might help to determine what improvements are necessary. Waiting for questions, however, is considered unsatisfactory with regard to 
implementation. A couple of calls or visits to the practical instructors and mentors who have received the tool shows involvement, which is expected to increase their willingness to use the tool and to stimulate its use as intended.

\subsubsection{Formative and summative evaluation of the product and processes}

As mentioned in Section 3.4.3, several experts were consulted after the development of the first version of the tool and their reactions were used to develop a second version. The reactions were, however, not based on actual use by mentors while interacting with a student at the workplace. It was therefore considered necessary to test the tool in a pilot study. In order to be helpful, the steps and guidelines must be perceived as clear, usable and useful by both mentor and student. Since the tool was developed to contribute to workplace learning and to increase its effectiveness, the effect of the tool on the acquisition of competencies is relevant and must be part of the evaluation. The data gathered can be used to adapt the tool a second time. At the same time, a pilot can reveal whether the mentors feel that substantial aspects of interaction are missing. Because the tool consists of a generic set of steps and guidelines, it is also necessary to test whether the tool is usable and effective in different kinds of situations or whether specific adaptations are necessary. The formative and summative evaluation of the tool form part of the chapters about the pilot study (Chapter 5) and the main study (Chapters 6,7 and 8). 


\section{Chapter 4}

\section{Design and instrumentation}

\subsection{Introduction}

The previous chapter presented a theoretical model for workplace learning. This model shows that the acquisition of competencies is influenced by the student's learning processes. Learning processes in turn are influenced by the interaction between student and work environment. Finally, interaction is influenced by student characteristics and workplace characteristics. To increase the effectiveness of workplace learning, guidelines for interaction between mentor and student were developed. These are derived from characteristics that have been shown to influence workplace learning, and from a set of learning activities. This chapter presents the research model to test the effects of the guidelines on the acquisition of job-relevant competencies, and the measurement models needed. It ends with the design of both a pilot study and the main study.

\subsection{Hypothesis and research model}

The development of a theoretical model to understand the effectiveness of workplace learning fits the empirical cycle of fundamental research. The objecttive of this cycle is to develop and test a theory ('t Hart, van Dijk, de Goede, Jansen, \& Teunissen, 2001). The theoretical model and the guidelines provide the ingredients for formulating a hypothesis that is tested empirically in this study:

Application of the guidelines for interaction by the mentor leads to significantly better acquisition of job-relevant competencies by the student.

The research model to test the hypothesis consists of a number of variables. The set of guidelines is the independent variable and the acquisition of job-relevant competencies, the dependent variable. These variables are connected by inter- 
action at the workplace between mentor and student. Workplace, mentor and student are constantly present and their influence cannot be eliminated. These three are included in the research model as control variables. The learning process is treated as a black box and is not included. The research model is presented in Figure 4.1.

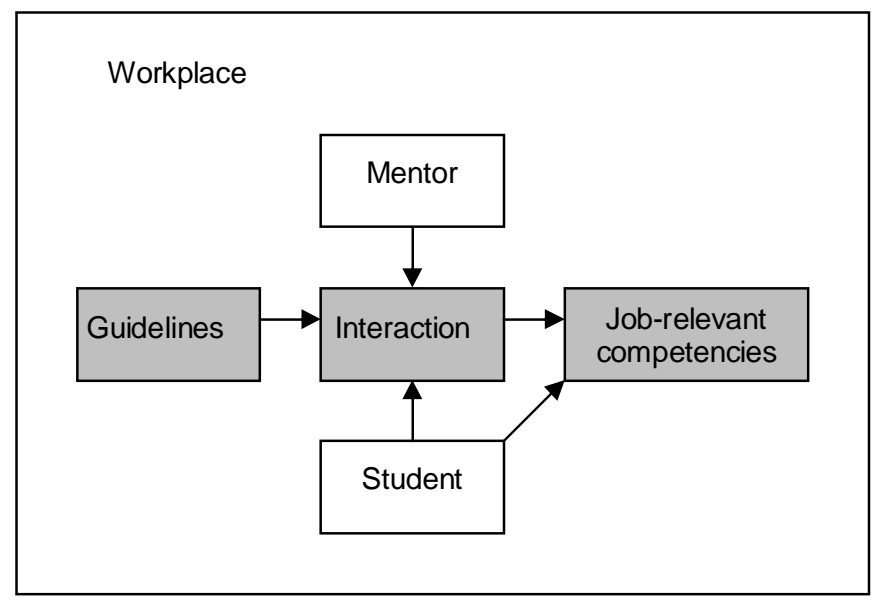

Figure 4.1 The research model.

In vocational education and training an important aim of workplace learning is to acquire job-relevant competencies. These competencies are needed in order to act adequately at the workplace (ACOA, 1999), which implies participating in daily work processes and conducting tasks. The presence of a competency will reveal itself in the performance of these tasks (Toolsema, 2003); the acquisition of job-relevant competencies will show itself in the mastery of tasks. However, measuring only one single time the extent to which a student has actually mastered a certain task is no guarantee that workplace learning has actually occurred. It is possible that a student had already mastered a task at a satisfactory level, but that he did not improve in performing it. For this reason the measurement also needs to focus on the difference between a post-test and a pre-test of mastery as an indicator of effectiveness.

Interaction is seen as the exchange of information between mentor and student to support the acquisition of job-relevant competencies; its target is the performance of tasks. In an ideal situation interaction takes place at the workplace according to the guidelines. Although it is not certain that this ideal situation exists, it is necessary to monitor how and to what extent the guidelines are actually applied. The effects of interaction do, however, not depend solely 
on the application of the guidelines. Interaction takes time and the time that is available for interaction will vary, due to work pressure and the availability of the mentor and the student. Their availability is influenced by among other things the work schedule, work planning, leave or illness. If the mentor is not present, the student works with another employee, who will interact in his own way. The effects of interaction also depend on its intensity. At the workplace students have the opportunity to perform several tasks and interaction will focus on the performance of these tasks. Some of the tasks can be conducted more frequently by the student and thus offer more opportunities to discuss the performance of these tasks. It is, however, up to the mentor and student to decide on what tasks the interaction will focus on and with what intensity.

The guidelines for interaction can be characterised as an instructional tool designed to increase the effectiveness of workplace learning. As mentioned in Chapter 3, they are derived from variables that have been shown to influence workplace learning. Learning activities have also been integrated into the guidelines. For this reason it is assumed that the guidelines in themselves are valuable. They are, however, to be used in interaction between mentor and student, and whether a mentor is willing and able to interact with the student according to the guidelines will depend on their clarity, usefulness and completeness. At the same time, the student has to understand what the mentor requires of him and to see this as useful in order for him to be willing to act accordingly. This means that for the guidelines to be valuable to both mentor and student, they will have to meet these conditions.

Learning and interaction take place at the workplace. The review in Chapter 2 shows that workplace characteristics influence learning and because interaction provides the input for learning, it is relevant to check for the influence of these characteristics on the interaction process. This relates to participation, variation, task autonomy, task information, task obscurity, work pressure and support.

The same review also shows the student characteristics that influence learning; these are self-efficacy, conscientiousness, locus of control, anxiety, motivation and learning style. Although the aim of workplace learning is to acquire job-relevant competencies, it is possible that learning will not take place. Prior knowledge and experience determine whether learning will take place and what kind of learning processes will occur (Illeris, 2002). It is necessary to measure these variables in relation to the tasks that are performed at the workplace. If there is some resistance on the part of the student or any kind of psychological defence, this will have a negative influence on learning (Illeris, 2002). Students are not always well prepared at the start of workplace learning (Blokhuis et al., 2002): some do not know where this period of learning is to take place or what is expected of them. Others, who have been well informed beforehand, sometimes prepare themselves by reading additional literature or textbooks or by working out what they want to achieve during that 
period and how they intend to do so. This difference in preparation can influence the treatment. In addition to these characteristics, general descriptive variables, such as the age and gender of the student, may also be of influence and these too are measured.

The mentor is an employee who has been given the task of supporting a student during his or her daily learning and work at the workplace for a certain period of time. A mentor will be more or less experienced, depending on the number of students he has supported. If the mentor has never supported a student before, he will not yet have developed his own way of interacting. At most, he will have some ideas about the way the interaction should occur, based on his own experience as a student or on the information of other mentors. If the mentor has some experience, his perceptions of interaction and the way he interacts will to some extent be fixed. Experience will therefore probably influence his willingness to interact in accordance with the guidelines and his ideas about interaction. The extent to which a mentor is willing to invest time and energy in a student will also depend on whether he feels that he can get along with the student and that supporting this student will be rewarding. Finally, the effects of interaction will also depend on preparation. Mentors want to be prepared for the student's arrival and to know who is coming, what they can expect and what they have to do (Blokhuis et al., 2002). Not being well prepared can result in a loss of motivation or time. Apart from experience, general descriptive variables, such as the age and gender of the mentor, are also measured.

The research model that includes all the variables described is presented in Figure 4.2. 


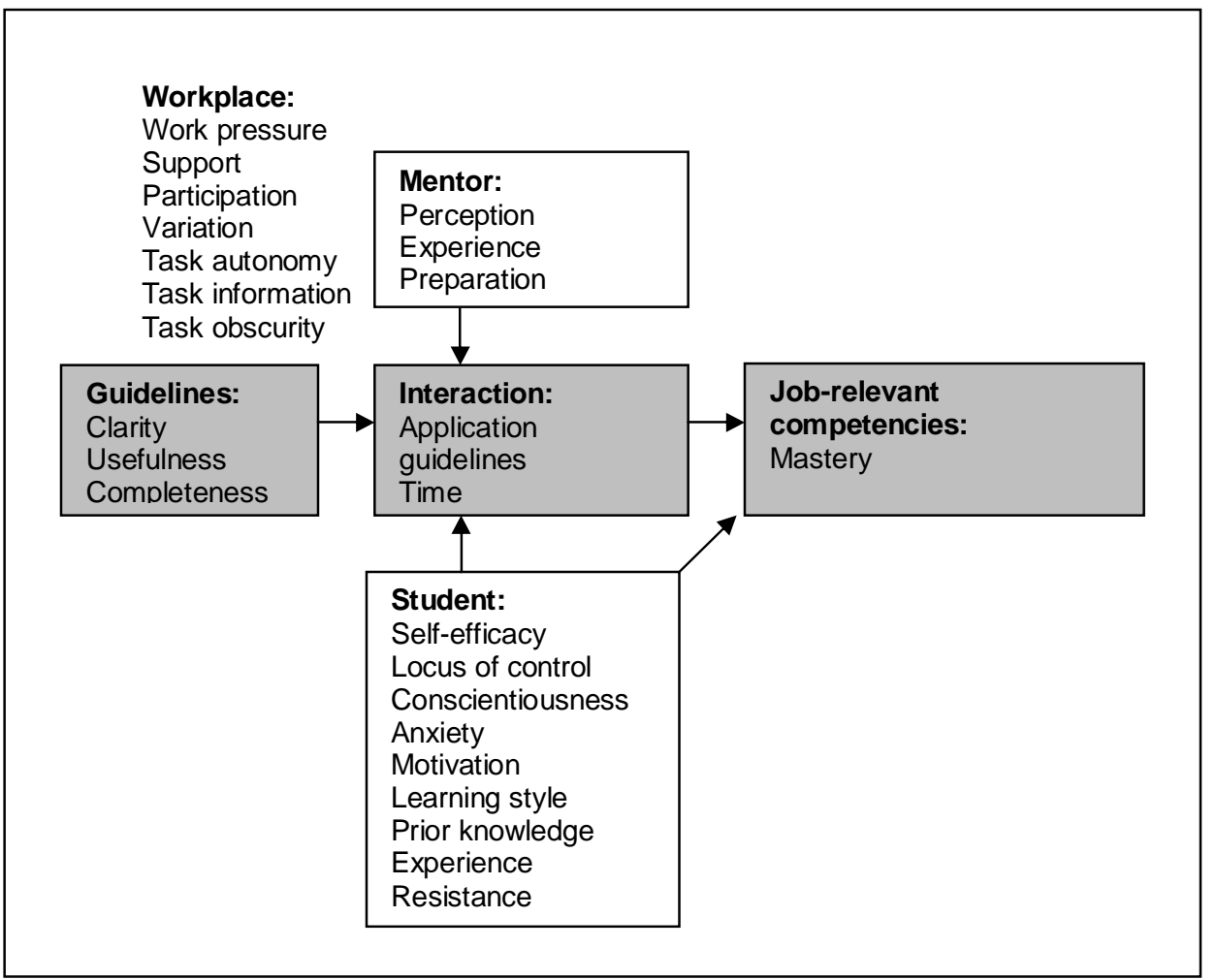

Figure 4.2 Expanded research model.

\subsection{Research design}

To test the hypothesis a quasi-experimental design was used. This is a design that is often used to test causal relations in situations where the check on external, intervening variables is not complete or when the researcher has to use existing groups (Cook \& Campbell, 1979).

To be able to test the main hypothesis to its fullest extent, a group of mentors are asked to interact with a student in accordance with the guidelines for a certain period. They are given information and instructions on their use and the complete set of guidelines is handed over to them. This is the treatment of the study. To ensure that differences in interaction occur during the study, another group of mentors who have not received the guidelines are included in the design. 
Figure 4.3 shows the general design of the quasi-experimental cases. It is a non-equivalent control group design ('t Hart et al., 2001).

\begin{tabular}{|c|c|c|c|c|}
\hline Experimental group & $\begin{array}{l}\mathrm{O} 1 \\
\mathrm{O} 2 \\
\mathrm{O} 3\end{array}$ & $x$ & $\mathrm{O} 4$ & $\begin{array}{l}\mathrm{O} 5 \\
\mathrm{O} 6 \\
\mathrm{O} 7\end{array}$ \\
\hline Control group & $\begin{array}{l}\text { O1 } \\
\text { O2 } \\
\text { O3 }\end{array}$ & & O4 & $\begin{array}{l}\text { O5 } \\
\text { O6 } \\
\text { O7 }\end{array}$ \\
\hline
\end{tabular}

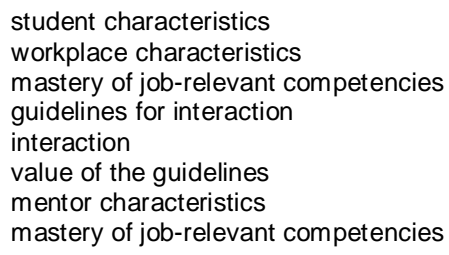

Figure 4.3 General quasi-experimental design.

\subsection{Instrumentation}

The research model can be divided into two measurement models, one for the application of the guidelines and the other for the acquisition of job-relevant competencies. The focus of the first model is implementation, and that of the second model, effectiveness. To measure the variables included in the research model, a number of scales and instruments were used, which are described in this section.

\subsubsection{Measurement model for implementation}

As mentioned in Section 4.2, the complete set of guidelines is handed over to the mentors in the experimental group and they are asked to interact with their student in accordance with these guidelines. It is necessary to establish whether the mentors act in accordance with this request. Several instruments have been developed and used to measure the variables that influence willingness to apply the guidelines and the way they are actually applied. These variables are connected to the guidelines, the treatment and the mentor.

The clarity and usefulness of the guidelines are both measured using a fivepoint response scale. The response scales differ with regard to their focus: the 
one scale reflects the extent to which each guideline is considered clear, with a range from 'very clear' to 'very unclear'. The other scale reflects the extent to which each guideline is considered useful, with a range from 'very useful' to 'not useful'. The items are used in a questionnaire that is completed by both mentor and student. They are also used in an interview, which provides the opportunity to question mentor or student should their opinion be negative.

Completeness is measured by means of an interview. Mentors are asked whether they missed any guidelines or whether they interacted with students in ways that were not included in the guidelines.

The treatment consists of the application of the guidelines during interaction. The way the guidelines are applied affects the acquisition of job-relevant competencies. To understand why the guidelines are applied in a certain way, two concepts are employed that have been used over the years in research that focuses on the implementation of educational innovations: levels of use and stages of concern.

The levels of use consist of eight different levels (Hall \& Loucks, 1978). In fact, these levels describe the development of routines (...). The lowest level is non-use, followed by orientation and preparation; the middle levels are mechanical use and routine. The highest levels are refinement, integration and renewal. Projected on this study the levels of use relate to the use of the guidelines. With regard to these levels, items have been developed and used in a pre-structured journal that the mentors have to complete each week. To prevent the journal from becoming too extensive and to limit the burden for the mentors, a selection of items is included in the journal. One of these is:

\section{I still think about what using the guidelines means to me (= orientation).}

Hall, George and Rutherford (1978) developed a manual for the use of a questionnaire to measure stages of concern. These stages deal with how users feel about an innovation. Users are first concerned about how an innovation will affect them; later, their concern shifts to how to complete tasks related to using the innovation and, finally, they become concerned with the impact on students (Hall \& Loucks, 1978). Houtveen and Van de Grift (1997) used these stages to develop a twelve-item scale to measure the intensity of involvement. Study results showed an $\alpha$-coefficient for internal consistency of .90. They also coupled interventions to support the users of an innovation to this scale. For this reason this scale is considered relevant to the study. To prevent the journal from becoming too extensive and to limit the burden for the mentors, a selection of items is included in the journal. One of these is:

I know what to do with the guidelines 
The items for levels, use and stages of concern are measured using a five-point response scale reflecting the extent to which a mentor agrees with it, ranging from 'totally disagree' to 'totally agree'.

On the Houtveen \& Van de Grift scale, a question was added to the semi-structured interview regarding whether the support the mentors received was sufficient.

The way the guidelines are applied can be characterised as adaptive if the mentor changes the sequence, does not use some of the guidelines, or adds new ones. When the mentor fully applies them as mentioned, his approach is of high fidelity (Van der Vegt, 1978). With regard to this main distinction, items were developed and used in the pre-structured journal the mentors have to complete each week. The mentor has to mark the items that are applicable. An example of some of these items is:

I applied the guidelines as intended.

I added guidelines.

I omitted guidelines.

If the mentors did not apply the guidelines as intended, they are asked in a semistructured interview why this was.

Items about the application of guidelines were also developed and used in a prestructured journal that students have to complete each week. Ten dichotomous items refer to groups of guidelines that are clustered as steps. The student has to mark whether the mentor conducted a step or not. An example of such an item is:

This week my mentor and I have spoken about the way I performed a task.

Some characteristics of the mentor have also been measured. The experience of the mentor in supporting students is measured using an item in a questionnaire on workplace characteristics and two items in a semi-structured interview. The mentor is asked how many students he has supported until now and from what educational sector these students came. He is also asked the number of years he has supported students. Experience, however, does not necessarily have to mean that the mentor also perceives himself as being capable. For this reason a selfperception question on capability is included in the semi-structured interview.

To measure the perception of mentors on learning, an instrument was developed that focused on the three mainstreams in learning theories: behaviourism, cognitivism, and social constructivism (Hoogerwaard, 2005). The characteristics of these mainstreams were translated into a number of constructs. Behaviourism consists of external steering, shaping, modelling, 
practice and feedback. Cognitivism consists of processing information, activating prior knowledge, and repetition, while constructivism consists of the constructs of reflection, active knowledge construction and social learning. Items were developed for each of these constructs. The total number of 62 items in a questionnaire are measured using a five-point response scale that reflects the extent to which a mentor agrees with it, ranging from 'totally disagree' to 'totally agree'. An example of such an item is:

Ifeel that a student has to understand why he does certain things.

Perception is also measured by items that contain important points of departure underlying the guidelines. These items are used in a semi-structured interview and measured using a five-point response scale reflecting the extent to which a mentor agrees with it $(1=$ totally disagree, $2=$ disagree, $3=$ don't agree or disagree, $4=$ agree, $5=$ totally agree). An example of such an item is:

I have to ensure that a student knows how well he performs tasks.

An open question is also included in the semi-structured interview on how the mentor perceived the past period of interacting with the student.

Finally, one item on the preparation by the mentor is used in the semi-structured interview:

Were you well prepared to support the student at the beginning of the period?

Table 4.4 provides an overview of the variables that are measured for implementation, the instrument used and the person who provides the corresponding data.

\subsubsection{Measurement model for effectiveness}

The dependent variable in this study is the acquisition of job-relevant competencies. Several instruments were developed and used to measure acquisition and the variables that influence this. These variables are connected to the student, the workplace and the treatment. 
Table 4.4 An overview of variables, instruments and respondents with regard to implementation

\begin{tabular}{|c|c|c|}
\hline Variable & $\begin{array}{l}\text { Instrument and } \\
\text { respondent }\end{array}$ & Aspects \\
\hline $\begin{array}{l}\text { Clarity of the guidelines } \\
\text { Usefulness of the guidelines }\end{array}$ & $\begin{array}{l}\text { Mentor questionnaire } \\
\text { Student questionnaire } \\
\text { Mentor interview } \\
\text { Student interview }\end{array}$ & \\
\hline $\begin{array}{l}\text { Completeness of the } \\
\text { guidelines }\end{array}$ & Mentor interview & $\begin{array}{l}\text { Missing guidelines } \\
\text { Alternative approaches }\end{array}$ \\
\hline Application of the guidelines & $\begin{array}{l}\text { Journal mentor } \\
\text { Mentor interview } \\
\text { Student journal }\end{array}$ & $\begin{array}{l}\text { Levels of use } \\
\text { Stages of concern } \\
\text { Adaptive vs. high-fidelity } \\
\text { approach } \\
\text { Reason for divergent } \\
\text { application } \\
\text { Received support } \\
\text { Application of steps }\end{array}$ \\
\hline Experience of mentor & $\begin{array}{l}\text { Mentor questionnaire } \\
\text { Mentor interview }\end{array}$ & $\begin{array}{l}\text { Number of years } \\
\text { Number of students } \\
\text { Educational sector students }\end{array}$ \\
\hline Perception & $\begin{array}{l}\text { Mentor questionnaire } \\
\text { Mentor interview }\end{array}$ & $\begin{array}{l}\text { Behaviourism } \\
\text { Cognitivism } \\
\text { Constructivism } \\
\text { Capability } \\
\text { Points of departure } \\
\text { guidelines } \\
\text { Past period of workplace } \\
\text { learning }\end{array}$ \\
\hline Preparation & Mentor interview & \\
\hline
\end{tabular}

As mentioned in Section 4.2, the acquisition of job-relevant tasks will show itself in the mastery of tasks. A task is a substantial part of the work process and contributes to the production of goods or services of a company. To measure the extent of mastery of a task, a six-point response scale is used, with a range from 'insufficient' to 'excellent'. It is, however, possible that a student had already mastered a task at a satisfactory level, but that he did not improve in performing it. The measurement therefore also focuses on the difference between a post-test and a pre-test on mastery as an indicator of effectiveness. For mastery, mentor and student have to complete the same short questionnaire with an overview of relevant tasks. The tasks are company and course-specific to ensure their 
relevance and are selected and formulated in close consultation with experts from the companies and the vocational education and training courses.

The treatment provides the input for the acquisition of the competencies. However, it is not only the extent to which the guidelines are applied that influences acquisition, time available for interaction is also measured. Mentor and student are asked to give an indication of the hours they spend daily and weekly on interaction. They are also asked how much time they were on leave or ill during the period of the study. In addition to time, the intensity of the treatment is also measured. Mentor and student are asked to mark in the pre-structured journal which tasks interaction had focused on that week.

Referring to the theoretical model, self-efficacy, conscientiousness, locus of control, anxiety, motivation and learning style were included in a questionnaire on student characteristics. All scales were derived from existing self-perception scales of personality. The questionnaire is to be completed by students.

Self-efficacy refers to the belief a student has in his or her own capabilities to achieve a desired result or aim (Bandura, 1997; Van Woerkom, 2003) To measure self-efficacy, a Dutch version of an IPIP scale is used (Hendriks, 1997).

Conscientiousness reflects qualities such as being reliable, hardworking, selfdisciplined and persevering (McCrae \& Costa in Colquitt \& Simmering, 1998). To measure conscientiousness, a Dutch version of an IPIP scale is used (Hendriks, 1997).

Locus of control refers to the control people perceive themselves to have over what happens to them and to the world surrounding them (Mitchell \& Larson, 1987; Noe, 1986). To measure locus of control, an IPIP scale (International Personality Item Pool, 2001) is used.

Anxiety refers to a feeling of being alone and helpless in a hostile world (Gleitman, 1991), existing as a chronic fear that has no particular object (Nijman, 2004). To measure anxiety, an IPIP scale (Costa \& McCrae, 1992) is used.

Motivation to learn refers to the direction, intensity and persistence of learningdirected behaviour in training contexts (Colquitt et al., 2000). To measure motivation to learn, a scale of Nijman (2004) was adapted to make it suitable for students in vocational education. 
These scales are measured using a five-point Likert-type response scale, reflecting the extent of applicability, with a range from 'not at all applicable' to 'entirely applicable'.

Learning style refers to a combination of preferred learning modes (Kolb, 1985). Hermanussen et al., (2000) developed the Questionnaire Practiceoriented Learning (QPL), which consists of five different scales representing different learning styles: immersion, conceptualisation, reflection, experimenttation and regulation. This questionnaire focuses on learning in practice and makes it suitable for research that focuses on workplace learning. An item is formulated as two opposite propositions. The scales for learning style are measured using a five-point response scale reflecting the extent to which a proposition fits the student: $(\mathrm{a}=$ proposition 1 fits much better than proposition $2, \mathrm{~b}=$ proposition 1 fits somewhat better than proposition $2, \mathrm{c}=$ it does not differ, $\mathrm{d}=$ proposition 2 fits much better than proposition 1 , e = proposition 2 fits somewhat better than proposition 1).

Table 4.5 provides an overview of the scales used in the questionnaire on student characteristics.

Table 4.5 Overview of the variables regarding student characteristics

\begin{tabular}{|c|c|c|c|c|}
\hline \multicolumn{5}{|c|}{ Measuring student characteristics } \\
\hline Variable & Original scale & $\begin{array}{l}\text { Number } \\
\text { of items }\end{array}$ & $\begin{array}{r}\alpha \text { original } \\
\text { scale }\end{array}$ & Adaptations \\
\hline Self-efficacy & $\begin{array}{l}\text { IPIP (Dutch } \\
\text { version) }\end{array}$ & 10 & .78 & 1 item adapted \\
\hline Conscientiousness & $\begin{array}{l}\text { IPIP (Dutch } \\
\text { version) }\end{array}$ & 10 & .81 & 5 items adapted \\
\hline Locus of control & IPIP & 20 & .86 & translated into Dutch \\
\hline Anxiety & IPIP & 10 & .83 & translated into Dutch \\
\hline Motivation & Nijman (2004) & 5 & .81 & $\begin{array}{l}\text { adapted for } \\
\text { vocational education }\end{array}$ \\
\hline $\begin{array}{l}\text { Learning style } \\
\text { (5 scales) }\end{array}$ & $\begin{array}{l}\text { Questionnaire } \\
\text { Practice-oriented } \\
\text { Learning (QPL) }\end{array}$ & 55 & $.62-.70$ & - \\
\hline
\end{tabular}


Prior knowledge, experience and resistance also determine whether learning will take place and what kind of learning processes will occur (Illeris, 2002). The student's prior knowledge and experience are measured using two items in a questionnaire and three items in a semi-structured interview. The student is asked in the questionnaire which year of the course he is in and whether he has a job. He is also asked in the interview about the number and locations of previous periods of workplace learning, what the student did during those periods, and whether he has become more experienced through jobs in his spare time. Resistance is measured by a number of items in the semi-structured interview. These items focus on the pleasure experienced during the period of workplace learning, and on unpleasant things that happened. Satisfaction with the mentor can decrease the negative effects of resistance. The student is asked to express the extent of his satisfaction in the journal and in the interview.

The interview also contains a question on whether the student was well prepared for this period of workplace learning.

Apart from the scales measuring the variables from the theoretical model, descriptive variables are included in the questionnaire: gender, age, vocational programme and level of prior education.

Referring to the research model, participation, variation, task autonomy, task information, task obscurity, work pressure, interaction and support were included in a questionnaire on workplace characteristics. Most of the scales were derived from existing instruments that have been used in research into workplace learning, and proved to be reliable (Nijman, 2004; Van Woerkom, 2003). The questionnaire is to be completed by mentors and other employees of the company.

Participation refers to the extent of influence an employee is given and actually has at the workplace. To measure participation, the scale of Van Woerkom (2003) is used. To measure variation, task autonomy, task information, task obscurity and work pressure, the VBBA scales are used (Van Veldhoven \& Meijman, 1994). The study results on these scales showed an acoefficient for internal consistency of between .79 and .85. For this reason the scale was considered suitable for inclusion in the questionnaire.

Interaction refers to the exchange of information at the workplace to support the performance of tasks. The items for this scale were not derived from other instruments. We developed these eight items ourselves.

To measure instrumental support, informational support, appraisal support and emotional support, the scales of Nijman (2004) are used. The study results on these scales showed an $\alpha$-coefficient for internal consistency of between .68 and .79. Because the focus of the questionnaire is on the characteristics of daily work, and not on support specifically related to the transfer of training, the items were reformulated and filled up. 
The scales mentioned are measured using a four-point Likert-type response scale, reflecting frequency $(1=$ hardly ever, $2=$ sometimes, $3=$ often, 4 = almost always).

Table 4.6 provides an overview of the scales used in the questionnaire on workplace characteristics.

Table 4.6 Overview of the variables regarding workplace characteristics

\begin{tabular}{|c|c|c|c|c|}
\hline \multicolumn{5}{|c|}{ Measuring workplace characteristics } \\
\hline Variable & Original scale & $\begin{array}{l}\text { Number } \\
\text { of items }\end{array}$ & $\begin{array}{r}\alpha \text { original } \\
\text { scale }\end{array}$ & Adaptations \\
\hline Participation & $\begin{array}{l}\text { VBBA \& Van } \\
\text { Woerkom }\end{array}$ & 10 & .91 & - \\
\hline Variation & VBBA & 6 & .79 & - \\
\hline Task autonomy & VBBA & 6 & .85 & - \\
\hline Task information & VBBA & 6 & .81 & - \\
\hline Task obscurity & VBBA & 6 & .80 & - \\
\hline Work pressure & VBBA & 6 & .81 & - \\
\hline Interaction & - & 8 & $?$ & $\begin{array}{l}\text { All items developed } \\
\text { ourselves }\end{array}$ \\
\hline $\begin{array}{l}\text { Support } \\
\text { (4 scales) }\end{array}$ & Nijman & 12 & $.68-.79$ & $\begin{array}{l}\text { All items were } \\
\text { adapted, } 14 \text { were } \\
\text { added }\end{array}$ \\
\hline
\end{tabular}

Table 4.7 provides an overview of all the variables measured, the instrument, and the person who provided the corresponding data.

\subsection{Reliability and validity}

There are several criteria for judging and improving the quality of a research design in general ('t Hart et al., 2001; Bastiaens, 1997; Swanborn, 1994; Yin, 1984): reliability, content validity, construct validity, internal validity and external validity. 
Table 4.7 An overview of variables, instruments and respondents with regard to effectiveness

\begin{tabular}{|c|c|c|}
\hline Variable & $\begin{array}{l}\text { Instrument and } \\
\text { respondent }\end{array}$ & Aspects \\
\hline Mastery & $\begin{array}{l}\text { Mentor questionnaire } \\
\text { Student questionnaire }\end{array}$ & \\
\hline Time spent on interaction & $\begin{array}{l}\text { Mentor journal } \\
\text { Student journal } \\
\text { Mentor interview } \\
\text { Student interview }\end{array}$ & $\begin{array}{l}\text { Hours spent weekly } \\
\text { Presence } \\
\text { Hours spent daily } \\
\text { Presence }\end{array}$ \\
\hline Intensity of interaction & $\begin{array}{l}\text { Journal mentor } \\
\text { Student journal }\end{array}$ & Selection of tasks \\
\hline $\begin{array}{l}\text { Self-efficacy } \\
\text { Conscientiousness } \\
\text { Locus of control } \\
\text { Anxiety } \\
\text { Motivation } \\
\text { Learning style }\end{array}$ & Student questionnaire & \\
\hline $\begin{array}{l}\text { Prior knowledge of student } \\
\text { Experience of student }\end{array}$ & $\begin{array}{l}\text { Student questionnaire } \\
\text { Student interview }\end{array}$ & $\begin{array}{l}\text { Year of the course } \\
\text { Previous periods of } \\
\text { workplace learning } \\
\text { Jobs in spare time }\end{array}$ \\
\hline Resistance & $\begin{array}{l}\text { Student interview } \\
\text { Student journal } \\
\text { Student interview }\end{array}$ & $\begin{array}{l}\text { Pleasure } \\
\text { Unpleasant or unexpected } \\
\text { events } \\
\text { Hindrance } \\
\text { Satisfaction }\end{array}$ \\
\hline Preparation & Student interview & \\
\hline $\begin{array}{l}\text { Age } \\
\text { Gender } \\
\text { Vocational program } \\
\text { Prior education }\end{array}$ & Student questionnaire & \\
\hline $\begin{array}{l}\text { Participation } \\
\text { Variation } \\
\text { Task autonomy } \\
\text { Task information } \\
\text { Task obscurity } \\
\text { Work pressure } \\
\text { Interaction } \\
\text { Support }\end{array}$ & Mentor questionnaire & \\
\hline
\end{tabular}


Reliability refers to the extent to which utterances are based on observations that are free of coincidental errors ('t Hart et al., 2001). In general, the larger the number of units that are observed during the study, the greater the reliability. One way to increase reliability is replication. This criterion is met by including a substantial number of mentors and students who interact in the study. Another way to increase reliability is to deploy several researchers. The interviews with mentors and students meet this criterion: they were carried out by various researchers. Finally, Cronbach's $\alpha$-coefficient is used to determine the internal consistency of scales, for instance of students' acquisition of job-relevant competencies, student characteristics and workplace characteristics. This refers to the accuracy or dependability of a measurement, for instance the extent of agreement between raters on their separate ratings of a variable (Cronbach, 1951).

Validity refers to the extent to which utterances are based on observations that are free of systematic errors ('t Hart et al., 2001). There are two major kinds of validity, the first being the validity of the selection of research units. It is far more important to assess this kind of validity in a survey than in a quasiexperiment. Moreover, it was not possible to assess this validity, because population information about mentors is not currently available. The second kind of validity is the validity of variables. When tests and scales are used, there are several ways of finding out whether what has been measured is what one intended to measure.

Content validity refers to the extent to which research instruments cover all the relevant aspects of the concept that they are intended to measure, while excluding redundant or irrelevant aspects (Swanborn, 1994). In this study, existing scales for constructs are used to increase content validity as much as possible. In other cases the scales were developed after reviewing relevant literature. The scales are also measured both in the pilot study and in the main study in order to filter out irrelevant aspects. And scales were also developed or adapted during discussions with expert reviewers.

Construct validity refers to establishing correct operational measures for the concepts being studied (Yin, 1984). The theoretical model and the scales instruments were developed after an extensive review of literature, and were also discussed with several expert reviewers. At the same time, the objective of the research design is to examine and validate the theoretical model for workplace learning. Triangulation of gathering data from both mentor and student is applied with regard to the interaction process and the extent to which students have acquired job-relevant competencies.

Internal validity refers to establishing a causal relationship, where certain conditions are shown to lead to other conditions (Yin, 1984). It is known that the internal validity of an experiment or quasi-experiment is threatened in several ways ('t Hart et al., 2001): by history, maturation, testing, 
instrumentation, regression, selection, mortality, diffusion of the treatment, compensatory equalisation of the treatment and compensatory rivalry. A nonequivalent control group design, however, is threatened by the interaction between several of these threats ('t Hart et al., 2001). The dependent variable in the study is the acquisition of job-relevant competencies. During the study the students spend a considerable amount of time at the workplace. They do not have many other opportunities to acquire the job-relevant competencies unless they have a job in their spare time. This job might cause history and maturation that could influence the extent to which students have grown and mastered tasks. Students are therefore asked whether they have worked in their spare time. The extent to which students have acquired job-relevant competencies is measured using a short questionnaire that is used a couple of times during the study. This neutralises the threat of instrumentation. The items in the questionnaire measure the acquisition of job-relevant competencies by asking to what extent students have mastered certain tasks. It is not likely that testing with these items will influence the acquisition of the competencies. To be able to check for the threat of regression and selection, the characteristics of the students in both the experimental group and the control group are compared. It is known that some students do not finish their period of workplace learning, because they do not meet the expectations of their mentor or the company, or they are dissatisfied with the situation at the workplace. In the case of mortality, the student and the mentor are asked why the student has ended the period of workplace learning prematurely. Their characteristics are also compared with those of the other students. The threat of diffusion of the treatment does not occur if each mentor works at a different company. As regards external validity, the study is not only conducted in small companies with just one mentor. If there are several mentors in one company, the division into experimental and control groups is based on units or Sections of the company. Mentors and students in the control group do not receive any kind of reward or compensation for participating in this group, to avoid the threat of compensatory equalisation. Finally, attempts are made to avoid compensatory rivalry by telling students and mentors that, during the study, information will be gathered about how workplace learning takes place. They are not told that the treatment is expected to improve the acquisition of job-relevant competencies. And only the mentors in the experimental group receive information about the guidelines.

External validity refers to establishing the domain to which the findings of a study can be generalised (Yin, 1984). It is known that the external validity of an experiment or quasi-experiment is threatened in several ways ('t Hart et al., 2001): interaction of testing and $X$, unrepresentative samples and reactive arrangements. A non-equivalent control group design, however, is mainly threatened by the interaction of testing and $\mathrm{X}$. The other two threats are less relevant to this design ('t Hart et al., 2001). The threat of interaction of testing and $\mathrm{X}$ is expected to be insignificant in this study, because the pre-test measures 
the students' mastery of job-relevant tasks, whereas the treatment consists of the guidelines for interaction for mentors. The threat of reactive arrangements is quite real, because the researcher is in contact with mentors and students when a) they have questions about the study or the instruments that are used, and b) they have not completed the measurement instruments. At the same time the researcher encourages the mentors in the experimental group to apply the guidelines for interaction so as to be able to test the hypothesis. This threat is considered while discussing the results of the study.

For a quasi-experiment it is difficult to create optimal conditions for both internal and external validity ('t Hart et al., 2001). Replication provides a solution to this research dilemma: mentors from different kinds of companies and students from different levels and from different routes are included in the study. To be able to include students from both routes, the study starts at the beginning of a period of workplace learning.

\subsection{Design of the study}

A pilot study must show to what extent the design and the instruments need to be adapted. The mentors and students of the experimental group are asked to judge the clarity, usefulness and completeness of the guidelines. At the same time the mentors in the experimental group are asked to interact with the student according to the guidelines, and the progress a student has made in acquiring a specific job-relevant competence is measured. This allows a first test of the hypothesis. The pilot study is also used to assess the reliability of the scales in the different instruments.

The main study must demonstrate how the treatment develops and to what extent the guidelines for interaction are applied by the mentors. It should also evaluate the effects of the treatment and test whether the expected causal relation exists. 


\subsubsection{General setting}

The study was conducted at the workplace where mentor and student interact.

The workplace is the physical environment where tasks are conducted that are needed to deliver the products or services of the company. The mentor is an employee who has been given the task of supporting a student in his or her daily learning and work at the workplace for a certain period of time. Although supporting the student is considered important by the company and the mentor, it is just one of his tasks. Most of the time he conducts tasks at the workplace that the student needs to learn in order to obtain his diploma. This provides the opportunity of working together, which increases the possibilities for interaction. It also provides the basis to truly evaluate the performance of students, because the mentor has seen this on a number of occasions. The mentor, however, will probably not be the only person with whom the student interacts: other employees too conduct tasks at the workplace. If the mentor is not available for some time, the student will turn to another employee for interaction. In small companies it is possible that the mentor is also a trained practical instructor, who maintains contact with the vocational education and training centre. In larger companies, however, the practical instructor often does not participate in the work processes on the floor. Mentors in a larger company will probably not have the opportunity to follow a course in interacting, because this would take too much time.

The student is someone who is participating in a secondary vocational education and training course. Courses are spread over four different training levels and two routes. The levels differ in a) complexity, varying from assistant's training to middle management training and specialist education, and b) duration, varying from six months to four years. The routes differ in the amount of time spent on learning at the workplace and the status of the participant. In a full-time college-based route a student spends $20 \%-60 \%$ of training time on workplace learning. In a part-time work-based route at least $60 \%$ of the training time has to be spent on workplace learning. The workplace learning of students is learning that takes place on the basis of participation in work processes at the workplace (see Chapter 2). It is programmed for certain periods of time, especially with regard to the full-time college-based route. Commonly, a period of workplace learning starts at the beginning of a quarter or a semester. It covers between ten and twenty weeks, and it is assumed that these periods allow for substantial competence development. Most students do not visit their schools during this period. Workplace learning in a part-time work-based route, however, is not restricted to a certain period of time, because students are employees, who work at least three days a week during their vocational education. 


\subsubsection{Design of the pilot study}

The pilot study was conducted in three different courses. The courses differed in level and sector; they included one course at level 2, one at level 3 and one at level 4 of the Dutch qualification structure for secondary vocational education and training. Level 1 was not included, because the number of courses and number of students at this level was far lower than at the other three levels.

Table 4.8 Courses in the pilot study

\begin{tabular}{lrl}
\hline Course & Level & Route \\
\hline Electrotechnical mechanic & 2 & part-time work-based \\
Orthopaedic shoemaker & 3 & part-time work-based \\
Educational assistant & 4 & full-time college-based
\end{tabular}

All the students of one class participated in the study. A class consists of between 20 and 40 students who are in the same year of their programme. The students attend their period of workplace learning at different companies and there is almost always just one student from that class in a company. The students are informed about the study at school by the researcher. It is common for companies to obtain their information, materials and instructions about the period of workplace learning through the regional centre for vocational education and training institute. The institute therefore asks the companies to participate in the study and invites the mentors for an information and instruction meeting at the school. The tasks that are selected for the study fit into the student's educational programme and the company's work processes. The study took place in the final quarter of the school year, which started in April and ended in July 2004. It lasted for ten weeks.

The research questions in the pilot study are:

1. Are the scales of student characteristics and workplace characteristics reliable?

2. Are the guidelines for interaction clear, usable and complete?

3. Are the guidelines actually used?

4. Does application of the guidelines by the mentor lead to significantly better acquisition of job-relevant competencies by the student?

To answer these questions, a quasi-experimental design is used. The treatment for the experimental group consists of the guidelines for interaction; the dependent variable is the acquisition of job-relevant competencies. Student characteristics and workplace characteristics are used as control variables. 
The student characteristics and workplace characteristics are measured using the scales and response scales mentioned in Subsection 4.4.2. For reasons of efficiency, students are asked to complete the questionnaire on student characteristics in the presence of a researcher at the beginning of the study at school. The mentors are asked to complete the questionnaire at the beginning of the study period. Mastery of the job-relevant competencies is measured several times: the first time being before the students have performed a chosen task, the second after the first performance and the third after the second performance. Both student and mentor are asked to complete these questionnaires. At the end of the study period mentors and students of the experimental group are asked to complete the questionnaire on the clarity and usefulness of the guidelines. In an interview they are also asked whether their mentor has applied the guidelines and whether the guidelines are complete. If mentors and students have not completed the questionnaire, they are asked their opinion of the guidelines during the interview.

Chapter 5 presents the results of the pilot study and their consequences for the design and the instruments for the main study. 


\section{Chapter 5}

\section{Pilot study}

\subsection{Introduction}

The previous chapter presented the research model and the instrumentation to test the hypothesis that application of the guidelines for interaction by a mentor leads to significantly better acquisition of job-relevant competencies by a student. To test this hypothesis, a quasi-experimental design was chosen and applied in a pilot study consisting of three settings. This chapter presents the results of the pilot study and the consequences for the design and the instruments for the main study.

\subsection{Research questions}

The research questions of the pilot study are:

1. Are the scales of student characteristics and workplace characteristics reliable?

2. Are the guidelines for interaction clear, usable and complete?

3. Are the guidelines actually used?

4. Does the application of the guidelines by the mentor lead to significantly better acquisition of job-relevant competencies by the student?

To answer the final question a quasi-experimental design was used. The treatment for the experimental group consists of the guidelines for interaction. The dependent variable is the acquisition of job-relevant competencies. Student characteristics and workplace characteristics are used as control variables.

The pilot study was conducted in three different settings. The settings differed in level and sector; they included one setting at level 2, one at level 3 and one at level 4 of the Dutch qualification structure for secondary vocational education and training. In each setting students from one class participated in the study.

The educational managers agreed to participate in the pilot study. After their approval, teachers advised the researcher about a job-relevant competency that would fit the student's prior knowledge and experience, the programme and 
the tasks in the company. In close consultation they developed a set of criteria to measure acquisition of that competency.

All the companies were also informed in good time about the aim of the study and the conditions. This was done by letter or during a visit by the workplace learning coordinator of the regional centre for vocational education and training. Attempts to organise a meeting for mentors of the companies at the regional centre to provide additional information and instructions about the study failed: either the mentors did not sign up for the meeting or the regional centre postponed it. For these reasons the mentors received the necessary information and instructions in writing. To ensure that the envelope was not mislaid within the company and to avoid loss of time, the students were asked to hand the envelope to their mentor.

The students were informed about the study and the research material during a thirty-minute meeting with the researcher at the regional centre. They were also told that the acquisition of the selected job-relevant competencies was part of the curriculum, not an additional assignment. The meeting was also used to find out whether the materials were clear to the students, who proved not to have any questions at that time. The experimental group and the control group were given their information separately. Students in the experimental group expected participation in the study to take extra time and effort.

The pilot study started in April and ended in July 2005.

Table 5.1 presents an overview of the three settings and the distribution of the numbers of students and numbers of companies between experimental group and control group. To prevent contact and exchange of information between these two groups as far as possible, the assignment of students to one of these groups was based on classes or groups that already existed at the vocational education and training centre. These existing groups had their own teachers at school, and/or their own timetables. Existing groups of students were assigned to the experimental group or the control group at random. If students had the same mentor at a company, these students were all assigned either to the experimental group or to the control group. 
Table 5.1 The three settings of the pilot study

\begin{tabular}{lrrrrrr}
\hline & & & $\begin{array}{c}\text { Number of } \\
\text { students }\end{array}$ & \multicolumn{2}{c}{$\begin{array}{c}\text { Number of } \\
\text { companies }\end{array}$} \\
Setting & Level & Route & Exp Cont & Exp & Cont \\
\hline $\begin{array}{l}\text { Electrotechnical } \\
\text { mechanic }\end{array}$ & 2 & Part-time work-based & 13 & 13 & 11 & 10 \\
$\begin{array}{l}\text { Orthopaedic shoemaker } \\
\text { Educational assistant }\end{array}$ & 3 & Part-time work-based & 12 & 12 & 11 & 9 \\
& 4 & Full-time college-based & 20 & 19 & 20 & 19 \\
& & Total & 45 & 44 & 42 & 38 \\
\hline
\end{tabular}

\subsection{Student characteristics and workplace characteristics}

\subsubsection{Results with regard to student characteristics}

Referring to the research design in Chapter 4, self-efficacy, conscientiousness, locus of control, anxiety, motivation and learning style were included in a questionnaire on student characteristics. Students, teachers and an expert reviewer were asked to comment on the first version, which was slightly adapted. During the pilot students were asked to complete this adapted, second version of the questionnaire.

The questionnaire was completed by 86 of the 89 students (97\%), which provided a solid basis for analysis of the internal consistency of the scales. Cronbach's $\alpha$-coefficient proved to be acceptable, with scores varying from .59 to .77. For some scales improvement in the scores could be realised by deleting an item. Critical reflection and adaptation of scales with an $\alpha$ below .60 was considered necessary for the main study.

Table 5.2 provides an overview of the scales used in the questionnaire on student characteristics and their $\alpha$. 
Table 5.2 Overview of the questionnaire on student characteristics

\begin{tabular}{|c|c|c|c|c|}
\hline Variable & Original scale & $\begin{array}{l}\text { Number } \\
\text { of items }\end{array}$ & $\begin{array}{r}\alpha \\
\text { original } \\
\text { scale }\end{array}$ & a pilot after correction \\
\hline Self-efficacy & $\begin{array}{l}\text { IPIP (Dutch } \\
\text { version) }\end{array}$ & 10 & .78 & $\begin{array}{c}.72 \text { (if one item is } \\
\text { deleted) }\end{array}$ \\
\hline Conscientiousness & $\begin{array}{l}\text { IPIP (Dutch } \\
\text { version) }\end{array}$ & 10 & .81 & $\begin{array}{c}.70 \text { (if one item is } \\
\text { deleted) }\end{array}$ \\
\hline Locus of control & IPIP & 20 & .86 & $\begin{array}{c}.75 \text { if one item is } \\
\text { deleted) }\end{array}$ \\
\hline Anxiety & IPIP & 10 & .83 & $\begin{array}{c}.77 \text { (if one item is } \\
\text { deleted) }\end{array}$ \\
\hline Motivation & Nijman (2004) & 5 & .81 & .74 \\
\hline Learning style: & $\begin{array}{l}\text { Questionnaire } \\
\text { Practice- } \\
\text { oriented } \\
\text { Learning (QPL) }\end{array}$ & & & \\
\hline Immersion & & 13 & .63 & $\begin{array}{c}.61 \text { (if one item is } \\
\text { deleted) }\end{array}$ \\
\hline Conceptualisation & & 12 & .70 & .77 \\
\hline Reflection & & 12 & 62 & $\begin{array}{l}.71 \text { (if one item is } \\
\text { deleted) }\end{array}$ \\
\hline Experimentation & & 8 & .69 & $\begin{array}{c}.68 \text { (if one item is } \\
\text { deleted) }\end{array}$ \\
\hline Regulation & & 10 & .64 & .59 \\
\hline
\end{tabular}

Looking at the mean scores for the student characteristics, students consider themselves highly motivated, their belief in their own capabilities (self-efficacy) is quite strong, their conscientiousness is quite high, and they feel that they have quite good control over what happens to them (locus of control). At the same time, they do not feel quite strongly alone or helpless (anxiety). The experimental groups and the control groups within the three settings differ significantly on locus of control (for the electrotechnical mechanic, $p<.05$ ) and on motivation (for the orthopaedic shoemaker, $\mathrm{p}=.01$ ). The three settings differ significantly on all these characteristics $(\mathrm{p}<.05)$, with students from the orthopaedic shoemaker course having the highest scores. This could be due to their age (their average age of 30 is much higher than that of the students from the other two settings, who are 18 years old) (see Table 5.5).

The learning style reveals that students characterise themselves as more immersed than detached, more generic than idiosyncratic, more learningoriented than performance-oriented, more inquiring-oriented than prescriptionoriented. They prefer external regulation slightly more then internal. The experimental group and the control group within the three settings differ significantly on experimentation (for the electrotechnical mechanic, $\mathrm{p}<.05$ ), on 
conceptualisation and experimentation (for the orthopaedic shoemaker, $\mathrm{p}<.1$ ), and on regulation (for the educational assistant, $\mathrm{p}<.05$ ). The three settings differ significantly on immersion and conceptualisation $(\mathrm{p}<.01)$, and on reflection $(\mathrm{p}<.1)$.

Table 5.3 and Table 5.4 present the mean scores for student characteristics. These indicate that the students already possess to a fairly large extent those characteristics that influence learning in a positive way. This might influence the effects of the guidelines on the acquisition of job-relevant competencies.

Table 5.3 Mean scores of experimental groups and control groups for student characteristics

\begin{tabular}{|c|c|c|c|c|c|c|}
\hline \multirow[b]{2}{*}{ Scale } & \multicolumn{2}{|c|}{$\begin{array}{l}\text { Electrotechnical } \\
\text { mechanic }\end{array}$} & \multicolumn{2}{|c|}{$\begin{array}{l}\text { Orthopaedic } \\
\text { shoemaker }\end{array}$} & \multicolumn{2}{|c|}{$\begin{array}{c}\text { Educational } \\
\text { assistant }\end{array}$} \\
\hline & $\begin{array}{r}\text { Exp } \\
(n=13)\end{array}$ & $\begin{array}{r}\text { Con } \\
(n=13)\end{array}$ & $\begin{array}{r}\text { Exp } \\
(n=12)\end{array}$ & $\begin{array}{r}\text { Con } \\
(n=12)\end{array}$ & $\begin{array}{r}\text { Exp } \\
(n=19)\end{array}$ & $\begin{array}{r}\text { Con } \\
(n=17)\end{array}$ \\
\hline Self-efficacy & 3.64 & 3.88 & 3.99 & 4.04 & 3.74 & 3.72 \\
\hline Conscientiousness & 3.70 & 3.88 & 3.92 & 4.07 & 3.52 & 3.51 \\
\hline Anxiety & 2.28 & 2.38 & 2.30 & 2.43 & 2.81 & 2.66 \\
\hline Motivation & 4.05 & 3.77 & 4.13 & 4.55 & 4.12 & 4.11 \\
\hline Locus of control & 3.63 & 3.95 & 3.82 & 3.93 & 3.63 & 3.64 \\
\hline Learning style: & & & & & & \\
\hline Immersion & 2.80 & 2.55 & 2.99 & 2.80 & 2.48 & 2.39 \\
\hline Conceptualisation & 2.65 & 2.57 & 2.53 & 2.06 & 2.82 & 2.89 \\
\hline Reflection & 2.80 & 2.78 & 2.69 & 2.24 & 2.53 & 2.45 \\
\hline Experimentation & 2.75 & 2.23 & 2.70 & 2.43 & 2.78 & 2.51 \\
\hline Regulation & 2.80 & 2.82 & 2.93 & 2.82 & 2.95 & 2.62 \\
\hline $\begin{array}{l}1=\text { not at all applicable } \\
2=\text { slightly applicable } \\
3=\text { moderately applicable } \\
4=\text { largely applicable } \\
5=\text { completely applicable }\end{array}$ & $\begin{array}{l}\text { Lear } \\
\text { Imm } \\
\text { Cono } \\
\text { Refle } \\
\text { Expe } \\
\text { Regu }\end{array}$ & $\begin{array}{l}\text { tyle: } \\
\text { lisation } \\
\text { tation }\end{array}$ & \multicolumn{2}{|c|}{$\begin{array}{l}1=\text { immersed } \\
1=\text { generic }(\text { strategic) } \\
1=\text { learning-oriented } \\
1=\text { inquiring } \\
1=\text { external regulation }\end{array}$} & \multicolumn{2}{|c|}{$\begin{array}{l}5=\text { detached } \\
5=\text { idiosyncratic (pragmatic) } \\
5=\text { performance-oriented } \\
5=\text { prescription-oriented } \\
5=\text { internal regulation }\end{array}$} \\
\hline
\end{tabular}


Table 5.4 Mean scores of settings for student characteristics

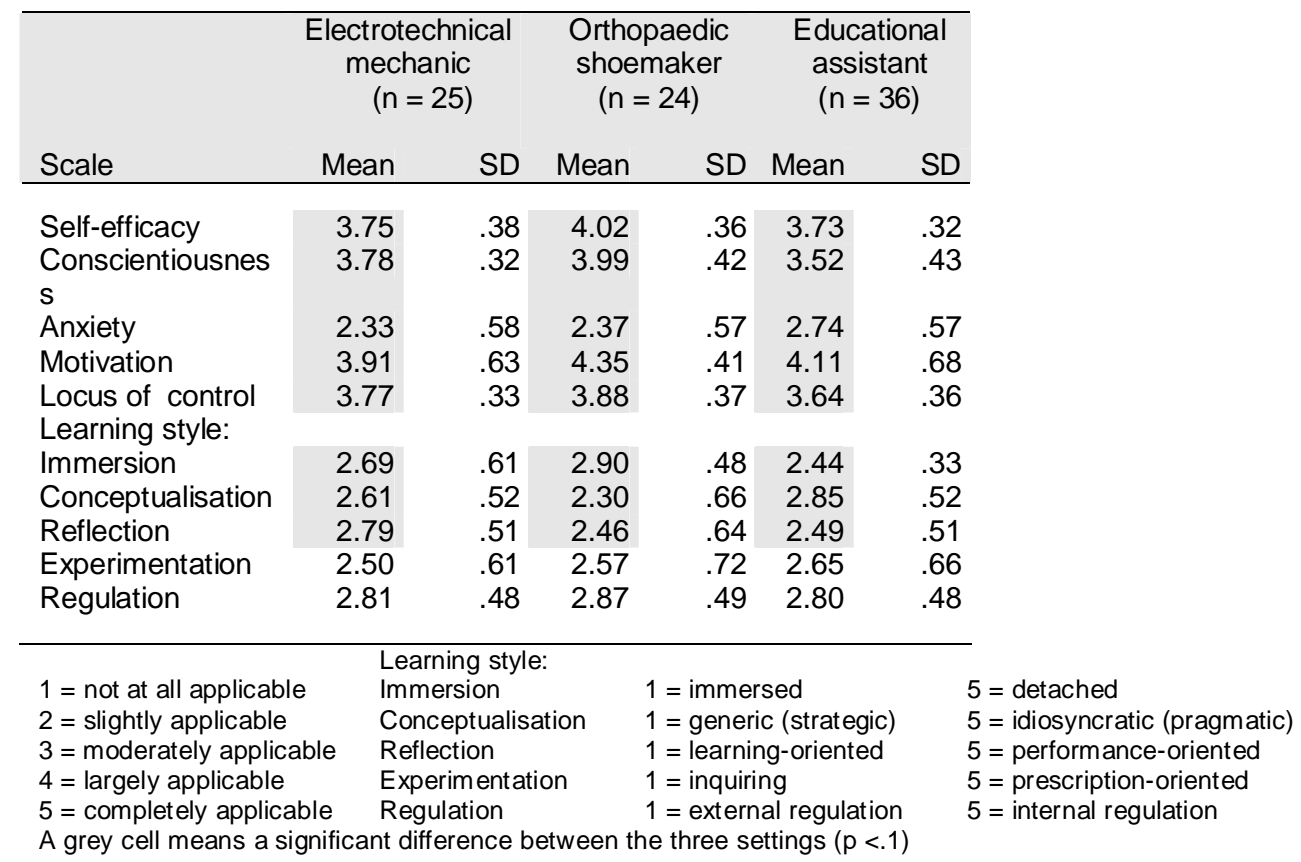

Table 5.5 Age of the students

\begin{tabular}{cccccr}
\hline \multicolumn{2}{c}{ Electrotechnical mechanic } & \multicolumn{3}{c}{ Orthopaedic shoemaker } & \multicolumn{3}{c}{ Educational assistant } \\
$\begin{array}{c}\text { Exp } \\
(\mathrm{n}=13)\end{array}$ & $\begin{array}{c}\text { Con } \\
(\mathrm{n}=13)\end{array}$ & $\begin{array}{c}\text { Exp } \\
(\mathrm{n}=12)\end{array}$ & $\begin{array}{c}\text { Con } \\
(\mathrm{n}=12)\end{array}$ & $\begin{array}{c}\text { Exp } \\
(\mathrm{n}=18)\end{array}$ & $\begin{array}{r}\text { Con } \\
(\mathrm{n}=17)\end{array}$ \\
\hline 17.08 & 17.54 & 27.58 & 32.50 & 17.78 & 17.94 \\
\hline
\end{tabular}

\subsubsection{Results with regard to workplace characteristics}

Referring to the research model, participation, variation, task autonomy, task information, task obscurity, pressure of work, interaction and support were included in a questionnaire on workplace characteristics. Workplace learning coordinators and an expert reviewer were asked to comment on the first version, which was adapted slightly. During the pilot mentors and other employees of 
the company were asked to complete this adapted, second version of the questionnaire.

The questionnaire was completed by mentors and employees of 39 of the 80 companies (49\%). In total, 98 questionnaires were received, which provided a solid basis for analysis of the internal consistency of the scales. For most scales Cronbach's $\alpha$-coefficient proved to be acceptable, with scores varying from .62 to .89. For some scales improvement in the scores could be realised by deleting an item. Adaptation of the scales was not necessary for the main study.

Table 5.6 provides an overview of the scales used in the questionnaire on workplace characteristics and their $\alpha$.

Table 5.6 Overview of the questionnaire on workplace characteristics

\begin{tabular}{llrrl}
\hline Variable & Original scale & $\begin{array}{r}\text { Number } \\
\text { of items }\end{array}$ & $\begin{array}{r}\alpha \text { original } \\
\text { scale }\end{array}$ & a pilot after correction \\
\hline Participation & $\begin{array}{l}\text { VBBA \& Van } \\
\text { Woerkom }\end{array}$ & 10 & .91 & .89 \\
Variation & VBBA & 6 & .79 & .75 \\
Task autonomy & VBBA & 6 & .85 & .67 (if one item is deleted) \\
Task information & VBBA & 6 & .81 & .83 (if one item is deleted) \\
Task obscurity & VBBA & 6 & .80 & .76 (if one item is deleted) \\
Pressure of work & VBBA & 6 & .81 & .66 \\
Interaction & - & 8 & -.62 \\
Support & Nijman & 26 & $.68-.79$ & .85 \\
(4 scales) & & & & \\
\hline
\end{tabular}

From the mean scores for the workplace characteristics, it is clear that mentors and their colleagues find they have a lot of variation and task autonomy. They often experience support. They feel that they can quite often influence what is happening at the workplace (participation) and they interact with their colleagues also quite often. At the same time, information necessary to conduct the tasks in the proper way is not always available and pressure of work is regularly rather high. The companies in the experimental groups and in the control groups differ significantly on participation (orthopaedic shoemaker, $\mathrm{p}<.1$, educational assistant, $\mathrm{p}<.05$ ), and on interaction (educational assistant, $\mathrm{p}<.1)$ The three settings indicate that the companies differ significantly on variation, support $(\mathrm{p}<.01)$ and interaction $(\mathrm{p}<.05)$. The mean scores show that the workplace situation in the electrotechnical companies is less ideal with regard to learning conditions than in those of the orthopaedic shoemakers and in elementary schools. Table 5.7 and Table 5.8 present the mean scores for the workplace characteristics. 
The mean scores indicate that learning conditions at the workplaces are already in existence and have been fulfilled to a fairly large extent. This might influence the effects of the guidelines on the acquisition of job-relevant competencies.

Table 5.7 Mean scores of experimental groups and control groups for workplace characteristics

\begin{tabular}{|c|c|c|c|c|c|c|}
\hline \multirow[b]{2}{*}{ Scale } & \multicolumn{2}{|c|}{$\begin{array}{l}\text { Electrotechnical } \\
\text { mechanic }\end{array}$} & \multicolumn{2}{|c|}{$\begin{array}{l}\text { Orthopaedic } \\
\text { shoemaker }\end{array}$} & \multicolumn{2}{|c|}{$\begin{array}{l}\text { Educational } \\
\text { assistant }\end{array}$} \\
\hline & $\begin{array}{r}\text { Exp } \\
(n=5)\end{array}$ & $\begin{array}{r}\text { Con } \\
(\mathrm{n}=5)\end{array}$ & $\begin{array}{r}\text { Exp } \\
(\mathrm{n}=17)\end{array}$ & $\begin{array}{r}\text { Con } \\
(n=11)\end{array}$ & $\begin{array}{r}\text { Exp } \\
(\mathrm{n}=17)\end{array}$ & $\begin{array}{r}\text { Con } \\
(\mathrm{n}=20)\end{array}$ \\
\hline Participation & 2.70 & 2.83 & 2.76 & 3.25 & 2.69 & 3.08 \\
\hline Variation & 2.93 & 2.97 & 3.45 & 3.48 & 3.33 & 3.43 \\
\hline Support & 2.57 & 2.87 & 2.93 & 3.02 & 2.95 & 3.04 \\
\hline Task autonomy & 2.73 & 3.07 & 2.99 & 3.17 & 2.97 & 3.12 \\
\hline $\begin{array}{l}\text { Task } \\
\text { information }\end{array}$ & 2.08 & 2.50 & 2.72 & 2.67 & 2.62 & 2.61 \\
\hline $\begin{array}{l}\text { Pressure of } \\
\text { work }\end{array}$ & 2.57 & 2.57 & 2.81 & 2.97 & 2.75 & 2.62 \\
\hline Interaction & 2.57 & 2.50 & 2.89 & 2.98 & 2.70 & 3.01 \\
\hline Task obscurity & 1.90 & 2.25 & 1.71 & 1.77 & 1.77 & 1.80 \\
\hline
\end{tabular}

A grey cell means a significant difference between experimental group and control group $(p<.1)$

Table 5.8 Mean scores of the settings for the workplace characteristics

\begin{tabular}{|c|c|c|c|c|c|c|}
\hline \multirow[b]{2}{*}{ Scale } & \multicolumn{2}{|c|}{$\begin{array}{l}\text { Electrotechnical } \\
\text { mechanic } \\
(n=16)\end{array}$} & \multicolumn{2}{|c|}{$\begin{array}{c}\text { Orthopaedic } \\
\text { shoemaker } \\
(n=31)\end{array}$} & \multicolumn{2}{|c|}{$\begin{array}{c}\text { Educational } \\
\text { assistant } \\
(n=43)\end{array}$} \\
\hline & Mean & SD & Mean & SD & Mean & SD \\
\hline Participation & 2.88 & .82 & 2.96 & .64 & 2.85 & .56 \\
\hline Variation & 3.03 & .57 & 3.42 & .38 & 3.40 & .40 \\
\hline Support & 2.70 & .35 & 2.97 & .32 & 3.00 & .31 \\
\hline Task autonomy & 3.05 & .65 & 3.08 & .52 & 3.21 & 1.18 \\
\hline $\begin{array}{l}\text { Task } \\
\text { information }\end{array}$ & 2.39 & .66 & 2.76 & .53 & 2.61 & .51 \\
\hline $\begin{array}{l}\text { Pressure of } \\
\text { work }\end{array}$ & 2.64 & .51 & 2.88 & .47 & 2.68 & .50 \\
\hline Interaction & 2.57 & .47 & 2.94 & .44 & 2.84 & .48 \\
\hline Task obscurity & 1.96 & .53 & 1.70 & .40 & 1.83 & .50 \\
\hline
\end{tabular}

A grey cell means a significant difference between the three settings $(p<.1)$ 


\subsection{Guidelines for interaction}

\subsubsection{Results with regard to clarity, usefulness and completeness}

Mentors and students in the experimental groups were asked to evaluate the clarity, usefulness and completeness of the guidelines for interaction. Eleven of the 45 students (24\%) and 13 of the 43 mentors (30\%) completed the questionnaire on clarity and usefulness and scored the guidelines on a five-point Likertlike response scale. Mentors and students who did not complete the questionnaire had various reasons for not doing so. One important reason was that about half the mentors and students did not use the guidelines and therefore had no experience with them (see also Section 5.3.2). Another reason was that mentors had not received the guidelines, because students had not handed the research material to them, or because students were assigned to other mentors, who had not received the material from their predecessor.

As described in Chapter 3, a total of 77 guidelines are clustered in 12 steps, which are spread over four phases in the interaction process. Cronbach's $\alpha$-coefficient for clarity is .99 and for usefulness it is .97. Looking at the scores of all 24 respondents, 73 of the guidelines (95\%) have a score between 1.6 and 2.0 for clarity, the remaining 4 guidelines have a score between 2.1 and $2.5(1=$ very clear, $2=$ clear, $3=$ moderately clear). The mentors' mean score on clarity of the guidelines is 1.77 , the students' mean score, 2.02. For the twelve steps, the mentors' scores vary from 1.58 to 1.89 . The students' scores are somewhat higher and vary from 1.75 to 2.36 . The scores of mentors and of students do not differ significantly, with the exception of step 2 ( $p<.05$ at $95 \%)$. The steps that belong to phase one of the interaction process (orientation) are the least clear. In general, the results do not require adaptation of the guidelines, because both mentors and students evaluated them as clear. The steps of phase 1, however, are less clear to the students and need to be re-examined to ensure that interaction with the student is not hampered by a lack of clarity.

The results in each of the three different settings show that the scores for clarity vary. In the orthopaedic shoemakers setting, mentors and students find the guidelines clearer than did the mentors and students in the electrotechnical mechanic setting. The results of the educational assistant setting fall between these two. These differences, however, are not significant, with the exception of steps 4 (mentors, $\mathrm{p}<.1$ ), 1 and 7 (students, $\mathrm{p}<.05$ ). It is not clear why the results of these settings differ.

Table 5.9 presents the scores for clarity. 
Table 5.9 Scores for clarity of the guidelines for interaction

\begin{tabular}{|c|c|c|c|c|c|c|c|c|c|c|c|c|c|}
\hline Mean & $\begin{array}{l}\text { Step } \\
1-12 \\
\end{array}$ & $\begin{array}{c}\text { Step } \\
1\end{array}$ & $\begin{array}{c}\text { Step } \\
2 \\
\end{array}$ & $\begin{array}{c}\text { Phase } \\
1 \\
\text { Step } \\
3 \\
\end{array}$ & $\begin{array}{c}\text { Step } \\
4\end{array}$ & $\begin{array}{c}\text { Step } \\
5\end{array}$ & $\begin{array}{c}\text { Step } \\
6\end{array}$ & $\begin{array}{c}\text { Phase } \\
2 \\
\text { Step } \\
7 \\
\end{array}$ & $\begin{array}{c}\text { Step } \\
8 \\
\end{array}$ & $\begin{array}{c}\text { Step } \\
9\end{array}$ & $\begin{array}{c}\text { Phase } \\
3 \\
\text { Step } \\
10 \\
\end{array}$ & $\begin{array}{c}\text { Step } \\
11 \\
\end{array}$ & $\begin{array}{c}\text { Phase } \\
4 \\
\text { Step } \\
12 \\
\end{array}$ \\
\hline $\begin{array}{l}\text { Mentor } \\
(n=13)\end{array}$ & 1.77 & 1.77 & 1.75 & 1.87 & 1.89 & 1.85 & 1.80 & 1.80 & 1.58 & 1.76 & 1.73 & 1.77 & 1.69 \\
\hline $\begin{array}{l}\text { Student } \\
(n=11)\end{array}$ & 2.02 & 2.22 & 2.36 & 2.03 & 2.21 & 2.35 & 2.10 & 1.82 & 1.75 & 1.89 & 1.89 & 1.95 & 1.92 \\
\hline $\begin{array}{l}\text { Mentor EM } \\
(n=3)\end{array}$ & 2.11 & 2.22 & 2.04 & 2.22 & 2.14 & 2.17 & 2.07 & 2.17 & 1.67 & 2.24 & 2.10 & 2.27 & 2.06 \\
\hline $\begin{array}{l}\text { Mentor OS } \\
(n=5)\end{array}$ & 1.58 & 1.53 & 1.48 & 1.59 & 1.57 & 1.60 & 1.52 & 1.78 & 1.52 & 1.57 & 1.64 & 1.64 & 1.57 \\
\hline $\begin{array}{l}\text { Mentor EA } \\
(n=5)\end{array}$ & 1.75 & 1.73 & 1.85 & 1.93 & 2.06 & 1.90 & 1.92 & 1.60 & 1.60 & 1.66 & 1.60 & 1.60 & 1.60 \\
\hline $\begin{array}{l}\text { Student EM } \\
(n=3)\end{array}$ & 2.30 & 3.50 & 2.50 & 2.22 & 2.43 & 3.00 & 2.40 & 2.09 & 1.67 & 1.95 & 2.03 & 2.07 & 1.72 \\
\hline $\begin{array}{l}\text { Student OS } \\
(n=4)\end{array}$ & 1.64 & 1.33 & 1.83 & 1.56 & 1.86 & 1.83 & 1.80 & 1.34 & 1.55 & 1.61 & 1.60 & 1.58 & 1.88 \\
\hline $\begin{array}{l}\text { Student EA } \\
(n=4)\end{array}$ & 2.19 & 1.92 & 2.65 & 2.25 & 2.32 & 2.25 & 2.25 & 2.09 & 2.00 & 2.13 & 2.08 & 2.23 & 2.13 \\
\hline
\end{tabular}

Looking at the scores of all 24 respondents for usefulness, 37 of the guidelines $(48 \%)$ have a score of between 1.6 and 2.0; 34 guidelines (44\%) have a score of between 2.1 and 2.5, and 6 guidelines (8\%) have a score of between 2.6 and 3.0 ( 1 = very useful, $2=$ useful, $3=$ moderately useful $)$.

The mentors' mean score for the usefulness of the guidelines is 2.16, which is close to useful. The students' score is comparable (2.20). For the twelve steps, the mentors' scores vary from 1.95 to 2.40 . The students' scores are somewhat higher and vary from 1.78 to 2.65 , but they do not differ significantly from the mentors' scores. The steps that belong to phase one of the interaction process (orientation) are the least useful.

The mentors consider the guidelines in steps 1, 4 and 11 the least useful. Step 1 is criticised because it gives students the possibility to choose a task they want to learn and perform. According to the mentors, at the workplace students often cannot choose; they have to do what they are asked. In spite of this criticism, the step will not be altered fundamentally because the possibility of choice motivates students and because it relates to participation and task autonomy, which have been shown to influence learning positively. Step 4 is criticised because of its distinction between learning at the workplace during 
working hours and after working hours. Learning at the workplace after working hours is not seen as realistic, because normally the mentor is not present and available then and the company is not always open. At the same time, the guidelines give students the possibility to say how they want to learn to master a task. As with step 1, this possibility is not seen as desirable or achievable, because the work process itself determines what is to be done and how. The guidelines in step 4 are also used in step 11; it is thus consistent that this step is also seen as less useful. Considering the scores on usefulness and the criticism expressed, steps 4 and 11 need to be adapted.

The students are critical of the usefulness of the steps in phase 1, which focuses on orientation to a new task. Their criticism of steps 2,3 and 5 concentrates on the difficulty of answering questions about a task a student does not know or is not yet familiar with. Their criticism of step 4 corresponds with that of the mentors. Step 6 is considered less useful for the same reasons as for the steps in phase 1 . The guidelines in step 4 are also used in step 11; it is therefore consistent that this step is also seen as less useful. In view of the scores for usefulness and the criticism expressed, steps 4 and 11 need to be adapted. The guidelines in the other steps are expected to become more useful if students are not asked about unknown tasks but are told by the mentor what they can expect and what is required of them to perform it adequately.

Looking at the results in each of the three different settings, the scores on clarity vary. In the eletrotechnical mechanic setting, mentors find the guidelines a little more useful than do the mentors in the educational assistant setting. The differences are not significant, with the exception of step $5(\mathrm{p}<.1)$. In the orthopaedic shoemaker setting, students find the guidelines more useful than do the students in the educational assistant setting. The students' scores differ significantly on steps 1,3 and 10 ( $\mathrm{p}<.1$ ), and steps 2 and 7 (students, $\mathrm{p}<.05)$. It is not clear why the results of the settings differ.

Table 5.10 presents the scores on usefulness.

The scores of the students on clarity and usefulness correlate significantly at the .01 level (2-tailed, Pearson Correlation is .845). This means that the more the guidelines are judged as unclear, the more their usefulness is doubted, which fits in with the reasoning "I can't use things I don't understand". This pattern is not found among the mentors, which means that their assessment of usefulness is not based on their perception of clarity. Other arguments must therefore have played a role, such as that the guidelines did not fit in with their one way of interacting or did not fit the work process at the workplace. 
Table 5.10 Scores on the usefulness of the guidelines for interaction

\begin{tabular}{|c|c|c|c|c|c|c|c|c|c|c|c|c|c|}
\hline Mean & $\begin{array}{l}\text { Step } \\
1-12\end{array}$ & $\begin{array}{c}\text { Step } \\
1\end{array}$ & $\begin{array}{c}\text { Step } \\
2\end{array}$ & $\begin{array}{c}\text { Phase } \\
1 \\
\text { Step } \\
3\end{array}$ & $\begin{array}{c}\text { Step } \\
4\end{array}$ & $\begin{array}{c}\text { Step } \\
5\end{array}$ & $\begin{array}{l}\text { Step } \\
6\end{array}$ & $\begin{array}{c}\text { Phase } \\
2 \\
\text { Step } \\
7\end{array}$ & $\begin{array}{c}\text { Step } \\
8\end{array}$ & $\begin{array}{c}\text { Step } \\
9\end{array}$ & $\begin{array}{c}\text { Phase } \\
3 \\
\text { Step } \\
10\end{array}$ & $\begin{array}{c}\text { Step } \\
11\end{array}$ & $\begin{array}{c}\text { Phase } \\
4 \\
\text { Step } \\
12\end{array}$ \\
\hline $\begin{array}{l}\text { Mentor } \\
(n=13)\end{array}$ & 2.16 & 2.33 & 2.11 & 2.28 & 2.40 & 2.19 & 2.11 & 2.13 & 1.95 & 2.14 & 1.98 & 2.32 & 2.00 \\
\hline $\begin{array}{l}\text { Student } \\
(n=11)\end{array}$ & 2.20 & 2.17 & 2.49 & 2.32 & 2.48 & 2.65 & 2.32 & 2.01 & 1.78 & 2.03 & 2.05 & 2.32 & 2.11 \\
\hline $\begin{array}{l}\text { Mentor EM } \\
(n=3)\end{array}$ & 2.03 & 2.00 & 2.08 & 2.11 & 2.00 & 2.33 & 2.07 & 2.08 & 1.47 & 2.10 & 1.97 & 2.07 & 2.06 \\
\hline $\begin{array}{l}\text { Mentor OS } \\
(n=5)\end{array}$ & 2.10 & 2.67 & 1.96 & 2.03 & 2.69 & 1.70 & 2.04 & 2.08 & 1.92 & 2.03 & 1.88 & 2.40 & 1.87 \\
\hline $\begin{array}{l}\text { Mentor EA } \\
(n=5)\end{array}$ & 2.30 & 2.20 & 2.29 & 2.63 & 2.34 & 2.60 & 2.20 & 2.23 & 2.28 & 2.29 & 2.10 & 2.40 & 2.10 \\
\hline $\begin{array}{l}\text { Student EM } \\
(n=3)\end{array}$ & 2.31 & 2.33 & 2.17 & 2.39 & 2.48 & 3.00 & 3.07 & 2.04 & 1.73 & 2.00 & 2.13 & 2.37 & 2.00 \\
\hline $\begin{array}{l}\text { Student OS } \\
(n=4)\end{array}$ & 1.76 & 1.33 & 2.00 & 1.56 & 2.28 & 1.83 & 1.60 & 1.63 & 1.40 & 1.71 & 1.65 & 2.10 & 1.83 \\
\hline $\begin{array}{l}\text { Student EA } \\
(n=4)\end{array}$ & 2.57 & 2.67 & 3.11 & 2.83 & 2.64 & 3.00 & 2.30 & 2.38 & 2.20 & 2.38 & 2.38 & 2.50 & 2.46 \\
\hline
\end{tabular}

Thirty-nine students and 24 mentors from the experimental group were interviewed about what they considered positive and what negative about the guidelines. The guidelines are seen as logical, orderly, structured, complete and useful. They offer something to hold on to and they contribute to the development of students' competencies and to the quality of the performance of work. The four phases are considered logical and coherent parts, although the distinction between the orientation phase and the preparation phase is not always clear; it was suggested to combine these two. Conversely, students and mentors find that there are many, or even too many, guidelines, which results in interaction taking more time than available. A second negative aspect is that the guidelines offer students choices that do not exist at the workplace.

The mentors were also asked whether there were any guidelines missing. None of them had anything to add, considering their own way of interacting with students or after reflecting on the guidelines.

The results call for an adaptation of the guidelines to improve their usefulness on some points. Some important items to consider are the overlap between some of the steps, the problems involved in answering questions about a task the 
student has not seen or performed before, and the sheer number of guidelines. Adaptation due to a lack of clarity or completeness was not necessary.

\subsubsection{Results with regard to the application of the guidelines}

At the halfway stage of the study, half the mentors and students had actually used the guidelines. Mentors not using them gave various reasons for this. One of these was that pressure of work at the workplace was too great: the mean score of 2.74 indicates that the mentors were quite often under great pressure (see Table 5.8). During the interviews it appeared that the pressure of work was higher than normal due to colleagues' illness and the end of the school year (in the case of the educational assistant in primary education). Another reason given was the lack of information about the study and what was expected of the mentors, which indicated that providing the information only in writing seemed to be insufficient. After receiving information about the study during the interview, mentors were willing to try to use the guidelines after all. According to them, it was not necessary to instruct them how to use the guidelines, because these were sufficiently clear. A third reason concerned the assignments that were included in the study. The assignments, which had been developed in close cooperation with teachers from the vocational education and training institute, proved to be inappropriate in some cases: students had already mastered them, or they could not be performed because the students were working on other assignments for their exam, or the assignments could not be conducted at the workplace. Because the use of the guidelines was linked with these assignments, they were not used. A final reason was that mentors had not received the guidelines, because students had either not handed the research material to them or had been assigned other mentors, who had not received the material from their predecessor. These findings have consequences for the implementation of the guidelines. First, the research materials will be handed to the mentors directly to make sure they receive both the information and the materials. Second, the acquisition of job-relevant competencies will be connected to the tasks that are conducted regularly at the workplace. This will increase their relevance and the likelihood that students can actually perform them. Although, according to the students, their mentors did not use the guidelines, the actual interaction process resembles the guidelines, at least in part. This means that the guidelines already match existing interaction processes, which could increase willingness to use them, since mentors would not have to drastically change their method of interaction.

The mentors who did use the guidelines had their own way of doing so. They did not use all the guidelines, because some were considered less useful (see Section 5.3.1). They also changed the sequence, depending on the course of the interaction, to create a natural form of conversation with their students, not 
structured strictly by the guidelines. In such cases they used the guidelines to check whether all aspects had been dealt with. As a result of this variety, the effects of applying the guidelines on the acquisition of job-relevant competencies will probably vary. The way the guidelines were actually applied was not measured explicitly in the pilot study. With regard to the main study, the implementation of the guidelines demands closer examination to be able to explain the effects.

\subsection{Effects of the guidelines}

To assess the mastery of competencies for each of the settings, an assignment was developed in close co-operation with the teachers. This assignment fits in with the curriculum and consists of a description of a task the student has to conduct at the workplace and of a number of criteria that refer to necessary knowledge, skills and attitudes. The assignment for the electrotechnical mechanic setting is installing pipes and consists of 18 criteria. The assignment for the orthopaedic shoemaker setting is making lasts and consists of 13 criteria, and that for the educational assistant setting is playing a game while singing a song and consists of 15 criteria. Each criterion is measured on a five-point Likert-type response scale for mastery. Before conducting the assignment, prior knowledge and experience are measured by asking the student how often he or she has conducted this or a comparable assignment before. The student is asked to conduct the assignment at least twice. The performance is assessed by student and mentor. Before the student conducts the tasks for the first time, he is asked to complete the same questionnaire on mastery.

The performance of the assignments to acquire job-relevant competencies is assessed by 10 mentors from the experimental group, by 3 mentors in the control group, by 10 students in the experimental group and by 3 students from the control group. The reasons for these small numbers have already been mentioned in subsection 5.3.2. An attempt to increase these numbers by approaching students in person and by sending both mentors and students a letter with the request to return their performance questionnaires had no effect. This is probably due to the time at which the study finished: at the end of the school year, when there were exams and the summer holidays were about to start.

The scores on mastery of the assignment vary from 1.85 to 5.00 , which means that mastery varies from 'insufficient' to 'completely mastered'. Table 5.11 and Table 5.12 present an overview of the scores. Cronbach's $\alpha$-coefficient for mastery is .90 . The scores of the students from the experimental group are somewhat higher than those of the students from the control group. This pattern is not found with the mentors. The differences are, however, not significant. 
From the three settings it is clear that the students in the educational assistant setting mastered their assignment best, while students in the orthopaedic shoemaker setting mastered it the least, probably because their assignment appeared to be a difficult one. Other analyses were not made, due to the small amount of data. These results do not affect the design of the main study, other than the choice of another period during the school year for conducting it.

Table 5.11 Scores on mastery of the assignment

\begin{tabular}{lccccc}
\hline & N & Minimum & Maximum & Mean & $\begin{array}{c}\text { Std. } \\
\text { deviation }\end{array}$ \\
\hline Mentors & 13 & 1.85 & 5.00 & 3.73 & .92 \\
Students & 14 & 2.77 & 5.00 & 3.92 & .77 \\
Mentor EM & 3 & 2.94 & 4.11 & 3.63 & .61 \\
Mentor OS & 3 & 1.85 & 3.08 & 2.67 & .71 \\
Mentor EA & 7 & 3.00 & 5.00 & 4.22 & .75 \\
Student EM & 3 & 3.67 & 4.50 & 4.00 & .44 \\
Student OS & 6 & 2.77 & 5.00 & 3.40 & .82 \\
Student EA & 5 & 3.87 & 4.87 & 4.51 & .39
\end{tabular}

$1=$ not mastered at all, $2=$ mastered insufficiently, $3=$ mastered sufficiently, $4=$ mastered amply, 5 $=$ mastered completely

Table 5.12 Scores on mastery of the assignment

\begin{tabular}{lccccccc}
\hline & $\begin{array}{c}\text { Electrotechnical } \\
\text { mechanic }\end{array}$ & \multicolumn{2}{c}{$\begin{array}{c}\text { Orthopaedic } \\
\text { shoemaker }\end{array}$} & \multicolumn{2}{c}{$\begin{array}{c}\text { Educational } \\
\text { assistant }\end{array}$} \\
Scale & Exp & Con & Exp & Con & Exp & Con \\
\hline Mentor & $\begin{array}{c}3.63 \\
(n=3)\end{array}$ & - & $\begin{array}{c}2.67 \\
(n=3)\end{array}$ & - & $\begin{array}{c}4.20 \\
(n=4)\end{array}$ & $\begin{array}{c}4.24 \\
(n=3)\end{array}$ \\
\hline \multirow{2}{*}{ Student } & 4.00 & - & $\begin{array}{c}3.56 \\
(n=4)\end{array}$ & $\begin{array}{c}3.08 \\
(n=2)\end{array}$ & $\begin{array}{c}4.63 \\
(n=3)\end{array}$ & $\begin{array}{c}4.33 \\
(n=2)\end{array}$ \\
& $(n=3)$ & & $(n=3)$
\end{tabular}




\subsection{Conclusions and consequences}

Four research questions were formulated for the pilot study:

1. Are the scales of student characteristics and workplace characteristics reliable?

2. Are the guidelines for interaction clear, usable and complete?

3. Are the guidelines actually used?

4. Does the application of the guidelines by the mentor lead to significantly better acquisition of job-relevant competencies by the student?

Before answering these four questions, it is necessary to conclude that the response was limited. Less than $30 \%$ of the mentors and students in the experimental groups completed the questionnaires on the clarity and usefulness of the guidelines, and some $50 \%$ actually used the guidelines. About $15 \%$ of all students and mentors completed the questionnaires on mastery of the assignment. These percentages make it impossible to draw conclusions on the effects of the intervention on the acquisition of job-relevant competencies, which was a major aim of the pilot. The results that are available are, however, being used to learn lessons for the main study, the most important being to pay more attention to the implementation of the guidelines. The usual, established way of providing information to mentors and companies and of distributing materials via the vocational education and training centres did not work. In the main study therefore both companies and mentors will receive information directly from the researcher.

The scales of student characteristics and workplace characteristics proved to be acceptable. For the main study the scales with an $\alpha$ below .70 were examined critically and adapted. Although the three settings differ significantly on some student characteristics and some workplace characteristics, the mean scores indicate that students and workplaces already possess to a fairly large extent those characteristics that influence learning in a positive way.

The guidelines proved to be clear and complete. Their clarity and resemblance to existing ways of interacting reduce the necessity to instruct mentors how to use the guidelines. At the same time, mentors need to be informed about the study and the research materials. Some of the guidelines proved to be less useful or overlapped. Mentors and students also criticised the large number of guidelines. For these reasons the guidelines for interaction have been adapted. Instead of 77 guidelines and 12 steps, as used for the pilot study, 66 steps and 10 steps will be used in the main study, a reduction of some $15 \%$. The four phases have not been adapted, because these were considered logical and coherent. Two steps relating to observing tasks have been integrated as 
guidelines into the first phase of orienting to a task. As a result of the criticism, guidelines in steps 4 and 11 have been removed or altered. Some other guidelines have been adapted to meet the criticism that the work process itself also determines what is to be done and how.

The same criteria were used for adapting the guidelines as for the original version.

Half the mentors from the experimental group used the guidelines for interaction. They used them in their own way, which resulted in a variety of interaction processes. This approach can be characterised as adaptive, because mentors changed the sequence, did not use all the guidelines, or changed them. To be able to address effects to the guidelines it is necessary to study the implementation process more closely. A weekly journal for both mentors and students was therefore developed and used. The other half did not use the guidelines but had various reasons for not doing so. Because the assignments did not always fit in with the programme or with work at the workplace, the acquisition of job-relevant competencies will be connected to tasks that are conducted regularly at the workplace. In the main study efforts must also be made to ensure that all mentors receive the information and research materials directly, to prevent non-participation. For this reason large companies will be asked to participate, to enable the quasi-experiments to be conducted.

The last research question is difficult to answer, due to the small numbers of students and mentors who completed and returned the questionnaires on mastery of the assignment. The mean scores do not, however, differ significantly between the experimental group and the control group. At the same time, the scores indicate that learning at the workplace has occurred, although not to the same extent for every student, as revealed by the minimum and maximum scores. Since most of the student characteristics and some of the workplace characteristics differ significantly between the three settings, these differences could account for the extent to which students have mastered their assignments. Further analyses to explain these differences were, however, not conducted, because of the small amount of data.

\subsection{Design of the main study}

The main study consists of three settings in three large companies in different sectors. The first setting is in a hospital, the second in a bank and the third in an installation and information technology company. In the hospital and the ICT company students from different regional centres for vocational education and training conduct their period of workplace learning. The students attend different courses, which are at levels 2,3 and 4 of the qualification structure. In 
the bank it is not students but employees who participate in the study. Between about 25 and 40 students (or employees) and their mentors participate in each setting. At the beginning of the study the students and the mentors receive their information and research materials at the company from the researcher. The tasks that are selected for the study are part of the company's work processes and they fit in with the student's educational programme. The study starts in the second and third quarters of the school year and lasts 12 weeks. The exact moment that it begins depends on the situation in the company and the start of the period of workplace learning.

The aim of the main study is to test the hypothesis that application of the guidelines for interaction by the mentor leads to significantly better acquisition of job-relevant competencies by the student. The quasi-experimental nonequivalent control group design is used to test this hypothesis. The treatment for the experimental group consists of the guidelines for interaction. The acquisition of job-relevant competencies is the dependent variable, while student characteristics, workplace characteristics and mentor characteristics are used as control variables. The implementation of the guidelines is also measured.

Student characteristics and workplace characteristics are measured using the adapted scales. Students are asked to complete the questionnaire on student characteristics at the beginning of the study. The mentors are also asked to complete the questionnaire at the beginning of the research period. Apart from the mentors, some of their colleagues too are asked to complete the questionnaire, thus providing a more representative picture of the situation at the workplace. Mastery of the job-relevant competencies is measured twice: the first time in the first week of the study, the second time in its final week. Both student and mentor are asked to complete these questionnaires. During the research period mentors and students are asked to complete weekly a prestructured journal, in which mentors and students can report their activities during that week. This focuses on the tasks conducted, the focus of the interaction and the application of the guidelines. Interviews with mentors and students take place at the end of the research period. In this interview students are asked about their preparation for the period of workplace learning, their prior knowledge and experience, their learning and their interaction with their mentor. Mentors are asked about their experience and their interaction with the student.

The Chapters 6, 7 and 8 will present the results of three experiments carried out in a hospital, a bank and an ICT-company. 


\section{Chapter 6}

\section{Workplace learning at a hospital}

\subsection{Introduction}

The previous chapter presented the results of the pilot study, which led to an adaptation of the instruments and the guidelines for interaction. The pilot also showed the necessity to chart the implementation of the guidelines. The aim of the main study is to test the hypothesis that application of the guidelines for interaction by the mentor leads to significantly better acquisition of job-relevant competencies by the student. For each experiment the setting is described, and then comes a short description of the methods and instruments that are used. Next, an account is given of the interaction process between mentors and students and the implementation and use of the guidelines, followed by the findings with regard to the mastery of job-relevant competencies. Then, the influence of co-variables on mastery is explored and, finally, the conclusions to be drawn from the experiment are presented. This chapter sets out the findings of the first experiment.

\subsection{Setting}

The first experiment was conducted at a general hospital in the eastern part of the Netherlands. This hospital has five locations and is one of the largest nonacademic hospitals in the country, with 4,000 employees, including 200 specialists. The hospital consists of six primary clusters of medical specialisms, a medical technical centre, a support services department and support staff. A cluster consists of several departments and is managed by a cluster manager; each department is managed by a department head. The annual budget is 190 million euro, although the hospital is having to economise.

It is also of one the largest non-academic medical training centres in the Netherlands for medically specialised functions and several clinical functions. Furthermore, it provides students from higher vocational education and training institutes the opportunity to carry out their period of workplace learning in the 
nursing departments of the clusters. In 2003 more than 100 students were given this opportunity. In the same year the hospital decided to provide some 30 to 40 students annually with the opportunity to carry out their period of workplace learning in the nursing departments and outpatient clinics of some of the clusters. (Not all clusters were considered appropriate because of their specialised work). These were students from secondary vocational education and training centres in the full-time college-based route who had finished the first part of their education. The cluster managers were informed about the number of students that would be admitted and, in consultation with their department heads, the students were divided over the departments.

Each nursing student was allocated to two nurses who had been appointed as mentors, to ensure that there was always a mentor available and present. Every nurse who has worked in the department for more than a year is expected to be willing and competent to coach a student. An experienced outpatient clinic employee was appointed for each doctor's assistant student. The selected mentors were informed when their student would start and what year of the educational programme the student was in. Shortly before the period of workplace learning started the student was invited to visit the department or the outpatient clinic to be introduced.

On their first day at the hospital students were received by one of the hospital's nine training officers, when they were informed about the hospital's expectations of them. One of the most important aspects is reflecting on their own learning and working. Each week students had to complete a form for their mentor about what they had done. On their first day the nursing students were also given their uniform, badge and the key to their locker, after which they were accompanied by the training officer to the department or outpatient clinic, where they were welcomed by their mentor.

There were three formal moments of coaching during the period of workplace learning: 1) in the first week, when mentors and students expressed their expectations, 2) halfway through the period, when mentors and students evaluated progress, and 3) at the end of the period, to evaluate the period and to assess the student. The students worked with their mentor as much as possible, which depended on the timetable. If the mentor was not working, the student had to inform a colleague about what she was able to do and what she wanted to learn. All the students from the full-time college-based route were supernumerary, which meant that they had time to study at work and were expected to do so for one hour a day. 


\subsection{Method and instrumentation}

To test the hypothesis that application of the guidelines for interaction by the mentor leads to significantly better acquisition of job-relevant competencies by the student, a quasi-experimental non-equivalent control group design was used. The treatment for the experimental group consisted of the guidelines for interaction. The acquisition of job-relevant competencies was the dependent variable, while workplace characteristics, mentor characteristics and student characteristics were used as co-variables. The interaction process and the implementation of the guidelines were also measured. Figure 6.1 shows the design of the experiment.

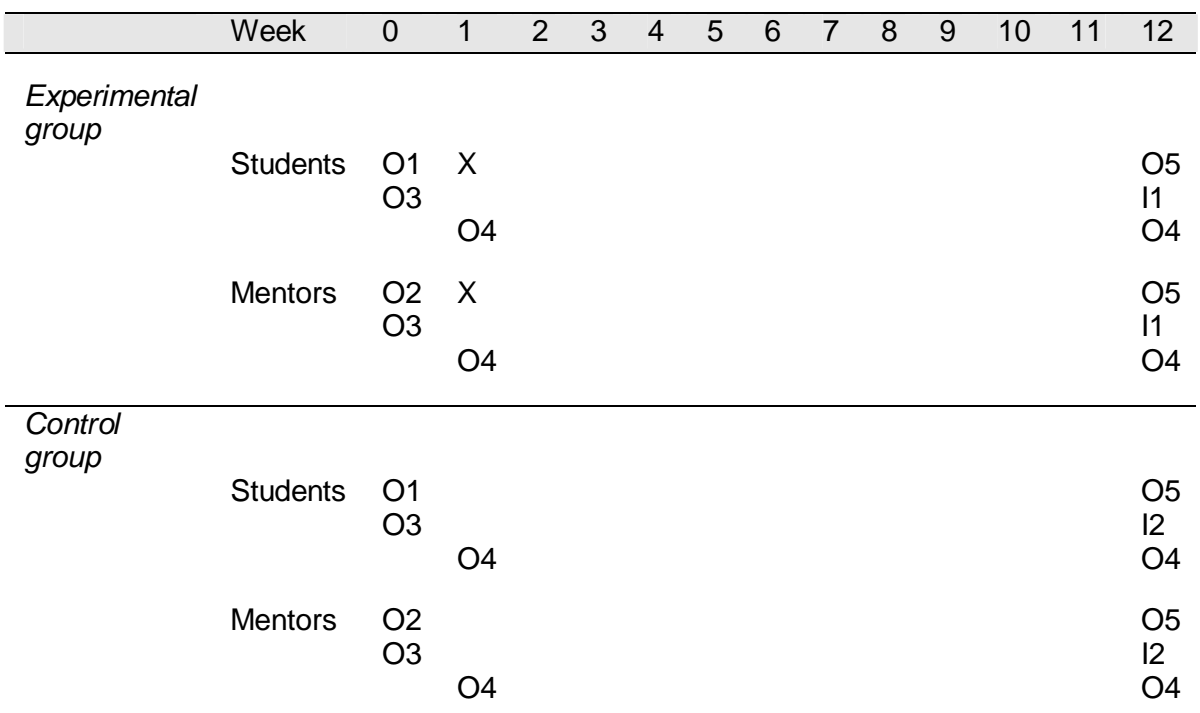

$\mathrm{O} 1$ = questionnaire on student characteristics

$\mathrm{O} 2$ = questionnaire on workplace characteristics

$\mathrm{O} 3$ = questionnaire on job-relevant competencies

$\mathrm{X}=$ guidelines for interaction

$\mathrm{O} 4$ = weekly journal interaction

O5 = questionnaire on job-relevant competencies

$I 1$ = interview interaction and guidelines

12 = interview interaction

Figure 6.1 Design and instruments of the experiment.

Before the experiment started the data collection instruments were presented to two of the hospital's training officers, to check their applicability to the hospital. The weekly journal was adapted to improve the mentors' willingness 
to respond conscientiously: they were asked their opinion of the guidelines once every two weeks, instead of every week. According to the training officers, the guidelines for interaction were clear and structured. They expected the mentors to benefit from an instrument for interaction. The coaching by the training officer and by the mentor is covered in the guidelines. Because most of the students were female, the guidelines were adapted slightly by using feminine pronouns. The job-relevant competencies matched the primary work processes and fitted in with the students' educational programmes.

The cluster managers, the heads of the departments and the training officers were all informed about the aim of the research project. The mentors and students had been informed in writing that they would be participating before the experiment started. In the first week of the period of workplace learning the mentors and students received the file with the data collection instruments. They were instructed when and how to complete the instruments and how to return them. They were also informed of the estimated amount of time participation in the research project would take. Students were also told that participation would not affect the assessment of their period of workplace learning. Whenever possible the students were given their information as a group, with the instruction taking some 30 minutes. The mentors were provided with their information individually in about 20 minutes, sometimes in the nursing department, sometimes elsewhere in the hospital. In most cases this took the maximum amount of time available, due to the work that had to be done in the departments or the outpatient clinics. Neither students nor mentors had any questions about the data collection instruments and both promised their cooperation. In addition, the mentors of the experimental group were instructed in the use of the guidelines. As little time was available, this instruction necessarily had to be brief. The aim and structure of the guidelines were clarified and the basic principles explained. The mentors were also advised to read the guidelines a couple of times before using them, to become acquainted with them. They were instructed to use the guidelines as drawn up and it was explained why they should do so. The mentors were additionally advised to keep the guidelines close at hand to ensure they could be used and consulted at any time. Finally, they were instructed not to hand the guidelines to anyone else.

As mentioned above, the hospital provides nursing students and doctor's assistant students from secondary vocational education and training institutes the opportunity to carry out their period of workplace learning in nursing departments and outpatient clinics. Students from both educational programmes were included in the experiment, which was conducted in 13 of the hospital's nursing departments and 7 of its outpatient clinics. The students and the mentors were randomly divided between the experimental group and the control group. 
To preclude the effects of differences between the two groups, variables that refer to mentor characteristics and student characteristics were compared (see Table 6.3). It proved that mentors did not differ significantly with regard to age, number of years they had worked at the hospital or the number of years they had coached students. The students did not differ significantly with regard to age, experience or learning route (13 in the full-time college-based route and six in the part-time work-based route).

One nursing department had students and mentors from both the experimental group and the control group, because almost all the students in the part-time work-based route were working in that department. Although the mentors of the experimental group were instructed explicitly not to hand the guidelines to anyone else, it is possible that in this department students and mentors of the control group became aware of the intervention. At the end of the experiment the mentors of the control group were asked whether they had seen the card with the steps and guidelines, to check if there had been an exchange of information; this proved not to be the case. In total, 56 mentors and 32 students participated. Table 6.2 provides an overview of the numbers of students and mentors in each condition.

Table 6.2 Numbers of mentors and students

\begin{tabular}{lrrrr}
\hline & \multicolumn{2}{c}{ Mentors } & \multicolumn{2}{c}{ Students } \\
& Exp & Cont & Exp & Cont \\
\hline Nursing & 23 & 21 & 12 & 12 \\
Doctor's assistant & 5 & 7 & 4 & 4 \\
& & & & \\
\hline
\end{tabular}

During the experiment one doctor's assistant student from the experimental group and one from the control group stopped prematurely, because they were not functioning as expected or required at the outpatient clinic. Another doctor's assistant student from the control group was absent most of the time due to illness. None of the nursing students stopped prematurely.

In addition, two mentors of the nursing students did not participate in the entire experiment because of leave. One nursing mentor stopped because of the limited number of shifts she was able to share with her student. 
Table 6.3 Comparison of groups on mentor and student characteristics

\begin{tabular}{|c|c|c|c|c|c|c|c|c|}
\hline & \multicolumn{4}{|c|}{ Mentors } & \multicolumn{4}{|c|}{ Students } \\
\hline & \multicolumn{2}{|c|}{ Experimental } & \multicolumn{2}{|c|}{ Control } & \multicolumn{2}{|c|}{ Experimental } & \multicolumn{2}{|c|}{ Control } \\
\hline & Mean & SD & Mean & SD & Mean & SD & Mean & SD \\
\hline Nursing & & & & & & & & \\
\hline Age & 32.24 & 10.33 & 30.16 & 6.90 & 25.92 & 9.64 & 26.58 & 12.68 \\
\hline Work experience & 9.00 & 9.03 & 6.74 & 6.28 & & & & \\
\hline Coaching & 5.42 & 7.32 & 5.72 & 5.44 & & & & \\
\hline $\begin{array}{l}\text { experience } \\
\text { Internship (weeks) }\end{array}$ & & & & & 44,13 & 21.21 & 48.78 & 21.16 \\
\hline Doctor's assistant & & & & & & & & \\
\hline Age & 33.75 & 16.26 & 41.00 & 16.82 & 19.60 & 1.95 & 18.80 & 1.10 \\
\hline Work experience & 13.75 & 14.89 & 11.67 & 4.93 & & & & \\
\hline $\begin{array}{l}\text { Coaching } \\
\text { experience }\end{array}$ & 5.75 & 6.19 & 9.00 & 12.17 & & & & \\
\hline Internship (weeks) & & & & & 27.33 & 11.02 & 30.00 & .00 \\
\hline
\end{tabular}

\subsection{Interaction at the workplace}

Looking at the theoretical framework for effective workplace learning (see Chapter 3), interaction provides the input of the learning processes and indirectly influences the acquisition of job-relevant competencies. This process is examined and described to explore whether differences in interaction actually influenced the learning results.

At the beginning of the experiment students in the full-time college-based route used the first few days of the period of workplace learning to find their way around the nursing department or the outpatient clinic, to get used to procedures and get to know colleagues and patients. They observed their mentors conducting tasks and they formulated their learning aims and worked out their learning plans. After two or three days the students started to conduct their first tasks. After three or four weeks students were able to participate in the primary work processes quite autonomously, with the mentor available and at hand in case they needed help or had questions. This pattern of gradual but rapidly increasing participation is representative of all the students in the full-time college-based route. It is probably due to the experience all the students had already had in caring before they started at the hospital.

Thanks to their experience and their familiarity with the work in nursing departments, the students in the part-time work-based route were already participating in the primary work processes from the beginning of the experi- 
ment. The difference between the two learning routes could influence the extent to which students acquire job-relevant competencies.

During their period of workplace learning each student carried out all or almost all of the tasks that were included in the experiment. This indicates that the students actually participated in the primary work processes. Some tasks, however, were not executed as frequently as others. According to the weekly journals, providing care and carrying out secretarial and administrative duties were the tasks executed most, compiling a medical history and conducting the intake were executed least. The most likely explanation for this is that the opportunity to execute a task varies, because some tasks simply occur more often than others.

The interaction between mentors and students also focused on all tasks, with the exception of conducting the intake. Table 6.4 provides an overview of the tasks conducted, of the focus of the interaction according to both the mentors and the students. The differences between the information from the mentors and the students are due to weekly journals being missing, because these were not completed by mentors, and to other colleagues supporting students when their mentors were not available. When the number of times tasks were executed are compared with the number of times the interaction focused on those tasks, they proved to correlate significantly at the .01 level (2tailed, Pearson correlation for mentors is .906, Pearson correlation for students is .956). When the tasks are ranked, the rankings also correlate significantly at the .01 level. This means that the more a task was executed, the more mentors interacted with their students about that task. It raises the question whether the interaction process is to be labelled as a natural process that is part of the primary work process or as a planned process. The finding that most of the interaction took place while students were executing tasks points to a more natural process. At any rate, it indicates that interaction is an interesting and logical starting point to influence the effectiveness of workplace learning. One interesting question is whether the number of times tasks were executed and the number of times interaction took place actually influenced the extent to which students acquired job-relevant competencies. The number of times tasks were executed and the number of times students interacted about the tasks do not correlate with students' mastery of job-relevant competencies. This gives rise to the assumption that it is the quality of the interaction that is important, not the quantity. 
Table 6.4 Number of times tasks were executed and focus of interaction

\begin{tabular}{|c|c|c|c|c|c|c|}
\hline & \multicolumn{2}{|c|}{ Executed tasks } & \multicolumn{2}{|c|}{$\begin{array}{l}\text { Focus } \\
\text { according to } \\
\text { mentors }\end{array}$} & \multicolumn{2}{|c|}{$\begin{array}{c}\text { Focus } \\
\text { according to } \\
\text { students }\end{array}$} \\
\hline & $\begin{array}{l}\mathrm{N} \text { of } \\
\text { times }\end{array}$ & Rank & $\begin{array}{c}\mathrm{N} \text { of } \\
\text { times }\end{array}$ & Rank & $\begin{array}{c}\mathrm{N} \text { of } \\
\text { times }\end{array}$ & Rank \\
\hline \multicolumn{7}{|l|}{ Nursing students $(n=24)$} \\
\hline Compiling medical history & 86 & 8 & 15 & 9 & 42 & 7 \\
\hline Formulating care problems & 107 & 5 & 18 & 7 & 57 & 3 \\
\hline Formulating care aims & 99 & 7 & 18 & 7 & 53 & 5 \\
\hline Providing care & 216 & 1 & 61 & 1 & 87 & 1 \\
\hline Adapting care & 104 & 6 & 35 & 3 & 41 & 8 \\
\hline Evaluating care & 138 & 2 & 29 & 4 & 56 & 4 \\
\hline $\begin{array}{l}\text { Applying prevention and providing } \\
\text { health information/advice }\end{array}$ & 120 & 4 & 20 & 6 & 44 & 6 \\
\hline Coordinating care & 132 & 3 & 44 & 2 & 76 & 2 \\
\hline Other tasks & 70 & 9 & 21 & 5 & 38 & 9 \\
\hline Total & 1075 & & 261 & & 494 & \\
\hline \multicolumn{7}{|l|}{ Doctor's assistant students $(n=8)$} \\
\hline $\begin{array}{l}\text { Preparing, executing and evaluating } \\
\text { consulting hours }\end{array}$ & 30 & 2 & 11 & 4 & 23 & 3 \\
\hline Conducting the intake & 8 & 10 & 0 & 10 & 7 & 10 \\
\hline Providing health information/advice & 17 & 8 & 6 & 5 & 15 & 6 \\
\hline Executing medical actions & 29 & 3 & 3 & 7 & 29 & 1 \\
\hline $\begin{array}{l}\text { Carrying out secretarial and } \\
\text { administrative duties }\end{array}$ & 31 & 1 & 12 & 2 & 28 & 2 \\
\hline Managing supplies & 13 & 9 & 2 & 8 & 12 & 8 \\
\hline $\begin{array}{l}\text { Managing instruments and } \\
\text { equipment }\end{array}$ & 21 & 6 & 1 & 9 & 18 & 4 \\
\hline Looking after the work rooms & 22 & 5 & 5 & 6 & 18 & 4 \\
\hline Taking blood & 20 & 7 & 12 & 2 & 11 & 9 \\
\hline \multirow[t]{2}{*}{ Other tasks } & 24 & 4 & 17 & 1 & 15 & 6 \\
\hline & 215 & & 69 & & 176 & \\
\hline
\end{tabular}

The time the mentor and the student spent on interaction varied during the shifts that they worked together. In both the experimental group and the control group about one-third spent less than half an hour on it, about one-third spent between 30 minutes and one hour, and about one-third spent more than an hour per shift. These differences are quite considerable and could influence the acquisition of job-relevant competencies, because time has proven to be an influential variable. Most of the time the interaction took place at the workplace while the student was executing tasks. Sometimes it took place before the shift started or after it had ended. The weekly journals provided the information that mentors 
had answered 442 times the question whether they had worked and interacted with their student during a week and that 244 times (55\%) the answer was 'no'. The mentor and the student thus did not work together frequently, due to timetables, illness or holidays. This percentage is rather high in the light of the hospital's policy of appointing two mentors to ensure continuity of coaching. About half the 24 mentors who were interviewed talked at least once a week with their fellow mentor or with another colleague who supported the student during shifts. This exchange of information with colleagues is considered relevant, because it allows mentors to adapt the interaction process to the actual state of the student's development As a result of time constraints (the high pressure of work and the limited number of joint shifts), almost $60 \%$ of the interviewed mentors could not support their student the way they would have liked. From a theoretical point of view, the frequent absence of mentors, the limited exchange of information between mentor and colleagues about the student's functioning and the finding that most mentors could not support their student the way they would have liked indicates that the situation as regards acquiring job-relevant competencies is not optimal - suboptimal at most. However, 15 of the 21 nursing students and 4 of the 6 doctor's assistant students did find the way their mentors interacted with them suitable in view of their own preferences of interaction. These students felt they had been taken seriously by their mentors, they could ask their mentors whatever they liked and their mentors had challenged them to execute tasks and use the capabilities they possessed. The students were satisfied or very satisfied with their mentors. Students from the experimental group were more satisfied with their mentors than those in the control group. The mean scores of the experimental group and the control group for student satisfaction with their mentors do not differ significantly, however.

Table 6.5 Student satisfaction with their mentors

\begin{tabular}{lcccc}
\hline & $\begin{array}{c}\text { Nursing } \\
\text { students } \\
(n=24)\end{array}$ & $\begin{array}{c}\text { Doctor's } \\
\text { assistant } \\
\text { students } \\
(\mathrm{n}=8)\end{array}$ & \\
& Mean & SD & Mean & SD \\
\hline Exp. group & 1.57 & .35 & 1.70 & .29 \\
Control group & 1.78 & .35 & 1.92 & .54
\end{tabular}

1 = very satisfied, 2 = satisfied, $3=$ neither satisfied, nor dissatisfied,

4 = dissatisfied, 5 = very dissatisfied 
Although the students were satisfied, they also had suggestions for stimulating learning and improving the effectiveness of workplace learning, based on their own experiences during the experiment. One important suggestion was that there should be regular joint shifts with a mentor during the entire period of workplace learning. This would guarantee continuity and increase trust. Lengthening the period of workplace learning was also considered important, with 20 weeks being seen as the minimum. Students need the first couple of weeks to get used to procedures and to become better acquainted with colleagues. Some found that the period ended just at the moment they were actually starting to participate, which, according to them, provided learning opportunities. Pressure of work should be reduced for students in the part-time work-based route, to create time for reflection and learning. Perhaps these students also felt some sense of injustice, because students in the full-time college based route were expected to study for at least one hour during a shift.

During the experiment most of the students did not substantially change the way they executed tasks, which indicates that the learning processes that took place were mainly assimilative in nature (see Chapter 3). This means that students incorporated new impressions into previously established structures. According to half the students, something hindered their learning process: sometimes something that happened at the workplace was unexpected or frightening (a patient had died or they had had to see to a grim-looking wound) or their own private situation needed attention.

In general, the period of workplace learning fulfilled the students' expectations. All the nursing students interviewed would like to work in a hospital. Two of the five doctor's assistant students who were interviewed would rather work for a family doctor because of the greater degree of variety.

\subsection{Use and implementation of the guidelines for interaction}

The theoretical framework presented in Chapter 3 was used to develop a set of guidelines for interaction. These guidelines aim at improving the effectiveness of workplace learning. To be able to test the hypothesis that application of the guidelines for interaction by the mentor leads to significantly better acquisition of job-relevant competencies by the student, it is necessary to examine and describe the extent to which the guidelines were actually used and how the mentors experienced their use. Explanations for the extent of use are also explored.

At the beginning of the experiment the 28 mentors from the experimental group received the card with the ten steps and accompanying guidelines for inter- 
action. During the experiment 20 mentors (71\%) actually used the card, most of them were relatively young ( 22 to 25 years of age) and, as a consequence, had relatively little experience of coaching students. The other, older ones did not use the card, because they expected it to take too much time or they took the view that the guidelines did not fit their way of interacting. The mentors used the steps and guidelines with different intensity.

Table 6.6 Intensity of the use of steps and guidelines

\begin{tabular}{cr}
\hline $\begin{array}{l}\text { Number of } \\
\text { mentors }\end{array}$ & Use of steps and guidelines \\
\hline 4 & $\geq 50 \%$ of the interaction time \\
5 & $20-50 \%$ of the interaction time \\
11 & $<20 \%$ of the interaction time \\
8 & not used at all
\end{tabular}

Because the mentors were only asked to what extent they had used the guidelines and not why the guidelines were used to that extent, it is not possible to give an explanation for these differences. In view of the fact that most of the interaction took place when students were executing tasks, it might be that mentors did not have it to hand (which could decrease the positive effects expected of interaction based on the guidelines). Another explanation could be that the interaction focused on small parts of a task or was limited to incidental remarks.

During the experiment eight mentors used all ten steps; nine mentors used at least six to nine steps and the other three mentors used a maximum of four steps. None of the missing steps was omitted systematically by the mentors.

Table 6.7 Number of mentors who used the steps for interaction

\begin{tabular}{lrrrrrrrrrr}
\hline & 1 & 2 & 3 & 4 & 5 & 6 & 7 & 8 & 9 & 10 \\
\hline $\begin{array}{l}\text { Mentors of nursing } \\
\begin{array}{l}\text { students } \\
(n=16)\end{array}\end{array}$ & 12 & 14 & 13 & 14 & 12 & 13 & 15 & 15 & 12 & 11 \\
$\begin{array}{l}\text { Mentors of doctor's } \\
\begin{array}{l}\text { assistant students } \\
(n=4)\end{array}\end{array}$ & 4 & 3 & 3 & 3 & 2 & 2 & 2 & 2 & 2 & 2 \\
\hline
\end{tabular}

8 mentors are missing because they did not use the steps 
Table 6.8 shows that during the experiment three of the steps were used to a lesser extent: step 5 (preparing for the execution of a chosen task), step 9 (determining the next steps necessary to learn to execute the task together), and step 10 (instructing the student to execute the tasks a couple of times more). One explanation is that some mentors find it hard to integrate steps into the work process. This reason holds especially for step 9, because this is carried out best at moments when mentor and student do not have to execute tasks. Although step 9 is considered an important one because it provides the input for a new cycle of preparation, executing and evaluating the execution of a task, the negative effects of omitting it are counterbalanced if the mentors start a new cycle with the orientation phase. Step 10 was probably used less, because students were expected to execute most of the tasks more than once in any case. This explanation is validated by the finding that students actually carried out tasks several times. In view of the findings of the pilot study, it is possible that mentors thought step 5 resembles and overlaps with the steps and guidelines of phase 1. The distinction between the orientation and the preparation phase was not regarded as clear. Although not executed to the same extent, none of the steps should be considered unsuitable or unnecessary, in view of the number of times mentors used them. Table 6.7, however, reveals that there were also fewer mentors who used these steps. This could mean that the use of the steps depends at least partly on the interaction preferences of the mentor. According to the students too the ten steps were indeed executed, although they believed that they had been executed more often. This is probably due to being coaching by two mentors and because of the mentors' missing weekly journals.

As mentioned above, the time spent on interaction and the time the card with steps and guidelines was actually used varied, indicating that the mentors of the experimental group interacted in different ways with their student. Table 6.9 provides an overview of the information the mentors gave about the way they interacted with their student. This shows that the mentors had their own way of interacting. The steps and guidelines were used as intended to a reasonable extent, with the guidelines used slightly more than the steps. At the same time, mentors adapted their use by changing the order, by omitting some and by adding their own. This was done to a fairly small extent. The finding that steps and guidelines were sometimes omitted matches the finding relating to the frequency with which they were used. The finding that mentors added their own steps and guidelines to some extent, albeit small, indicates that the card provides a virtually complete way of interacting. 
Table 6.8 Frequency of use of the steps for interaction

\begin{tabular}{|c|c|c|}
\hline Step & Mentors & Students \\
\hline \multicolumn{3}{|l|}{ Phase 1: Orienting to the task } \\
\hline 1. Select together a task the student wants to learn to execute. & 42 & 138 \\
\hline $\begin{array}{l}\text { 2. Talk through together the task the student wants to learn to } \\
\text { execute. }\end{array}$ & 44 & 128 \\
\hline $\begin{array}{l}\text { 3. Determine together what the student already knows and is } \\
\text { capable of. }\end{array}$ & 42 & 126 \\
\hline $\begin{array}{l}\text { 4. Discuss together how the student wants to learn to execute the } \\
\text { task. }\end{array}$ & 36 & 135 \\
\hline \multicolumn{3}{|l|}{ Phase 2: Preparing for the execution of the task } \\
\hline 5. Prepare together for the execution of the task. & 29 & 132 \\
\hline 6. Make sure all the student needs to execute the task is available. & 38 & 124 \\
\hline \multicolumn{3}{|l|}{$\begin{array}{l}\text { Phase 3: Supervising the execution of the task and discussing } \\
\text { performance }\end{array}$} \\
\hline 7. Supervise the execution of the task. & 41 & 139 \\
\hline $\begin{array}{l}\text { 8. Discuss performance with the student immediately after } \\
\text { execution. }\end{array}$ & 43 & 144 \\
\hline $\begin{array}{l}\text { 9. Determine together the next steps necessary to learn to execute } \\
\text { the task. }\end{array}$ & 28 & 123 \\
\hline \multicolumn{3}{|l|}{ Phase 4: Improving ability } \\
\hline 10. Instruct the student to $\mathrm{e}$ & 27 & 151 \\
\hline
\end{tabular}

The mentors were not asked to mention in the weekly journal what steps and guidelines they had added. In the interview at the end of the experiment the same question proved hard to answer, probably because it was difficult to recall the moments when they had added their own. This indicates that this addition depended on the situation and proved not to be a fundamental one that they used all the time. In the interview the mentors also stated that their way of interacting with the student matched the guidelines - at least to a large extent. This answer does not match the information extracted from the weekly journals, as presented in Table 6.9. Probably the time span the mentors had in mind when answering the question is due to this difference. The difference could also be due to the necessity mentors felt during the interview to answer in a socially desirable way. The finding about adaptive use makes it relevant to examine the implementation process somewhat more closely. When studying the information on use per week (see Table 6.10), this shows that mentors used the steps and the guidelines as intended the most during the first few weeks. In week 6 the mentors adapted their use most. 
Table 6.9 Mean scores for the use of the steps and guidelines (mentors of experimental group)

\begin{tabular}{lcc}
\hline & \multicolumn{2}{c}{$\begin{array}{c}\text { Mentors } \\
(\mathrm{n}=20)\end{array}$} \\
& Mean & SD \\
\hline Steps & & \\
I use the steps as intended & 2.77 & .56 \\
I adapt the use of the steps: & 2.52 & .69 \\
- I use the steps in a different order & 2.62 & .90 \\
- I omit steps & 2.59 & .98 \\
- I add my own steps & 2.36 & .82 \\
& & \\
Guidelines & & \\
I use the guidelines as intended & 2.92 & .65 \\
I adapt the use of the guidelines: & 2.42 & .80 \\
- I use the guidelines in a different order & 2.41 & .82 \\
- I omit guidelines & 2.43 & .86 \\
- I add my own guidelines & 2.43 & .95 \\
& & \\
\hline 1 = not at all, 2 = to a small extent, 3 = to a reasonable extent, 4 = to a large extent, $5=$ only
\end{tabular}

This could indicate that mentors wanted to try another approach, to experience the effects of that approach. The lesser degree of adaptation that followed could mean that it did not appeal to them. In week 10 mentors used the steps and guidelines more as intended. Perhaps the upcoming interview influenced their behaviour.

Table 6.10 Mean scores for the use of the steps and guidelines per week (mentors of experimental group)

\begin{tabular}{lcccccccccccc}
\hline & 1 & \multicolumn{11}{c}{ Week } \\
& 1 & 2 & 3 & 4 & 5 & 6 & 7 & 8 & 9 & 10 & 11 & 12 \\
\hline $\begin{array}{l}\text { I use the steps as intended } \\
\text { I adapt the use of the steps }\end{array}$ & 3.20 & 3.50 & 2.80 & 2.86 & 2.80 & 2.60 & 2.86 & 2.60 & 2.78 & 3.29 & 2.80 & 2.67 \\
& 1.87 & 1.50 & 2.00 & 2.52 & 2.56 & 3.28 & 2.57 & 2.67 & 2.67 & 2.67 & 2.20 & 2.56 \\
I use the guidelines as & 3.20 & 3.50 & 2.80 & 2.71 & 2.80 & 3.00 & 3.43 & 3.00 & 3.00 & 3.57 & 3.25 & 3.00 \\
intended \\
$\begin{array}{l}\text { I adapt the use of the } \\
\text { guidelines }\end{array}$
\end{tabular}

$1=$ not at all, $2=$ to a small extent, $3=$ to a reasonable extent, $4=$ to a large extent, $5=$ only 
It is not only the way steps and guidelines were used that is relevant to gain a clear view of the implementation process. Supplementary information about levels of use, stages of concern and the support of others also provides an insight into that process.

At the end of the experiment the mentors of the experimental group knew the basic principles of the guidelines and also knew fairly well what to do with the guidelines. Most of the mentors thought they were able to integrate the use of the guidelines into their daily work and were able to handle them the way they were intended. They no longer had to think very much about what the guidelines meant to them or how they wished to use them. The mentors gradually became somewhat more enthusiastic. The pattern of using the guidelines as intended (see Table 6.10) indicates that their use had not yet become routine. On the other hand, mentors used them in their own way, which points to some kind of refinement, indicating that they probably differ in the level of use they reached. During the experiment the mentor's stage of concern increased somewhat, judging by the scores of the weekly journals and the scores of the interview held at the end of experiment. However, the mentors still worried about questions related to time and organisation, in their search to simplify the use of the guidelines and to make them work smoothly. Although the implementation process made progress, the highest stage of concern (impact) was not reached.

Almost all the mentors (82\%) reported that they had received sufficient support from the researcher in using the guidelines. Because not all their colleagues received them, the mentors did not experience much appreciation or support from them.

Besides the time span, there is another possible explanation why the highest levels of use and highest stages of concern were not reached. The guidelines for interaction are based on a number of basic principles. These were described on the card. If mentors do not agree on these points, their willingness to use them will decrease. The mentors, however, agreed fully on most of the basic principles (see Table 6.12). They agreed less that they had to ensure that students could participate fully, because the students still had a lot to learn and were not expected to be able to execute all tasks or be allowed to do so. It is also possible that this opinion correlates with the small extent to which the mentors are allowed to participate in work processes themselves (see Section 6.7.1). Mentors also agreed less that they had to ensure that students knew how well they were performing the work. According to them, this was also a responsibility of the student, who has to reflect constantly on her own functioning. 
Table 6.11 Levels of use and stages of concern with regard to the guidelines

\begin{tabular}{|c|c|c|c|c|}
\hline & \multicolumn{2}{|c|}{$\begin{array}{c}\text { Interview } \\
\left(n=10^{*}\right)\end{array}$} & \multicolumn{2}{|c|}{$\begin{array}{l}\text { Journal } \\
\left(n=16^{* *}\right)\end{array}$} \\
\hline & Mean & SD & Mean & SD \\
\hline \multicolumn{5}{|l|}{ Levels of use } \\
\hline $\begin{array}{l}\text { I still think about what using the guidelines means to } \\
\text { me }\end{array}$ & 2.60 & 1.35 & 2.95 & .89 \\
\hline I still think about how I want to use the guidelines & 2.70 & 1.25 & 3.08 & .91 \\
\hline I am able to integrate the guidelines into my daily work & 3.50 & .71 & 3.47 & .67 \\
\hline \multicolumn{5}{|l|}{ Stages of concern } \\
\hline I know the basic principles of the guidelines & 4.40 & .52 & 3.97 & .44 \\
\hline I know what to do with the guidelines & 3.80 & 1.03 & 3.67 & .59 \\
\hline I can handle the guidelines well & 3.50 & .97 & 3.34 & .60 \\
\hline $\begin{array}{l}\text { I am able to work according to the requirements of the } \\
\text { guidelines }\end{array}$ & 3.60 & .84 & 3.44 & .45 \\
\hline Using the guidelines is easy & 3.00 & 1.05 & 2.45 & .60 \\
\hline \multicolumn{5}{|l|}{ Attitude } \\
\hline I am enthusiastic about the guidelines & 3.40 & 1.17 & 2.99 & .87 \\
\hline \multicolumn{5}{|l|}{ Support } \\
\hline $\begin{array}{l}\text { I experience the support of others while using the } \\
\text { guidelines }\end{array}$ & 2.40 & 1.08 & 2.37 & .84 \\
\hline I receive help when I ask for it & 3.40 & .97 & 3.36 & .78 \\
\hline I receive appreciation for using the guidelines & 2.50 & 1.18 & 2.54 & .90 \\
\hline $\begin{array}{l}\text { My experience is that others find it important I use the } \\
\text { guidelines }\end{array}$ & 2.30 & 1.06 & 2.29 & .90 \\
\hline
\end{tabular}

* Only half the mentors of the experimental group were interviewed.

${ }^{* *}$ Not all the mentors who used the steps and guidelines completed these items.

$1=$ totally disagree, $2=$ disagree, $3=$ neither agree nor disagree, $4=$ agree, $5=$ totally agree

The students who were interviewed did recognise the basic principles in the way that their mentor interacted with them. This indicates that mentors actually interacted according to the basic principles. Considering these findings, the guidelines probably did not conflict with the opinions and preferences of most of the mentors with regard to interaction. It is therefore assumed that the guidelines themselves did not hinder the implementation process. 
Table 6.12 Agreement on the basic principles of the guidelines

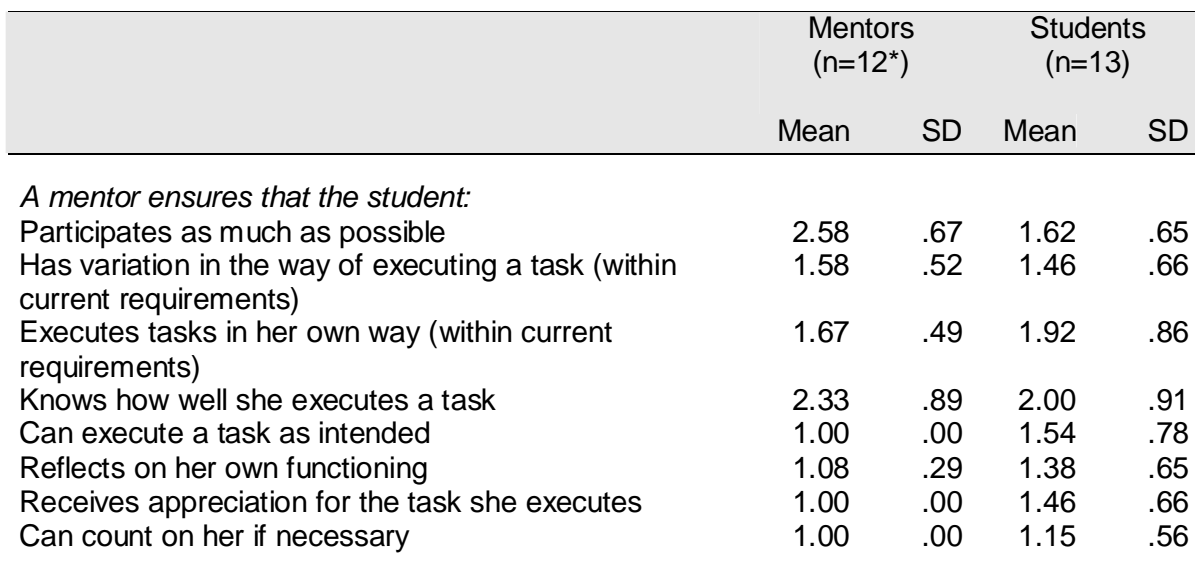

* Only half the mentors of the experimental group were interviewed.

$1=$ totally agree, 2 = agree, $3=$ neither agree nor disagree, $4=$ disagree, $5=$ totally disagree

Finally, the finding about the different extent to which mentors used the card with the steps and the guidelines makes it relevant to search for additional explanations related to workplace characteristics, mentor characteristics and student characteristics.

It is plausible that the mentor's environment influences willingness and possibilities to use the card. T-tests show that mentors who used the card more extensively perceived their workplace as an environment with a higher degree of participation, interaction and informational support than did their colleagues who used the card less or not at all (see Table 6.13). It seems that a workplace where exchange of information and communication is perceived as more common is also a more stimulating place to use an instrument with comparable characteristics. Looking at the mentor characteristics, younger and less experienced mentors used the card more extensively than did their older and more experienced ones (see also the beginning of this subsection), probably because they were looking for a suitable way of interaction and did not have to change routines. The extent of the use of the card does not depend on the students' characteristics, which indicates the card's suitability for all the students. Table 6.13 shows the findings. 
Table 6.13 Influence of workplace and mentor characteristics on the use of the card

\begin{tabular}{|c|c|c|c|c|}
\hline & \multicolumn{2}{|c|}{$\begin{array}{l}\text { Extensive use of } \\
\text { the card } \\
(n=9)\end{array}$} & \multicolumn{2}{|c|}{$\begin{array}{l}\text { Limited or no } \\
\text { use of the card } \\
\quad(n=17)\end{array}$} \\
\hline & Mean & SD & Mean & SD \\
\hline \multicolumn{5}{|l|}{ Workplace characteristics } \\
\hline Participation* & 2.52 & .28 & 2.21 & .43 \\
\hline Interaction** & 3.04 & .26 & 2.83 & .40 \\
\hline Informational support*** & 2.69 & .51 & 2.21 & .36 \\
\hline \multicolumn{5}{|l|}{ Mentor characteristics } \\
\hline Age $\left(\right.$ years) ${ }^{* *}$ & 26.00 & 4.36 & 36.13 & 12.09 \\
\hline Work experience (years) ** & 4.22 & 3.15 & 12.65 & 11.07 \\
\hline \multicolumn{5}{|c|}{$\begin{array}{l}\text { * The groups differ significantly at } \alpha=.1 \text { level } \\
{ }^{* *} \text { The groups differ significantly at } \alpha=.05 \text { level } \\
{ }^{* *} \text { The groups differ significantly at } \alpha=.01 \text { level }\end{array}$} \\
\hline
\end{tabular}

\subsection{Mastery of job-relevant competencies}

The aim of the experiment was to test the hypothesis that application of the guidelines for interaction by the mentor leads to significantly better acquisition of job-relevant competencies by the student. The items used to measure the acquisition focused on the mastery of relevant skill-oriented tasks of the daily work process at the workplace. Cronbach's $\alpha$-coefficient was calculated before the mean scores for mastery were computed. This is acceptable, with scores that vary from .91 (students score) to .95 (mentors score).

At the beginning of the experiment students already perceived mastery of the job-relevant competencies as quite sufficient, probably due to their experience and spare-time jobs. However, according to their mentors, the students from the experimental group mastered the job-relevant competencies significantly less well than did the students from the control group $(\mathrm{p}<.01)$. From the post-test it is clear that students mastered the competencies quite well or well. Because students are in the second half of their educational programme (third or fourth year), this score is considered satisfactory, and it allows students to participate in the daily work processes. As with the pre-test, the students from the experimental group mastered the job-relevant competencies less well. In view of the differences between the post-test and the pre-test, students from the experimental group grew somewhat more during the experiment. Although it 
was possible for the students from the experimental group to grow more when looking at the pre-test scores, both groups still had room for mastering the competencies substantially better. As the experiment lasted only 12 weeks, a difference of at least 1.00 on a six-point scale is considered substantial growth.

Table 6.14 presents the mean scores for the mastery of job-relevant competencies.

Table 6.14 Mastery of job-relevant competencies

\begin{tabular}{|c|c|c|c|c|c|c|}
\hline \multirow[t]{2}{*}{ Hospital } & \multicolumn{2}{|c|}{ Pre-test } & \multicolumn{2}{|c|}{ Post-test } & \multicolumn{2}{|c|}{ Difference } \\
\hline & Mean & SD & Mean & SD & Mean & SD \\
\hline \multicolumn{7}{|l|}{ Mentors } \\
\hline $\begin{array}{l}\text { Exp. group } \\
(\mathrm{n}=15)\end{array}$ & 1.68 & .62 & 3.19 & 1.00 & 1.51 & 1.13 \\
\hline $\begin{array}{l}\text { Control group } \\
(n=12)\end{array}$ & 2.42 & .94 & 3.73 & 1.17 & 1.31 & 1.32 \\
\hline \multicolumn{7}{|l|}{ Students } \\
\hline $\begin{array}{l}\text { Exp. group } \\
(n=15)\end{array}$ & 2.19 & .74 & 3.30 & .76 & 1.11 & .90 \\
\hline $\begin{array}{l}\text { Control group } \\
(\mathrm{n}=14)\end{array}$ & 2.38 & .94 & 3.35 & .71 & .96 & 1.07 \\
\hline
\end{tabular}

Although the students from the experimental group grew more than did the students from the control group, the difference between the final and the first measurement of both groups is not significant. As a result of this finding and because the mentors of the experimental group used the steps and guidelines for interaction to a reasonable extent, the hypothesis of the experiment is rejected: application of the guidelines for interaction by the mentor under the conditions available does not lead to significantly better acquisition of job-relevant competencies by the student.

As described above, the measurement of mastery is coupled to selected skilloriented tasks. It is possible, however, that other learning also occurred. In the interview students were asked what they considered the most important thing they had learned during the period of the experiment. Their answers varied: some students referred to one or more of the selected tasks, others pointed to social competencies, such as treating patients and their relatives and working with colleagues. Personal development was mentioned a couple of times, as was gaining insight into one's own functioning. The period of workplace learning also provided insight and an overview with regard to the complexity of 
working. Finally, the period had helped the students to make up their mind where they would like to work. The variety of answers shows that workplace learning might contribute to the simultaneous development of different kinds of competencies.

\subsection{The effects of independent variables}

The rejection of the hypothesis calls for some other analyses that could provide explanations for the differences with regard to the mastery of job-relevant competencies. The research model contains variables for further analyses. In the next subsections the effects of variables with regard to workplace characteristics, mentor characteristics and student characteristics on the dependent variable are examined. There is also an exploration of the effects of the interaction process.

\subsubsection{The effect of workplace characteristics}

At the beginning eleven workplace characteristics were measured. If these characteristics are actually present to a high degree, external learning conditions for the learning process are considered to be fulfilled to a large extent and the workplace itself is considered a potentially powerful learning environment. Table 6.15 presents the mean scores for the workplace characteristics measured. These scores indicate that mentors experienced a lot of emotional and instrumental support and found that they had a lot of variation and interaction at their work. They quite frequently experienced appraisal support and informational support. They also felt that they were quite autonomous in their work. At the same time, information necessary to conduct the tasks in the proper way was not always available and the pressure of work was quite regularly rather high. They did not very often perceive that they could influence what was happening at the workplace (participation). On the other hand, task obscurity was fairly low. The mean scores indicate that the external learning conditions at the workplaces were fulfilled to a reasonable extent.

To be able to exclude the influence of differences between the experimental group and the control group on students' mastery of job-relevant competencies, the means for these two groups were also computed. This proved that the groups did not differ significantly on workplace characteristics. 
Table 6.15 Mean scores for workplace characteristics

\begin{tabular}{l|cccccc}
\hline $\begin{array}{l}\text { Workplace } \\
\text { characteristics }\end{array}$ & $\begin{array}{c}\text { Hospital } \\
\text { total } \\
(\mathrm{n}=49)\end{array}$ & \multicolumn{3}{c}{$\begin{array}{c}\text { Hospital } \\
\text { exp. group } \\
(\mathrm{n}=26)\end{array}$} & $\begin{array}{c}\text { Hospital } \\
\text { control group } \\
(\mathrm{n}=23)\end{array}$ \\
& Mean & SD & Mean & SD & Mean & SD \\
\hline Participation & 2.37 & .44 & 2.32 & .41 & 2.43 & .48 \\
Variation & 2.99 & .38 & 2.90 & .36 & 3.08 & .38 \\
Task autonomy & 2.59 & .47 & 2.53 & .40 & 2.65 & .55 \\
Task information & 2.38 & .39 & 2.37 & .42 & 2.39 & .36 \\
Task obscurity & 1.77 & .34 & 1.83 & .37 & 1.72 & .31 \\
Pressure of work & 2.42 & .45 & 2.49 & .44 & 2.35 & .47 \\
Interaction & 3.05 & .34 & 3.00 & .36 & 3.10 & .31 \\
Instrumental support & 2.85 & .45 & 2.82 & .51 & 2.87 & .36 \\
Informational support & 2.42 & .49 & 2.37 & .47 & 2.47 & .52 \\
Appraisal support & 2.60 & .44 & 2.53 & .43 & 2.68 & .45 \\
Emotional support & 3.23 & .43 & 3.21 & .44 & 3.25 & .43 \\
& & & & & & \\
\hline
\end{tabular}

1 = hardly ever, 2 = sometimes, 3 = often, $4=$ almost always

A regression analysis was conducted for each of the workplace characteristics to search for variables that would explain the variance in the extent to which jobrelevant competencies were acquired by the students. Interaction at the workplace explained $13 \%$ of the variance (Fchange $=3.542, \mathrm{p}<.1$ ). This finding underlines the theoretical assumption (see Chapter 3) that interaction is an important factor in learning processes.

Table 6.16 Significant regression weights of regression analyses predicting mastery of job-relevant competencies

\begin{tabular}{lrrrrrr}
\hline Dependent variable: & $\mathrm{R}^{2}$ & Independent variable & $\mathrm{B}$ & $\mathrm{SE}$ & $\beta$ \\
\hline Difference post-test and pre-test & .13 & Interaction & 1.12 & .59 & .37 \\
\hline $\mathrm{p}<.1$ & & & & & &
\end{tabular}




\subsubsection{The effect of mentor characteristics}

On average the mentors were 32 years old and had worked for about 9 years at the hospital. Almost all of them were female (90\%) and they had some experience of coaching students $(85 \%)$. Most of them had until now coached one or two students. Whether they were experienced or not, they all felt skilled to coach because they had enough work experience and knowledge of the work. According to one-third of the mentors, they were not well prepared when their students' period of workplace learning started. They were informed very late that they would have to coach (sometimes on the day the student arrived), they lacked information about the student's educational programme and educational requirements, they had not met the student before or they did not know who the other mentor was.

From the mentors' perception of interaction research model, it is clear that their experience and preparation for coaching were considered potentially influential variables with regard to workplace learning.

The mentors' perception of coaching was measured by asking them to what extent they subscribed to the basic principles for interaction. As mentioned in Section 6.4, they fully agreed with most of them.

The mentors' experience has two different variables: the first being experience of coaching students. Students who were coached by mentors who had had at most two years of experience of coaching grew significantly more than did students who were coached by mentors who had had at least three years of experience ( $\mathrm{p}<.01$ ) (see Table 6.17). There are several possible explanations for this finding. Mentors with little experience probably reflect more on their way of interacting, in their search for the most adequate way, which apparently has a positive influence on quality. In addition, these mentors were young and had only recently ended their educational programme. Their own workplace learning experiences and their knowledge of the current educational programme influenced the way they interacted. A regression analysis shows that experience of coaching explains $34 \%$ of the variance in growth $($ Fchange $=9.924, \mathrm{p}<.01)$.

The second variable with regard to experience is work experience. Because mentors with little experience of coaching have less work experience, in view of their age, it is to be expected that work experience also influences the acquisition of job-relevant competencies. Students who were coached by mentors who had worked for a maximum of three years at the hospital grew more than did students who were coached by mentors who had worked there for at least four years. This difference is, however, not significant. Experience of coaching and work experience at the hospital correlates significantly at the .01 level (2-tailed, Pearson Correlation for mentors is .578). 
Table 6.17 Years of experience of coaching and mastery of job-relevant competencies

\begin{tabular}{|c|c|c|}
\hline \multirow[t]{2}{*}{ Experience of coaching } & \multicolumn{2}{|c|}{$\begin{array}{c}\text { Difference } \\
\text { between post- } \\
\text { test and pre-test }\end{array}$} \\
\hline & Mean & SD \\
\hline $\begin{array}{l}\text { At most } 2 \text { years of experience of coaching } \\
(n=11)\end{array}$ & 1.76 & 1.21 \\
\hline $\begin{array}{l}\text { At least } 3 \text { years of experience of coaching } \\
(n=10)\end{array}$ & .45 & .54 \\
\hline
\end{tabular}

The groups differ significantly at $\alpha=.01$ level

Table 6.18 Significant regression weights of regression analyses predicting mastery of job-relevant competencies

\begin{tabular}{lllllll}
\hline Dependent variable: & $\mathrm{R}^{2}$ & Independent variable & $\mathrm{B}$ & $\mathrm{SE}$ & $\beta$ \\
\hline Difference post-test and pre-test & .34 & Experience of coaching & -1.31 & .42 & -.59 \\
\hline $\mathrm{p}<.01$ & & & & & &
\end{tabular}

The final mentor characteristic is preparation for coaching. As mentioned in the first part of the subsection, not all mentors were well prepared at the moment the student's period of workplace learning started. The difference in preparation is expected to influence the acquisition of job-relevant competencies. An independent-samples $\mathrm{T}$-test shows that students who interacted with wellprepared mentors grew significantly more $(\mathrm{p}<.05)$ (Table 6.19). A regression analysis shows that preparation explains $27 \%$ of the variance in growth (Fchange $=4.844, \mathrm{p}<.05)($ Table 6.20). 
Table 6.19 Preparation for coaching and mastery of job-relevant competencies

\begin{tabular}{|c|c|c|}
\hline \multirow[t]{2}{*}{ Preparation for coaching } & \multicolumn{2}{|c|}{$\begin{array}{c}\text { Difference } \\
\text { between post- } \\
\text { test and pre-test }\end{array}$} \\
\hline & Mean & SD \\
\hline $\begin{array}{l}\text { Not well prepared }(n=6) \\
\text { Well prepared }(n=9)\end{array}$ & $\begin{array}{r}.87 \\
2.10\end{array}$ & $\begin{array}{r}.73 \\
1.23\end{array}$ \\
\hline
\end{tabular}

Table 6.20 Significant regression weights of regression analyses predicting mastery of job-relevant competencies

\begin{tabular}{lllllll}
\hline Dependent variable: & $\mathrm{R}^{2}$ & Independent variable & $\mathrm{B}$ & $\mathrm{SE}$ & $\beta$ \\
\hline Difference post-test and pre-test & .27 & Preparation for coaching & -1.24 & .56 & -.52 \\
\hline $\mathrm{p}<.05$ & & & & & &
\end{tabular}

\subsubsection{The effect of student characteristics}

At the beginning of the experiment students completed a questionnaire on student characteristics. The questionnaire measured their perception of ten student characteristics that have been shown to influence workplace learning (see the review in Chapter 2). If these characteristics are actually present to a high degree, internal learning conditions for the learning process are considered to have been fulfilled to a large extent. Before the mean scores for these student characteristics are presented, some other descriptive information about the students is given.

On average the students are 24 years old and almost all are female (94\%). Most of them are in the third or final year of their educational programme $(75 \%)$ and are following the full-time college-based route (75\%). Although they have spent some 40 weeks on workplace learning so far, for most students this period is their first at a hospital. During the previous periods, however, at least $80 \%$ of the students had already conducted the tasks they had to perform at the hospital. Most of the students (78\%) have spare-time jobs in the care sector. More than half of them (55\%) felt they were not well prepared at the start of this period of workplace learning. They were informed very late by the vocational education and training centre or by the hospital where they would spend their next period. 
They were therefore unable to read specific literature or work out their aims and learning plans in time.

The mean scores for student characteristics show that the students find themselves highly motivated and conscientious, their belief in their own capabilities (self-efficacy) is strong, and they think they have quite good control over what happens to them (locus of control). At the same time, they do not feel quite strongly alone or helpless (anxiety). Looking at learning style, students characterise themselves as learning-oriented and generic. They also feel that they are a little more immersed then detached, a little more inquiring-oriented and they prefer external regulation slightly more then internal. The mean scores indicate that the internal learning conditions have been fulfilled to a reasonable extent.

The means for these two groups were also computed to be able to exclude the influence of differences between the experimental group and the control group on students' mastery of job-relevant competencies. The experimental group and the control group differ significantly on motivation $(\mathrm{p}<.05)$ and regulation $(\mathrm{p}<.1)$. The students in the experimental group are highly motivated and prefer to regulate their learning process themselves somewhat more than do the students in the control group. These differences could have affected the extent to which students acquired job-relevant competencies.

Table 6.21 Mean scores for student characteristics

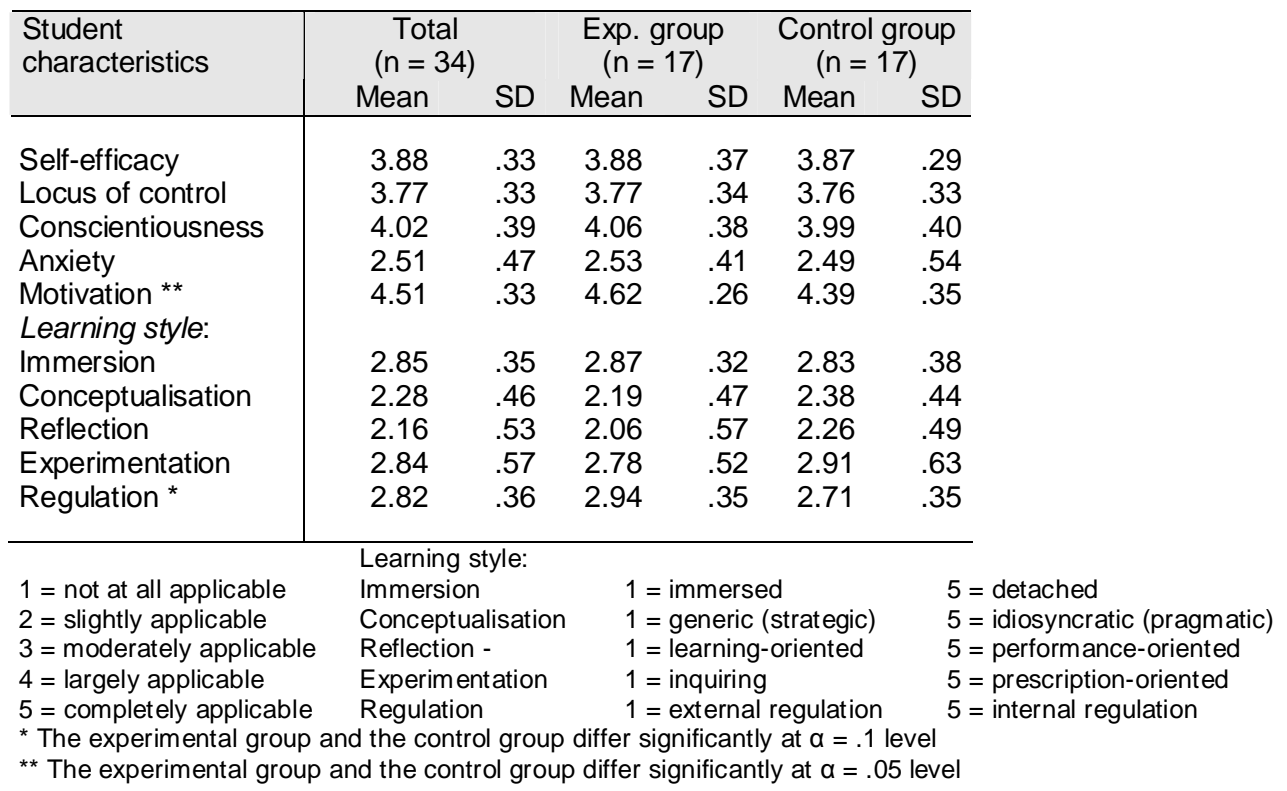


A regression analysis was conducted for each of the student characteristics to search for variables that would explain the variance in the extent to which jobrelevant competencies were acquired by the students. Self-efficacy explained $17 \%$ of the variance (Fchange $=5.694, \mathrm{p}<.05$ ), locus of control 14\% (Fchange $=4.398, \mathrm{p}<.05)$ and reflection $17 \%$ (Fchange $=5.443, \mathrm{p}<.05)$. If a stepwise regression analysis is conducted using these three variables, two of them prove to be strong predictors with a total $\mathrm{R}^{2}$ of .37 . Considering the negative scores on beta $(\beta)$, students with a lower score for self-efficacy grew more than did students with a higher degree. Perhaps their lesser degree of belief in their own capabilities urged them to work harder, resulting in a better learning result. The scores for reflection reveal that students who reflected more on their learning process (which corresponds with a lower score on the scale) grew more than did students who reflected more on their performance.

Table 6.22 Significant regression weights of regression analyses predicting mastery of job-relevant competencies

\begin{tabular}{llrrrrr}
\hline Dependent variable: & $\mathrm{R}^{2}$ & Independent variables & $\mathrm{B}$ & $\mathrm{SE}$ & $\beta$ \\
\hline Difference post-test and pre-test & .37 & Self-efficacy & -1.28 & .45 & -.45 \\
& & Reflection & -.93 & .33 & -.44 \\
\hline $\mathrm{p}<.05$ & & & & & &
\end{tabular}

$\mathrm{p}<.05$

Students from both learning routes in secondary vocational education and training participated in the experiment. One important difference between the routes was the amount of time spent at the workplace. Students in a full-time college-based route spent less time at the workplace than did their colleagues in a part-time work-based route. Time is considered an important predictor of learning results. At the same time, students in a full-time college-based route are supernumerary, which means they have more time to learn, because they do not necessarily have to participate in the work processes all the time at the same pace as their colleagues in the part-time work-based route, who are seen as employees. An independent-samples T-test shows that students in the full-time college-based route learn significantly more ( $\mathrm{p}<.1)$. A regression analysis shows that the learning route explains $7 \%$ of the variance in growth (Fchange $=3.855$, $\mathrm{p}<.1)$. 
Table 6.23 Learning route and mastery of job-relevant competencies

\begin{tabular}{lrr}
\hline Route & $\begin{array}{c}\text { Difference } \\
\text { between post- } \\
\text { test and pre-test } \\
\text { Mean }\end{array}$ & SD \\
\hline $\begin{array}{l}\text { College-based } \\
(n=43)\end{array}$ & 1.37 & 1.09 \\
$\begin{array}{l}\text { Work-based } \\
(n=13)\end{array}$ & .71 & .97 \\
\hline The routes differ significantly at $\alpha=.1$ level (mentors and students together)
\end{tabular}

Table 6.24 Significant regression weights of regression analyses predicting mastery of job-relevant competencies

\begin{tabular}{llllllll}
\hline Dependent variable: & $\mathrm{R}^{2}$ & Independent variable & $\mathrm{B}$ & $\mathrm{SE}$ & $\beta$ \\
\hline Difference post-test and pre-test & .07 & Learning route & -.66 & .34 & -.26 \\
\hline $\mathrm{p}<.1$ & & & & & & &
\end{tabular}

Students who reported that something had hindered their learning process grew less. Although this difference is not significant, the finding itself is interesting. Apparently students are able to feel and mention whether something really stood in the way of their learning process. It indicates that students should be regularly asked whether something is hindering their learning process to be able to cater for it.

In addition to the variables directly related to learning, other descriptive variables were also analysed. Gaining experience of caring outside the education programme (for instance, because of spare-time jobs) did not affect students' growth. The extent to which students felt well prepared for their period of workplace learning did not significantly affect growth either. And finally, the extent to which students' expectations about the period of workplace learning had been met affected growth: the better the expectations were met, the more students grew. However, the difference between those whose expectations were met and those whose expectations were not is not significant. 


\subsubsection{The effect of the guidelines for interaction}

The final subsection of this chapter focuses once more on interaction. Section 6.5 describes how mentors of the experimental group used the steps and guidelines for interaction in their own way. Some of them used them quite intensively, others did not use them very much or not at all. To test whether the extent to which the steps and guidelines were used affects the extent of growth, a final statistical analysis was carried out. The mentors of the control group were also included in this test, because they did not receive the card with the steps and guidelines. The mean scores for growth were compared with the intensity with which the steps and guidelines had been used. Although the Anova table did not indicate a significant effect, the mean scores actually did differ. From Table 6.22 it is clear that the pattern is that the more mentors use the steps and guidelines for interaction, the better students acquire job-relevant competencies. This finding indicates the value of the guidelines.

Table 6.25 Intensity of using the guidelines for interaction and mastery of jobrelevant competencies

\begin{tabular}{lrr}
\hline & \multicolumn{2}{c}{$\begin{array}{c}\text { Difference } \\
\text { between post- } \\
\text { test and pre-test }\end{array}$} \\
& Mean & SD \\
\hline Mentors* & & \\
$1(n=7)$ & 1.65 & 1.49 \\
$2(n=8)$ & 1.38 & .77 \\
$3(n=12)$ & 1.31 & 1.32
\end{tabular}

1: Mentors experimental group: used guidelines most extensively

2: Mentors experimental group: used guidelines least extensively

3: Mentors control group 


\subsection{Summary and conclusions}

The first experiment to test the hypothesis was carried out at a large general hospital. Mentors of the experimental group received a card with steps and guidelines for interaction. They agreed on the basic principles of the guidelines. Although a high-fidelity approach was aimed at (meaning that the steps and guidelines should be used as drawn up), mentors proved to have used the steps and guidelines in their own adaptive way. The time available to use the steps and guidelines prevented them reaching the higher levels of use and stages of concern. Their use had not yet become a routine and the mentors' main concern related to fitting the use of the steps and the guidelines into their daily work processes. Workplace characteristics, such as participation, interaction and informational support, and mentor characteristics, such as age and experience, also seemed to affect their use.

At the end of the experiment students had mastered the selected jobrelevant competencies substantially better. The experimental group, however, had not mastered them significantly better than had students in the control group. The hypothesis that application of the guidelines for interaction by the mentor under the available conditions leads to significantly better acquisition of job-relevant competencies by the student was therefore rejected. However, further analysis revealed some interesting findings with regard to the effectiveness of workplace learning. It showed that the more intensively the guidelines for interaction were used, the better students acquired the competencies. This indicates that the guidelines can contribute to the effectiveness of workplace learning. The analysis also showed that students of young and inexperienced mentors acquired competencies better than did those of older and more experienced mentors. And students also benefit when mentors are well prepared for coaching at the beginning of period of workplace.

Looking at workplace characteristics, interaction proved to be an important variable with regard to explaining variance in mastery of job-relevant competencies. This indicates the theoretical importance of interaction for learning. From student characteristics it is clear that self-efficacy and reflection on learning proved to be important variables. However, students with a lesser degree of belief in their own capabilities performed better, perhaps because it urged them to work harder. And, finally, students in a full-time college-based route acquired job-relevant competencies significantly better than did those in a part-time college-based route.

In summary, the coaching of students in full-time college-based routes by young, inexperienced, but well-prepared mentors who are provided with the guidelines for interaction is an interesting option to increase the effectiveness of workplace learning in this hospital. 
Figure 6.26 presents a model that contains the variables that predict mastery of job-relevant competencies. This model is based on analyses with separate variables.

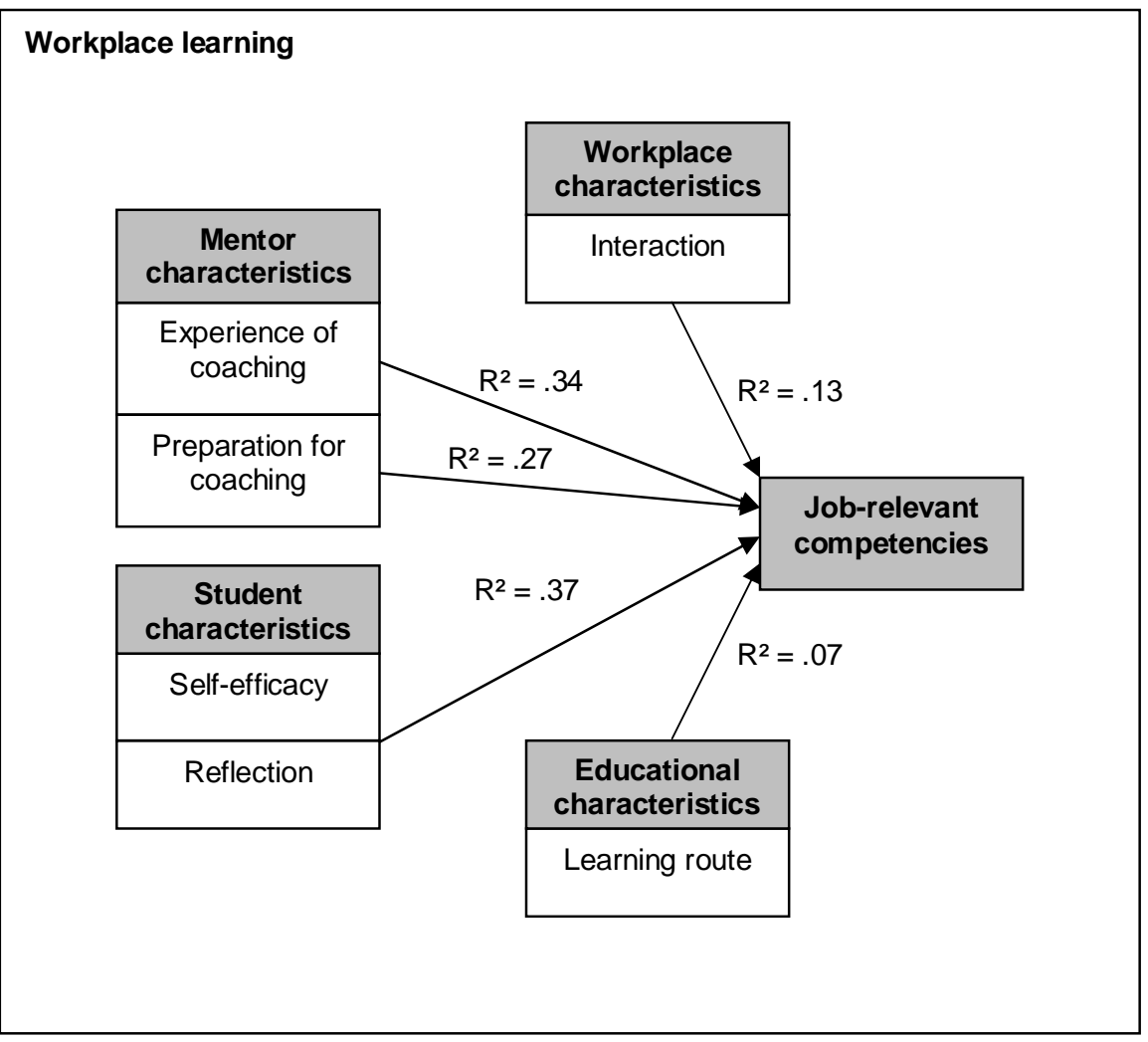

Figure 6.26 Variables predicting the mastery of job-relevant competencies at the hospital. 


\section{Chapter 7}

\section{Workplace learning at a bank}

\subsection{Introduction}

This chapter presents the findings of the second experiment, which was carried out concurrently with the first. For this experiment the setting is described, and then comes a short description of the methods and instruments used. Next, an account is given of the interaction process between mentors and team members and the implementation and use of the guidelines, followed by the findings with regard to the mastery of job-relevant competencies. Then, the influence of covariables on mastery is explored and, finally, the conclusions to be drawn from the experiment are presented.

\subsection{Setting}

The second experiment was carried out in a district of a large international bank, which has over 3,400 branches in more than 60 countries. The bank has a staff of 97,000 full-time equivalents and total assets of 609 billion euros. It offers financial services and solutions for consumer and commercial clients, wholesale clients and private clients. The Netherlands business unit has about 4.5 million consumer clients, some 350,000 small to medium-sized enterprise clients and around 3,500 corporate clients. The bank has divided its Netherlands business unit into 28 districts. In total there are some 550 bankshops.

The district that participated in this experiment is located at a large Dutch airport and has eight locations in the departures and arrivals halls. The main tasks of the district are selling and buying currency, and selling products such as insurance. These tasks are carried out at the counters of the locations according to the service standards of the bank and under the guidance of a supervisor. The number of counters per location varies from two to eight. The clients of the district are travellers from all over the world and the languages of communication at the counters are Dutch and English. The employees work in shifts. The pressure of work depends on the location and the time of day. 
The employees are grouped in teams, which are managed by location managers. A team consists of some 20 people and a location manager. Both teams and employees are expected to realise targets. The district wishes to improve the performance of the teams, in particular with regard to selling products and the conscientiousness with which money transactions are executed. The district does not offer opportunities for workplace learning to students from vocational education and training centres. Employees should be able to think and work at secondary vocational education and training level, and location managers at higher vocational education and training level.

The setting of this experiment differs substantially from the first. Here the participants are employees, who are being challenged to improve their performance, instead of students who need to learn to execute the tasks. This relates thus to human resource development rather than vocational education and training.

\subsection{Method and instrumentation}

A quasi-experimental non-equivalent control group design was used to test the hypothesis that application of the guidelines for interaction by the mentor leads to significantly better acquisition of job-relevant competencies by the team members. The treatment for the experimental group consisted of the guidelines for interaction. The acquisition of job-relevant competencies was the dependent variable, while workplace characteristics and personal characteristics were used as co-variables. The interaction process and the implementation of the guidelines were also measured. Figure 7.1 shows the design of the experiment.

Before the experiment started the data collection instruments were presented to the resource manager of the district to check their applicability to the bank. Her comment concerned the job-relevant competencies that had been formulated on the basis of the function profiles she had sent in. The formulations were adapted accordingly to make them both representative of the work of the team members and recognisable for them and the location managers. She questioned whether the location managers would be willing to use the guidelines, because of their higher vocational education and training background. At the same time she thought the guidelines would structure and deepen the interaction. Because the amount of time that the location managers had to interact with team members was expected to be limited, it was decided that the team members would also receive and use the guidelines. This would provide them with the opportunity to interact accordingly with each other. 


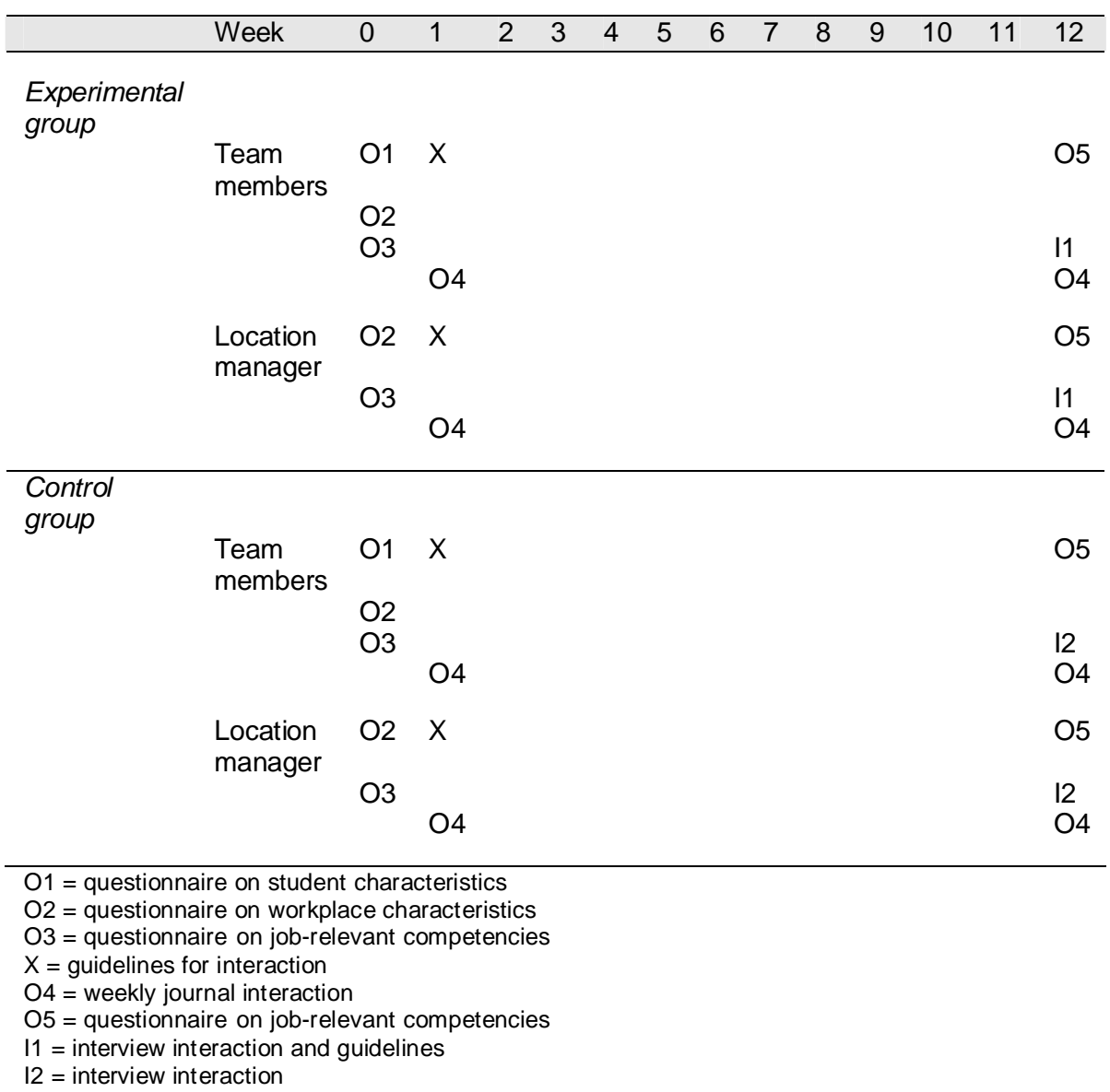

Figure 7.1 Design and instruments of the experiment.

This is another difference compared to the first experiment, where only the mentors received the card, not those who were expected to learn. The district manager and the resource manager had chosen two teams to participate. To exclude the effects of differences between the two teams, variables that referred to the characteristics of the location managers and team members were compared (see Table 7.3). These proved not to differ significantly with regard to age, work experience or coaching experience. There were also no significant differences with regard to gender (about $73 \%$ were female) or prior education (45\% had upper secondary education, 55\% lower secondary education). 
The experimental group was informed about the research project and given instructions during a meeting two weeks before the experiment actually started. The researcher informed the team members that they would be participating in a research project that focused on workplace learning. The file with the data collection instruments was handed to the team members on the spot and the researcher informed them how to use them and the estimated amount of time it would take to complete the different questionnaires. He also informed the team members about the aim and basic principles of the guidelines and how to use them. The team members were advised to read the guidelines a couple of times before use to become acquainted with them. They were instructed to use the guidelines as drawn up and it was explained why they should do so. The mentors were also advised to keep the guidelines close at hand to ensure they could be used and consulted at any time. The team members were asked to choose a task they would like to focus on and a team member to interact with. Because teams are mixed during shifts, the members were specifically and emphatically instructed to use the guidelines just for their own team. Although the team members wanted to know why their team had been chosen, with some of them being suspicious about this, their reactions were less critical than the resource manager and the location manager had expected. The team members promised their cooperation. The location manager of the experimental group was provided with information and instructions separately. She expected that the research project would motivate her team members to invest in their own development, something that had been lacking until then. Interaction in accordance with guidelines was new to her; she was used to a less structured way of interaction that took its form from the situations that occurred. After the period of instruction of 45 minutes, she had no questions and promised her cooperation. Because only half her team members were present at the meeting, it was agreed that she would discuss with the resource manager how to give the other members the information and instructions at short notice.

The location manager of the control group was also provided with information and instructions separately. First she was given the information and instructed how to use her own data collection instruments. Like the team members of the experimental group, she too asked why her team had been chosen. After that she was provided with information about the data collection instruments for her team and about how to instruct her team members, because it was not possible to organise a meeting for them. The location manager promised her cooperation.

According to the resource manager, the information and instructions were structured and clear.

The experiment started on January 1, 2005 and lasted twelve weeks, which meant that it could not build on experiences from the first experiment. This period was chosen because it was a relatively quiet one for the district and thus provided more opportunities for interaction. 
In the first week the location manager of the control group had provided instructions to almost all her team members, with the exception of two. According to her there were no questions about the data collection instruments. Not all team members of the experimental group had yet received the data collection instruments.

In the next couple of weeks the researcher visited the district three times to ask team members whether the information was sufficient and if they had any questions about the data collection instruments.

Table 7.2 provides an overview of the numbers of location managers and team members in each condition.

Table 7.2 Numbers of location managers and team members

\begin{tabular}{l|crrr}
\hline & \multicolumn{2}{c}{$\begin{array}{c}\text { Location } \\
\text { managers }\end{array}$} & \multicolumn{2}{c}{$\begin{array}{c}\text { Team } \\
\text { members }\end{array}$} \\
& Exp & Cont & Exp & Cont \\
\hline Bank & 1 & 1 & 19 & 19 \\
\hline
\end{tabular}

Table 7.3 Comparison of the experimental group and control group

\begin{tabular}{lrrrr}
\hline & \multicolumn{2}{c}{$\begin{array}{c}\text { Experimental } \\
\text { Group }\end{array}$} & \multicolumn{2}{c}{$\begin{array}{c}\text { Control } \\
\text { group }\end{array}$} \\
& Mean & SD & Mean & SD \\
\hline Location manager & & & & \\
Age & 26 & - & 28 & - \\
Work experience & 3 & - & 2 & - \\
Coaching & 3 & - & 2 & - \\
experience & & & & \\
Team member & & & & \\
Age & 26.87 & 5.94 & 30.53 & 8.14 \\
Work experience & 3.64 & 4.13 & 3.82 & 4.29 \\
Coaching & 2.89 & 4.76 & 3.54 & 5.81 \\
experience & & & & \\
\hline The groups do not differ significantly & & &
\end{tabular}

During the experiment none of the team members or location managers stopped prematurely. 


\subsection{Interaction at the workplace}

Looking at the theoretical framework for effective workplace learning (see Chapter 3), interaction provides the input of the learning processes and indirectly influences the acquisition of job-relevant competencies. This process was examined and described in order to be able to explore whether differences in interaction actually influenced the learning results.

During the experiment team members executed skill-oriented tasks that had been selected for the experiment: the processing of money transactions, selling other products, and passing on knowledge and skills to colleagues. According to the weekly journals, the first two tasks were executed considerably more than the last one (see Table 7.4). One likely explanation for this is that the last task was carried out mainly by the few team members who were supervisors. Another is that team members had to spend most of the time on money transactions and selling, leaving little time for other things. However, considering the 130 times knowledge and skills were passed on, it seems that team members were quite regularly in need of additional information and some training at the workplace to be able to execute tasks correctly. At the same time, team members perceived that interaction took place far less: during the entire experiment 25 times in total. One possibility is that team members interacted with colleagues from teams that did not participate in the experiment (as mentioned above, the teams were mixed during shifts). Another is that team members did not perceive the passing on of knowledge and skills as coaching, but as some kind of natural and daily routine incorporated into the work. In that case team members will have been unaware whether learning occurred.

The more formal interaction between team members focused mainly on selling. According to the team members and location managers, they mastered this task less well than the processing of money transactions. The team members also found it difficult to meet the target related to selling. Interaction related to improving the passing on of knowledge and skills took place least. As mentioned above, this was considered a task of the supervisors, who were few in number. The interaction between team member and location manager, again very limited, shows a different pattern. Most of the interaction focused on other things than the three tasks. It mainly concerned functioning in general, not the executing of specific tasks. This shows that the focus of the location manager differed considerably and was more remote from the daily work processes of the team members. This finding is confirmed by the significant negative correlation between the focus of the location manager and the number of times tasks were executed (for the rankings $\mathrm{p}=.1,2$-tailed, Pearson correlation is 1.000).

The number of times tasks were executed and the number of times interaction took place do not correlate significantly with the team members' 
mastery of job-relevant competencies. This means that mastery does not depend on the frequency of execution of tasks or interaction, which gives rise to the assumption that it is quality of interaction that is important, not quantity.

Table 7.4 Number of times tasks were executed and focus of interaction

\begin{tabular}{|c|c|c|c|c|c|c|}
\hline & \multicolumn{2}{|c|}{ Executed tasks } & \multicolumn{2}{|c|}{$\begin{array}{c}\text { Focus of the } \\
\text { location } \\
\text { manager }\end{array}$} & \multicolumn{2}{|c|}{$\begin{array}{l}\text { Focus of the } \\
\text { colleagues }\end{array}$} \\
\hline & $\begin{array}{c}\mathrm{N} \text { of } \\
\text { times }\end{array}$ & Rank & $\begin{array}{l}\mathrm{N} \text { of } \\
\text { times }\end{array}$ & Rank & $\begin{array}{l}\mathrm{N} \text { of } \\
\text { times }\end{array}$ & Rank \\
\hline Processing of money transactions & 361 & 1 & 2 & 4 & 5 & 2 \\
\hline Selling other products & 330 & 2 & 4 & 3 & 15 & 1 \\
\hline Passing on knowledge and skills & 130 & 3 & 6 & 2 & 3 & 3 \\
\hline Other tasks & - & - & 13 & 1 & 2 & 4 \\
\hline Total & 821 & & 25 & & 25 & \\
\hline
\end{tabular}

Because of time restrictions the location managers did not coach their own team members frequently or extensively. The location manager of the experimental group spent 11 hours in total on coaching eight members of her team. Two of them were coached twice, the others once. It is not clear why these team members were coached and the others were not. The scores on the pre-test do not indicate a necessity, because their scores were even better than the scores of the other team members. It indicates that the coaching focused on other things than performance of the selected tasks. Of the 183 times that team members answered the question whether they interacted with their location manager during a week, 178 times (97\%) the answer was 'no'. This means thus that in only $3 \%$ of the shifts they worked was there any kind of coaching by their manager. The location manager of the control group spent more time on interaction (25 hours) and coached more team members (16) during the experiment. Four of these members were coached at least three times. One member was coached twice, the others once. Like the experimental group, it is not clear why these team members were coached and the others were not. The scores for the pre-test do not indicate a necessity, because their scores were no worse than the scores of the other team members. Again, it indicates that the coaching focused on other things than the performance of the selected tasks. According to the team, in $11 \%$ of the shifts (20 of the 181) that they worked there was some kind of coaching by their manager. In most cases coaching took place at the locations where the members executed their tasks, sometimes during a break. The time spent on interaction with a team member amounted to 
15 minutes at most. The location managers talked to colleagues about the learning and working of their team members at least once a week. In view of the limited interaction and the focus of the interaction, this is not expected to significantly influence the acquisition of the selected job-relevant competencies. The fact that the location manager of the control group spent more time with more team members on coaching is expected to have a positive influence on the extent of growth of her team members.

As mentioned earlier, it was not only the location managers who coached, so did team members. And they coached more, judging by the number of times they passed on knowledge and skills. As presented in Table 7.4, their focus was mainly on the selling of other products, something most of the team members wanted to improve. As with the location managers the time for coaching was limited, because of the work that needed to be done. During a shift the time spent on interaction was less than 15 minutes. In addition, team members did not work together all the time and they therefore had to wait until their timetables matched again. This did not mean that there were no opportunities to interact with each other. Quiet moments were, however, used to put away receipts, rearrange the cashbox or restock it with currency. The intensity of coaching did not differ between the experimental group and the control group. According to the team members of the experimental group, interaction aimed at improving the execution of tasks took place 13 times and nine team members were coached by colleagues. In the control group interaction occurred 12 times, but only three colleagues were coached here.

Although the time for interaction was limited, the team members found the way their location managers and colleagues interacted with them suitable, considering their own preferences of interaction. They were satisfied or very satisfied with it. Team members of the experimental group were more satisfied with their location manager and their colleagues than were team members of the control group. At the same time interacting with a colleague was valued more. The mean scores of the experimental group and the control group for team members' satisfaction do not differ significantly.

\subsection{Use and implementation of the guidelines for interaction}

The theoretical framework presented in Chapter 3 was used to develop a set of guidelines for interaction. The guidelines aim at improving the effectiveness of workplace learning. To be able to test the hypothesis that application of the guidelines for interaction leads to significantly better acquisition of job-relevant competencies by the team members, it is necessary to examine and describe the extent to which the guidelines were actually used and how they were used. Explanations for the extent of use are also explored. 
Table 7.5 Team members' satisfaction with their location manager and team members

\begin{tabular}{lcrrr}
\hline Satisfaction & \multicolumn{2}{c}{$\begin{array}{l}\text { With location } \\
\text { manager }\end{array}$} & \multicolumn{2}{c}{ With colleague } \\
& Mean & SD & Mean & SD \\
\hline $\begin{array}{l}\text { Exp. group } \\
(\mathrm{n}=6)\end{array}$ & 1.67 & .52 & 1.25 & .50 \\
$\begin{array}{l}\text { Control group } \\
(\mathrm{n}=10)\end{array}$ & 1.88 & .34 & 1.67 & .58 \\
& & & & \\
\hline
\end{tabular}

1 = very satisfied, 2 = satisfied, 3 = neither satisfied nor dissatisfied, 4 = dissatisfied, 5 = very dissatisfied

At the beginning of the experiment the location manager and the 19 team members of the experimental group received the card with the ten steps and the accompanying guidelines for interaction. During the experiment 14 team members (74\%) actually used the card - not in interaction with their colleagues, but for their own learning process. These team members were somewhat older, had more experience of coaching and had worked at the district longer than their colleagues who did not use it. This could indicate that the older, more experienced team members were more focused on learning and on improving the execution of tasks than were the younger, less experienced ones. It raises the question whether the acquisition of job-relevant competencies benefits from using the card just for one's own learning and not in interaction with others.

Table 7.6: Age, years of experience of team members and use of the card with steps and guidelines

\begin{tabular}{lrrrrrr}
\hline & \multicolumn{2}{c}{ Age } & \multicolumn{3}{c}{$\begin{array}{c}\text { Work } \\
\text { experience }\end{array}$} & \multicolumn{3}{c}{$\begin{array}{c}\text { Coaching } \\
\text { experience }\end{array}$} \\
& Mean & SD & Mean & SD & Mean & SD \\
\hline $\begin{array}{l}\text { Used the card } \\
(n=14)\end{array}$ & 27.4 & 7.26 & 4.33 & 5.05 & 4.80 & 5.84 \\
$\begin{array}{l}\text { Did not use the } \\
\text { card } \\
(n=5)\end{array}$ & 25.8 & 1.64 & 2.40 & 1.14 & .50 & 1.00 \\
& & & & & & \\
\hline The groups do not differ significantly & & & & & \\
\end{tabular}


The location manager did not use the card with the guidelines, because she did not have the card at hand at moments that interaction took place, or she was too busy. According to the team members she coached, however, she did execute some of the steps. Logically, the steps of phase 3 (supervising the execution and discussing the performance) were omitted, because it was not her job to supervise the executing of tasks by team members. It is understandable that she took the view that the steps and guidelines did not fit into the daily work processes. Almost all the steps she executed were used once during the experiment. Only the step which focuses on talking through the task a team member wants to learn to execute better was used three times. This step does not have to be used just before, during or just after executing a task. It therefore probably fits better into the location manager's work pattern.

The team members who used the card for interaction with each other only made very limited use of the steps and guidelines. Because of the amount of time spent on interaction and the frequency of interaction, this finding is not surprising. The timetables of those team members who had asked a colleague to coach them did not match and it was not easy to find moments to interact during joint shifts.

The team members who coached colleagues used more steps and focused more on the preparation for executing a task and on supervising the execution than did their location manager. They only omitted step 9, which focuses on determining the next steps necessary to learn to execute the task. Leaving out this step indicates that the team members already expected that they would not interact more often. The limited use of the card is probably due to the rather restricted opportunities for interaction at the counter in front of clients. As a consequence team members probably did not have the card at hand, and for this reason it could not be used during the few moments that were available for structured interaction. According to team members, using the card would also take too much time, and did not fit into their daily work processes. The steps and guidelines were considered neither unclear nor illogical.

The team members who used the card just for themselves were not asked to what extent they had used the steps and guidelines, because the focus of the experiment was on interaction with others.

Table 7.7 provides an overview of the number of times the steps were used. The differences in the pattern of use indicate that the interaction of the location manager and the team members were complementary. 
Table 7.7 Frequency of the use of steps for interaction

\begin{tabular}{|c|c|c|}
\hline Step & $\begin{array}{l}\text { Location } \\
\text { manager }\end{array}$ & $\begin{array}{l}\text { Team } \\
\text { member }\end{array}$ \\
\hline \multicolumn{3}{|l|}{ Phase 1: Orienting to the task } \\
\hline $\begin{array}{l}\text { 1. Select together a task the team member wants to learn to } \\
\text { execute. }\end{array}$ & 1 & 1 \\
\hline $\begin{array}{l}\text { 2. Talk through together the task the team member wants to learn } \\
\text { to execute. }\end{array}$ & 3 & 1 \\
\hline $\begin{array}{l}\text { 3. Determine together what the team member already knows and } \\
\text { is capable of. }\end{array}$ & 1 & 1 \\
\hline $\begin{array}{l}\text { 4. Discuss together how the team member wants to learn to } \\
\text { execute the task. }\end{array}$ & 1 & 2 \\
\hline \multicolumn{3}{|l|}{ Phase 2: Preparing for the execution of the task } \\
\hline 5. Prepare together for the execution of the task. & 1 & 2 \\
\hline $\begin{array}{l}\text { 6. Make sure all the team member needs to execute the task is } \\
\text { available. }\end{array}$ & - & 2 \\
\hline \multicolumn{3}{|l|}{$\begin{array}{l}\text { Phase 3: Supervising the execution of the task and discussing } \\
\text { performance }\end{array}$} \\
\hline 7. Supervise the execution of the task. & - & 1 \\
\hline $\begin{array}{l}\text { 8. Discuss performance with the team member immediately after } \\
\text { execution. }\end{array}$ & - & 3 \\
\hline $\begin{array}{l}\text { 9. Determine together the next steps necessary to learn to execute } \\
\text { the task. }\end{array}$ & 1 & - \\
\hline \multicolumn{3}{|l|}{ Phase 4: Improving ability } \\
\hline $\begin{array}{l}\text { 10. Instruct the team member to execute the task a couple of times } \\
\text { more. }\end{array}$ & 2 & 1 \\
\hline
\end{tabular}

The team members were not only asked whether the steps had been used, but also to what extent they had been executed as drawn up. Table 7.8 provides an overview of the way the location manager and her colleagues interacted with them. As a result of the steps that the location manager used, her way of interacting matched the card only to a reasonable extent. She adapted their use to a reasonable extent by changing the order, by omitting some and by adding her own. This shows that she had her own way of interacting. A likely reason for this adaptation is the focus of the interaction on the general functioning of team members, instead of on the execution of specific tasks. The team members used the steps and guidelines more as drawn up and adapted their use only to a small extent. This points to a high-fidelity approach, which indicates that the card provided them with a virtually complete way of interacting. The location manager and the team members were not asked to mention in the weekly journal what steps or guidelines they had added or omitted. In the interview at the end of the experiment the same question proved hard to answer, probably 
because it was difficult to recall the moments when they had added their own. This indicates that this adaptation depended on the situation and proved not to be a fundamental one that they used all the time. In the interview the location manager stated that her way of interacting with the team members matched the guidelines - at least to a large extent. This answer does not match the information extracted from the weekly journals, as presented in Table 7.8. Probably the time span the location manager had in mind when answering the question caused this difference. The difference could also be due to the necessity the location manager felt during the interview to answer in a socially desirable way.

Table 7.8 Mean scores for the use of the steps and guidelines according to team members (experimental group)

\begin{tabular}{lrr}
\hline $\mathrm{N}=8$ & $\begin{array}{r}\text { Location } \\
\text { manager } \\
\text { Mean }\end{array}$ & $\begin{array}{r}\text { Team } \\
\text { member }\end{array}$ \\
& & \\
& & \\
Steps & 3.50 & 4.00 \\
I use the steps as intended & 3.17 & 1.87 \\
I adapt the use of the steps: & 3.25 & 2.00 \\
- I use the steps in a different order & 2.80 & 2.00 \\
- I omit steps & 3.20 & 1.60 \\
- I add my own steps & & \\
& & \\
Guidelines & 3.20 & 4.00 \\
I use the guidelines as intended & 3.05 & 1.80 \\
I adapt the use of the guidelines: & 2.80 & 2.00 \\
- I use the guidelines in a different order & 3.00 & 2.00 \\
- I omit guidelines & 3.25 & 1.40 \\
- I add my own guidelines & & \\
& & \\
\hline 1 = not at all, 2 = to a small extent, 3 = to a reasonable extent, $4=$ to a large extent, $5=$ only
\end{tabular}

Because the interaction was very limited and only three team members provided information during the interviews, there is little point in examining the levels of use and the stages of concern more closely. It is reasonable to assume that the use of the steps and guidelines could not become routine, and that the location manager and team members were concerned only about the impact these would have on their work.

Finally, the findings about the use of the card with the steps and guidelines by team members makes it relevant to search for additional explanations related to workplace characteristics, mentor characteristics and student characteristics. 
It is plausible that the team members' environment influenced willingness and opportunities to use the card. T-tests show that team members who used the card for themselves perceived their workplace as an environment with a higher degree of participation, variation, task information and informational support than did their colleagues who did not use the card at all. It seems that a workplace where exchange of information and communication is perceived as more common is also a more stimulating place to use an instrument with comparable characteristics. From the personal characteristics it is clear that team members who were highly motivated were apparently also motivated to use the card, probably because they wanted to execute the tasks as well as possible.

Team members who used the card while interacting with colleagues had no significantly different scores for workplace characteristics compared to colleagues who did not. They did, however, have a significantly higher score for regulation, indicating that they preferred being in control of the learning processes. Table 7.9 shows the findings.

Table 7.9 Influence of workplace and personal characteristics on the use of the card

\begin{tabular}{|c|c|c|c|c|c|c|}
\hline & \multicolumn{2}{|c|}{$\begin{array}{l}\text { Used for } \\
\text { themselves } \\
\qquad(n=14)\end{array}$} & \multicolumn{2}{|c|}{$\begin{array}{l}\text { Not used for } \\
\text { themselves } \\
(n=5)\end{array}$} & \multicolumn{2}{|c|}{$\begin{array}{l}\text { Used during } \\
\text { interaction } \\
\qquad(n=3)\end{array}$} \\
\hline & Mean & SD & Mean & $\mathrm{SD}$ & Mean & SD \\
\hline \multicolumn{7}{|c|}{ Workplace characteristics: } \\
\hline Participation* & 2.05 & .40 & 1.66 & .38 & & \\
\hline Variation ${ }^{* *}$ & 2.45 & .55 & 1.83 & .31 & & \\
\hline Task information ${ }^{\star \star *}$ & 3.03 & .38 & 2.33 & .37 & & \\
\hline Informational support* & 2.57 & .45 & 2.20 & .14 & & \\
\hline \multicolumn{7}{|l|}{ Personal characteristics: } \\
\hline Motivation* ${ }^{*}$ & 4.30 & .34 & 3.96 & .26 & & \\
\hline Regulation* & & & 3.03 & .40 & 3.53 & .31 \\
\hline \multicolumn{7}{|c|}{$\begin{array}{l}{ }^{*} \text { The groups differ significantly at } \alpha=.1 \text { level } \\
{ }^{* *} \text { The groups differ significantly at } \alpha=.05 \text { level } \\
\text { *** The groups differ significantly at } \alpha=.01 \text { level }\end{array}$} \\
\hline \multicolumn{7}{|c|}{$\begin{array}{l}\text { Workplace characteristics: } \\
1=\text { hardly ever, } 2 \text { = sometimes, } 3 \text { = often, } 4 \text { = almost always } \\
\text { Personal characteristics: } \\
\text { Motivation: } 1=\text { not at all applicable, } 2=\text { sliahtly applicable, } 3=\text { moderately applicable. }\end{array}$} \\
\hline
\end{tabular}


In summary, although most of the team members of the experimental group used the card with the steps and guidelines for themselves, the card was hardly used during interaction with colleagues. Some important reasons for its limited use were the small number of shifts that team members worked jointly, shortage of time and its unsuitability for use during daily work processes at the counters in front of clients. If case team members used the card they did so to a large extent as drawn up. The location manager used it more in her own way and adapted the steps and guidelines to make them suitable for her aim and focus of interaction. As a result of the limited use of the card, the team members did not have much opportunity to experiment and refine the steps and guidelines on the basis of experience, which means they did not reach the higher levels of use or higher stages of concern. Another consequence of its limited use is that it will not have any impact on the acquisition of job-relevant competencies.

\subsection{Mastery of job-relevant competencies}

The aim of the experiment was to test the hypothesis that application of the guidelines for interaction leads to significantly better acquisition of job-relevant competencies by the team members. The items used to measure acquisition focused on the mastery of relevant tasks in the daily work process at the workplace. Before the mean scores for mastery were computed Cronbach's $\alpha$ coefficient was calculated. This was acceptable, with scores varying from .82 (team member score) to .75 (location manager score).

At the beginning of the experiment team members had already perceived mastery of the job-relevant competencies as quite good, due to their work experience. According to the location manager the team members of the experimental group mastered the job-relevant competencies slightly better than did the team members of the control group. Judging by the self-assessment of the team members, the reverse was the case. The team members of the control group thought they had already mastered the competencies well. The scores for mastery did not, however, differ significantly. The post-test reveals that the members mastered the competencies quite well or well.

The six-point scale for mastery indicates that there was room for growth for both groups to master the competencies substantially better than they had at the beginning. However, although the experimental group grew somewhat more than did the control group, a difference between the post-test and pre-test of .30 at most is considered very small. This is probably due to the level of mastery at the beginning and the small amount of interaction at the workplace aimed at improving performance. It is also possible that a period of twelve weeks was not long enough to change routines that had been built up in the previous years. 
Table 7.10 presents the mean scores for the mastery of job-relevant competencies.

Table 7.10 Mastery of job-relevant competencies

\begin{tabular}{lcccccr}
\hline Mastery & \multicolumn{2}{c}{ Pre-test } & \multicolumn{2}{c}{ Post-test } & \multicolumn{2}{c}{ Difference } \\
& Mean & SD & Mean & SD & Mean & SD \\
\hline $\begin{array}{l}\text { Location } \\
\text { manager }\end{array}$ & & & & & & \\
$\begin{array}{l}\text { Exp. group } \\
(n=1)\end{array}$ & 3.29 & 1.08 & 3.50 & 1.03 & .21 & .50 \\
$\begin{array}{l}\text { Control group } \\
(n=1)\end{array}$ & 3.16 & 1.08 & 3.46 & 1.21 & .30 & 1.25 \\
$\begin{array}{l}\text { Team members } \\
\begin{array}{l}\text { Exp. group } \\
(n=9)\end{array}\end{array}$ & 3.70 & .63 & 3.96 & .63 & .26 & .46 \\
$\begin{array}{l}\text { Control group } \\
(n=10)\end{array}$ & 4.13 & 1.25 & 4.20 & 1.29 & .07 & .58 \\
\end{tabular}

Mastery: 1 = insufficient, 2 = sufficient, $3=$ quite good, $4=$ good, $5=$ very good, $6=$ excellent

Although team members of the experimental group grew slightly more than did the members of the control group, the difference between the post-test and pretest of the two groups does not differ significantly. As a result of this finding and because the location manager and the team members of the experimental group hardly used the steps and guidelines for interaction, the hypothesis of the experiment is rejected: application of the guidelines for interaction does not lead to significantly better acquisition of job-relevant competencies by the team members.

It also means that the more intensive coaching by the location manager of the control group did not bear fruit.

\subsection{The effects of independent variables}

The rejection of the hypothesis calls for some other analyses that could provide explanations for the differences with regard to the mastery of job-relevant competencies. The research model contains variables for further analyses. The next subsections examine the effects of variables with regard to workplace characteristics and personal characteristics on the dependent variable. There is also an exploration of the effects of both the interaction process and the targets. 


\subsubsection{The effect of workplace characteristics}

At the beginning eleven workplace characteristics were measured. If these characteristics are actually present to a high degree, external learning conditions for the learning process are considered to have been fulfilled to a large extent and the workplace itself is considered a potentially powerful learning environment. Table 7.11 presents the mean scores for the workplace characteristics measured. These scores indicate that the team members experienced a lot of emotional and instrumental support and they interacted often at their work. They experienced appraisal support and informational support somewhat less, but still quite regularly. The members were also informed about the tasks they had to execute and the quality with which they were expected to do so. The other workplace characteristics were experienced considerably less. The variation is limited and members felt that they did not have a lot of influence on what was happening at the workplace; they were also not very autonomous in their work. On the other hand, pressure of work and task obscurity were fairly low. The mean scores indicate that learning conditions at the workplaces were available and fulfilled to some extent. The workplace at the bank was therefore in itself not a powerful learning environment.

To be able to exclude the influence of differences between the experimental group and the control group on team members' mastery of jobrelevant competencies, the means for these two groups were also computed. This proved that the groups differed significantly on task obscurity $(\mathrm{p}<.1)$, which means that the experimental group knew better what was expected.

Table 7.11 Mean scores for workplace characteristics

\begin{tabular}{|c|c|c|c|c|c|c|}
\hline \multirow[t]{2}{*}{$\begin{array}{l}\text { Workplace } \\
\text { characteristics }\end{array}$} & \multicolumn{2}{|c|}{$\begin{array}{c}\text { Bank } \\
\text { total } \\
(n=34)\end{array}$} & \multicolumn{2}{|c|}{$\begin{array}{c}\text { Bank } \\
\text { exp. group } \\
(n=16)\end{array}$} & \multicolumn{2}{|c|}{$\begin{array}{c}\text { Bank } \\
\text { control group } \\
(n=18)\end{array}$} \\
\hline & mean & SD & Mean & SD & Mean & SD \\
\hline Participation & 1.97 & .58 & 1.93 & .41 & 2.01 & .70 \\
\hline Variation & 2.18 & .60 & 2.25 & .54 & 2.11 & .66 \\
\hline Task autonomy & 2.07 & .63 & 1.96 & .51 & 2.17 & .71 \\
\hline Task information & 2.67 & .57 & 2.74 & .54 & 2.61 & .60 \\
\hline Task obscurity * & 1.69 & .48 & 1.54 & .39 & 1.81 & .52 \\
\hline Pressure of work & 1.76 & .37 & 1.65 & .35 & 1.85 & .36 \\
\hline Interaction & 3.01 & .41 & 2.94 & .39 & 3.08 & .42 \\
\hline Instrumental support & 3.04 & .43 & 3.06 & .44 & 3.02 & .43 \\
\hline Informational support & 2.47 & .49 & 2.43 & .40 & 2.51 & .57 \\
\hline Appraisal support & 2.51 & .50 & 2.47 & .28 & 2.54 & .64 \\
\hline Emotional support & 3.17 & .38 & 3.21 & .35 & 3.13 & .41 \\
\hline
\end{tabular}


A regression analysis was conducted for each of the workplace characteristics to search for variables that would explain the variance in the extent to which jobrelevant competencies were acquired by the team members. Instrumental support explained $17 \%$ of the variance $($ Fchange $=3.981, \mathrm{p}<.1$ ). This finding underlines the importance of support for workplace learning. The other workplace characteristics did not explain variance to a significant level.

Table 7.12 Significant regression weights of regression analyses predicting mastery of job-relevant competencies

\begin{tabular}{llllll}
\hline Dependent variable: & $\mathrm{R}^{2}$ & Independent variable & $\mathrm{B}$ & $\mathrm{SE}$ & $\beta$ \\
\hline $\begin{array}{l}\text { Difference between post-test } \\
\text { and pre-test }\end{array}$ & .17 & Instrumental support & .65 & .33 & .42 \\
\hline $\mathrm{p}<.1$ & & & & & \\
\hline
\end{tabular}

\subsubsection{The effect of personal characteristics}

At the beginning of the experiment team members completed a questionnaire on personal characteristics. The questionnaire measured their perception of ten personal characteristics that have been shown to influence workplace learning (see the review in Chapter 2). If these characteristics are actually present to a high degree, internal learning conditions for the learning process are considered to have been fulfilled to a large extent. Before presenting the mean scores for these personal characteristics, some other descriptive information about the team members is given.

On average the team members were 29 years old and had worked at the district for about 3.75 years. Most of them were female (75\%). On average they had 3.25 years' experience of coaching colleagues and they felt skilled to do so. The extent to which the members had already had experience of executing the tasks before they started to work at the bank varied. Because of the number of years they had worked at the district it was assumed that prior experience would no longer influence their performance. About $45 \%$ of the team members had upper secondary education as preparatory education, the rest had lower secondary education.

The mean scores for personal characteristics show that the team members found themselves highly motivated and conscientious, and they had a strong belief in their own capabilities (self-efficacy). They also found that they had good control over what happened to them (locus of control). At the same time, they 
did not feel alone or helpless (anxiety). From the learning style one sees that the team members characterised themselves as learning and inquiring-oriented. They believed themselves to be more generic then idiosyncratic, and more immersed then detached. They preferred internal regulation to external regulation. The mean scores indicate that the team members already possessed to a large extent those characteristics that have a positive influence on learning.

To be able to exclude the influence of differences between the experimental group and the control group on team members' mastery of jobrelevant competencies, the means for these two groups were also computed. The groups differ significantly on regulation $(p<.1)$. The team members of the control group preferred to regulate their learning process themselves somewhat more than did those of the experimental group. This could indicate that interaction in the experimental group has more impact and effect, because team members were more willing to let others help them with their learning. These differences could have affected the extent to which team members acquired jobrelevant competencies. A regression analysis proved, however, that regulation does not explain the variance in the mastery of job-relevant competencies to a significant level.

Table 7.13 Mean scores for personal characteristics

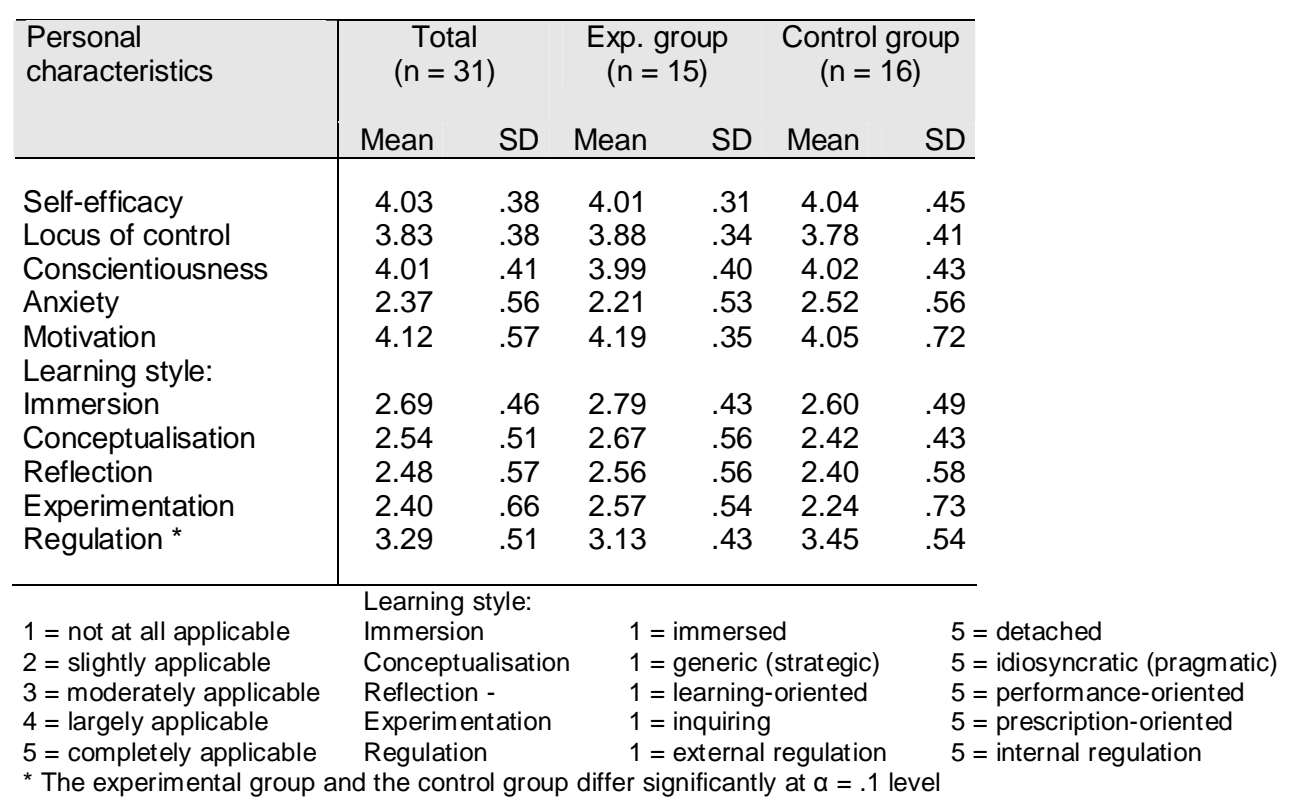


A regression analysis was carried out for each of the personal characteristics to search for variables that would explain the variance in the extent to which jobrelevant competencies were acquired by team members. None of the characteristics explained the variance to a significant level.

Looking at the research model of Chapter 3, the experience of team members is considered a potentially influential variable with regard to workplace learning. Experience has two different variables, the first one being experience of coaching. This proved that team members who had coached for at least three years grew significantly more than did those who had coached for two years at most $(\mathrm{p}<.1)$. It is possible that more experienced team members were focused more on learning and an improvement in performance. The more experienced team members had higher scores, meaning they possessed to a larger extent those characteristics that influence learning in a positive way. This finding underlines the theoretical assumptions of Chapters 2 and 3 and indicates the relevance of the chosen personal characteristics. A regression analysis shows that experience of coaching explains $10 \%$ of the variance in growth (Fchange $=3.601, \mathrm{p}<.1$ ).

Although the more experienced team members also had more work experience (the second variable), this variable has no significant effect.

Table 7.14 Years of experience of coaching and mastery of job-relevant competencies

\begin{tabular}{lccc}
\hline Experience of coaching & \multicolumn{2}{c}{$\begin{array}{c}\text { Difference } \\
\text { between post- } \\
\text { test and pre-test } \\
\text { Mean }\end{array}$} & SD \\
\hline $\begin{array}{l}\text { At most 2 years of experience of coaching } \\
(n=28)\end{array}$ & .11 & .98 \\
$\begin{array}{l}\text { At least } 3 \text { years of experience of coaching } \\
(n=7)\end{array}$ & .86 & .72 \\
\hline
\end{tabular}

The groups differ significantly at $\alpha=.1$ level 
Table 7.15 Significant regression weights of regression analyses predicting mastery of job-relevant competencies

\begin{tabular}{lclcrrr}
\hline Dependent variable: & $\mathrm{R}^{2}$ & Independent variable & $\mathrm{B}$ & $\mathrm{SE}$ & $\beta$ \\
\hline $\begin{array}{l}\text { Difference between post-test } \\
\text { and pre-test }\end{array}$ & .10 & $\begin{array}{l}\text { Experience of } \\
\text { coaching }\end{array}$ & .75 & .40 & .31 \\
\hline $\mathrm{p}<.1$ & & & &
\end{tabular}

\subsubsection{The effects of interaction processes}

This subsection focuses once more on interaction. As the steps and guidelines for interaction were hardly used, the focus is not on the effects of the intensity with which they were used. It is, however, possible to look for the effects of the card when it was not used for interaction but just for one's own learning. The question whether coaching in general had an effect was also examined. The subsection ends with a brief exploration of whether the targets team members had to meet influenced the acquisition of job-relevant competencies.

As mentioned above, 14 team members of the experimental group used the card for themselves; five of them did not use it. The two groups did not differ in age, work experience or coaching experience. An analysis proved that the team members who used it for themselves did not master job-relevant competencies significantly better than their colleagues who did not use it. On the contrary, their scores were even worse. Although it is not known how they used the card, this indicates the rightness of the theoretical assumption that interaction with others is important and that the guidelines must be used for interaction with others to be effective:

Table 7.16 Use of card and mastery of job-relevant competencies

\begin{tabular}{lcc}
\hline & $\begin{array}{c}\text { Difference between post-test } \\
\text { and pre-test }\end{array}$ & \\
& Mean & SD \\
\hline $\begin{array}{l}\text { Used for themselves } \\
(\mathrm{n}=12)\end{array}$ & .11 & .47 \\
$\begin{array}{l}\text { Did not use for themselves } \\
(\mathrm{n}=4)\end{array}$ & .50 & .58 \\
\hline
\end{tabular}


The team members who coached others all felt skilled to coach because they had had enough work experience and because of their knowledge of the work. In total, 11 team members were coached by a colleague, and 24 were coached by their location manager. Irrespective of the way it was conducted, coaching proved to have a positive effect on the acquisition of job-relevant competencies. It proved to be significant when team members interacted with their colleagues. The effect of interaction with their location manager was less and was not significant, probably because the interaction focused primarily on the functioning of team members in general and less on the performance of the selected task. Another possible explanation for the positive effects of interaction with colleagues is that they know better what is required to execute the tasks, and they empathise more.

A regression analysis shows that interaction explains $8 \%$ of the variance (Fchange $=3.027, \mathrm{p}<.1$ ). This finding underlines the importance of interaction for workplace learning.

Table 7.17 Person team members interacted with and mastery of job-relevant competencies

\begin{tabular}{|c|c|c|}
\hline & $\begin{array}{r}\text { Diffe } \\
\text { betwe } \\
\text { test and }\end{array}$ & $\begin{array}{l}\text { ce } \\
\text { ost- } \\
\text { e-test }\end{array}$ \\
\hline & Mean & SD \\
\hline Interacted w & & \\
\hline Yes $(n=11)$ & .67 & .68 \\
\hline No $(n=24)$ & .07 & 1.04 \\
\hline Interacted w & & \\
\hline Yes $(n=22)$ & .36 & 1.08 \\
\hline No $(n=13)$ & .08 & .75 \\
\hline
\end{tabular}

Table 7.18 Significant regression weights of regression analyses predicting mastery of job-relevant competencies

\begin{tabular}{lcllll}
\hline Dependent variable: & $\mathrm{R}^{2}$ & Independent variable & $\mathrm{B}$ & $\mathrm{SE}$ & $\beta$ \\
\hline $\begin{array}{l}\text { Difference between post-test } \\
\text { and pre-test }\end{array}$ & $.08 \begin{array}{l}\text { Interacted with } \\
\text { colleague }\end{array}$ & .60 & .34 & .29 \\
\hline $\mathrm{p}<.1$ & & &
\end{tabular}




\subsubsection{The effects of targets}

The final subsection of this chapter focuses on the targets the bank uses to measure the performance of teams and team members.

During the experiment the acquisition of job-relevant competencies was not the only available measure of growth. As mentioned in Section 7.2, the district works with targets for teams and team members. Every quarter, teams and team members have to achieve a score on the processing of money transactions and the selling of other products. Teams and team members are awarded points for having a balanced cashbox and for selling different products. The district made it known that during the experiment the experimental group team performed better than did all the other teams of the district. In view of the lower scores and ranking in the period before the experiment, this improvement indicates that growth was realised. Although the location managers were of the opinion that targets had a large influence on performance, the opinions of their team members varied. Team members who were of the opinion that targets had some influence performed better than those who felt that they had hardly any influence or, conversely, a great deal of influence. Those who experienced no influence from the targets were probably not challenged to perform better; those who experienced a lot of influence were probably hindered by it. The influence of targets has a significant effect on mastery $(\mathrm{p}<.05)$.

A regression analysis shows that the opinions of team members about the influence of targets on their performance explains $48 \%$ of the variance (Fchange=6.517, $\mathrm{p}<.05)$. It shows the influence this has on the mastery of jobrelevant competencies.

Table 7.19 Perception of influence of targets on performance and mastery of job-relevant competencies

\begin{tabular}{lrr}
\hline $\begin{array}{l}\text { Extent of } \\
\text { influence of } \\
\text { targets }\end{array}$ & \multicolumn{2}{c}{$\begin{array}{c}\text { Difference between } \\
\text { post-test and pre-test }\end{array}$} \\
& Mean & SD \\
\hline Not at all $(n=2)$ & -.50 & .71 \\
Very little $(n=1)$ & -1.33 & .00 \\
A little $(n=5)$ & .73 & .80 \\
Some $(n=7)$ & .19 & .60 \\
Much $(n=2)$ & -1.33 & 1.41 \\
\hline$p<.05$ & & \\
\hline
\end{tabular}


Table 7.20 Significant regression weights of regression analyses predicting mastery of job-relevant competencies

\begin{tabular}{lllllll}
\hline Dependent variable: & $\mathrm{R}^{2}$ & Independent variable & $\mathrm{B}$ & $\mathrm{SE}$ & $\beta$ \\
\hline $\begin{array}{l}\text { Difference between post-test } \\
\text { and pre-test }\end{array}$ & .48 & Influence of targets & .25 & .10 & .69 \\
\hline $\mathrm{p}<.05$ & & & & & \\
\hline
\end{tabular}

\subsection{Summary and conclusions}

The second experiment to test the hypothesis was carried out at a district of a large international bank. The district wished to improve the performance of its teams and agreed to participate in the experiment with two teams. One of the teams received a card with steps and guidelines for interaction. Although the experiment was carried out during a relatively quiet period, to increase the chances of interaction, team members hardly interacted with their colleagues or their manager. As a consequence, the card with steps and guidelines was used to a very limited extent and its use did not become routine. The team members' main concern was related to fitting the use of the steps and guidelines into their daily work processes at the counters in front of clients. Team members who were willing to use the card just for themselves did not benefit from it. This underlines the importance of interaction and the necessity of using the steps and guidelines in interaction. Workplace characteristics such as participation, variation and informational support, and personal characteristics such as motivation and regulation also seem to affect their use.

At the end of the experiment the team members had mastered the jobrelevant competencies just slightly better and the experimental group had not mastered job-relevant competencies significantly better than had the control group. The hypothesis that application of the guidelines for interaction leads to significantly better acquisition of job-relevant competencies by the team members was therefore rejected.

Further analysis, however, revealed some interesting findings with regard to the effectiveness of workplace learning. First of all, it showed the importance of interaction. Team members who were not coached mastered the competencies less well than did those who did interact with colleagues and location manager. At the same time, interaction with colleagues proved to be most effective, probably because they know better what is required to execute the tasks and they empathise more. Analyses also proved that team members with substantial coaching experience mastered the competencies better than did their colleagues with limited experience, probably because they were focused more on learning and improvement in performance. With regard to personal 
development, this is an interesting finding and it challenges companies to stimulate employees to coach.

Studying the workplace characteristics, the existing situation at the district indicates that the workplace is not a very powerful learning environment in itself. However, instrumental support proved to be an important variable with regard to explaining the variance in the mastery of job-relevant competencies. It indicates the importance of support for learning. The effects of the personal characteristics proved to be non-significant, although the somewhat older team members who mastered the competencies better also scored higher for these characteristics. Finally, during the experiment the team of the experimental group performed better than did all the other teams of the district, as regards the targets teams and team members had to realise. Judging from their lower scores and ranking in the period before the experiment, this change indicates that growth was realised. Targets show that they can also stimulate performance improvement if team members are challenged to meet them.

In summary, interaction between colleagues proved to be effective and should be stimulated in order to increase the effectiveness of workplace learning. Gaining experience of coaching also contributes to effectiveness, since it stimulates the integration of learning and reflection on one's work.

Figure 7.21 presents a model that contains the variables that predict the mastery of job-relevant competencies. This model is based on analyses with separate variables. 


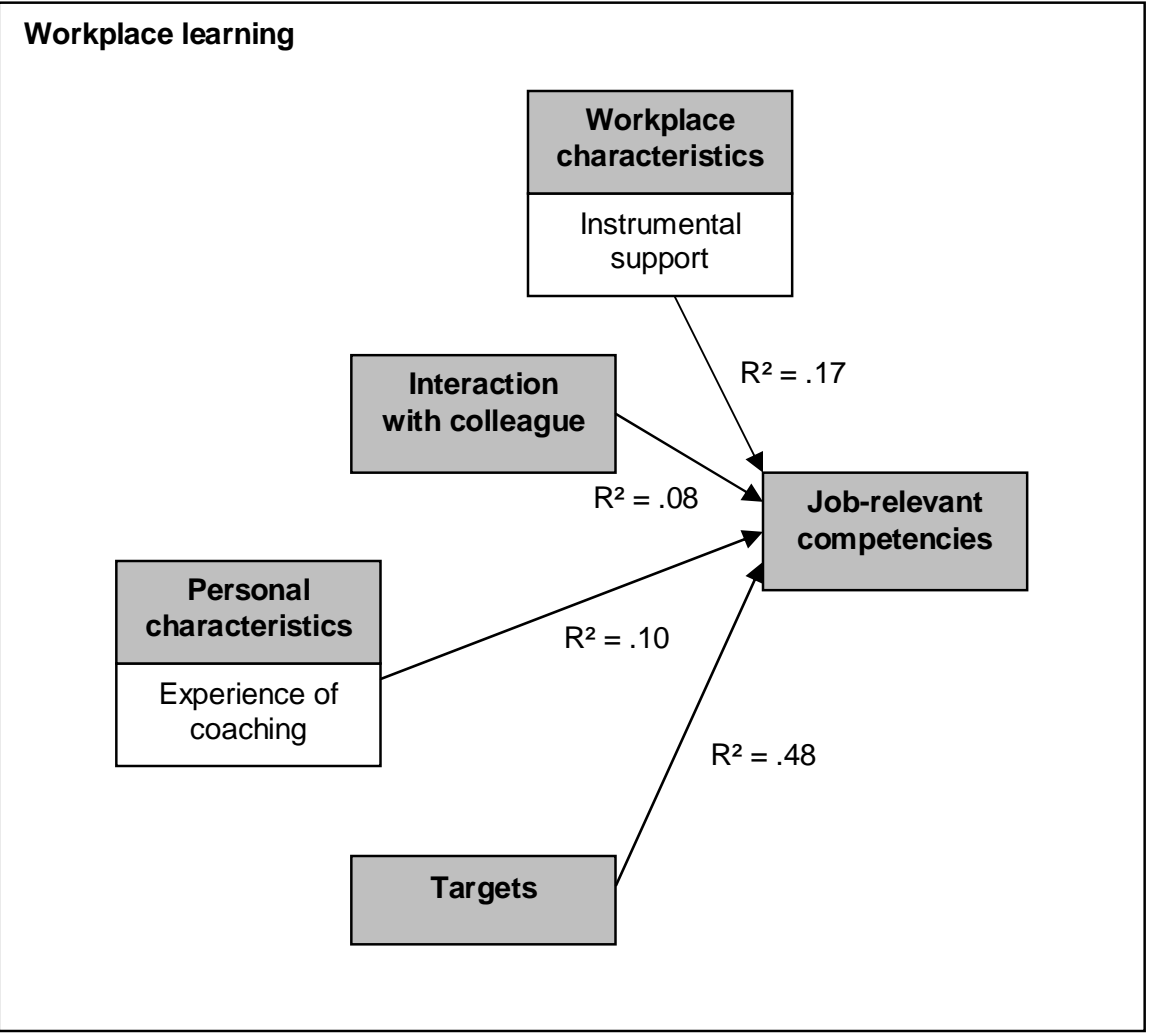

Figure 7.21 Variables predicting the mastery of job-relevant competencies at the bank. 


\section{Chapter 8}

\section{Workplace learning at an ICT company}

\subsection{Introduction}

This chapter presents the findings of the third experiment. As in the previous chapters, first of all the setting is described, and then comes a short description of the methods and instruments used. Next, an account is given of the interaction process between mentors and team members and the implementation and use of the guidelines, followed by the findings with regard to the mastery of job-relevant competencies. Then, the influence of co-variables on mastery is explored, and finally, the conclusions to be drawn from the experiment are presented.

\subsection{Setting}

The third experiment was carried out in a large international ICT company that has 22,000 employees in 30 countries and annual returns of 3 billion euro. The company offers solutions that add to performance improvement and reduce costs. Several services (including application, security, workspace management, communication and technology transformation services) are provided at sectors such as finance, healthcare, industry, public sector and local government. In the Netherlands the company has offices in more than 20 cities and over 10,000 employees, which makes it one of the largest ICT companies in the country.

The employees are part of a team, which consists of a project manager, a project coordinator, one or more chief mechanics, and a number of mechanics and assistants. According to the Training \& Development manager, the company wants and needs to recruit young people. They are to be selected from the vocational education and training students in the full-time college-based route who attend their period of workplace learning at the company. The company also has employees in the part-time work-based route who have already worked at the company for some years. They are able to carry out part of the work on their own and are coached by one of the company's instructors, 
who monitors their progress and meets them once every two or three months. Sometimes the employees are also coached by a chief mechanic, although this kind of coaching is not structural. There are no fixed, permanent combinations of employees as mentor and apprentice; the work that needs to be done determines which combinations occur. The employees in the part-time workbased route attend school one or two evenings a week.

At the beginning of their period of workplace learning, students in the full-time college-based route are trained for the work they will execute. Training is given by the company's instructors at a training centre, and lasts about 4 to 6 days. After training the students are put into service on company projects. They are coached by chief mechanics, who have been selected on the basis of their social skills. Most of the students work two or three days a week, and are at school for the remaining days.

The setting of this experiment resembles the first experiment, which was carried out at a hospital. In both settings the mentors from different departments or locations and their students participated. At the ICT company, however, only one mentor was appointed to each student, instead of two, and students in the part-time work-based route worked more on their own compared to the hospital. One major difference was that students of the full-time college-based route started their period of workplace learning in a training centre to learn to execute tasks in the way the company wanted. The situation of the part-time collegebased route somewhat resembled that at the bank. In both settings employees with work experience were challenged to improve their performance.

\subsection{Method and instrumentation}

A quasi-experimental non-equivalent control group design was used to test the hypothesis that application of the guidelines for interaction by the mentor leads to significantly better acquisition of job-relevant competencies by the student. The treatment for the experimental group consisted of the guidelines for interaction. The acquisition of job-relevant competencies was the dependent variable, while workplace characteristics, mentor characteristics and student characteristics were used as co-variables. The interaction process and the implementation of the guidelines were also measured. Figure 8.1 shows the design of the experiment. 


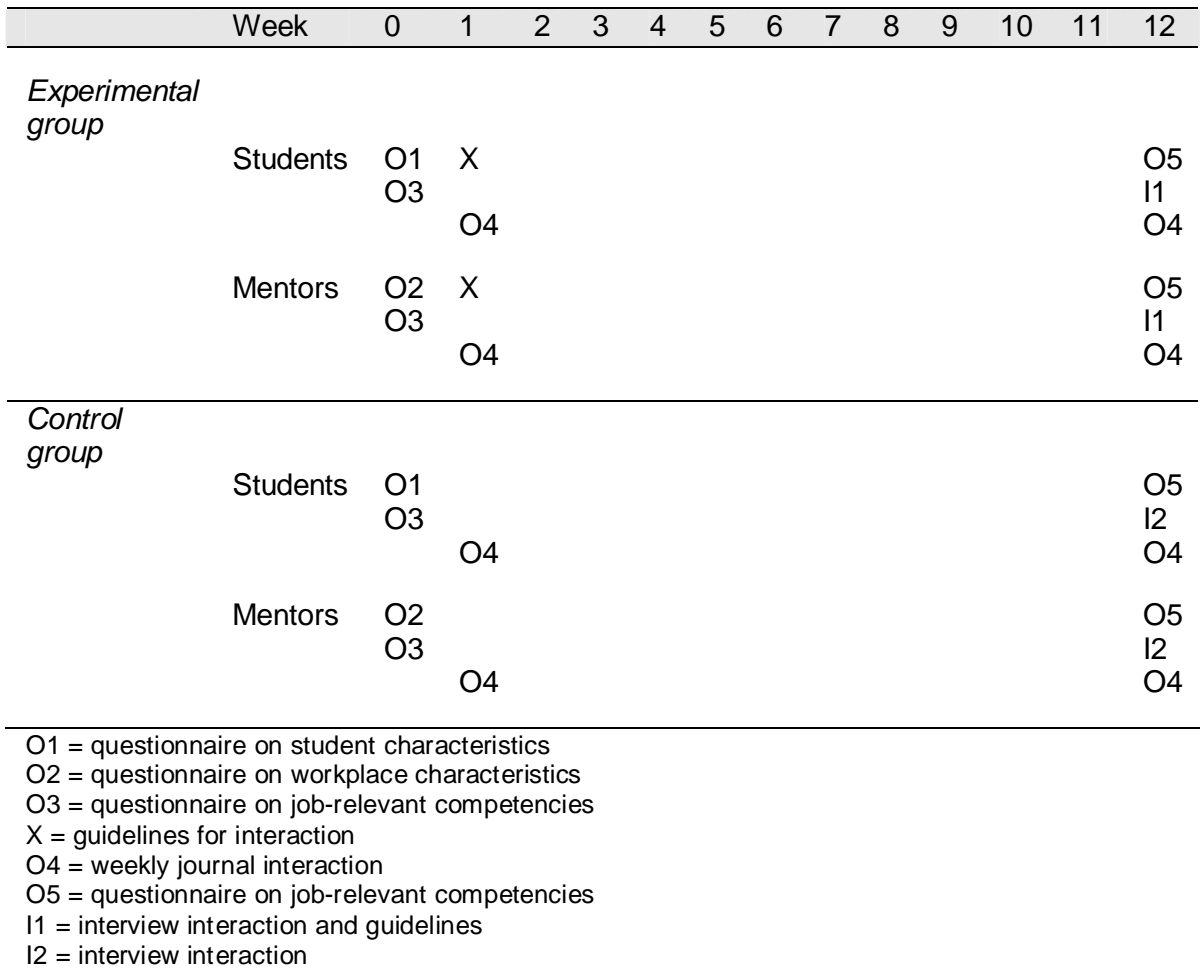

Figure 8.1 Design and instruments of the experiment.

Before the experiment started the data collection instruments were presented to one of the instructors of the company and the Training \& Development manager. The data collection instruments needed no adaptation. The instructor was handed a list of tasks that employees had to execute. One question that was discussed extensively was how to pair mentors and students. It was concluded that chief mechanics would act as mentors, who, because of their position in the teams, were expected to see and talk to students regularly. At the same time, the aim was to form fixed pairs with students. Project coordinators would be asked to put these mentor-student pairs into service together as much as possible. There was also an extensive discussion of the method to be employed both to distribute the data collection instruments and to provide the students and mentors with information. As it proved impossible to organise a meeting for every mentor and student, it was agreed that the instructor would inform and instruct the students about the research project, since he already had appointments to visit them. The researcher would provide information to the 
mentors who could attend the meeting, and the others would be informed by the instructor or by one of the company's project coordinators on the basis of the researcher's instructions. During the meeting mentors were informed about the research project and instructed how to use the data collection instruments. Some mentors felt that the list of tasks was not complete. If students executed other tasks, the list would be expanded by the mentors and students. In addition, the aim and structure of the guidelines were clarified and the basic principles explained. The mentors were advised to read the guidelines a couple of times before use to become acquainted with them. They were instructed to use the guidelines as drawn up and it was explained why they should do so. The mentors were also advised to keep the guidelines close at hand to ensure they could be used and consulted at any time. Finally, they were instructed not to hand the guidelines to anyone else. After the instruction some mentors questioned the relevance of step 1 of the guidelines (selecting a task together), because students have to do what they are told. The researcher explained the necessity of the step and provided them with a solution on how to apply it.

Offices in 3 cities participated: one in the west, one in the centre and one in the south of the Netherlands. In total 21 mentors and 31 students participated. Table 8.2 provides an overview of the numbers of students and mentors in each condition. Teams were randomly assigned to one of the conditions. To preclude the effects of differences between the two groups, variables that refer to mentor characteristics and student characteristics were compared (see Table 8.3). It proved that mentors did not differ significantly with regard to age, number of years they had worked at the company or the number of years they had coached students. The students did not differ significantly with regard to age, year in the educational programme or learning route (6 and 7 in the full-time college-based route and 7 in the part-time work-based route).

The experiment started in March and ended in June 2005, which meant that it could not build on experiences from the first two experiments.

Table 8.2 Numbers of mentors and students

\begin{tabular}{lrrrrr}
\hline & $\begin{array}{c}\text { Number of } \\
\text { mentors }\end{array}$ & \multicolumn{2}{c}{$\begin{array}{c}\text { Number of } \\
\text { students }\end{array}$} \\
Exp & Cont & Exp & Cont \\
\hline ICT company & 9 & 7 & 13 & 14 \\
\hline
\end{tabular}


Table 8.3 Comparison of groups on mentor and student characteristics

\begin{tabular}{|c|c|c|c|c|}
\hline & \multicolumn{2}{|c|}{$\begin{array}{l}\text { Experimental } \\
\text { group }\end{array}$} & \multicolumn{2}{|c|}{$\begin{array}{l}\text { Control } \\
\text { group }\end{array}$} \\
\hline & Mean & SD & Mean & SD \\
\hline \multicolumn{5}{|l|}{ Mentor } \\
\hline Age & 36.50 & 5.04 & 33.71 & 2.75 \\
\hline Work experience & 13.60 & 5.74 & 11.00 & 3.27 \\
\hline Coaching experience & 6.70 & 5.23 & 7.00 & 4.29 \\
\hline \multicolumn{5}{|l|}{ Student } \\
\hline Age & 21.46 & 4.47 & 24.43 & 4.65 \\
\hline Year in educational programme & 2.00 & .50 & 2.25 & .87 \\
\hline
\end{tabular}

During the experiment one student from the experimental group stopped prematurely, because he was not functioning as expected and required. One student from the control group stopped prematurely, because he was given another position in the company.

\subsection{Interaction at the workplace}

As mentioned earlier, students in the full-time college-based route started their period of workplace learning at the company training centre. In six days instructors trained them to execute relatively simple tasks in the way the company required. After training the students participated in several projects. The number of projects depended on their size and on the work that needed to be done. Students switched if they were needed somewhere else. At the beginning of the working day students were picked up by a colleague and together they drove to the location where the work had to be done. Because students had some training, they were from the start able to assist more experienced mechanics. Sometimes students executed tasks on their own after they had received some instructions; at other times students and colleagues worked together. At the end of the working day they drove back together. The students in the part-time work-based route had already had work experience and most of them had carried out their work on their own and autonomously, depending on the projects on which they had to work.

During the experiment all tasks were executed, although the frequency varied greatly. According to the weekly journals, students laid cables more often than any other task. Two other tasks, placing modules and placing field cupboards, 
were seldom carried out. The most likely explanation for this is that the opportunity to execute a task differs, because some tasks simply occur more often than others. Considering the number of times students carried out other tasks, the remark made by the mentors that the list of tasks was incomplete proved to be right. According to the students, the interaction with their mentors focused on almost all the tasks executed, although, again, the frequency varied. Students were, however, coached most on the tasks they executed most. According to the mentors, they focused the interaction on all tasks and this information matches that of the students. Table 8.4 provides an overview of the tasks conducted, of the focus of the interaction according to both the mentors and the students. The differences between the information from the mentors and the students are partly due to weekly journals being missing, because these were not completed by students. It is also possible that students and mentors differ in their perception of interaction. When the number of times tasks were executed is compared with the number of times the interaction focused on those tasks, they proved to correlate significantly at the .01 level (2-tailed, Pearson correlation for mentors is .919, Pearson correlation for students is .947). The ranking also correlates significantly at the .01 level, which means that the more a task was executed, the more mentors interacted with their students about that task. It raises the question whether the interaction process is to be labelled as a natural process that is part of the primary work process or as a planned process. The finding that part of the interaction took place while students were executing tasks points to a more natural process. At any rate, it indicates that interaction is an interesting and logical starting point to influence the effectiveness of workplace learning. One interesting question is whether the number of times tasks were executed and the number of times interaction took place actually influenced the extent to which students acquired job-relevant competencies. The number of times tasks were executed and the number of times students interacted about the tasks do not correlate significantly with students' mastery of job-relevant competencies; the ranking, however, does. Mastery of competencies correlates strongest with the frequency of execution $(p=.01,2-$ tailed, Pearson correlation $=.658$ ). It correlates at the .05 level with the focus according to the students and at the .1 level with the focus according to the mentor. It seems that interaction has less impact than just carrying out tasks.

During the days that the mentor and the student worked together, the time they spent on interaction differed substantially. According to four of the seven students who were interviewed, their mentor spent less than half an hour on this. According to the others, the time varied: between half an hour and an hour (one student), between an hour and a half and two hours (one student), and more than two hours (one student). This information corresponds with that of the mentors. 
Table 8.4 Number of times tasks were executed and focus of interaction

\begin{tabular}{|c|c|c|c|c|c|c|}
\hline & \multicolumn{2}{|c|}{ Executed tasks } & \multicolumn{2}{|c|}{$\begin{array}{c}\text { Focus } \\
\text { according to } \\
\text { mentors }\end{array}$} & \multicolumn{2}{|c|}{$\begin{array}{c}\text { Focus } \\
\text { according to } \\
\text { students }\end{array}$} \\
\hline & $\begin{array}{r}\mathrm{N} \text { of } \\
\text { times }\end{array}$ & Rank & $\begin{array}{r}\mathrm{N} \text { of } \\
\text { times } \\
\end{array}$ & Rank & $\begin{array}{r}\mathrm{N} \text { of } \\
\text { times }\end{array}$ & Rank \\
\hline Assembling wall gutters & 49 & 5 & 15 & 7 & 16 & 3 \\
\hline Installing gutter facilities & 31 & 10 & 17 & 6 & 10 & 7 \\
\hline Laying cables & 127 & 1 & 45 & 1 & 33 & 1 \\
\hline Final assembly of wall outlets & 43 & 7 & 27 & 3 & 8 & 8 \\
\hline Installing connectors & 71 & 3 & 23 & 4 & 16 & 3 \\
\hline Placing patch panels & 45 & 6 & 7 & 10 & 12 & 6 \\
\hline Placing 19-inch cupboards & 27 & 11 & 9 & 8 & 6 & 9 \\
\hline Placing dish poles & 14 & 13 & 5 & 12 & 1 & 12 \\
\hline Placing modules & 4 & 16 & 3 & 14 & 0 & 14 \\
\hline Placing field cupboards & 5 & 15 & 1 & 16 & 1 & 12 \\
\hline Placing 220-volt facilities & 50 & 4 & 20 & 5 & 16 & 3 \\
\hline Connecting power supply cables & 40 & 8 & 9 & 8 & 6 & 9 \\
\hline Applying press connections & 33 & 9 & 6 & 11 & 0 & 14 \\
\hline $\begin{array}{l}\text { Executing assembly work at gsm } \\
\text { masts }\end{array}$ & 14 & 13 & 3 & 14 & 0 & 14 \\
\hline Directing satellite dishes & 20 & 12 & 5 & 12 & 2 & 11 \\
\hline Another task & 86 & 2 & 28 & 2 & 28 & 2 \\
\hline Total & 659 & & 223 & & 155 & \\
\hline
\end{tabular}

The interaction took place at several moments: not only during work, but also at the beginning of the working day when they were driving to the location where they were to work, at the end of the working day when they were driving back, and during a break. Of the 149 times the mentors answered the question whether they worked and interacted with their student during a week, 93 times $(62 \%)$ the answer was 'no'. This shows that the mentor and the student worked together only during one-third of the weeks, mainly because of the different projects that mentors and students worked on, and due to illness or holidays. The aim of having project coordinators form fixed pairs of mentors and students and of putting these pairs into service together as much as possible was therefore not realised. During the other weeks colleagues took over the coaching of the mentor only to a small extent (18\% of the cases). Consequently, half the time students did not have a mentor. Mentors asked colleagues about the learning and working of their students a few times a month at most. Some of them did not do that at all. From a theoretical point of view, the frequent absence of mentors and the limited exchange of information between mentor and colleagues about the functioning of the student indicates that the situation to acquire job-relevant competencies was not optimal - suboptimal at most. 
Although the possibilities to interact with their students were limited, the mentors were satisfied about the way they interacted. According to the interviewed mentors, they could support their student the way they liked and the students found the way their mentors interacted with them suitable in view of their own preferences of interaction. The students were satisfied or very satisfied with their mentors. Students from the experimental group were more satisfied with their mentor than were students from the control group. The mean scores for student satisfaction with the mentor do not differ significantly. These scores are, however, not representative of all participating students. The students who answered the question differ significantly on some aspects from the students who did not. The students who answered it are younger $(\mathrm{p}<.01)$, more motivated $(\mathrm{p}<.1)$ and are mainly in the full-time college-based route. Judging by their learning style, they are also detached $(\mathrm{p}<.05)$, more prescription-oriented, and prefer external regulation $(\mathrm{p}<.01)$. The lack of response from students in the part-time work-based route gives the impression that they actually worked more on their own and were coached less.

Table 8.5 Students' satisfaction with their mentors

\begin{tabular}{lcc}
\hline Satisfaction & \multicolumn{2}{c}{ ICT company } \\
& Mean & SD \\
\hline $\begin{array}{l}\text { Exp. group } \\
(\mathrm{n}=9)\end{array}$ & 1.65 & .52 \\
$\begin{array}{l}\text { Control group } \\
(\mathrm{n}=8)\end{array}$ & 2.01 & .36 \\
\hline
\end{tabular}

$1=$ very satisfied, $2=$ satisfied, $3=$ neither satisfied nor dissatisfied, $4=$ dissatisfied, $5=$ very dissatisfied

Although the students were satisfied, some had suggestions for stimulating learning and improving the effectiveness of workplace learning, based on their own experiences during the experiment. One of the things students in the parttime work-based route mentioned more often was the provision of feedback about their progress by mentors. This indicates the importance of interaction. Students in the full-time college-based route preferred to start to work as quickly as possible, instead of observing, and they wanted to work more independently.

During the experiment most of the students did not drastically change the way they executed tasks, probably as a result of both the training at the training centre and work experience. This indicates that the learning processes that took 
place were mainly assimilative in nature (see Chapter 3), which means that students incorporated new impressions into previously established structures. According to three of the students who were interviewed $(n=8)$, their learning process was hindered because of unexpected situations at work or their private situation at home.

In general, the period of workplace learning fulfilled the students' expectations. About $75 \%$ of them would like to work at the company.

\subsection{Use and implementation of the guidelines for interaction}

The theoretical framework presented in Chapter 3 was used to develop a set of guidelines for interaction. These guidelines aim at improving the effectiveness of workplace learning. To be able to test the hypothesis that application of the guidelines for interaction by the mentor leads to significantly better acquisition of job-relevant competencies by the student, it is necessary to examine and describe the extent to which the guidelines were actually used and how the mentors experienced their use. Explanations for the extent of use are also explored.

At the beginning of the experiment the nine mentors from the experimental group received the card with the ten steps and accompanying guidelines for interaction. During the experiment all mentors actually used the card. They used the steps and guidelines with different intensity.

Table 8.6 Intensity of use of the steps and guidelines

\begin{tabular}{lr}
\hline $\begin{array}{l}\text { Number of } \\
\text { mentors }\end{array}$ & Use of steps and guidelines \\
\hline 2 & $\geq 95 \%$ of the interaction time \\
2 & $20-25 \%$ of the interaction time \\
5 & $<10 \%$ of the interaction time \\
\hline
\end{tabular}


Because the mentors were only asked to what extent they had used the guidelines and not why the guidelines were used to that extent, it is not possible to give an explanation for these differences. It is probably due to the fact that some mentors did not have students for part of the time. It is also possible that mentors did not have the card at hand all the time or that the interaction focused on small parts of a task or was limited to incidental remarks.

During the experiment one mentor used all ten steps. Five mentors used at least six to nine steps; the other three mentors used three to five steps. None of the missing steps was left out systematically by the mentors, for instance some mentors left out step 10, while others used it.

Table 8.7 Number of mentors who used the steps for interaction

\begin{tabular}{llllllllllr}
\hline & 1 & 2 & 3 & 4 & 5 & 6 & 7 & 8 & 9 & 10 \\
\hline \multirow{2}{*}{ Mentors } & 3 & 3 & 7 & 7 & 7 & 9 & 9 & 6 & 5 & 4 \\
\hline
\end{tabular}

Table 8.8 shows that during the experiment three of the steps were used to a lesser extent: step 1 (selecting a task the student wants to learn to execute), step 2 (talking through together the task the student wants to learn to execute), and step 10 (instructing the student to execute the tasks a couple of times more). As mentioned in Section 8.3, some mentors questioned the relevance of step 1 of the guidelines (selecting a task together) from the beginning, because students have to do what they are told, there is no choice. Their way of acting was consistent. Step 2 was carried out best at quiet moments while student and mentor did not have to execute tasks. These moments were available while mentor and student were driving to the location where they had to work. There must therefore have been another reason. The most likely explanation is that mentors did not see the relevance of this step: why ask about a task students have not yet executed? Step 10 was probably used less, because students were expected to execute most of the tasks more than once in any case. This explanation is validated by the finding that students actually carried out most tasks several times. It is also plausible that mentors omitted this step because they did not know whether or when they would be working together again at the same task. Mentors and students were put into action where they were needed most. Table 8.7 reveals that there were also fewer mentors who used these steps. This could mean that the use of the steps depends at least partly on the interaction preferences of the mentor. Steps 6 and 7 were used by all mentors. These steps fit in with the work process best. At the beginning of a working day mentors collected the supplies they needed. They also executed tasks together, 
which made it very easy to supervise. Although not all the steps were executed to the same extent, none of them should be considered unsuitable or unnecessary, in view of the number of times mentors used them. According to the students the ten steps were indeed executed, although they believed that they had been executed more often. This is probably due to their being coached not only by their mentor but also by other colleagues and because of the mentors' missing weekly journals. It is striking, however, that the patterns of mentors and students differ. According to the mentors, they executed steps 6 and 7 most and steps 1, 2 and 10 least. According to the students, steps 2 and 6 were executed most and step 10 least. This indicates that using the card leads to interaction patterns that differ from common interaction which is not inspired by the card.

Table 8.8 Frequency of use of the steps for interaction

\begin{tabular}{|c|c|c|}
\hline Step & Mentors & Students \\
\hline \multicolumn{3}{|l|}{ Phase 1: Orienting to the task } \\
\hline 1. Select together a task the student wants to learn to execute. & 13 & 51 \\
\hline $\begin{array}{l}\text { 2. Talk through together the task the student wants to learn to } \\
\text { execute. }\end{array}$ & 11 & 64 \\
\hline $\begin{array}{l}\text { 3. Determine together what the student already knows and is } \\
\text { capable of. }\end{array}$ & 18 & 56 \\
\hline $\begin{array}{l}\text { 4. Discuss together how the student wants to learn to execute the } \\
\text { task. }\end{array}$ & 21 & 53 \\
\hline \multicolumn{3}{|l|}{ Phase 2: Preparing for the execution of the task } \\
\hline 5. Prepare together for the execution of the task. & 26 & 60 \\
\hline 6. Make sure all the student needs to execute the task is available. & 33 & 67 \\
\hline \multicolumn{3}{|l|}{$\begin{array}{l}\text { Phase 3: Supervising the execution of the task and discussing } \\
\text { performance }\end{array}$} \\
\hline 7. Supervise the execution of the task. & 31 & 52 \\
\hline $\begin{array}{l}\text { 8. Discuss performance with the student immediately after } \\
\text { execution. }\end{array}$ & 22 & 59 \\
\hline $\begin{array}{l}\text { 9. Determine together the next steps necessary to learn to execute } \\
\text { the task. }\end{array}$ & 18 & 50 \\
\hline \multicolumn{3}{|l|}{ Phase 4: Improving ability } \\
\hline 10. Instruct the student to execute the task a couple of times more. & 16 & 43 \\
\hline
\end{tabular}

The difference between the amount of time spent on interaction and the time the card with steps and guidelines was actually used indicates that mentors of the experimental group interacted in other ways with their student. Table 8.9 provides an overview of the information the mentors gave about the way they interacted with their student. This shows that the mentors had their own way of 
interacting. The steps and guidelines were used as intended to a reasonable extent, with the guidelines used slightly more as intended than the steps. At the same time, mentors adapted their use by changing the order, by omitting some and by adding their own. This was done to a fairly small extent. The finding that steps and guidelines were sometimes omitted matches the finding relating to the frequency with which they were used. The finding that mentors added their own steps and guidelines to some extent indicates that the card did not provide the mentors with a complete way of interacting. The mentors were not asked to mention in the weekly journal what steps and guidelines they had added. In the interview at the end of the experiment the same question was hard to answer, probably because it was difficult to recall the moments when they had added their own. This indicates that the addition depended on the situation and proved not to be a fundamental one they used all the time. In the interview the mentors also stated that their way of interacting with the student matched the guidelines to a reasonable extent. This answer matches the information extracted from the weekly journals, as presented in Table 8.9.

Table 8.9 Mean scores for the use of the steps and guidelines (mentors of experimental group)

\begin{tabular}{lcc}
\hline & \multicolumn{2}{c}{$\begin{array}{c}\text { Mentors } \\
(n=9)\end{array}$} \\
& Mean & SD \\
\hline Steps & & \\
I use the steps as intended & 3.17 & .53 \\
I adapt the use of the steps: & 2.64 & .76 \\
- I use the steps in a different order & 3.06 & .55 \\
- I omit steps & 2.78 & 1.07 \\
- I add my own steps & 2.47 & .91 \\
& & \\
Guidelines & 3.29 & .38 \\
I use the guidelines as intended & 2.67 & .41 \\
I adapt the use of the guidelines: & 2.66 & .70 \\
- I use the guidelines in a different order & 2.79 & .98 \\
- I omit guidelines & 2.57 & .84 \\
- I add my own guidelines & & \\
& &
\end{tabular}

$1=$ not at all, $2=$ to a small extent, $3=$ to a reasonable extent, $4=$ to a large extent, $5=$ only

The finding about adaptive use makes it relevant to examine the implementation process somewhat more closely. The information on use per week (see Table 8.9) shows that mentors used the steps and the guidelines most as intended 
during the first half of the experiment. From week 8 the mentors adapted the use more, indicating that they wanted to try another approach, to experience the effects of that approach. It could also mean that the routines they had developed before the experiment started had recurred.

Table 8.10 Mean scores for the use of the steps and guidelines per week (mentors of experimental group)

\begin{tabular}{|c|c|c|c|c|c|c|c|c|c|c|c|c|}
\hline & \multicolumn{12}{|c|}{ Week } \\
\hline & 1 & 2 & 3 & 4 & 5 & 6 & 7 & 8 & 9 & 10 & 11 & 12 \\
\hline I use the steps as intended & 3.25 & 3.38 & 3.20 & 3.50 & 3.67 & 3.33 & 3.33 & 3.67 & 3.67 & 3.67 & 4.00 & 3.67 \\
\hline I adapt the use of the steps & 2.75 & 2.79 & 2.53 & 2.83 & 2.67 & 2.78 & 2.60 & 3.00 & 3.00 & 3.56 & 3.67 & 3.44 \\
\hline I use the guidelines as intended & 3.25 & 3.29 & 3.40 & 3.00 & 3.00 & 3.33 & 3.67 & 3.33 & 3.67 & 3.67 & 4.00 & 3.33 \\
\hline I adapt the use of the guidelines & 2.50 & 2.46 & 2.50 & 2.67 & 2.78 & 3.22 & 2.78 & 3.33 & 3.33 & 3.10 & 4.00 & 2.78 \\
\hline
\end{tabular}

It is not only the way steps and guidelines were used that is relevant to gain a clear view of the implementation process. Supplementary information about levels of use, stages of concern and the support of others also provides an insight into that process.

From the answers to presented propositions about use and implications, it emerges that the mentors did not develop a clear opinion about the steps and guidelines (see Table 8.11). On the one hand, the mentors did not have to think much how to use the steps and the guidelines whereas, on the other, they were not able to use the guidelines in their daily work or to handle them well. The pattern of using the guidelines as intended (see Table 8.9), indicates that their use had not yet become routine. Conversely, mentors used them in their own way, which points to some kind of refinement, indicating that they probably differed in the level of use they reached. The mentors also seemed to be concerned about questions related to time and organisation in their search to simplify the use of the guidelines and make them work smoothly.

The mentors were neutral about the support they had received. They did not, however, experience appreciation from others for using the guidelines, probably because not all their colleagues received them. The standard deviation indicates that some mentors became quite skilled in using them, while others did not. 
Table 8.11 Levels of use and stages of concern with regard to the guidelines

\begin{tabular}{|c|c|c|}
\hline & \multicolumn{2}{|c|}{$\begin{array}{c}\text { Journal } \\
(n=9)\end{array}$} \\
\hline & Mean & SD \\
\hline \multicolumn{3}{|l|}{ Levels of use } \\
\hline I still think about what using the guidelines means to me & 2.67 & .99 \\
\hline I still think about how I want to use the guidelines & 2.68 & 1.00 \\
\hline I am able to integrate the guidelines into my daily work & 2.70 & .99 \\
\hline \multicolumn{3}{|l|}{ Stages of concern } \\
\hline I know the basic principles of the guidelines & 2.69 & .95 \\
\hline I know what to do with the guidelines & 2.87 & 1.07 \\
\hline I can handle the guidelines well & 2.76 & 1.02 \\
\hline I am able to work according to the requirements of the guidelines & 2.74 & .99 \\
\hline Using the guidelines is easy & 2.64 & .90 \\
\hline \multicolumn{3}{|l|}{ Attitude } \\
\hline I am enthusiastic about the guidelines & 2.62 & 1.04 \\
\hline \multicolumn{3}{|l|}{ Support } \\
\hline I experience the support of others while using the guidelines & 3.06 & 1.11 \\
\hline I receive help when I ask for it & 3.12 & 1.21 \\
\hline I receive appreciation for using the guidelines & 2.38 & .99 \\
\hline My experience is that others find it important I use the guidelines & 2.50 & .99 \\
\hline
\end{tabular}

Finally, the finding about the different extent to which mentors used the card with the steps and guidelines makes it relevant to search for additional explanations related to workplace characteristics, mentor characteristics and student characteristics.

It is plausible that the mentor's environment influenced willingness and possibilities to use the card. T-tests show that mentors who used the card more extensively perceived their workplace as an environment with a higher degree of interaction than did their colleagues who used the card less, or not at all. It seems that a workplace where exchange of information and communication is perceived as more common is also more a stimulating place to use an instrument with comparable characteristics. Looking at mentor characteristics such as age, work experience and coaching experience, no significant differences were found with regard to the extent of use. The extent of use of the card also depends on reflection: it seems that students who reflect more on their learning invite mentors to use the card. Table 8.12 shows the findings. 
Table 8.12 Influence of workplace and student characteristics on the use of the card

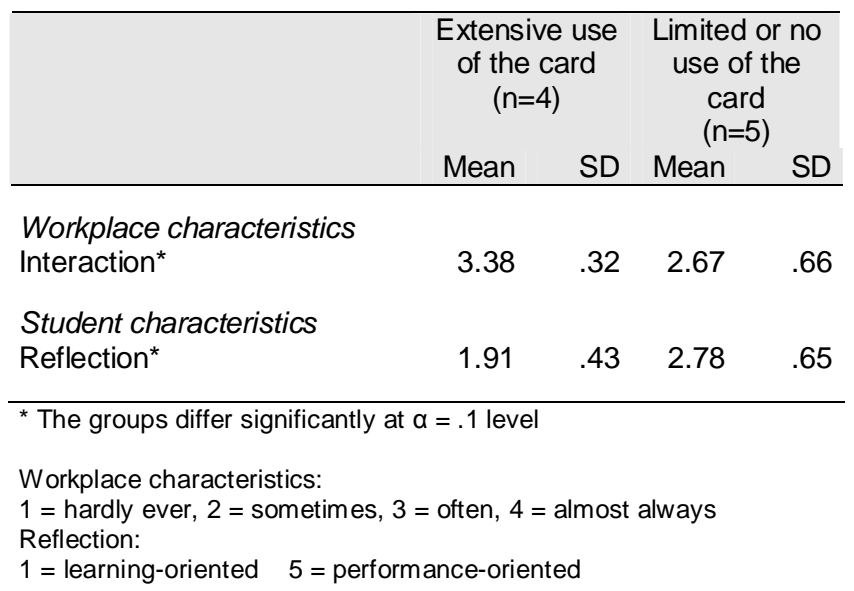

\subsection{Mastery of job-relevant competencies}

The aim of the experiment was to test the hypothesis that application of the guidelines for interaction by the mentor leads to significantly better acquisition of job-relevant competencies by the student. The items used to measure the acquisition focused on the mastery of relevant tasks of the daily work process at the workplace. Before the mean scores for mastery were computed Cronbach's $\alpha$-coefficient was calculated. This is acceptable, with scores that vary from .87 (students score) to .91 (mentors score).

At the beginning of the experiment students from the control group mastered the job-relevant competencies equally to slightly less well than students from the experimental group. The difference between the scores of the mentors and those of the students is considerable. According to the mentors, their students had mastered the job-relevant competencies sufficiently, the students, however, were more optimistic and thought they had already mastered them quite well. The mean scores of the experimental group and the control group on the pre-test do not differ significantly.

From the post-test, it is clear that students mastered the competencies quite well. Because most students were in the second half of their educational programme this score is considered satisfactory, and it allows students to participate in the daily work processes. Again, the scores of the two groups do not differ significantly. In view of the differences between the post-test and the pre-test, according to the mentors, students from the experimental group 
improved their mastery. Students from the control group did not; their score was almost equal to the score on the pre-test. However, there is a strange phenomena when looking at the scores of the students in the experimental group. According to them, they did not improve at all; on the contrary, their mastery decreased. Perhaps these students adapted their view of mastery during the period of workplace learning, because they experienced what was really needed to execute tasks at this company. This makes it hard to formulate an unambiguous conclusion. In spite of the negative score, the mean scores of the experimental and control group do not differ significantly.

The pre-test scores on the six-point scale indicate that there was room for growth for both groups to master the competencies substantially better. A difference between the post-test and pre-test of .38 at most is considered very small. This is probably due to a combination of factors: the level of mastery at the beginning, the limited possibility to execute all the tasks during the experiment, and the limited interaction at the workplace between students from the part-time work-based route and mentors aimed at improving their performance.

Table 8.13 Mastery of job-relevant competencies

\begin{tabular}{|c|c|c|c|c|c|c|}
\hline \multirow[t]{2}{*}{ Mastery } & \multicolumn{2}{|c|}{ Pre-test } & \multicolumn{2}{|c|}{ Post-test } & \multicolumn{2}{|c|}{ Difference } \\
\hline & Mean & SD & Mean & SD & Mean & SD \\
\hline \multicolumn{7}{|l|}{ Mentors } \\
\hline $\begin{array}{l}\text { Exp. group } \\
(n=4)\end{array}$ & 2.68 & .84 & 3.04 & .61 & .36 & 1.12 \\
\hline $\begin{array}{l}\text { Control group } \\
(n=3)\end{array}$ & 2.68 & 1.45 & 2.70 & 1.19 & .02 & .92 \\
\hline \multicolumn{7}{|l|}{ Students } \\
\hline $\begin{array}{l}\text { Exp. group } \\
(n=9)\end{array}$ & 3.44 & .98 & 3.11 & 1.02 & -.33 & 1.19 \\
\hline $\begin{array}{l}\text { Control group } \\
(n=12)\end{array}$ & 3.29 & 1.10 & 3.66 & .71 & .38 & .83 \\
\hline
\end{tabular}

Mastery: 1 = insufficient, 2 = sufficient, 3 = quite good, $4=$ good, $5=$ very good, 6 excellent

Although students from the experimental group grew more than did students from the control group according to their mentors, the difference between the post-test and pre-test of the two groups does not differ significantly. As a result of this finding and because the mentors of the experimental group used the steps and guidelines for interaction to a reasonable extent, the hypothesis of the experiment is rejected: application of the guidelines for interaction by the 
mentor under the conditions available does not lead to significantly better acquisition of job-relevant competencies by the student.

As described the measurement of mastery is coupled to selected skill-oriented tasks. It is, however, possible that other learning also occurred. In the interview students were asked what they considered the most important thing they had learned during the period of the experiment. Their answers varied. Some students found it hard to answer the question, because they could not choose one particular item; others pointed to working autonomously. Remarkably, none referred to one or more of the selected tasks.

\subsection{The effects of independent variables}

The rejection of the hypothesis calls for some other analyses that could provide explanations for the differences with regard to the mastery of job-relevant competencies. The research model contains variables for further analyses. The next subsections examine the effects of variables with regard to workplace characteristics, mentor characteristics and student characteristics on the dependent variable. There is also an explanation of the effects of the interaction process.

\subsubsection{The effect of workplace characteristics}

At the beginning eleven workplace characteristics were measured. If these characteristics are actually present to a high degree, external learning conditions for the learning process are considered to have been fulfilled to a large extent and the workplace itself is regarded as a potentially powerful learning environment. Table 8.14 presents the mean scores for the workplace characteristics measured.

These mean scores for workplace characteristics indicate that the mentors experienced a lot of emotional and instrumental support and they found they had a lot of autonomy, variation and interaction at their work. At the same time, information necessary to conduct the tasks in the proper way was available. They experienced appraisal support quite frequently and informational support to a lesser extent. They were also aware that they could influence what was happening at the workplace to a fairly large extent (participation). The pressure of work was quite regularly rather high; task obscurity, on the other hand, wais fairly low. The mean scores indicate that learning conditions at the workplaces were available and fulfilled to a reasonable extent.

To be able to exclude the influence of differences between the experimental group and the control group on students' mastery of job-relevant 
competencies, the means for these two groups were also computed. This proved that mentors of the experimental group experienced less variation $(p<.1)$, less pressure of work $(\mathrm{p}<.01)$ and less informational support $(\mathrm{p}<.1)$. The learning conditions for the experimental group therefore seem to be less fulfilled than for the control group, which could influence the mastery of job-relevant competencies.

Table 8.14 Mean scores for workplace characteristics

\begin{tabular}{l|rrrrrrr}
\hline Workplace characteristics & $\begin{array}{c}\text { ICT company } \\
\text { total } \\
(\mathrm{n}=16)\end{array}$ & $\begin{array}{c}\text { ICT company } \\
\text { exp. group } \\
(\mathrm{n}=9)\end{array}$ & $\begin{array}{c}\text { ICT company } \\
\text { control group } \\
(\mathrm{n}=7)\end{array}$ \\
& Mean & SD & Mean & SD & Mean & SD \\
\hline Participation & 2.65 & .38 & 2.62 & .37 & 2.70 & .42 \\
Variation * & 3.03 & .31 & 2.93 & .33 & 3.19 & .19 \\
Task autonomy & 3.09 & .36 & 3.10 & .43 & 3.07 & .22 \\
Task information & 2.92 & .37 & 2.87 & .44 & 3.00 & .21 \\
Task obscurity & 1.70 & .43 & 1.72 & .50 & 1.67 & .33 \\
Pressure of work *** & 2.34 & .32 & 2.19 & .30 & 2.60 & .17 \\
Interaction & 3.04 & .53 & 2.95 & .64 & 3.18 & .26 \\
Instrumental support & 3.14 & .33 & 3.13 & .40 & 3.16 & .22 \\
Informational support * & 2.44 & .37 & 2.30 & .37 & 2.67 & .28 \\
Appraisal support & 2.80 & .45 & 2.70 & .49 & 2.97 & .34 \\
Emotional support & 3.26 & .35 & 3.30 & .37 & 3.19 & .35 \\
& & & & & & \\
\hline
\end{tabular}

$1=$ hardly ever, 2 = sometimes, 3 = often, 4 = almost always

* The experimental group and the control group differ significantly at $\alpha=.1$ level

${ }^{* * *}$ The experimental group and the control group differ significantly at $\alpha=.01$ level

A regression analysis was also conducted for each of the workplace characteristics to search for variables that would explain the variance in the extent to which job-relevant competencies were acquired by the students. None of the variables explained the variance to a significant level. 


\subsubsection{The effect of mentor characteristics}

On average the mentors were 35 years old and had worked at the company for about 13 years. All of them were male and almost all had had at least 2 years of experience of coaching students (87\%). The number of students they had coached varied from 0 to more than 10 . Whether they were experienced or not, they all felt skilled to coach because they had enough work experience and knowledge of the work. According to the mentors who were interviewed $(n=6)$, half of them were not well prepared when their students' period of workplace learning started. They were informed very late that they would have to coach or they lacked information about the student's educational programme and educational requirements.

From the mentors' perception of interaction research model, it is clear that their experience and their preparation for coaching were considered potentially influential variables with regard to workplace learning.

The mentors' perception of coaching was measured by asking them to what extent they subscribed to the basic principles for interaction. Although, unfortunately, only two of the nine mentors of the experimental group were interviewed, these mentors did agree with them, as did students who were interviewed.

The mentors' experience has two different variables: the first being experience of coaching students. As in the experiment at the hospital, it seems that coaching by highly experienced mentors did not bear fruit. There are several possible explanations for this finding. Mentors with less experience probably reflect more on their way of interacting in their search for the most adequate way, which apparently has a positive influence on quality. At the same time, mentors with very little or no experience probably have to find out too much about coaching, which makes it ineffective: they simply do not yet know what works. Perhaps highly experienced mentors could be paired with inexperienced colleagues, to pass on their coaching knowledge.

The second variable with regard to experience is work experience. Although it is reasonable to expect work experience and coaching experience to correlate, judging by the findings of the experiment at the hospital, at the ICT company they do not. The most likely explanation for this is that coaching is connected to a particular function, which employees acquire at different moments. As with coaching experience, work experience does not affect the mastery of job-relevant competencies to a significant level.

The final mentor characteristic is preparation for coaching. As mentioned in the first part of the subsection, not all mentors were well prepared at the moment the student's period of workplace learning started. The difference in preparation is expected to influence the acquisition of job-relevant competencies. Because only three mentors who provided information on 
preparation filled out the questionnaires on mastery, there is little point in carrying out an analysis. However, students of the two mentors who felt skilled but not prepared mastered the competencies considerably less well and even had a negative growth. This finding is consistent with the findings at the hospital, where students benefited from well-prepared mentors.

\subsubsection{The effect of student characteristics}

At the beginning of the experiment students completed a questionnaire on student characteristics. The questionnaire measured their perception of ten student characteristics that have been shown to influence workplace learning (see the review in Chapter 2). If these characteristics are actually present to a high degree, internal learning conditions for the learning process are considered to have been fulfilled to a large extent. Before the mean scores for these student characteristics are presented, some other descriptive information about the students is given.

On average the students were 23 years old and all were male. Most of them were in the second year of their educational programme (62\%). Twenty-four percent were in their first year; the others in their third or fourth year. Half of them were following the full-time college-based route, the other half were following the part-time work-based route. Before the experiment started students in the full-time college-based route had already carried out some of the tasks that were executed by the company, and half the students in this route had spare-time jobs in the ICT sector. Most of them felt that when they started this period of workplace learning they were well prepared $(80 \%)$.

The mean scores for the student characteristics show that the students find themselves highly motivated, their belief in their own capabilities (self-efficacy) is strong, and they think they have good control over what happens to them (locus of control). They also find themselves highly conscientious. At the same time, they do not feel alone or helpless (anxiety). Looking at learning style, students characterise themselves as generic and learning-oriented. They also feel that they are a little more inquiring-oriented and they prefer internal regulation somewhat more than external regulation. They are neither immersed nor detached. The mean scores indicate that the students already possess to a large extent those characteristics that influence learning in a positive way.

The means for these two groups were also computed to be able to exclude the influence of the differences between the experimental group and the control group on students' mastery of job-relevant competencies. The groups did not differ significantly on the student characteristics. 
Table 8.15 Mean scores for student characteristics

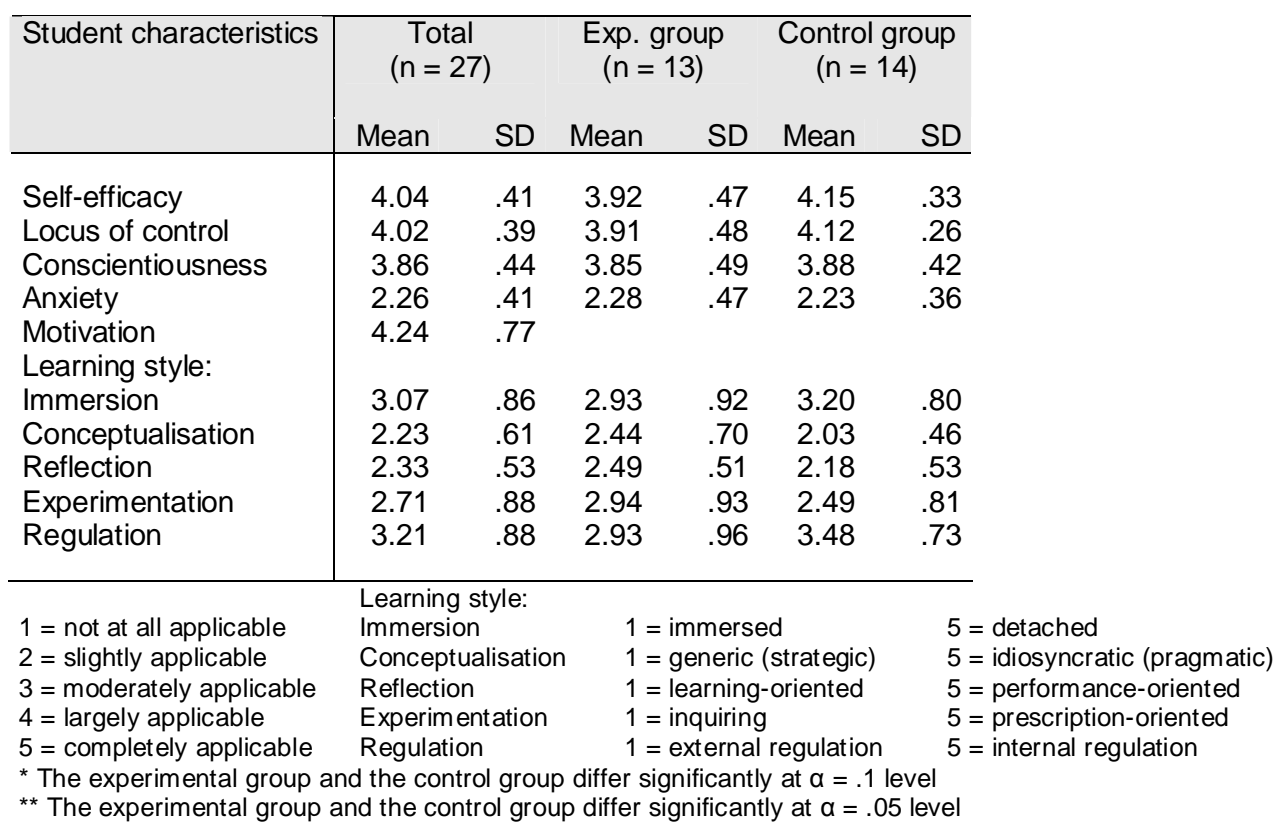

A regression analysis was conducted for each of the student characteristics to search for variables that would explain the variance in the extent to which jobrelevant competencies were acquired by the students. None of the variables explained the variance to a significant level.

In the experiment students from both learning routes in secondary vocational education and training participated. One important difference between the routes is the amount of time spent at the workplace. Students in a full-time college-based route spend less time at the workplace than do their colleagues in a part-time work-based route. Time is considered an important predictor of learning results. At the same time, students in a full-time college-based route are supernumerary, which, in theory, means that they have more time to learn, because they do not necessarily have to participate all the time in the work processes at the same pace as their colleagues in the part-time work-based route, who are seen as employees. An independent samples T-test shows that students in the full-time college-based route did not significantly learn more. On the contrary, they had a negative growth and learned less. It is quite likely that this is the cause of the lack of continuity in interaction. As mentioned earlier, they had their own mentor at hand for about one-third of the entire period of the 
experiment, because mentors and students switched if they were needed on another project. As a result of these switches and lack of continuity, students who were not accustomed to working at the company could have become confused, which might have hindered their learning process. This finding indicates the importance of having one mentor during the entire period of workplace learning, which was also pointed out during the experiment at the hospital as a point to consider. The students' limited growth in the part-time work-based route is probably due to the lack of interaction, because most of the time these students worked on their own. The findings of the experiment at the hospital showed that students in this route can grow more under different circumstances with mentors at hand.

Table 8.16 Learning route and mastery of job-relevant competencies

\begin{tabular}{lccccccc}
\hline Route & \multicolumn{2}{c}{$\begin{array}{c}\text { Difference } \\
\text { between post- } \\
\text { test and pre-test }\end{array}$} & & Age & \multicolumn{3}{c}{$\begin{array}{c}\text { Year in } \\
\text { educational } \\
\text { programme }\end{array}$} \\
& Mean & SD & Mean & SD & Mean & SD \\
\hline $\begin{array}{l}\text { College-based } \\
(n=9)\end{array}$ & -.10 & .91 & 21.9 & 5.04 & 1.82 & .41 \\
$\begin{array}{l}\text { Work-based } \\
(n=12)\end{array}$ & .20 & 1.15 & 24.0 & 4.35 & 2.10 & .99 \\
& & & & & & \\
\hline
\end{tabular}

There are no significant differences with regard to difference between post-test and pre-test, age, and year in educational programme between college-based and work-based.

In addition, the variables directly related to learning were analysed, as were the other descriptive variables. Gaining experience outside the education programme (for instance as a result of spare-time employment) did not affect students' growth. Neither did the extent to which students felt well prepared for their period of workplace learning significantly affect growth. And finally, the extent to which students' expectations about the period of workplace learning were met did not affect growth.

\subsubsection{The effect of the guidelines for interaction}

The final subsection of this chapter focuses once more on interaction. Section 8.5 describes how mentors of the experimental group used the steps and guidelines for interaction in their own way. Some of them used them quite extensively, others did not use them very much or not at all. To test whether the extent to which the steps and guidelines were used affected the extent of 
growth, a final statistical analysis was carried out. The mentors of the control group were also included in this test, because they did not receive the card with the steps and guidelines. The mean scores for growth were compared with the intensity with which the steps and guidelines had been used. Although this did not indicate a significant effect, the mean scores did actually differ. From Table 8.17 it is clear that the pattern is that extensive use of the steps and guidelines for interaction results in better mastery of job-relevant competencies. This finding underlines the value of the guidelines.

Table 8.17 Intensity of using the guidelines for interaction and mastery of jobrelevant competencies

\begin{tabular}{lc}
\hline & $\begin{array}{c}\text { Difference } \\
\text { between post- } \\
\text { test and pre-test }\end{array}$ \\
& Mean $\quad$ SD \\
\hline $\begin{array}{l}\text { Mentors } \\
1(n=2)\end{array}$ & $1.02 \quad .48$ \\
$2(n=8)$ & $.03 \quad 1.00$ \\
\hline $\begin{array}{l}\text { 1: Mentors experimental group: used guidelines very extensively } \\
\text { 2: Mentors experimental and control group: used guidelines hardly or not }\end{array}$
\end{tabular}

\subsection{Summary and conclusions}

The third experiment to test the hypothesis was carried out at a large international ICT company. Mentors of the experimental group received a card with steps and guidelines for interaction. Those who were interviewed agreed on the basic principles of the guidelines. Although a high-fidelity approach was aimed at (meaning that the steps and guidelines should be used as drawn up) mentors proved to have used the steps and guidelines in their own adaptive way. The time available to use the steps and guidelines prevented them reaching the higher levels of use and stages of concern. Their use had not yet become routine and the mentors' main concern related to fitting the use of the steps and guidelines into their daily work processes. The workplace characteristic of interaction and the student characteristic of reflection also seemed to affect their use.

At the end of the experiment students from the experimental group had not mastered job-relevant competencies significantly better than had students in the control group. The hypothesis that application of the guidelines for interaction by the mentor leads to significantly better acquisition of job-relevant competencies by the student was therefore rejected. 
Further analysis, however, revealed some interesting findings with regard to the effectiveness of workplace learning. It seems that when the guidelines for interaction were used extensively students acquired the competencies better. This indicates that the guidelines can contribute to the effectiveness of workplace learning. It also seems that coaching by highly experienced mentors does not bear fruit. Students benefit most from mentors who have some experience and routine. Students of mentors who felt skilled but not prepared also seem to have mastered the competencies considerably less well.

Looking at workplace characteristics and student characteristics, none of them explains the variance in mastery of job-relevant competencies to a significant level. An analysis of the influence of the learning route seems to point to the importance of interaction and its continuity. Students in the parttime work-based route hardly interacted and grew only very slightly. Students in the full-time college-based route lacked continuity in interaction.

In summary, the experiment at the ICT company did not provide evidence for explaining differences in mastery. 


\section{Chapter 9}

\section{Conclusions and discussion}

\subsection{Introduction}

This study has focused on the effectiveness of workplace learning. Workplace learning is an essential part of every vocational education and training course in the Netherlands. As in other countries, the workplace is regarded as an environment with great learning potential (Bailey et al., 2004; Billett, 1999), and learning in such an environment is considered indispensable for the development of job-relevant competencies. As a consequence, a substantial amount of training time is spent on workplace learning and its importance is stressed by law, which states that a diploma is to be awarded to a student only when he has satisfactorily completed the period of workplace learning. Nevertheless, important as it is, workplace learning is also problematic. Studies point to insufficient preparation, interaction and organisation. Improving the quality of workplace learning is considered necessary by all the parties involved. The interesting question is how.

In order to answer this question, a review was carried out to identify concepts of workplace learning (Chapter 1) and to select variables that have been shown to influence this kind of learning (Chapter 2). The selected variables were combined with a contemporary learning theory (Illeris, 2002) to design guidelines for high quality interaction at the workplace between mentor and student (Chapter 3). A quasi-experimental design was chosen to test the effects of the guidelines on the acquisition of job-relevant competencies, and a hypothesis was formulated (Chapter 4). The empirical part of the study started with a pilot study (Chapter 5) to test the clarity and usefulness of the guidelines and the way mentors used the guidelines. The reliability of scales and the adequacy of the research design were also tested. For the main study, experiments were carried out at three large companies to test the hypothesis that application of the guidelines for interaction by the mentor leads to significantly better acquisition of job-relevant competencies by the student (Chapters 6, 7 and 8). 
This chapter continues with critical reflection on the study. It starts with the findings of the experiments and goes on to discuss some methodological issues regarding the research design chosen. Finally, the implications of the study for theory, research and practice are presented.

\subsection{Findings of the experiments}

The aim of the experiments was to test the hypothesis that application of the guidelines for interaction by the mentor leads to significantly better acquisition of job-relevant competencies by the student. The items used to measure acquisition focused on the mastery of skill-oriented tasks in the daily work process at the workplace. Mastery was measured at the beginning of the experiment (pre-test) and at the end (post-test) on a six-point Likert-type response scale. The difference between the post-test and the pre-test was considered an indicator of growth. Table 9.1 provides an overview of the mean scores of the experimental group and the control group for growth. The scores of the two groups do not differ significantly. This was relevant from a scientific point of view, but regrettable if one really wishes to improve the effectiveness of workplace learning: the hypothesis is rejected - at least under the conditions given.

Table 9.1 Mastery of job-relevant competencies

\begin{tabular}{lrrrrrr}
\hline $\begin{array}{l}\text { Difference between post-test } \\
\text { and pre-test }\end{array}$ & \multicolumn{2}{c}{ Hospital } & \multicolumn{2}{c}{ Bank } & \multicolumn{3}{c}{ ICT company } \\
& Mean & SD & Mean & SD & Mean & SD \\
\hline Mentors & & & & & & \\
Experimental group & 1.51 & 1.13 & .21 & .50 & .36 & 1.12 \\
Control group & 1.31 & 1.32 & .30 & 1.25 & .02 & .92 \\
& & & & & & \\
Students / team members & & & & & & \\
Experimental group & 1.11 & .90 & .26 & .46 & -.33 & 1.19 \\
Control group & .96 & 1.07 & .07 & .58 & .38 & .83
\end{tabular}

Differences between experimental group and control group are not significant

This conclusion calls for reflection that would provide answers to the question of why the designed intervention did not contribute substantially to the acquisition of job-relevant competencies. To provide possible explanations, the use of the guidelines, the availability and willingness of the mentor, the time spent on interaction and the potential power of the guidelines were discussed. 
A major explanation is to be found in the way the guidelines were used. The mentors who received the guidelines were asked to use them as drawn up. From the beginning, however, mentors adapted the guidelines by changing the order, or by adding their own or omitting some. Virtually all of them used the guidelines for only part of the time they spent on interaction. Some used them extensively, others to some extent or not at all. In fact, almost none used the guidelines consistently as intended and requested during the experiment. It is intriguing why this was so, because the mentors mentioned that they did not lack information or training. According to non-users, using the guidelines takes too much time, does not fit in with their work or their own way of interacting. Only the last reason really seems to stand up, since other mentors in comparable situations managed to use them. Perhaps non-users just did not want to use something they felt had been imposed on them.

The adaptive and limited use of the guidelines is, however, not the only explanation for the rejection of the hypothesis. In the experiments the intention was to have fixed couples of mentor and student. However, because of timetables, illness and holidays, mentors and students did not work together very often: for at least half the time the mentor was not at hand. As a consequence, students frequently worked with colleagues, who did not have the guidelines at their disposal and who had their own, perhaps divergent, way of interacting. On the days that mentor and student did work together, they spent on average half an hour at most on interaction. However, frequent use of the guidelines is necessary in order to become used to them and to develop some routine. The moments available for interaction probably did not allow mentors to achieve higher levels of use or higher stages of concern. This means that the implementation process was not completed. At this stage using the guidelines requires extra time and effort on top of their regular work, as well as willingness to do so and a stimulating environment. Mentors did not, however, experience any support or appreciation from their colleagues or managers when using the guidelines. The lack of a stimulating environment could not be attributed to the attitudes of colleagues, but rather to the design of the experiment. Only the mentors received the guidelines and they were instructed not to share these or their experiences with colleagues to prevent diffusion of the treatment.

In summary, the adapted and limited use of the guidelines, the limited availability of mentors, limited time spent on interaction and the lack of a supportive environment reduced the potential power of the guidelines and their effect.

Merely looking at the way the guidelines were used produces no definite conclusions. Another relevant question is whether the guidelines as drawn up are truly potentially powerful.

In the pilot study mentors and students were asked to judge the clarity and usefulness of the guidelines. Their answers were positive with regard to 
clarity and they considered the guidelines to be a supportive and usable tool that covered all the relevant aspects of interaction. Their comments concerned the number of guidelines and some unnecessary overlap. The revised version that was used in the main study consisted of fewer guidelines. The main study proved that the mentors endorsed the basic principles of the guidelines, and students confirmed that their mentors had acted accordingly. The mentors did not comment on their clarity or usefulness. These findings indicate that the guidelines themselves were acceptable to the mentors.

Even so, mentors adapted the guidelines and they must have had reasons for doing so. One possible reason is that the guidelines lacked essential aspects of interaction or contained unnecessary elements. This reason does not, however, stand up. The main study showed that steps and guidelines were neither omitted nor added systematically. It indicates that the guidelines provided the mentors with a virtually complete set of instructions. In addition, the guidelines did not conflict with the student's interaction preference. Mentors did not mention this as a reason for adaptation. More importantly, the students in the experimental group were more satisfied with their mentor than were the students in the control group. It is, however, questionable whether this effect is purely due to the use of the guidelines, because not all mentors used them. It is possible that providing the mentors with the guidelines caused them to reflect on their way of interaction, which could have resulted in higher quality. Although it had been neither foreseen nor intended, this side effect is valuable. The remaining reasons for adaptation mentioned by the mentors themselves were that the guidelines did not fit their way of interacting or they did not fit specific situations. These reasons focus attention on a potential weakness of the guidelines: they were drawn up as a generic set that was expected to be useful to all mentors in all kinds of situations. They do not invite mentors to differentiate, nor do they provide suggestions on how to do so. Adding such suggestions could enrich the guidelines, but would also take away their simplicity, which might discourage mentors from using them (and if they are not used, there is no effect). The most valuable indication with regard to the potential power of the guidelines advocates leaving them as they are: extensive use of the guidelines seems to result in improved mastery of job-relevant competencies (see Table 9.2). This finding also matches one of the premises Billett (1999) formulated with regard to workplace learning - that the kinds of guidance that students access will determine the quality of learning. 
Table 9.2 Intensity of using the guidelines for interaction and mastery of jobrelevant competencies

\begin{tabular}{|c|c|c|}
\hline \multirow[t]{2}{*}{$\begin{array}{l}\text { Intensity of using the } \\
\text { guidelines }\end{array}$} & \multicolumn{2}{|c|}{$\begin{array}{l}\text { Difference between post-test } \\
\text { and pre-test }\end{array}$} \\
\hline & Mean & SD \\
\hline \multicolumn{3}{|l|}{ Mentors hospital* } \\
\hline $1(n=7)$ & 1.65 & 1.49 \\
\hline $2(\mathrm{n}=8)$ & 1.38 & .77 \\
\hline $3(n=12)$ & 1.31 & 1.32 \\
\hline \multicolumn{3}{|l|}{ Mentors ICT company ${ }^{* *}$} \\
\hline $1(\mathrm{n}=2)$ & 1.02 & .48 \\
\hline $2(\mathrm{n}=8)$ & 03 & 1.00 \\
\hline \multicolumn{3}{|c|}{ * } \\
\hline \multicolumn{3}{|c|}{$\begin{array}{l}\text { 1: Mentors experimental group: used guidelines most extensively } \\
\text { 2: Mentors experimental group: used guidelines least extensively } \\
\text { 3: Mentors control group } \\
\star \star\end{array}$} \\
\hline \multicolumn{3}{|c|}{$\begin{array}{l}\text { 1: Mentors experimental group: used guidelines very extensively } \\
\text { 2: Mentors experimental and control group: hardly used guidelines or did not use them at all. }\end{array}$} \\
\hline
\end{tabular}

The experiments focused not only on the guidelines. The theoretical framework and the research model used for the experiments included variables that referred to workplace, mentor and student characteristics. Because the guidelines did not account for major differences in the mastery of job-relevant competencies, the next question to be answered is whether these variables did.

Eleven workplace characteristics and ten student characteristics that have been shown to influence workplace learning were selected on the basis of a review (see Chapter 2). The mean scores for these characteristics indicated that external and internal learning conditions in all three experiments were fulfilled to a fairly large extent. In the light of the review, it is reasonable to expect a substantial contribution to the mastery of job-relevant competencies. Nonetheless, in spite of expectations, mastery did not improve substantially in two of the experiments. Neither did the experiment where the conditions seemed to be fulfilled best (the ICT company) produce the best scores for mastery. The theoretical framework for workplace learning (see Chapter 3) provides a possible explanation for these findings. The framework shows that workplace and student characteristics are expected to influence interaction that provides the input for learning. The influence of these characteristics on mastery is thus merely indirect and the findings of the experiments seem to confirm this assumption. Five workplace characteristics and three student characteristics influence interaction (see Table 9.5). Additionally, the experiment where mentors interacted most with their students (at the hospital) 
produced the greatest improvement with regard to mastery. These findings underline the importance of interaction. Interaction as a workplace characteristic also proved to explain variance in the mastery of job-relevant competencies at a significant level $\left(\mathrm{R}^{2}=.13\right.$ for the hospital, and .08 for the bank). Another workplace characteristic and two student characteristics also explained variance, which points to some kind of direct influence: instrumental support $\left(\mathrm{R}^{2}=.17\right)$, self-efficacy and reflection $\left(\mathrm{R}^{2}=.37\right)$. Instrumental support indicates the necessity of providing the facilities that are needed to execute tasks as expected and required. Looking at self-efficacy, it seems that a lesser degree of belief in their own capability urged students to work harder, which resulted in improved mastery. Reflection on learning also seems to be of importance. This kind of reflection adds to the value of the guidelines, which focus somewhat more on reflection on performance. The other remaining variables, if important with regard to mastery of job-relevant competencies, probably relate to variables other than interaction and mastery, making the theoretical framework for workplace learning more complex than presented. It is also possible that the selected variables influence other kinds of learning aims instead of the jobrelevant competencies related to skill-oriented tasks. A critical re-examination of the review and additional analyses of the data are necessary to check for these assumptions. Another interesting finding from one of the experiments is the influence of the targets that employees have to meet $\left(\mathrm{R}^{2}=.48\right)$. Skule $(2003)$ already indicated the importance of a high degree of exposure to the demands of the organisation, although this aspect is an element of a model for informal learning. Apparently performance criteria imposed by the company strongly influence learning and learning outcomes, but not only positively. This consequently questions the conclusion that exposure to demands contributes to learning.

The research model also included mentor characteristics, which proved that these variables are of importance. Coaching experience, work experience, preparation and age all influence interaction or explain the variance in the mastery of job-relevant competencies (see Table 9.5). Students of young and less experienced mentors mastered competencies better than did those of older and more experienced ones. Mentors with little experience probably reflect more on their way of interacting, in their search for the most effective method, which apparently has a positive influence on quality. Further, these mentors were young and had only recently completed their educational programme; their own workplace learning experiences and knowledge of the current educational programme probably helped them to interact properly. The older mentors might have had a greater amount of experience concentration, which negatively influenced their willingness and ability to learn and apply something new (Thijssen, 1996). Another finding was that students who interacted with wellprepared mentors also mastered competencies better. 
Table 9.3 Years of experience in coaching and mastery job-relevant competencies

\begin{tabular}{lrr}
\hline Experience in coaching & \multicolumn{2}{c}{$\begin{array}{c}\text { Difference } \\
\text { between post- } \\
\text { test and pre-test }\end{array}$} \\
& Mean & SD \\
\hline $\begin{array}{l}\text { Hospital } \\
\text { At most } 2 \text { years of experience in coaching } \\
(n=11)\end{array}$ & 1.76 & 1.21 \\
$\begin{array}{l}\text { At least } 3 \text { years of experience in coaching } \\
(n=10)\end{array}$ & .45 & .54 \\
$\begin{array}{l}\text { ICT company } \\
\text { At most } 4 \text { years of experience in coaching } \\
(n=1)\end{array}$ & -1.00 & \\
$\begin{array}{l}5 \text { to } 9 \text { years of experience in coaching } \\
(n=3)\end{array}$ & .65 & .32 \\
$\begin{array}{l}\text { At least } 10 \text { years of experience in coaching } \\
(n=2)\end{array}$ & .13 & 1.84 \\
\hline
\end{tabular}

Table 9.4 Preparation for coaching and mastery of job-relevant competencies

\begin{tabular}{lrr}
\hline Preparation for coaching & \multicolumn{2}{c}{$\begin{array}{c}\text { Difference } \\
\text { between post- } \\
\text { test and pre-test }\end{array}$} \\
& Mean & SD \\
\hline Hospital & & \\
Not well prepared $(\mathrm{n}=6)$ & .87 & .73 \\
Well prepared $(\mathrm{n}=9)$ & 2.10 & 1.23 \\
ICT company & & \\
Not well prepared $(\mathrm{n}=2)$ & -.37 & .90 \\
Well prepared $(\mathrm{n}=1)$ & .88 & - \\
\hline
\end{tabular}

On the other hand, employees benefited from their coaching experience when they themselves had to improve their own performance and to master jobrelevant competencies. It is possible that they were more used to focusing on learning and on improving their performance. This points to the relevance of providing employees with the opportunity to gain coaching experience. The experiments also showed that the focus of interaction differed depending on the function of the mentors. The interaction of managers focused more on 
functioning in general. Mentors on the work floor focused on all the tasks in the daily work processes, which makes them a very interesting group to focus on when one wants to create high quality interaction concerning the execution of tasks and the participation of students in work processes. They really know what is needed. At the same time they all felt sufficiently skilled to coach students, because they had working experience, they knew what was required to execute tasks or had a great deal of coaching experience. Remarkably, almost none mentioned specific coaching skills. This indicates a particular view of coaching and interaction, where sharing knowledge and experience in itself is considered more important than the way this is done. The guidelines fill that gap.

Finally, it is not only workplace characteristics, student characteristics and mentor characteristics that are important; so is a vocational education characteristic (see also Baldwin \& Ford, 1988; Van der Klink, 1999). This relates to the learning route. Different learning routes result in different mastery. It seems that students in the full-time college-based route grow more, because participation in daily work processes is less commonplace to them than to students in the part-time college-based route or to employees with working experience. The latter group seems to be in extra need of interaction to be able to master the job-relevant competencies better.

In summary, the findings relating to the independent variables indicate that the theoretical framework as described in Chapter 3 and the research model as described in Chapter 4 are usable as a point of departure for research: workplace characteristics, student characteristics and mentor characteristics are of importance with regard to interaction and mastery of job-relevant competencies. Some adaptations are, however, necessary to tailor the framework to the findings. First, the characteristics not only influence interaction, but also mastery. Second, vocational education characteristics also carry weight. Because the experiments mainly provided findings and conclusions related to the specific settings, an adapted, general framework has not been developed; models per setting are necessary to provide the appropriate information. This finding is in accordance with the theorem of Boud and Garrick (1999) that there is no universal model for learning at work; there is a diversity of factors that shape learning. Models for workplace learning in vocational education and training, however, should take into account the influence of workplace characteristics, mentor characteristics, student characteristics and interaction with regard to the mastery of job-relevant competencies. 
Table 9.5 Effects of independent variables

\begin{tabular}{|c|c|c|c|}
\hline Independent variables & Effect & Size & Experiment \\
\hline \multicolumn{4}{|l|}{ Workplace characteristics } \\
\hline Participation & $\begin{array}{l}\text { Influences the use of the } \\
\text { guidelines }\end{array}$ & $\alpha=.1$ level & $\begin{array}{l}\text { Hospital } \\
\text { Bank }\end{array}$ \\
\hline Variation & $\begin{array}{l}\text { Influences the use of the } \\
\text { guidelines }\end{array}$ & $\alpha=.05$ level & Bank \\
\hline Task information & $\begin{array}{l}\text { Influences the use of the } \\
\text { guidelines }\end{array}$ & $\alpha=.01$ level & Bank \\
\hline Interaction & $\begin{array}{l}\text { Influences the use of the } \\
\text { guidelines }\end{array}$ & $\begin{array}{l}\alpha=.05 \text { level } \\
\alpha=.1 \text { level } \\
B^{2}-13\end{array}$ & $\begin{array}{l}\text { Hospital } \\
\text { ICT comp. }\end{array}$ \\
\hline & Explains variance in mastery & $\mathrm{R}^{2}=.08$ & Bank \\
\hline Instrumental support & Explains variance in mastery & $\mathrm{R}^{2}=.17$ & Bank \\
\hline Informational Support & $\begin{array}{l}\text { Influences the use of the } \\
\text { guidelines }\end{array}$ & $\begin{array}{l}\alpha=.01 \text { level } \\
\alpha=.1 \text { level }\end{array}$ & $\begin{array}{l}\text { Hospital } \\
\text { Bank }\end{array}$ \\
\hline Targets & Explains variance in mastery & $\mathrm{R}^{2}=.48$ & Bank \\
\hline \multicolumn{4}{|l|}{ Mentor characteristics } \\
\hline Age & $\begin{array}{l}\text { Influences the use of the } \\
\text { guidelines }\end{array}$ & $\alpha=.05$ level & Hospital \\
\hline Working experience & $\begin{array}{l}\text { Influences the use of the } \\
\text { guidelines }\end{array}$ & $\alpha=.05$ level & Hospital \\
\hline Coaching experience & Explains variance in mastery & $\begin{array}{l}\mathrm{R}^{2}=.34 \\
\mathrm{R}^{2}=.10\end{array}$ & $\begin{array}{l}\text { Hospital } \\
\text { Bank }\end{array}$ \\
\hline Preparation for coaching & Influences mastery & $\alpha=.05$ level & Hospital \\
\hline \multicolumn{4}{|l|}{ Student characteristics } \\
\hline Self-efficacy* ${ }^{*}$ & Explains variance in mastery & $\mathrm{R}^{2}=.37$ & Hospital \\
\hline Motivation & $\begin{array}{l}\text { Influences the use of the } \\
\text { guidelines }\end{array}$ & $\alpha=.1$ level & Bank \\
\hline Reflection* & $\begin{array}{l}\text { Influences use of the guidelines } \\
\text { Explains variance in mastery }\end{array}$ & $\begin{array}{l}\alpha=.1 \text { level } \\
\mathrm{R}^{2}=.37\end{array}$ & $\begin{array}{l}\text { ICT comp. } \\
\text { Hospital }\end{array}$ \\
\hline Regulation & $\begin{array}{l}\text { Influences the use of the } \\
\text { guidelines }\end{array}$ & $\alpha=.1$ level & Bank \\
\hline \multicolumn{4}{|l|}{$\begin{array}{l}\text { Vocational education } \\
\text { characteristics }\end{array}$} \\
\hline Learning route & Explains variance in mastery & $\mathrm{R}^{2}=.07$ & Hospital \\
\hline
\end{tabular}

${ }^{*}$ Result of a stepwise regression analysis

This section ends with the subject it started with: mastery. The experiments have shown that students mastered job-relevant competencies better at the end of the experiment. The question that arises is whether workplace learning is worthwhile, in view of the amount of growth. 
The experiments lasted twelve weeks, a time span that fits the duration of internships in the full-time college-based routes, which usually varies from ten to twenty weeks. The situation in the part-time work-based route is, of course, different, because students are employees of the company. At the beginning of the experiments all the students had the opportunity to grow substantially. Looking at the mean scores of the mentors, students and team members of the bank grew from between .02 and 1.51 on a six-point scale. A mean growth of 1.51 in twelve weeks is regarded as considerable; a mean score of 0.2 indicates that students did not grow at all. It seems that growth is influenced positively by extensive interaction with young, less experienced, but well-prepared mentors who are at hand most of the time and are willing to reflect on their own way of interacting. If not, students spending time at the workplace provide the company with an extra pair of hands but this leaves the students themselves empty-handed. The focus of interaction too seems to be of importance. Interacting while participating in daily work processes increases the likelihood that interaction will focus on tasks that are performed most frequently. Students can, however, practise and observe these tasks often. Perhaps focusing interaction on tasks that are less common contributes more to growth and mastery, because there is simply less opportunity to practise and observe. The kind of task does not seem to account for differences in mastery. Most of the tasks include technical-instrumental, social and cognitive aspects. The indication that extensive use of the guidelines adds to growth is an interesting one, but does require the willingness of mentors to act accordingly and a supportive environment. Acting as requested, however, proves to be difficult (Bastiaens, 1997; Gielen, 1996; Van der Klink, 1999), but necessary (Ellström, 2002).

According to Sfard (1998), the acquisition of job-relevant competencies as chosen for this study is just one of two valuable metaphors for explaining learning. Participation with the objective of becoming a member of a community is the other. Although this second metaphor is used in the guidelines, its returns have not been measured. This means that the potential power of workplace learning has not been measured to its fullest extent. The data from the experiments revealed that students were allowed and able to participate in daily work processes. It is unlikely, however, that students in the full-time college-based route could become true members of a team at such short notice. The inclusion of both metaphors in measuring the returns of workplace learning is interesting and valuable for testing what duration is necessary and what learning conditions need to be fulfilled. According to Garrick (1999), proof of workplace learning results does not necessarily have to be limited to what is observable and measurable; subjective expertise is also considered relevant.

In interviews students mentioned that they had not radically changed the way they executed tasks. This indicates that mainly assimilative learning 
occurred, a type of learning that students prefer, because it is less demanding and requires less effort (Billett, 1999; Illeris, 2002). For true development, however, assimilation and accommodation are considered necessary. Although the guidelines were intended to stimulate reflection, which contributes to accommodation, the extent of their use and the time available for learning and interaction probably was not sufficient. According to Ellström (2002), two kinds of learning are relevant with regard to workplace learning. Adaptive learning is closely related to the development and use of the routines needed for production; it resembles assimilative learning. Developmental learning requires reflection, experimentation, risk-taking and tolerance for variation and mistakes. This resembles accommodation. Time is a crucial learning resource, which influences the kind of learning that occurs. The likelihood of accommodation or developmental learning occurring seems to be greater for students in the fulltime college-based route, who are given both opportunity and permission to spend time on learning, because they are surplus to requirements. Students in the part-time work-based route are expected to produce. When examining the influence of the learning route on mastery (see Table 9.5), it is questionable whether both routes are equivalent, as is assumed in the Dutch Adult \& Vocational Education Act of 1996.

\subsection{Methodological issues}

It was decided to use a quasi-experimental design to test the hypothesis that application of the guidelines for interaction by the mentor leads to significantly better acquisition of job-relevant competencies by the student. Such a design allows for the testing of causal relations. Although potentially powerful, it has to meet certain criteria to be truly valid and reliable.

The design and the execution of the pilot study and the experiments of the main study reveal that most of the validity threats ('t Hart et al., 2001) have been neutralised. History, maturation, testing, instrumentation, selection, mortality, compensatory equalisation of the treatment, compensatory rivalry, and reactive arrangements: not one emerged. However, some threats could have occurred and could therefore have had some impact on the results.

In the first place, the vocational education and training centres in the pilot study and the companies in the main study had participated voluntarily. They were interested in the study and its aim and expected to benefit from both participation and the results. Moreover, it was not the researcher who selected the departments, teams and offices that participated but the companies themselves, and they could have had a particular interest in designating those that needed the treatment most. However, the researcher did make the assignment to the conditions, which limits the possible effects of regression. 
Secondly, it is possible that the treatment diffused during the experiment. The mentors of the companies that participated in the main study were colleagues who saw each at the workplace with some regularity, for instance during their lunch break, while collecting materials at the warehouse or during shared shifts. Although the researcher explicitly asked mentors not to hand the guidelines to anyone else, they could have exchanged experiences or asked each other about their particular part in the research project. It is also possible that students passed on information to colleagues, because they did not work with their mentor all the time. And although the students did not receive the guidelines, it is possible that they transferred them, because their mentor used them for interaction. Conversely, mentors might have used the guidelines while interacting with a student from the control group. To evaluate whether the threat of diffusion actually occurred, mentors and students from the control group were asked at the end of the experiment whether they had seen the card with the steps and guidelines. This proved not to be the case. It is, however, still possible that exchange of information did take place.

Thirdly, the instruments used could have interacted with the way mentors used the guidelines. If students had a low score on the first measurement of mastery, this might have stimulated their mentors to invest additionally in interaction to help the student master the competencies at a satisfactory level. Mentors of the experimental group also had to complete weekly journals, which contained items about the use of the guidelines, and these might have influenced their behaviour. However, it appears from the data and the non-significant differences on mastery that this threat probably did not occur.

Finally, the experiments in the main study were carried out in different settings. They had one thing in common, however: they were all large companies, because of the large numbers of mentors and students required. As regards the Dutch situation, most students attend their period of workplace learning at small or medium-sized enterprises (SMEs), which means that the experiment is not representative of all settings. This threat of external validity is compensated partly by the pilot, in which smaller companies participated. Because the pilot did not provide information about the effect of the guidelines on mastery of job-relevant competencies, it is still difficult to generalise the findings. All the settings, however, provided information on the perceived relevance of the guidelines and the way in which they were used.

Several instruments were used for the pilot study and the experiments to gather the data needed to describe interaction processes and to explain effects. Most of the instruments were questionnaires, which were used to measure workplace characteristics, student characteristics and mentor characteristics. The use of existing and already validated scales proved to be useful as regards reliability. Measurement of the mastery of job-relevant competencies was also reliable. 
However, mastery was measured with perception measures, which is risky because its permits social desirability to influence the data, especially if the variable is considered beneficial (see also Nijman, 2004). In order to increase validity, it was not only the students who were asked to respond, the mentors, who have no direct interest in higher scores, also answered the same questions. Because the scores of the students and mentors correlated and did not differ significantly, it is probable that social desirability did not occur. Students and mentors were also told that the scores would not affect judgement of the period of workplace learning, which is extremely important for students. An alternative method of measurement - assessment by impartial assessors - although preferable because of its higher level of objectivity, was not used. This was because it would have been too great a burden to the participating companies.

As with most of the variables, the use of the guidelines was measured with questionnaires. As with mastery, their use was measured with perception measures. Observation is considered a valuable alternative for collecting data on behaviour, because it makes it possible to see what is happening. For this study, however, it was considered less valid, because it was expected also to influence the behaviour of the mentors. Observation would probably also have disturbed daily work processes, especially in the case of the hospital and the bank, where patients and clients are involved when tasks are executed. And although the aim was to test the effects of the guidelines, mentors should be allowed to use them as they themselves wished. To increase the objectivity of the data, students were asked whether mentors had executed the steps and in the interview at the end they were asked to what extent the mentors had used the guidelines as described on the card. Nevertheless, some kind of observation, if this had been possible, would have strengthened the experiment.

The last methodological issue discussed is the power of the data. Carrying out quasi-experiments to test effects of workplace learning is challenging yet difficult. To provide significant effects, experiments must include large numbers of students and mentors to avoid great differences being needed. Although the numbers of participating students and mentors were considerable, they still are small; larger numbers, however, are hard to find. To increase the power of the data, the same instruments and variables were used and measured in all experiments. Even so, the settings differ for instance with regard to tasks that had to be executed, and those that had to acquire job-relevant competencies (students or employees).

In summary, the design chosen and the instruments used seemed to be adequate when considering the aim of the study and the hypothesis formulated. Most validity threats were neutralised or validity was checked to ensure it had not been affected. The power of the data is limited but, under the existing circumstances, increased as much as possible. 


\subsection{Implications of the study}

This final section briefly explores the theoretical, the research and the practical implications of the study.

\subsubsection{Theoretical implications}

In this study a theoretical framework for workplace learning was developed. Interaction was considered an important variable with regard to this kind of learning. The data from the experiments point in that direction and seem to confirm this assumption. They also revealed the influence and effects of some of the workplace characteristics, mentor characteristics and student characteristics. This indicates that all these kinds of characteristics are of importance and should be taken into account when looking for explanations and predictors of workplace learning (see also Nijman, 2004). However, the relations between these selected variables were probably naively represented as merely direct. There are probably some kinds of indirect relations between these variables and the mastery of job-relevant competencies.

The study also tried to increase the effectiveness of workplace learning through its design approach. The guidelines for interaction that were developed and presented as an instructional tool for mentors affected the mastery of jobrelevant competencies to some extent. It was, however, necessary to distribute the guidelines and to ensure some kind of use of extensive contacts with the participating companies and this bore fruit. Mentors also used the guidelines for interaction in their own way. The possibility of actually designing workplace learning therefore seems to be limited and to require at least the full cooperation of the companies.

As mentioned at the start of this chapter, workplace learning is considered indispensable for the development of job-relevant competencies. This study showed that students master job-relevant competencies better after some weeks, which points to the potential power of workplace learning. Some conditions, however, need to be fulfilled, such as continuity of interaction and mentors who a) are available during the entire period of workplace learning, b) really know what is required to perform tasks and participate in daily work processes, c) are well-prepared, and d) are willing to search for ways of interaction instead of just using fixed routines. If not, an improvement in mastery will be very limited.

\subsubsection{Research implications}

The theoretical part of the study consisted of a review, which was carried out to select variables that have been shown to influence the effectiveness of work- 
place learning. Research with a larger number of respondents and in a larger number of settings is, however, necessary to test whether all these variables have a direct or indirect effect on the acquisition of job-relevant competencies and how they relate to each other. Additionally, the theoretical model did not include variables that referred to the culture and organisational climate of companies, which might also affect workplace learning (Sambrook, 2005) or some of the workplace characteristics that have proved to influence informal learning, such as a high degree of exposure to the demands of the organisation (Skule, 2003). This gap should be filled to complete the theoretical framework. An additional review is considered necessary.

The empirical part of the study consisted of experiments carried out in different settings. These experiments showed the relevance of interaction and the potential power of the guidelines. However, due to the limited numbers of mentors and students, the positive effects of using the guidelines were not significant because large differences in mastery were not found. Nevertheless, the differences, although small, suggest that it would be interesting to carry out a study on a larger scale to test the hypothesis again. To increase the power of the data from a new study, it would be useful to add more extensive training of mentors in using the guidelines, the use of multiple instruments to measure mastery and an extensive evaluation with mentors of interaction. It would also be interesting to test the effect of the distribution of the guidelines to students and vocational education and training centres. Distribution to students could increase the efficiency of interaction, because they know what to expect. The pilot study showed that the guidelines were also clear to the students. Distribution to centres could increase the effect if teachers are willing to interact accordingly. The principle of external consistency, which means in this particular situation that different parties share the same view and way of interaction, has proved to be influential (Kessels, 1996).

Although experiments with regard to workplace learning are difficult yet challenging to organise, they are very interesting for testing causal relations. This kind of research should be carried out more. Its importance has been stressed in recent studies (Nijman, 2004; Onderwijsraad, 2006). This ensures that choices and intended changes are not based merely on ideas and expectations, which happens all too often in the field of education.

One of the expectations in Dutch vocational education and training is that the two learning routes are equivalent. Theoretical notions (Billett, 1999; Ellström, 2002; Illeris, 2002) and one of the findings of the experiments urge a critical re-examination of this. It seems that students in the full-time collegebased route can develop more than those in the part-time work-based route. 


\subsubsection{Practical implications}

The experiments showed the willingness of companies to provide students with the opportunity to carry out their period of workplace learning. However, the time available to invest in workplace learning was and still is limited. It would therefore be interesting to look for opportunities to increase the likelihood of interaction in existing situations. One of the possibilities is to appoint to the role of mentor employees who themselves carry out the tasks that students must learn to perform. They know what is needed to carry out these tasks. They are, however, at present not provided with tools. In the current situation in vocational education and training, practical instructors of the companies are allocated a crucial role. They are trained in coaching and are provided with knowledge and tools to coach students by the national bodies and vocational education and training centres. This study shows other possibilities for interaction.

The finding that less experienced mentors achieve better results than do their older, far more experienced colleagues advocates a shift in roles vis-à-vis the current situation. Consideration should be given to allotting the role of student mentor to young employees with a couple of years of working experience, who still know what it means to be a student and what is required to learn the tasks that they have now mastered. They will, however, have to be provided with a supportive tool, such as the guidelines developed. The older, more experienced mentors could become counsellors to their young colleagues, because they know from experience what is required to interact with students. They should be challenged to do so. In this way experience concentration is used positively. Because students work not only with their mentors, their colleagues too should be provided with supportive tools to increase the prospects of consistent and comparable interaction. The company's practical instructor could become a key figure in achieving such situations.

Finally, interaction seems to be a theoretically and empirically relevant concept with regard to the effectiveness of workplace learning. National bodies or vocational education and training centres should invest in monitoring interaction processes at the workplace and the extent of growth and mastery of students with regard to the competencies needed. 


\section{Summary}

\section{Introduction}

Workplace learning is an essential part of every secondary vocational education and training course in the Netherlands. As in other countries, the workplace is regarded as an environment with great learning potential, and learning in such an environment is considered indispensable for the development of job-relevant competencies. As a consequence, a substantial amount of training time is spent on workplace learning and its importance is stressed by law, which states that a diploma is to be awarded to a student only when he has satisfactorily completed the period of workplace learning. Nevertheless, important as it is, workplace learning is also problematic. Studies point at insufficient preparation, interaction and organisation. Improving the quality of workplace learning is considered necessary by all the parties involved. The interesting question is how.

\section{Review}

In order to answer this question a review was carried out to identify concepts of workplace learning (Chapter 1). This review shows that workplace learning can be characterised as a multiform, influenceable, individual and social process of development, which occurs by means of participation in work processes and has as its aim understanding, handling and influencing work situations. It consists of eight dimensions, which can be used to position a study, including this one. This study focused on students' workplace learning, which was planned and designed to facilitate the acquisition of job-relevant competencies. The learning process was considered generic and partly controlled by the student who wished to become a competent professional. 
The review was also used to identify variables that have been shown to influence workplace learning (Chapter 2). An analysis was made of studies of vocational education and training, corporate training, and learning in general. The variables found were classified into three categories, which correspond with the parties that are directly involved in workplace learning: the student, the company and the vocational education and training centre. This classification has also been used in other studies that have contributed to the understanding of the effectiveness of workplace learning. The variables that were found related to two kinds of common learning aims: acquiring competencies and applying the acquired competencies, which cover the great diversity of specific learning aims that were mentioned in the studies analysed.

\section{Design of guidelines}

The selected variables were combined with a contemporary learning theory in order to design an intervention to increase the effectiveness of workplace learning (Chapter 3). This resulted in a theoretical framework for workplace learning.

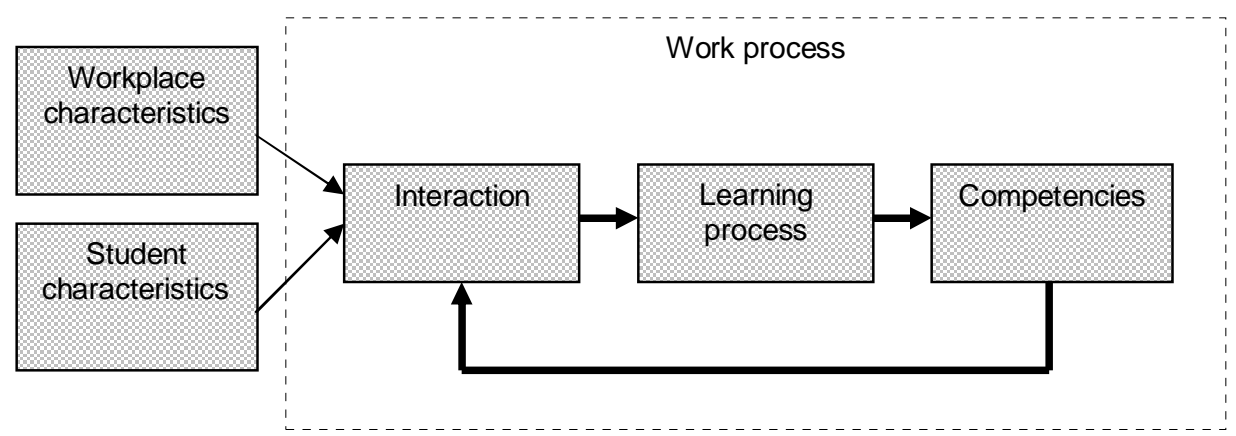

Figure 1 Theoretical framework for workplace learning.

Interaction was chosen as the starting point for the design of effective workplace learning, because it provides the input of learning processes. A set of steps and guidelines was developed to achieve high quality interaction at the workplace between mentor and student. These guidelines incorporate learning activities and selected influential variables. To ensure maximum use of the guidelines, these were formulated as clear and simple instructions for mentors who do not have the opportunity to attend training. 
Phase 1: Orientating to the task

1. Select together a task the student wants to learn to execute.

2. Talk through together the task the student wants to learn to execute.

3. Determine together what the student already knows and is capable of

4. Discuss together how the student wants to learn to execute the task.

5

Phase 2: Preparing for the execution of the task

5. Prepare together for the execution of the task.

6. Make sure all the student needs to execute the task is available.

Phase 3: Supervising the execution of the task and discussing performance 7. Supervise the execution of the task.

8. Discuss performance with the student immediately after execution.

9. Determine together the next steps necessary to learn to execute the task.

Phase 4: Improving ability

10. Instruct the student to execute the task a couple of times more.

Figure 2 Steps for interaction.

\section{Research design and instrumentation}

It was decided to use a quasi-experimental design to test the effects of the guidelines for interaction on the acquisition of job-relevant competencies, and a hypothesis was formulated (Chapter 4):

Application of the guidelines for interaction by the mentor leads to significantly better acquisition of job-relevant competencies by the student.

The research model to test the hypothesis consisted of a number of variables. The set of guidelines was the independent variable, and the acquisition of jobrelevant competencies, the dependent variable. These variables are connected by interaction at the workplace between mentor and student. Workplace, mentor and student are constantly present and their influence cannot be eliminated. These three were therefore included in the research model as control variables. The learning process was treated as a black box and was not included. 


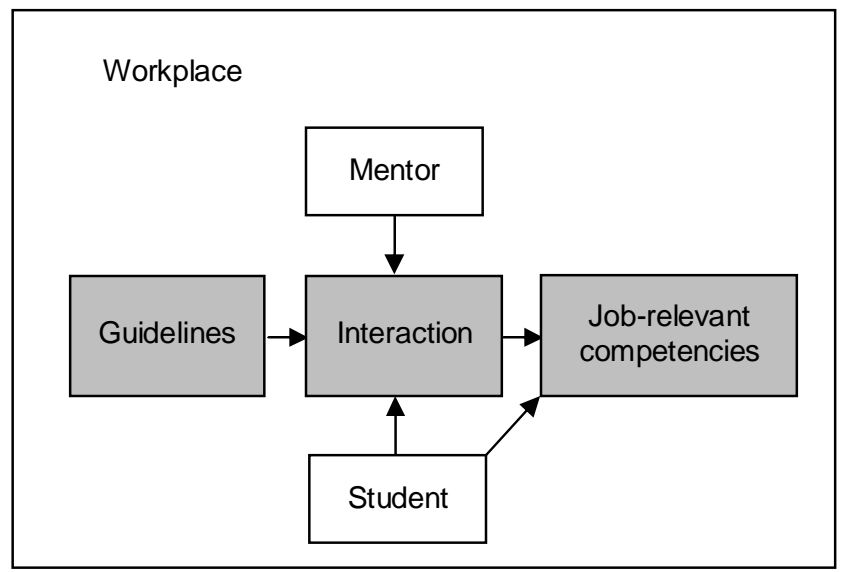

Figure 3 The research model.

\section{Pilot study}

The empirical part of the study started with a pilot study (Chapter 5). The aim of this pilot study was to test the hypothesis for the first time and to gain an insight into the usefulness of the guidelines, the instruments and the research design for the main study. The pilot study was carried out in three different settings, each representing workplace learning in a specific vocational education and training course. The decision to conduct the experiment in close cooperation with the centres proved to be inefficient in some respects. It led to the fundamentally different decision to recruit companies instead of courses and centres for the main study. The instruments to measure workplace and student characteristics proved to be reliable. According to the mentors and students, the guidelines were clear and complete; no supplements were needed. In general the guidelines were seen as an instrument that was able to support mentors, if they were allowed to use them as they wished. However, some adaptations were considered advisable to improve their usefulness. The number of steps and guidelines was reduced to take account of the comment that these were too numerous and that too much time was required to use all of them. This resulted in a revised version, which was used in the main study. The pilot study showed that mentors use the guidelines in their own way. Although these had been developed as a tool aimed at a high fidelity approach, mentors from the beginning adapted them to fit into their daily work processes and to achieve a more natural kind of interaction that suited them. One rather reassuring finding was that mentors had no need of extensive training to be able to use the guidelines. It was not possible to test the hypothesis, because the numbers of 
students and mentors who had completed and returned the questionnaires on the acquisition of job-relevant competencies was too small.

\section{Three experiments}

For the main study, three experiments were carried out at large companies: a hospital, a bank, and an ICT company (Chapters 6, 7 and 8). The experiments were carried out to test the hypothesis already formulated.

To avoid the situations that had occurred in the pilot study in the main study, companies were involved in the experiments from the beginning. Representatives of the companies were asked to comment on the instruments to make them suitable for the specific situations at their company. This resulted in lists of tasks that, in the main, corresponded to their daily work processes. It also made it clear that employees who were appointed as mentor did not have interaction instruments or other supportive instruments at their disposal; the guidelines filled a gap. As a consequence of the findings of the pilot study, all mentors were provided with information and instructions. It again proved impossible, however, to organise meetings and the time available was limited. Nevertheless, these brief instructions provided the mentors with the necessary information. In all, the strategy to involve companies was successful.

As in the pilot study, the instruments used proved reliable and the time needed to complete the questionnaires was limited. The mean scores for the workplace characteristics and the student characteristics indicated that learning conditions were fulfilled to a fairly large extent. This is in itself a favourable situation, as it might positively influence the mastery of job-relevant competencies. However, the experiment where the conditions seemed to be fulfilled best (experiment 3 ) did not produce the best scores for mastery. There must therefore be another explanation for the importance of interaction.

Interaction between mentor and student, although important, remained limited. Students did not work very much with their mentors, even if they had two. When mentors were not at hand, other colleagues took over their role, which ensured some continuity of interaction. It is quite possible, however, that each colleague had his or her own way of working and interacting, which might have confused students and hindered their learning. This was probably the case, in view of the students' desire to work more with their own mentor. Not only was the frequency of interaction with the mentor limited, so was the time devoted to it: in the majority of cases, 30 minutes a day at most. Nevertheless, it seemed to bear fruit, which again indicates that interaction is important. Most of the interaction occurred while students were executing their tasks, which is understandable if work is the top priority. It is also a natural consequence when 
students are allowed to participate in daily work processes, which is considered beneficial to learning. The experiments also showed that the focus of interaction differed depending on the function of the mentors. The interaction of managers focused more on functioning in general. Mentors on the work floor focused on all the tasks in the daily work processes, which makes them a very interesting group to focus on when one wants to create high quality interaction concerning the execution of tasks and the participation of students in work processes. They really know what is needed. At the same time they all felt sufficiently skilled to coach students, because they had working experience, they knew what was required to execute tasks or had a great deal of coaching experience. Remarkably, almost none mentioned specific coaching skills. This indicates a particular view of coaching and interaction, where sharing knowledge and experience in itself is considered more important than the way this is done. With regard to coaching experience, the analyses of the experiments showed some interesting findings. One of these was that the students of young and less experienced mentors mastered competencies better than did those of older and more experienced ones. Mentors with little experience probably reflect more on their way of interacting, in their search for the most effective method, which apparently has a positive influence on quality. Further, these mentors were young and had only recently completed their educational programme; their own workplace learning experiences and knowledge of the current educational programme probably influenced the way they interacted. The older mentors might have had a greater amount of experience concentration, which negatively influenced their willingness and ability to learn and apply something new. Another interesting finding was that students who interacted with well-prepared mentors also mastered competencies better. On the other hand, employees benefited from their coaching experience when they themselves had to improve their own performance and to master job-relevant competencies. It is possible that they were more used to focusing on learning and on improving their performance. This points to the relevance of providing employees with the opportunity to gain coaching experience.

The guidelines for interaction were meant as an instructional tool to be used by mentors as prescribed. A short instruction was sufficient to provide mentors with the information necessary to start. In all the experiments only some of the mentors used them. Some used them mainly as intended; others used them in their own way and adapted the guidelines by changing the order, or adding their own or omitting some. The reasons mentioned for adaptation or non-use were lack of time, of experience and of an existing routine in interaction, and problems to fit them into their daily work processes. The steps and guidelines did, however, seem to be relevant, because none was systematically omitted nor were any added structurally. Adaptation seems to depend on the situations that 
occurred. The basic principles of the guidelines were endorsed by the mentors, and the guidelines were considered clear and logical.

The amount of time available to spend on interaction allowed mentors to become used to the guidelines to some extent, but probably did not allow the development of routines. Their focus was mainly on how to integrate interaction into their work. A workplace where exchange of information and communication was perceived as commonplace stimulated the use of the guidelines. However, the mentors did not notice any support or appreciation from their colleagues with regard to the use of the guidelines, because most of their colleagues had not received these. Because their colleagues also interacted with the students quite regularly, distributing the guidelines on a broader scale could have positively influenced the learning process in two ways. First, it could have increased the consistency in interaction and, second, it might have created a more supportive environment.

The use of the guidelines seems to positively influence mastery of jobrelevant competencies. In general students in the experimental group grew more and were more satisfied with their mentors than students in the control group. In addition, students benefited when their mentors used the guidelines more extensively. These differences were, however, not significant. This was relevant from a scientific point of view, but regrettable if one really wishes to improve the effectiveness of workplace learning. The hypothesis that application of the guidelines for interaction by the mentor leads to significantly better acquisition of job-relevant competencies by the student is rejected - at least under the conditions given.

Workplace characteristics and student characteristics were used as co-variables. These characteristics correspond to the variables selected on the basis of the review, meaning that they were expected to influence workplace learning. Regression analyses revealed that a few of the variables explained the variance in the mastery of job-relevant competencies at a significant level. These were the variables of interaction, instrumental support, self-efficacy and reflection. Several other variables influenced the use of the guidelines: participation, variation, task information, informational support (all workplace characteristics), the age and work experience of the mentors and the motivation, reflection and regulation of the students. The other variables did not significantly affect interaction or mastery.

The findings with regard to the co-variables reveal that the theoretical framework and the research model are usable as a point of departure for research: workplace characteristics, student characteristics and mentor characteristics are of importance with regard to interaction and mastery of job-relevant competencies. Some adaptations are necessary to tailor the framework to the findings. First, the characteristics not only influence interaction, but also influence mastery. Second, vocational education characteristics also carry 
weight. The experiments mainly provided findings and conclusions related to the specific settings. It thus seems difficult to develop a universal model for learning at work. Models for workplace learning in vocational education and training, however, should take into account the influence of workplace characteristics, mentor characteristics, student characteristics and interaction with regard to mastery of job-relevant competencies.

\section{Critical reflection}

The rejection of the hypothesis called for reflection that would provide answers to the question of why the designed intervention did not contribute substantially to the acquisition of job-relevant competencies.

A quasi-experimental design allows for the testing of causal relations. Although potentially powerful, it has to meet certain criteria to be truly valid and reliable. In the experiments most threats to validity were neutralised or validity was checked to ensure it had not been affected. To provide significant effects, however, experiments must include large numbers of students and mentors to avoid great differences being needed. Although the numbers of students and mentors participating were considerable, they were still too small. To increase the power of the data, the same instruments and variables were used and measured in all experiments. The power of the data was thus limited but, under the existing circumstances, increased as much as possible.

In the experiment mentors were asked to use the guidelines as drawn up. However, the adaptive and limited use of the guidelines, the limited availability of mentors, limited time spent on interaction and the lack of a supportive environment reduced the potential power of the guidelines and their effect. Merely looking at the way the guidelines were used produces no definite conclusions. Another relevant question was whether the guidelines as drawn up are truly potentially powerful. Mentors and students judged the guidelines to be a usable tool that was clear and complete; mentors endorsed the basic principles of the guidelines and students confirmed that their mentors had acted accordingly. These findings indicate that the guidelines themselves were acceptable to the mentors. According to some mentors, however, the guidelines did not coincide with their way of interacting or did not fit specific situations. These reasons focus attention on a potential weakness of the guidelines: they were drawn up as a generic set that was expected to be useful to all mentors in all kinds of situations. However, the most valuable indication of the potential power of the guidelines advocates leaving them as they are: extensive use of the guidelines seems to result in improved mastery of job-relevant competencies.

The experiments focused not only on the guidelines. The theoretical framework and the research model used for the experiments included variables 
that referred to workplace, mentor and student characteristics. The findings relating to these independent variables pointed to the rightness of the theoretical framework as described in Chapter 3 and the research model as described in Chapter 4: workplace characteristics, student characteristics and mentor characteristics are of importance with regard to interaction. Some adaptations are, however, necessary to tailor the framework to the findings. First, the characteristics mentioned influence not only interaction, but also mastery. Second, vocational education characteristics are also of consequence. Additionally, some variables did not affect interaction or mastery. It is possible that the settings of the experiments differed too much from the settings in the empirical studies used for the review. Other possible explanations are that the variables had not been combined to form one theoretical framework before or that these variables only influenced workplace learning indirectly because of interdependencies.

Finally, although the hypothesis was rejected, the experiments showed that students mastered job-relevant competencies better at the end of the experiment. The question that arises is whether workplace learning is worthwhile, in view of the amount of growth. In the three experiments only the students in the experiment at the hospital showed considerable growth. It seems that growth is influenced positively by extensive interaction with young, less experienced, but well-prepared mentors who are at hand most of the time and are willing to reflect on their own way of interacting. If not, students spending time at the workplace provide the company with an extra pair of hands but leave the students themselves empty-handed. The potential power of workplace learning was, however, not measured to it fullest extent. Acquisition of job-relevant competencies as chosen for this study is just one of two metaphors for explaining learning. Participation with the objective of becoming a member of a community is the other. The inclusion of both metaphors in measuring the returns of workplace learning is interesting and valuable, as it also allows an assessment of what duration of workplace learning is beneficial.

Although this was not measured thoroughly, it seems that mainly assimilative learning occurred. This is a type of learning that students prefer because it is less demanding and requires less effort. For true development, however, assimilation and accommodation are considered necessary. Although the guidelines were intended to stimulate reflection, which contributes to accommodation, the extent of their use and the time available for learning and interaction was probably not sufficient. The likelihood of accommodation or developmental learning occurring seems to be greater for students in the fulltime college-based route, who are given the opportunity and permission to spend time on learning. Students in the part-time work-based route are expected to produce. Consequently, to increase the power of workplace learning, accommodative learning should also be stimulated and achieved. 


\section{Implications of the study}

In this study a theoretical framework for workplace learning was developed. Interaction was considered an important variable with regard to this kind of learning. The data from the experiments point in that direction and seem to confirm this assumption. In addition, they revealed the influence and effects of some of the workplace characteristics, mentor characteristics and student characteristics. All these types of characteristics are of importance and should be taken into account when looking for explanations and predictors of workplace learning.

The study also tried to increase the effectiveness of workplace learning through its design approach. However, the possibility of actually designing workplace learning seems to be limited and at least to require the full cooperation of the companies. With regard to interaction, some conditions need to be fulfilled, such as continuity of interaction and mentors who a) are available during the entire period of workplace learning, b) really know what is required to perform tasks and participate in daily work processes, c) are well-prepared, and d) are willing to search for ways of interaction instead of just using fixed routines. If not, an improvement in mastery will be very limited.

The theoretical part of the study consisted of a review, which was carried out to select variables that have proved to influence the effectiveness of workplace learning. Research with a larger number of respondents and in a larger number of settings is necessary to test for the direct or indirect effect on the acquisition of job-relevant competencies and to examine how they relate to each other. The theoretical model also did not include variables that referred to the culture and organisational climate of companies, which might also affect workplace learning. This gap should be filled to complete the theoretical framework. An additional review is considered necessary.

The findings with regard to mastery and the potential power of the guidelines suggest that it would be interesting to carry out a study on a larger scale to test the hypothesis again. To increase the power of the data from a new study, it would be beneficial to add more extensive training of mentors in using the guidelines, the use of multiple instruments to measure mastery, and an extensive evaluation with mentors of interaction. It would also be interesting to test the effect of the distribution of the guidelines among students and vocational education and training centres. Theoretical notions of workplace learning and one of the findings of the experiments also urge a critical reexamination of the equivalence of the two learning routes in Dutch vocational education and training.

Finally, this study showed possibilities for interaction at the workplace not yet common in vocational education and training. One of these is to appoint to the role of mentor young employees with a couple of years of working experience, 
who themselves carry out the tasks that students must learn to perform. They know what is needed to carry out these tasks. They must, however, be provided with a supportive tool, such as the guidelines developed. Their colleagues too should be provided with supportive tools to increase the prospects of consistent and comparable interaction. The company's practical instructor could become a key figure in achieving such situations. The older, more experienced mentors could become counsellors to their young colleagues. National bodies or vocational education and training centres should invest in monitoring interaction processes at the workplace and the extent of growth and mastery of students with regard to the competencies needed. This monitoring provides information they can use to discuss the quality of workplace learning with companies. 


\section{Samenvatting}

\section{Inleiding}

Werkplekleren is een essentieel onderdeel van elke middelbare beroepsopleiding in Nederland. Net als in vele Europese landen, de Verenigde Staten en Australië wordt de werkplek gezien als een omgeving met een groot leerpotentieel. Het leren in zo'n omgeving wordt onmisbaar geacht als het gaat om de verwerving van beroepsrelevante competenties. Het gevolg is dat het belang is wettelijk vastgelegd en dat een substantieel deel van de opleidingstijd wordt besteed aan werkplekleren. In de Wet Educatie Beroepsonderwijs staat dat een diploma alleen verstrekt wordt als een student aan de eisen van de beroepspraktijkvorming, de BPV, heeft voldaan. Ondanks het belang blijkt dat werkplekleren de nodige problemen kent. Eerder onderzoek wijst op een gebrekkige voorbereiding op werkplekleren, een gebrekkige interactie tussen betrokkenen en een gebrekkige organisatie van het leerproces. Volgens alle partijen die betrokken zijn bij het beroepsonderwijs is het verbeteren van de kwaliteit van werkplekleren noodzakelijk. De interessante vraag die daarop volgt is hoe.

\section{Review}

Om de gestelde vraag te kunnen beantwoorden is een review uitgevoerd om concepten van werkplekleren te identificeren (Hoofdstuk 1). De review laat zien dat werkplekleren getypeerd kan worden als een veelvorming, beïnvloedbaar en individueel en sociaal ontwikkelingsproces dat optreedt door deelname aan werkprocessen. Het leidt tot het begrijpen, hanteren en beïnvloeden van werksituaties. Uit de review laten zich acht dimensies destilleren (zie Figuur 1). Voor deze studie geldt dat de focus het werkplekleren van studenten is. Het gaat in deze studie om het ontwerpen van gepland leren gericht op de verwerving van beroepsrelevante competenties. Het leerproces zelf wordt gezien als een generiek proces dat soortgelijke kenmerken voor elke student heeft. Het wordt deels gestuurd door de student die een competente professional wil worden en deels door de begeleider op de werkplek. 


\begin{tabular}{llr}
\hline Dimensie & \\
\hline Eenheid: & Individu & Groep \\
Sturing: & Intern & Extern \\
Motief: & Intern & Extern \\
Leeromgeving: & Niet ontworpen & Ontworpen \\
Leerproces: & Generiek & Uniek \\
Status: & Niet gepland & Gepland \\
Bewustzijn: & Onbewust & Bewust \\
Doel: & Verwerving & Participatie \\
\hline
\end{tabular}

Figuur 1 Dimensies van werkplekleren.

De review is niet alleen uitgevoerd om concepten van werkplekleren te achterhalen, maar ook om variabelen te identificeren die hebben laten zien dat ze werkplekleren effectief beïnvloeden (Hoofdstuk 2). Studies naar werkplekleren in het beroepsonderwijs, naar bedrijfsopleidingen en naar leren in het algemeen zijn geanalyseerd. De gevonden variabelen zijn verdeeld in drie categorieën die corresponderen met de partijen die direct betrokken zijn bij werkplekleren in het beroepsonderwijs: de student, het bedrijf en het opleidingsinstituut. Deze classificatie is ook gebruikt in andere studies die hebben bijgedragen tot inzicht in de effectiviteit van werkplekleren. Figuur 2 laat zien om welke variabelen het gaat. De variabelen zijn te relateren aan twee leerdoelen: het verwerven en het leren toepassen van competenties. Deze twee dekken het grote aantal specifieke leerdoelen die in de verschillende, geanalyseerde studies zijn genoemd.

\section{Ontwerp van richtlijnen}

Om tot een ontwerp van effectief werkplekleren te komen, is na de review een theoretisch kader opgesteld (Hoofdstuk 3). Variabelen die van invloed zijn op werkplekleren zijn gecombineerd met de leertheorie van Illeris. Het theoretisch kader voor werkplekleren dat zo ontstaat, is op hoofdlijnen weergegeven in Figuur 3. 


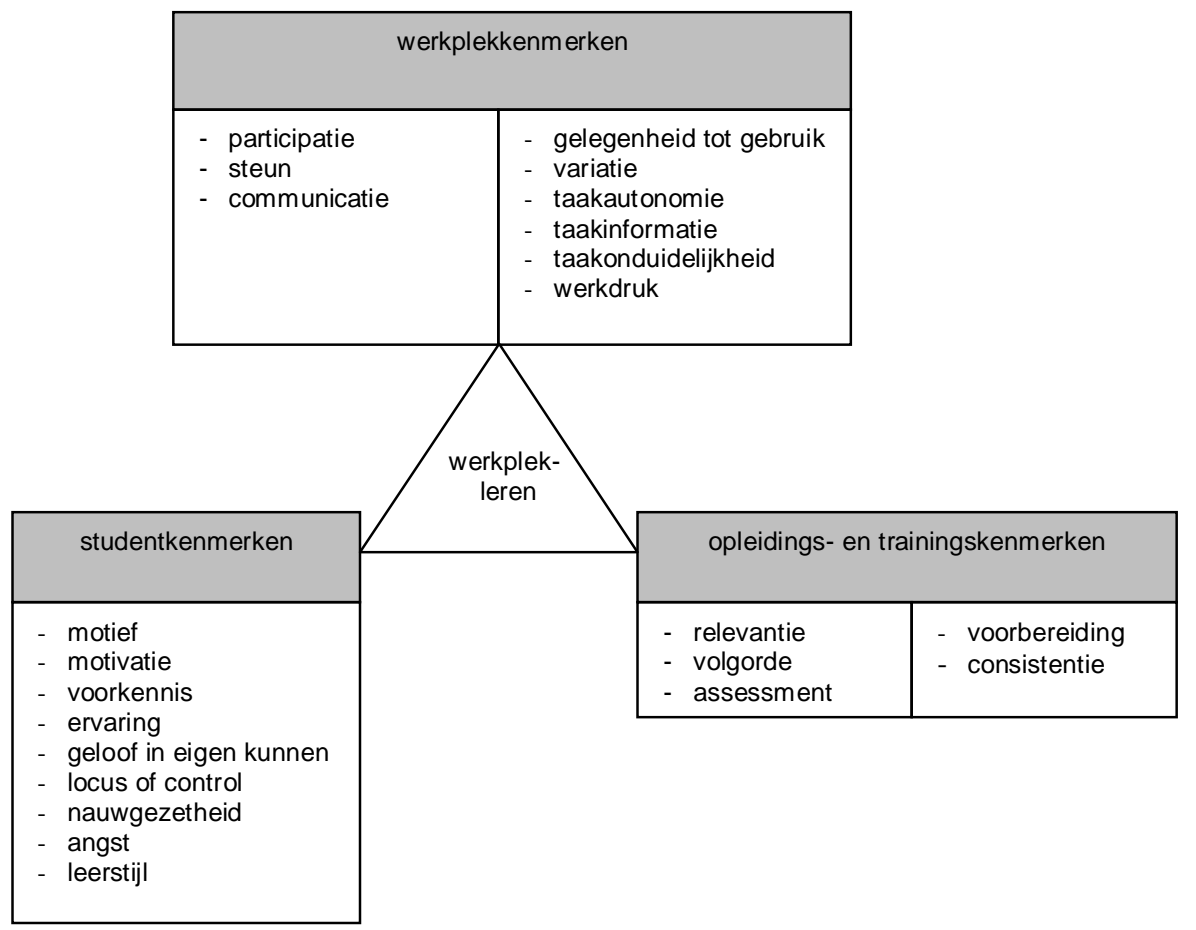

Figuur 2 Geselecteerde variabelen die van invloed zijn op werkplekleren.

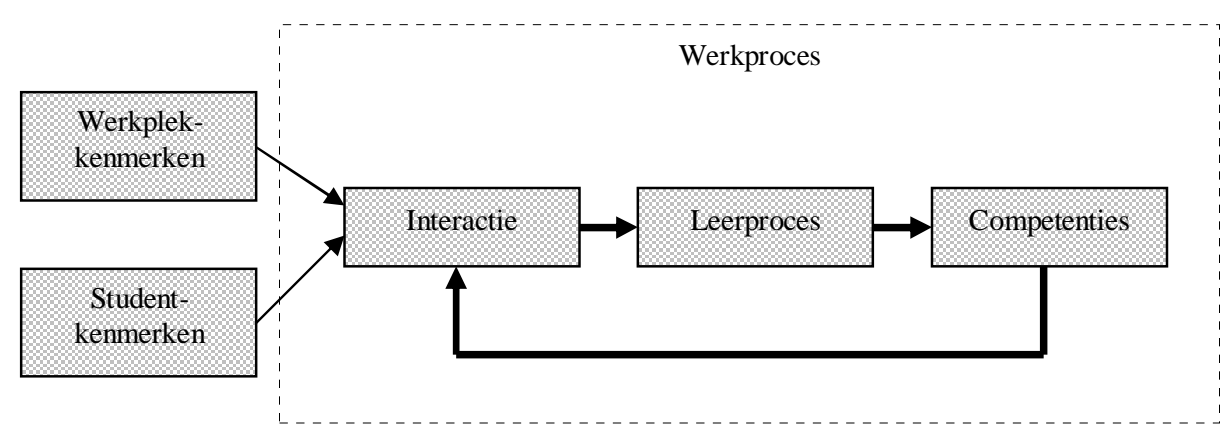

Figuur 3 Theoretisch kader voor werkplekleren. 
Van de aangrijpingspunten die het theoretische kader biedt voor het ontwerp is interactie als hoofdproces gekozen, want dit levert de directe input voor leerprocessen. De interactie is toegespitst op een situatie die binnen het beroepsonderwijs veelvuldig voorkomt, namelijk die tussen begeleider en student op de werkplek. De begeleider is iemand die als werknemer meedraait in de dagelijkse, primaire werkprocessen waarmee ook de student in aanraking komt. Om tot kwalitatief hoogwaardige interactie te komen, zijn ontwerpspecificaties ontleend aan het theoretisch kader en de context waarin werkplekleren plaatsvindt. Vervolgens is een instrument ontwikkeld dat bestaat uit een aantal stappen en richtlijnen (zie Figuur 4). De richtlijnen omvatten cognitieve, affectieve en regulatieve leeractiviteiten. De geselecteerde invloedrijke variabelen zijn verwerkt. De richtlijnen zijn geformuleerd als instructies voor de begeleiders. Omdat deze vaak niet in de gelegenheid zijn om een training in het gebruik van de richtlijnen te volgen, zijn ze zo helder en eenvoudig mogelijk geformuleerd.

\begin{tabular}{lr}
\hline Stap & $\begin{array}{r}\text { Aantal } \\
\text { richtlijnen }\end{array}$ \\
\hline
\end{tabular}

Begeleidingsmoment 1: Oriënteren op de taak

1. Kies samen met de student een taak die hij beter wil leren uitvoeren. 5

2. Bespreek samen met de student de taak die hij beter wil leren uitvoeren. 9

3. Stel samen met de student vast wat hij al weet en kan gelet op de taak die 6 zij beter wil leren uitvoeren.

4. Bespreek samen met de student hoe hij de tak in de vingers wil krijgen. 3

Begeleidingsmoment 2: Voorbereiden op de uitvoering van de taak

5. Bereid met de student de uitvoering van de taak voor.

6. Zorg dat alles voorhanden is om de taak te kunnen uitvoeren.

Begeleidingsmoment 3: Toezien op de uitvoering van de taak en het nabespreken

7. Houd toezicht op de uitvoering van de taak.

8. Bespreek direct na uitvoering de taak met de student.

9. Stel samen met de student noodzakelijke volgende stappen vast.

Begeleidingsmoment 4: Verder bekwamen

10. Geef de student opdracht de taak nog minimaal twee keer uit te voeren.

Figuur 4 Instrument voor interactie op de werkplek. 


\section{Onderzoeksopzet en instrumentatie}

Om de effecten van de richtlijnen op de verwerving van beroepsrelevante competenties vast te stellen, is gekozen voor een quasi-experimenteel design (Hoofdstuk 4). Daarbij is als hypothese geformuleerd:

De toepassing van de richtlijnen voor interactie door de begeleider leidt bij de student tot een significant betere verwerving van beroepsrelevante competenties.

Het onderzoeksmodel dat nodig is om de hypothese te testen, bestaat uit verschillende variabelen. De set richtlijnen is de onafhankelijke variabele, de verwerving van beroepsrelevante competenties de afhankelijke. Deze variabelen zijn verbonden via interactie op de werkplek tussen begeleider en student. Werkplek, begeleider en student zijn, vanzelfsprekend, voortdurend aanwezig en hun invloed kan niet vermeden worden. Daarom zijn deze drie als controlevariabelen aan het onderzoeksmodel toegevoegd (zie Figuur 5).

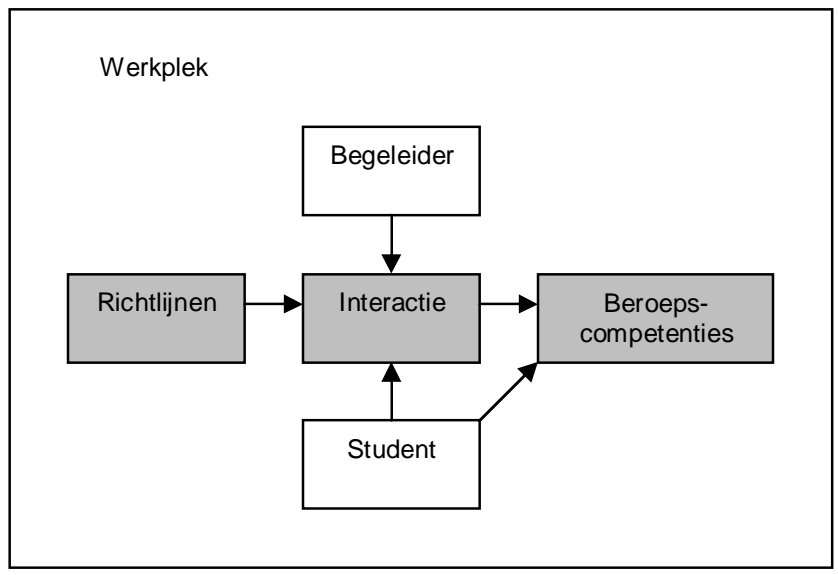

Figuur 5 Het onderzoeksmodel.

\section{Pilot}

Het empirisch deel van de studie begint met een pilot (Hoofdstuk 5). Het doel daarvan is om de hypothese voor de eerste keer te toetsen. Daarnaast moet de pilot inzicht geven in de duidelijkheid en bruikbaarheid van de richtlijnen en de 
meetinstrumenten. Ook moet de pilot aantonen of de onderzoeksopzet voor het hoofdonderzoek haalbaar is. De pilot zelf is in nauwe samenwerking met roc's uitgevoerd bij drie verschillende opleidingen van verschillende niveaus en met verschillende leerwegen. De keuze om dit samen met onderwijsinstellingen komt voort uit de eindverantwoordelijkheid van de instellingen voor opleiden.

De instrumenten die ontwikkeld zijn om werkplekkenmerken en studentkenmerken te meten, blijken betrouwbaar te zijn. Volgens begeleiders en studenten zijn de richtlijnen helder en compleet. Er zijn volgens hen geen aanvullingen nodig. In het algemeen worden de richtlijnen gezien als een instrument dat begeleiders kan ondersteunen bij de interactie met studenten, als het gebruikt kan worden zoals zij dat het liefste willen. De pilot laat zien dat de bruikbaarheid van de richtlijnen vergroot kan worden. Het aantal stappen en richtlijnen is verminderd gelet op het commentaar van begeleiders dat het er teveel zijn en het gebruik ervan (te)veel tijd in beslag neemt. Het resulteert in een herziene, ingekorte versie voor het hoofdonderzoek. De pilot laat verder zien dat begeleiders de richtlijnen op hun eigen manier gebruiken. Hoewel gemikt is op een 'high-fidelity' benadering, waarin de richtlijnen gebruikt worden zoals bedoeld, passen begeleiders ze vanaf het eerste moment aan. Als redenen noemen ze de dynamiek van werkprocessen en hun al ontwikkelde routines. Met het inpassen proberen de begeleiders tot een meer natuurlijke manier van interacteren te komen. Een bevinding uit de pilot is dat begeleiders naar eigen zeggen geen uitgebreide training in het gebruik van de richtlijnen nodig hebben. De kans op daadwerkelijke implementatie in bedrijven die niet staan te trappelen om zwaar te investeren in trainingen ten koste van productietijd, is daarmee groter. Het toetsen van de hypothese blijkt helaas niet mogelijk. Het aantal begeleiders en studenten dat de vragenlijsten over de verwerving van beroepsrelevante competenties heeft ingevuld, is te gering.

Ten slotte, de samenwerking met de onderwijsinstellingen blijkt niet doelmatig te zijn. Voor het hoofdonderzoek leidt dat tot de fundamenteel andere keuze om direct bedrijven te werven en niet eerst opleidingen en instellingen.

\section{Drie experimenten}

Het empirisch deel van de studie krijgt een vervolg in het hoofdonderzoek. Daarin zijn experimenten in drie grote bedrijven uitgevoerd: in een ziekenhuis, een bank en een ICT-bedrijf (de Hoofdstukken 6, 7 en 8).

Omdat het in de pilot lastig bleek om via onderwijsinstellingen bedrijven te betrekken en betrokken te houden bij het onderzoek, zijn de drie bedrijven vanaf het moment van voorbereiding al ingeschakeld. Vertegenwoordigers van de bedrijven is gevraagd om hun commentaar te geven op de meetinstrumenten, zodat ze zo goed mogelijk zouden aansluiten op de specifieke situatie in hun 
bedrijf. Daarnaast is er in nauwe samenspraak een lijst met taken opgesteld die correspondeert met de dagelijkse werkprocessen waarin ook de studenten zullen participeren. Tijdens de voorbereiding wordt duidelijk dat de bedrijven en de begeleiders niet over instrumenten beschikken die gericht zijn op de ondersteuning van en interactie met studenten. In die zin voorzien de richtlijnen in een behoefte. Hoewel de pilot heeft laten zien dat een uitgebreide training niet noodzakelijk is, krijgen alle begeleiders zowel mondeling als schriftelijk informatie en instructies over het gebruik van de richtlijnen en de meetinstrumenten. De korte vaak individuele uitleg en instructie voorziet de begeleiders van de informatie die zij nodig hebben.

\section{Beheersing}

Tijdens de experimenten is de beheersing van beroepsrelevante competenties twee keer gemeten. Het verschil tussen de eerste meting aan het begin van het experiment (pre-test) en de laatste aan het einde (pre-test) geeft een indicatie van de groei die in de perceptie van studenten en begeleiders is opgetreden. Het blijkt dat de scores van de experimentele groep en de controlegroep niet significant verschillen. Dat betekent dat de hypothese wordt verworpen: toepassing van de richtlijnen voor interactie leidt bij studenten niet tot een significant betere verwerving van beroepsrelevante competenties. Deze conclusie vraagt om reflectie die antwoorden kan leveren op de vraag waarom de interventie niet substantieel aan de verwerving van die competenties heeft bijgedragen.

\section{Gebruik van de richtlijnen}

Een belangrijke verklaring voor het verwerpen van de hypothese kan gevonden worden in de manier waarop de richtlijnen zijn gebruikt. Vanaf het begin hebben de begeleiders de richtlijnen aangepast door de volgorde te veranderen, door eigen richtlijnen toe te voegen en door richtlijnen weg te laten. Vrijwel iedereen gebruikte de richtlijnen slechts een deel van de tijd die aan interactie werd besteed. In feite gebruikte geen van de begeleiders de richtlijnen zoals bedoeld en gevraagd tijdens het experiment. Volgens de niet-gebruikers onder hen vroeg het gebruik van de richtlijnen teveel tijd, pasten ze niet in hun manier van werken of hun manier van interacteren.

Het adaptieve gebruik van de richtlijnen is echter niet de enige verklaring voor de verwerping van de hypothese. In de experimenten was het de bedoeling te werken met vaste koppels van begeleider en student. Minimaal de helft van de tijd was de begeleider niet beschikbaar. Het gevolg was dat studenten regelmatig met andere werknemers werkten, die niet de beschikking 
hadden over de richtlijnen. Op de dagen dat begeleider en student wel samen werkten, besteedden ze gemiddeld maximaal een half uur aan interactie. Frequent gebruik van de richtlijnen is echter nodig om ermee vertrouwd te raken en enige routine te ontwikkelen. Bovendien vraagt het gebruik van de richtlijnen in deze fase om extra tijd en inspanning tijdens het dagelijkse werk, de bereidheid om ze te gebruiken en om een stimulerende omgeving. Begeleiders ervoeren geen steun of waardering van hun collega's of leidinggevenden wanneer zij de richtlijnen gebruikten.

\section{Potentie van de richtlijnen}

Een andere relevante vraag is of de ontworpen richtlijnen in potentie ook zinvol en ondersteunend zijn,

Aan begeleiders en studenten is gevraagd om de duidelijkheid en bruikbaarheid van de richtlijnen te beoordelen. Zij beschouwen de richtlijnen als een bruikbaar en ondersteunend instrument dat alle relevante aspecten van interactie afdekt. Begeleiders onderschrijven de uitgangspunten onder de richtlijnen en studenten bevestigden dat hun begeleider in overeenstemming met deze uitgangspunten handelden. Deze bevindingen wijzen erop dat de richtlijnen acceptabel zijn voor de begeleiders.

Toch pasten de begeleiders de richtlijnen aan en ze moeten daar hun redenen voor hebben gehad. De experimenten lieten zien dat stappen en richtlijnen niet systematisch werden weggelaten dan wel toegevoegd. Dat wijst erop dat de richtlijnen een vrijwel complete set instructies vertegenwoordigen. Daar komt bij dat de richtlijnen niet conflicteerden met de voorkeuren voor interactie van de kant van studenten. Studenten uit de experimentele groep waren meer tevreden over hun begeleider dan de studenten in de controlegroep. Het is mogelijk dat begeleiders na het ontvangen van de richtlijnen meer zijn gaan reflecteren op hun eigen manier van interactie wat op zijn beurt geresulteerd kan hebben in kwalitatief hoogwaardiger interactie. Zoals al genoemd gaven begeleiders aan dat de richtlijnen niet altijd pasten in hun eigen manier van interactie of niet pasten in specifieke situaties die zich voordeden op de werkplek. Deze redenen wijzen op een potentiële zwakte van het instrument: de richtlijnen zijn geformuleerd als een generieke set die bruikbaar wordt geacht voor elke begeleider in elke situatie. Ze bieden geen handreikingen tot differentiëren. Het toevoegen van dergelijke handreikingen zou een verrijking van het instrument kunnen betekenen, tegelijkertijd neemt het de eenvoud weg wat een drempel voor gebruik opwerpt. De meest waardevolle indicatie voor daadwerkelijk gebruik is de richtlijnen te laten zoals ze zijn: intensief gebruik resulteert in een betere beheersing van beroepsrelevante competenties. 


\section{Soorten leerprocessen}

Hoewel het leerproces zelf niet expliciet in kaart is gebracht en gemeten, lijkt het erop dat vooral assimilatief leren is opgetreden. Het gaat daarbij om het inpassen van nieuwe impressies in al bestaande psychologische structuren. Studenten hebben een natuurlijke voorkeur voor dit type leren, omdat het minder inspanning kost. Voor echte ontwikkeling is echter ook accommodatief leren noodzakelijk. Daarbij worden al bestaande psychologische structuren geherstructureerd en opnieuw opgebouwd. Hoewel de richtlijnen met dat oogpunt ook de reflectie bij studenten willen stimuleren, zijn daarvoor de mate van interactie en de beschikbare tijd voor leren mogelijk niet toereikend. De kans dat accommodatief leren optreedt, lijkt overigens groter te zijn binnen de beroepsopleidende leerweg in het beroepsonderwijs. Studenten in deze route hebben de gelegenheid en toestemming om tijd aan leren te besteden. Van studenten in de beroepsbegeleidende leerweg wordt verwacht dat zij vooral produceren. Om de potentie van werkplekleren te vergroten moet dus ook accommodatief leren gestimuleerd en gerealiseerd worden.

\section{Invloed van werkplek-, student- en mentorkenmerken}

De experimenten resulteerden niet alleen in bevindingen over de richtlijnen. Het theoretisch kader en het onderzoeksmodel bevatten werkplek-, mentor- en studentkenmerken. Omdat het gebruik van de richtlijnen geen verklaring leverde voor de verschillen in beheersing van de competenties is de volgende vraag of deze variabelen dat wel doen.

De gemiddelde scores op de geselecteerde kenmerken lieten zien dat leercondities in elk experiment al in behoorlijke mate waren vervuld. Ze leveren daardoor een substantiële bijdrage leveren aan de verwerving van beroepsrelevante competenties. De beheersing nam in twee van de drie experimenten echter niet substantieel toe. Bovendien bleek het experiment waarin de leercondities het beste vervuld leken te zijn (bij het ICT-bedrijf), niet de grootste mate van beheersing op te leveren. Het theoretisch kader voor werkplekleren levert een mogelijke verklaring voor deze bevinding. Het kader veronderstelt dat werkplek- en studentkenmerken van invloed zijn op interactie die op zijn beurt de input voor het leerproces levert. De invloed van deze kenmerken is dus indirect. De bevindingen uit de experimenten lijken deze aanname te bevestigen. Vijf werkplekkenmerken en drie studentkenmerken beïnvloeden interactie. Aanvullend geldt dat het experiment in het ziekenhuis waar de begeleiders het meest interacteerden met hun student de grootste mate van beheersing opleverde. Deze bevindingen onderstrepen het belang van interactie als het gaat om werkplekleren. Interactie als werkplekkenmerk blijkt op zijn beurt op een significant niveau variantie te verklaren in de beheersing 
van competenties $\left(\mathrm{R}^{2}=.13\right.$ bij het ziekenhuis en .08 bij de bank). Een ander werkplekkenmerk en twee studentkenmerken verklaren ook variantie in beheersing wat in tegenstelling tot de aanname in het theoretisch kader wijst op een vorm van directe invloed: instrumentele steun $\left(\mathrm{R}^{2}=.17\right)$, geloof in eigen kunnen en reflectie $\left(\mathrm{R}^{2}=.37\right)$. Instrumentele steun wijst op de noodzaak faciliteiten te leveren die nodig zijn om taken uit te voeren zoals verwacht en vereist. Als het gaat om het geloof in eigen kunnen lijkt het dat een geringere mate van dat geloof studenten aanzet om harder te werken wat resulteert in een betere beheersing. Reflecteren op leren is ook van belang. Dit type reflectie voegt meerwaarde toe aan de richtlijnen, omdat daar de aandacht vooral uitgaat naar reflectie op de uitvoering van de taken. De resterende variabelen zijn waarschijnlijk te relateren aan andere variabelen dan interactie en verwerving van competentie. Het maakt het theoretische kader voor werkplekleren complexer dan gepresenteerd. Het is ook mogelijk dat de geselecteerde variabelen andere soorten competenties beïnvloeden dan geformuleerd voor de experimenten. Een andere interessante bevinding uit een van de experimenten is de invloed van 'targets' die een bedrijf oplegt aan medewerkers $\left(\mathrm{R}^{2}=.48\right)$. In onderzoek naar informeel leren is al gewezen op het belang van eisen die een organisatie stelt en de noodzaak medewerkers aan deze eisen bloot te stellen. Deze eisen hebben echter niet voor elke werknemer een positieve uitwerking. Werknemers die aangeven zich helemaal niet te laten leiden door targets dan wel erg veel druk voelen door die targets leren minder.

Het onderzoeksmodel bevatte ook begeleiderkenmerken. Ervaring in begeleiden, werkervaring, voorbereiding op de komst van de student en leeftijd beïnvloeden allemaal interactie dan wel verklaren variantie in beheersing van beroepsrelevante competenties. Studenten van jonge, minder ervaren begeleiders beheersten de competenties beter dan studenten van de oudere, meer ervaren begeleiders. Begeleiders met weinig ervaring reflecteren waarschijnlijk meer op hun manier van interactie in hun speurtocht naar een effectieve manier. Verder hebben jonge begeleiders recentelijk hun opleiding afgerond. Hun eigen ervaringen met werkplekleren en hun kennis van de huidige opleidingsprogramma's helpt hen waarschijnlijk om op een passende manier te interacteren met hun student. De oudere begeleiders hebben waarschijnlijk een grotere ervaringsconcentratie die de bereidheid en de bekwaamheid tot leren en toepassing van iets nieuws in negatieve zin beïnvloedt. Een andere bevinding uit de experimenten is dat de beheersing baat had bij goed voorbereide begeleiders. De experimenten lieten ook zien dat de focus van de interactie afhangt van de functie van de begeleider. Managers richten zich meer op het functioneren in algemene zin. Begeleiders op de werkvloer die meedraaien in de werkprocessen waarin ook de studenten zitten, richten zich in hun interactie vooral op de taken binnen die processen. Met het oog op het realiseren van hoogwaardige interactie gericht op de uitvoering van taken en de participatie 
van studenten in werkprocessen is de laatste groep een interessante. Deze begeleiders weten wat dat werkelijk vraagt.

De experimenten lieten zien dat er ook een opleidingskenmerk is dat er toe doet. Het betreft de leerweg in het middelbaar beroepsonderwijs. De beide leerwegen, de beroepsopleidende (schoolse) en de beroepsbegeleidende (duale), resulteren in verschillende mate van beheersing. Het lijkt erop dat studenten in de beroepsopleidende leerweg competenties beter verwerven, omdat participatie in werkprocessen voor hen minder gebruikelijk en vertrouwd is dan hun collega's in de beroepsbegeleidende leerweg of werknemers die al de nodige werkervaring bezitten. Deze laatste groep lijkt gebaat te zijn bij extra interactie om beroepsrelevante competenties te verwerven.

\section{Theoretisch kader en onderzoeksdesign}

De verwerping van de hypothese vraagt ook om een reflectie op het gekozen onderzoeksdesign. Een quasi-experimenteel design maakt het mogelijk om veronderstelde causale relaties te toetsen. Hoewel zo'n design in potentie krachtig is, moet het wel aan een aantal criteria voldoen wil het werkelijk valide en betrouwbaar zijn. In de experimenten zijn de meeste validiteitbedreigers geneutraliseerd of is er gecontroleerd in hoeverre ze zijn opgetreden. Echter om tot significante effecten te komen, moeten experimenten grote aantallen respondenten hebben, willen kleine verschillen tussen experimentele groep en controlegroep significant zijn. Hoewel het aantal begeleiders en studenten gelet op de situaties in het beroepsonderwijs op zich aanzienlijk is, blijkt het toch gering te zijn. Om de kracht van data zo groot mogelijk te maken, zijn in alle experimenten dezelfde meetinstrumenten gebruikt en variabelen gemeten.

Het theoretisch kader en het onderzoeksmodel bevatten controlevariabelen die verwijzen naar werkplek-, begeleider- en studentkenmerken. Aanpassingen zijn nodig. Ten eerste, de genoemde kenmerken beïnvloeden niet alleen interactie, maar ook competentieverwerving. Ten tweede doen ook opleidingskenmerken er toe. Daarnaast zijn er variabelen die noch invloed hebben op interactie noch op competentieverwerving. Het is mogelijk dat de situaties in de experimenten te veel verschillen van de situaties in de empirische studies die voor de review zijn gebruikt. Andere mogelijke verklaringen zijn dat de gekozen variabelen niet eerder samen in een theoretisch kader zijn geplaatst of dat variabelen alleen indirect van invloed zijn op werkplekleren door intermediaire relaties met de andere gekozen variabelen. 


\section{Leerpotentieel van de werkplek}

Hoewel de hypothese is verworpen toonden de experimenten dat studenten beroepsrelevante competenties beter beheersen aan het eind van het experiment. De vraag die dan nog openstaat, is of werkplekleren ondanks de richtlijnen als zodanig waardevol is gelet op de mate van groei van studenten. Van de drie experimenten vertoont alleen het experiment in het ziekenhuis een aanzienlijke groei bij studenten. Het lijkt erop dat groei in positieve zin wordt beïnvloed door intensieve interactie van jonge, minder ervaren maar goed voorbereide begeleiders die het meest van de tijd beschikbaar zijn en die bereid zijn op hun manier van begeleiden te reflecteren. Als dat niet het geval is leveren de studenten het bedrijf extra handen, maar blijven de studenten zelf met lege handen achter. De potentiële kracht van werkplekleren is echter niet in volle omvang gemeten. Verwerving van beroepsrelevante competenties zoals dat voor dit onderzoek is gekozen, is een van de twee metaforen voor het interpreteren van leren (zie ook Figuur 1). Participatie met als doel lid van een werkgemeenschap te worden is een andere. Het betrekken van beide metaforen in het meten van de opbrengsten van werkplekleren is interessant en waardevol. Daarnaast is het relevant vast te stellen wat de benodigde duur van werkplekleren is om deze beide doelen te realiseren. $\mathrm{Nu}$ zijn er percentages opleidingstijd gekozen, die (nog) niet berusten op empirische bevindingen.

\section{Implicaties van het onderzoek}

In dit onderzoek is een theoretisch kader voor werkplekleren ontwikkeld. Daarbinnen is interactie als een cruciale variabele gezien. De gegevens uit de experimenten wijzen in die richting en lijken deze aanname te bevestigen. Aanvullend toonden de experimenten de invloed en effecten van sommige werkplek-, begeleider- en studentkenmerken. Elk van deze typen kenmerken is van belang en moet meegenomen worden als er gezocht wordt naar verklaringen en voorspellingen van werkplekleren.

Het theoretische deel van het onderzoek bestond uit een review die is uitgevoerd om variabelen te selecteren die de effectiviteit van werkplekleren beïnvloeden. Onderzoek met een groter aantal respondenten en in een groter aantal settings is noodzakelijk om te toetsen welke directe en indirecte relaties er tussen variabelen onderling en tussen variabelen en competentieverwerving bestaan. Het theoretische kader omvatte nog geen variabelen die gerelateerd zijn aan de cultuur en het klimaat in bedrijven en die ook van invloed kunnen zijn. Deze witte vlek moet ingevuld worden om het theoretische kader te completeren. Een aanvullende review is dan noodzakelijk. Het onderzoek probeerde ook de effectiviteit van werkplekleren te vergroten via een ontwerpbenadering. De mogelijkheden tot het werkelijk ontwerpen van werkplekleren lijken beperkt 
te zijn en vragen ten minste de volledige samenwerking van bedrijven. Met betrekking tot interactie gelden condities zoals continuitteit in interactie en begeleiders die a) beschikbaar zijn gedurende de gehele periode van werkplekleren, b) weten wat de uitvoering van taken en het participeren in werkprocessen vragen, c) goed voorbereid zijn en d) bereid zijn naar nieuwe manieren van interactie te zoeken in plaats van alleen gericht zijn op de eigen routines. Als deze voorwaarden niet vervuld zijn, zal een betere competentieverwerving slechts zeer beperkt haalbaar zijn.

De bevindingen met betrekking tot competentieverwerving en de potentiële kracht van de richtlijnen maken het toetsen van de geformuleerde hypothese in een onderzoek op grotere schaal interessant. Om de kracht van de gegevens in een nieuw onderzoek te vergroten is een intensievere training van begeleiders in het gebruik van de richtlijnen, het gebruik van meervoudige meetinstrumenten voor competentieverwerving en een intensieve evaluatie van interactie met begeleiders wenselijk. Het is ook interessant om de effecten van het uitzetten van de richtlijnen onder studenten en roc's te meten. Daarnaast leiden de theoretische noties over werkplekleren en de bevindingen in één van de experimenten tot de noodzaak de gelijkwaardigheid van de beide leerwegen in het beroepsonderwijs nog eens kritisch onder de loep te nemen.

Ter afronding. Het onderzoek toonde mogelijkheden tot interactie op de werkplek die nog niet gebruikelijk zijn binnen het beroepsonderwijs. Een van die mogelijkheden is het toedelen van de rol van begeleider aan jonge werknemers met een paar jaar werkervaring die ook de taken uitvoeren die studenten moeten leren. Zij weten wat er bij die uitvoering komt kijken. Zij zijn geholpen met een ondersteunend instrument, zoals de ontwikkelde richtlijnen. Hun collega's moeten ook de beschikking krijgen over zo'n instrument om de kansen op een consistente en vergelijkbare aanpak te vergroten. De praktijkopleider van het leerbedrijf kan fungeren als een sleutelfiguur in het realiseren van die situatie. De oudere, meer ervaren begeleiders zouden in plaats van studentbegeleider de rol van mentor van jonge begeleiders kunnen krijgen. Kenniscentra beroepsonderwijs bedrijfsleven zouden daarnaast moeten investeren in het monitoren van interactieprocessen op de werkplek in combinatie met de mate van groei en de mate van competentieverwerving. Zo'n vorm van monitoring levert informatie op die gebruikt kan worden voor een discussie met de bedrijven over de kwaliteit van werkplekleren. 


\section{References}

ACOA (1999). Een wending naar kerncompetenties: De betekenis van kerncompetenties voor de versterking van de kwalificatiestructuur secundair beroepsonderwijs. 's-Hertogenbosch: ACOA.

Alliger, G. M., \& Janak, E. A. (1989). Kirkpatrick's levels of training criteria: Thirty years later. Personell Psychology, 42, 331-342.

Alliger, G. M., Tannenbaum, S. I., Bennet, J. W., Traver, H., \& Shotland, A. (1997). A meta-analysis of the relations among training criteria. Personell Psychology, 50, 341-358.

Bailey, T. R., Hughes, K. L., \& Moore, D. T. (2004). Working knowledge: Work-based learning and educational reform. New York: Routledge Falmer.

Baldwin, T. T., \& Ford, J. K. (1988). Transfer of training: A review and directions for future research. Personnel Psychology, 41, 63-105.

Bandura, A. (1986). Social foundations of thought and action: A social cognitive theory. Englewood Cliffs, NJ: Prentice-Hall.

Bandura, A. (1997). Self-efficacy: The exercise of control. New York: Freeman and company.

Bastiaens, T. J. (1997). Leren en werken met electronic performance support systems. Enschede: Twente University.

Billett, S. (1999). Guided learning at work. In D. Boud \& J. Garrick (Eds.), Understanding learning at work. (pp. 151-164). London: Routledge.

Billett, S. (2002). Workplace pedagogic practices. Lifelong Learning in Europe, 2002, 2, 94-103.

Blokhuis, F., Jellema, M., \& Nijhof, W. J. (2002). De kwaliteit van de beroepspraktijkvorming: Een onderzoek naar praktijken en ervaringen met de beroepspraktijkvorming bij ROC Eindhoven. Enschede: Universiteit Twente.

Bloom, B. S. (1956). Taxonomy of educational objectives: The classification of educational goals. Handbook 1: The cognitive domain. New York: McKay/Longman.

Blum, F., Hensgen, A., Kloft, C., \& Maichle, U. M. (1995). Erfassung von Handlungskompetenz in den Prüfungen der Industrie- und Handelskammern. Bonn: Institut für Bildungsforschung. 
Boekaerts, M. (1997). Self-regulated learning: A new concept embraced by researchers, policy makers, educators, teachers, and students. Learning and Instruction, 7(2), 161-186.

Boekaerts, M., \& Simons, P. R. J. (1993). Leren en instructie: Psychologie van de leerling en het leerproces. Assen: Dekker \& Van de Vegt.

Bolhuis, S., \& Simons, P. R. J. (1999). Leren en werken. Deventer: Kluwer.

Boreham, N. (2002). Work process knowledge in technological and organizational development. In N. Boreham, R. Samurçay \& M. Fischer (Eds.), Work process knowledge. London: Routledge.

Boshuizen, H. P. A. (2003). Expertise development: The transition between school and work. Inaugural address. Heerlen: Open Universiteit Nederland.

Bosker, R. J., \& Scheerens, J. (1989). Criterion choice, effect size and stability. Three fundamental problems in school effectiveness research. In B. P. M. Creemers, T. Peters \& D. Reynolds (Eds.), School effectiveness and school improvement. Proceedings of the second international congress, Rotterdam 1989. Lisse: Swets \& Zeitlinger.

Boud, D., \& Garrick, J. (1999). Understanding learning at work. London: Routledge.

Bransford, J. D., Brown, A. L., \& Cocking, R. R. (2000). How people learn: Brain, mind, experience, and school: Expanded edition. Washington, D.C.: National Academy Press.

Brown, J. S., Collins, A., \& Duguid, P. (1989). Situated cognition and the culture of learning. Educational Researcher, 18, 32-42.

Bve-Raad. (2002). Feiten en cijfers bve. De Bilt: Bve Raad.

Cheetham, G., \& Chivers, G. (2001). How professionals learn in practice: An investigation of informal learning amongst people working in professions. Journal of European Industrial Training, 25(5), 247-292.

Collins, A., Brown, J. S., \& Newman, S. E. (1989). Cognitive apprenticeship: Teaching the crafts of reading, writing, and mathematics. In L. B. Resnick (Ed.), Knowing, learning, and instruction: Essays in honor of Robert Glaser. Hillsdale, NJ: Erlbaum.

Colquitt, J. A., LePine, J. A., \& Noe, R. A. (2000). Towards an integrative theory of training motivation: A meta-analytic path analysis of 20 years or research. Journal of Applied Psychology, 85(5), 678-707.

Commissie Dualisering. (1993). Beroepsvorming langs vele wegen. Den Haag: Smets \& Hover.

Cook, T. D., \& Campbell, D. T. (1979). Quasi-experimentation: Design \& analysis issues for field settings. Chicago: Rand McNally.

Costa, P. T. J., \& McCrae, R. R. (1992). Revised neo personality inventory (neo-pi-r) and neo five-factor inventory (neo-ffi) professional manual. Odessa, FL: Psychological Assessment Resources. 
Creemers, B. P. M. (1991). Effectieve instructie: Een empirische bijdrage aan de verbetering van het onderwijs in de klas. 's-Gravenhage: S.V.O.

Creemers, B. P. M. (1992). Procesindicatoren: Verklaring en bewaking van kwaliteit. In B. P. M. Creemers \& W. T. J. G. Hoeben (Red.), Indicatoren van onderwijseffectiviteit. Groningen: ICO.

Cronbach, L., \& Snow, R. (1977). Aptitudes and instructional methods: A handbook for research on interactions. New York: Irvington.

Cullen, J., Hadjivassiliou, K., Hamilton, E., Kelleher, J., Sommerlad, E., \& Stern, E. (2002). Review of current pedagogic research and practice in the fields of post-compulsory education and lifelong learning: Final report. Submitted to the economic and social research council by Tavistock institute. London: ESRC.

De Block, A. (1975). Taxonomie van leerdoelen. Antwerpen: Standaard wetenschappelijke uitgeverij.

De Corte, E., Geerligs, C. T., Lagerweij, N. A. J., Peters, J. J., \& Vandenberghe, R. (1981). Beknopte didaxologie. Groningen: Wolters-Noordhoff.

De Jong, J. A. (1995). Opleiden op de werkplek: Een review. Pedagogische Studiën, 72 (1), 9 - 22.

Dehnborstel, P. (1996). Lernorte in der Berufsbildung - konzeptionelle Erweiterungen in der Modellversuchreihe "dezentrales Lernen". In P. Dehnborstel, H. Holz \& H. Novak (Eds.), Neue Lernorte und Lernortkombinationen: Erfahrungen und Erkenntnisse aus dezentralen Berufsbildungskonzepten. Berlin: Bundesinstitut für Berufsbildung.

Den Boer, P., \& Nieuwenhuis, L. (2002). Wendbaar beroepsonderwijs. Wageningen: Stoas Onderzoek.

Den Ouden, M. (1992). Transfer na bedrijfsopleidingen. Een veldonderzoek naar de rol van voornemens, sociale norm, beheersing en sociale steun bij opleidingstransfer. Amsterdam: Thesis Publishers.

De Vries, B. (1988). Het leven en de leer. Een studie naar de verbinding van leren en werken in de stage. Nijmegen: Instituut voor Toegepaste Sociale wetenschappen.

De Vries, B., \& Meijer, F. (1983). Werkend leren in het beroepsonderwijs. Eindrapport van het leerplaatsenproject. Nijmegen: ITS.

Ellström, P. E. (2001). Integrating learning and work: Problems and prospects. Human Resource Development Quarterley, 12(4), 421-434.

Ellström, P. E. (2002). Time and the logic of learning. Lifelong Learning in Europe, 2, 86-93.

Eraut, M. (2000). Non formal learning, implicit learning and tacit knowledge in professional work. In F. Coffield (Ed.), The necessity of informal learning. Bristol: The policy press.

Eraut, M., Maillardet, F., Miller, C., Steadman, S., Ali, A., Blackman, C., et al. (2004). Learning in the first three years of postgraduate employment: Annual Report to ESRC / TLRP. 
Fischer, M., \& Rauner, F. (2002). The implications of work process knowledge for vocational education and training. In N. Boreham, R. Samurçay \& M. Fischer (Eds.), Work process knowledge. London: Routledge.

Fitzpatrick, J. (2001). Nursing work and nurses at work. In C. Velde (Ed), International perspectives on competence in the workplace: Research, policy and practice (pp. 9-25). Dordrecht: Kluwer Academic Publishers.

Frietman, J. (1990). De kwaliteit van de praktijkcomponent in het leerlingwezen. Nijmegen: Instituut voor Toegepaste Sociale wetenschappen.

Garrick, J. (1998). Informal learning in the workplace: Unmasking human resource development. London: Routledge.

Garrick, J. (1999). The dominant discourse of learning at work. In D. Boud, D. \& J. Garrick, (Eds.). Understanding learning at work (pp. 216-231). London: Routledge.

Geertshuis, S., Holmes, M., Geertshuis, H., Clancy, D., \& Bristol, A. (2002). Evaluation of workplace learning. Journal of Workplace Learning, 14(1), 11-18.

Gerber, R. (2001). Learning in small business enterprises. In C. Velde (Ed.), International perspectives on competence in the workplace: Research, policy and practice. Dordrecht: Kluwer Academic Publishers.

Gielen, E. W. M. (1996). Transfer of training in corporate setting: Testing a model. Paper presented at the AHRD Conference 1996.

Glaudé, M.Th. (1997). Werkplek-opleiden als innovatie. Amsterdam: Glaudé.

Gleitman, H. (1991). Psychology (3 ed.). New York: W.W. Norton \& Company.

Gustafson, K., \& Branch, R. (1997). Survey of instructional development models (3rd ed.). Syracuse, New York: Syracuse University.

Hall, G. E., \& Loucks, S. F. (1978). Innovation configurations: Analyzing the adaptations of innovations. Austin (Tex): Research and Development Center for Teacher Education of the University of Texas at Austin.

Harris, R., \& Simons, M. (2001). Workplace trainers in action: Their role in building a training/learning culture. In C. Velde (Ed.), International perspectives on competence in the workplace: Research, policy and practice. Dordrecht: Kluwer Academic Publishers.

Hendriks, A. A. J. (1997). The construction of the five-factor personality inventory (ffpi). Groningen: University of Groningen.

Hermanussen, J., De Jong, J. A., Wierstra, R. F. A., \& Thijssen, J. G. L. (2000). Learning styles in vocational work experience. Journal of Vocational Education Research, 25(4).

Hoekstra, M. R., \&. (1998). Gedragsbë̈nvloeding door cursussen: Een studie naar de effecten van persoons-, cursus- en omgevingskenmerken. Amsterdam: Vrije Universiteit. 
Hoeve, A., \& Nieuwenhuis, L. (2002). Learning in innovation processes, Onderwijs Research Dagen. Antwerpen: Wageningen: Stoas Onderzoek.

Holton III, E. F. (1996). The flawed four-level evaluation model. Human Resource Development Quaterly, 7(1), 5-21.

Illeris, K. (2002). The three dimensions of learning: Contemporary learning theory in the tension field between the cognitive, the emotional and the social. Frederiksberg: Roskilde University Press.

Illeris, K. (2003). Workplace learning and learning theory. Journal of Workplace Learning, 15(4), 167-178.

Illeris, K., \& Andersen, V. N. (2004). Learning in working life. Frederiksberg: Roskilde University Press.

International Personality Item Pool. (2001). A scientific collaboratory for the development of advanced measures of personality and other individual differences. http://ipip.ori.org

Jacobs, R., \& Jones, M. J. (1995). Structured on-the-job training: Unleashing employee expertise in the workplace. San Francisco: Berrett-Koehler.

Janssen-Noordman, A. M. B., \& Van Merriënboer, J. J. G. (2002). Innovatief onderwijs ontwerpen: Via leertaken naar complexe vaardigheden. Groningen/Houten: Wolters-Noordhoff.

JOB (2001). De nieuwe JOB-Norm. Amsterdam: Jongeren Organisatie Beroepsonderwijs.

Jonassen, D.H. (undated). Thinking technology: Toward a constructivist design model. http://ouray.cudenver.edu/ slsanfor/cnstdm.txt

Karasek, R., \& Theorell, R. (1990). Healthy work: Stress, productivity, and the reconstructing of working life. New York: Basic Books.

Keller, J. M. (1983). Motivational design of instruction. In C. M. Reigeluth (Ed.), Instructional-design theories and models: An overview of their current status. Hillsdale, New Jersey: Lawrence Erlbaum Associates.

Kessels, J. W. M. (1996). Succesvol ontwerpen: Curriculumconsistentie in opleidingen. Deventer: Kluwer Bedrijfswetenschappen.

Kirkpatrick, D. L. (1987). Evaluation. In R. L. Craig (Ed.), Training and development handbook: A guide to human resource development (3 ed.). New York: McGraw-Hill Book Company.

Knowles, M. S. (1975). Self-directed learning. Chicago: Follett.

Kolb, D. A. (1984). Experiential learning: Experience as the source of learning and development. Englewood Clifs, NJ: Prentice Hall.

Kolb, D. A. (1985). Learning style inventory 1985: Technical manual. Boston: McBer \& Company.

Koper, R. (2000). Van verandering naar vernieuwing: Onderwijstechnologische grondslagen van elektronische leeromgevingen. Inaugurele reden. Heerlen: Open Universiteit Nederland. 
Kulik, J. A., \& Kulik, C.-L. C. (1988). Timing of feedback and verbal learning. Review of Educational Research, 58(1), 79-97.

Limm, D. H., \& Johnson, S. D. (2002). Trainee perceptions of factors that influence learning transfer. International Journal of Training and Development, 6(1), 36-48.

Lodewijks, J. G. L. C. (1981). Leerstofsequenties: Van conceptueel netwerk naar cognitieve structuur. Tilburg.

Lowyck, J., \& Terwel, J. (2003). Ontwerpen van leeromgevingen. In N. Verloop \& J. Lowyck (Red.), Onderwijskunde: Een kennisbasis voor professionals (pp. 284-329). Groningen/Houten: Wolters-Noordhoff.

Marsick, V. J., \& Volpe, M. (1999). The nature of and need for informal learning. In V. J. Marsick \& M. Volpe (Eds.), Informal learning on the job. Los Angelos: Academy of Human Resource Development.

Marsick, V. J., \& Watkins, K. E. (1990). Informal and incidental learning in the workplace. London: Routledge.

Martin, B. L., \& Reigeluth, C. M. (1999). Affective education and the affective domain: Implications for instructional-design theories and models. In C. M. Reigeluth (Ed.), Instructional-design theories and models: A new paradigm of instructional theory. Mahwah, New Jersey: Lawrence Erlbaum Associates, publishers.

Meijer, K., \& Lucassen, P. (1986). Effectieve stages in het beroepsonderwijs. Stagiairs, docenten en begeleiders aan het woord. 's-Gravenhage: SVO.

Mergel, B. (1998). Instructional design \& learning theories. Saskatchewan: University of Saskatchewan. http://www.usask.ca/education/coursework $/ 802$ papers/mergel/brenda.htm

Ministerie van Onderwijs, Cultuur en Wetenschappen (1996). Wet Educatie en Beroepsonderwijs: De wettekst. NV Sdu: Den Haag.

Mitchell, T. R., \& Larson, J. R. (1987). People in organizations: An introduction to organizational behavior (3 ed.). New York: McGrawHill.

Moerkamp, T., De Bruijn, E., Van der Kuip, I., Onstenk, J., \& Voncken, E. (2000). Krachtige leeromgevingen in het mbo. Amsterdam: SCOKohnstamm Instituut.

Mulder, R. H. (1997). Leren ondernemen: Ontwerpen van praktijkleersituaties voor het beroepsonderwijs. Rotterdam: Erasmus Universiteit.

Nieuwenhuis, A. F. M. (1991). Complexe leerplaatsen in school en bedrijf: Een studie naar de implementatie en effecten van participerend leren in het middelbaar beroepsonderwijs. Groningen: RION.

Nijman, D. J. J. M. (2004). Supporting transfer of training: Effects of the supervisor. Enschede: Twente University. 
Noe, R. A. (1986). Trainees' attributes and attitudes: Neglected influences on training effectiveness. Academy of Management Journal, 11(4), 736749.

Noss, M. (2000). Selbstgesteuertes Lernen am Arbeitsplatz. Wiesbaden: Gabler.

O'Connor, M. C. (1998). Can we trace the "efficacy of social constructivism"? In P. D. Pearson \& A. Iran-Nejad (Eds.), Review of research in education (Vol. 23). Washington: American Educational Research Association.

Oeij, P. R. A., Dhondt, S., \& Wiezer, N. M. (2003). Organisational conditions for low stress risk jobs: Europe's case, fourth interdisciplinary conference on occupational stress and health 'Work stress and health: new challenges in a changing workplace. Toronto.

Onderwijsraad. (2006). Naar meer evidence based onderwijs. Den Haag: Onderwijsraad.

Onstenk, J. H. A. M., Moerkamp, T., Voncken, E., \& Van den Dool, P. C. (1990). Leerprocessen in stages. Amsterdam: SCO-Kohnstamm Instituut.

Onstenk, J., Oudejans, J., \& Tamerus, M. (in press). De rol van de praktijkopleider. In: J. Onstenk \& H. Janmaat (Red.), Samen werken aan werkplekleren: Op weg naar co-makership van scholen en bedrijven.

Pieters, J. M., \& Verschaffel, L. (2003). Beïnvloeden van leerprocessen. In N. Verloop \& J. Lowyck (Red.), Onderwijskunde: Een kennisbasis voor professionals (pp. 250-283). Groningen/Houten: Wolters-Noordhoff.

Poell, R. F. (1998). Organizing work-related learning projects: A network approach. Nijmegen: Katholieke Universiteit Nijmegen.

Poortman, C. L., Nijhof, W. J., \& Nieuwenhuis, L. F. M. (2003). Competence development through workplace learning. Paper presented at the human capital workshop, 15-16 december 2003. Roa: Maastricht university.

Reigeluth, C. M. (1999). What is instructional-design theory and how is it changing? In C. M. Reigeluth (Ed.), Instructional-design theories and models: A new paradigm of instructional theory. Mahwah, New Jersey: Lawrence Erlbaum Associates, publishers.

Reigeluth, C. M., \& Moore, J. (1999). Cognitive education and the cognitive domain. In C. M. Reigeluth (Ed.), Instructional-design theories and models: A new paradigm of instructional theory. Mahwah, New Jersey: Lawrence Erlbaum Associates, publishers.

Russ-Eft, D. (2002). A typology of training design and work environment factors affecting workplace learning and transfer. Human Resource Development Review, 1, 45-65.

Salomon, G., \& Perkins, D. N. (1998). Individual and social aspects of learning. Review of research in education, 23, 1-24. 
Sambrook, S. (2005). Factors influencing the context and process of workrelated learning: synthesizing findings from two research projects. Human Resource Development International, 8(1), 101-119.

Schuman, L. (1996). Perspectives on instruction. http://edweb.sdsu.edu/courses/ edtec540/Perspectives/Perspectives.html

Sfard, A. (1998). On two metaphors for learning and the dangers of choosing just one. Educational Researcher, 27(2), 4-13.

Simons, R. J., Bolhuis, S., \& Onstenk, J. (2000). Leertheoretische visie. In J.Onstenk (Ed.), Op zoek naar een krachtige beroepsgerichte leeromgeving: Fundamenten voor een onderwijsconcept voor de bvesector. 's-Hertogenbosch: CINOP.

Skule, S. (2003). Learning conditions at work: A framework to understand and measure informal learning in the workplace. Paper presented at the 3rd International Conference of Researching Work and Learning, July 25th - 27th. Work and lifelong learning in different contexts. Proceedings Book III. Theme 5: Learning Communities, Tampere, Finland.

Slaats, J. A. M. H. (1999). Reproduceren \& construeren: Leerstijlen van leerlingen in het middelbaar beroepsonderwijs. Tilburg: Katholieke Universiteit Brabant.

Snow, R. (1989). Aptitude-treatment interaction as a framework for research on individual differences in learning. In P. Ackerman, R. J. Sternberg \& R. Glaser (Eds.), Learning and individual differences. New York: W.H. Freeman.

Sternberg, R. J. (2001). Metacognition, abilities, and developing expertise: What makes an expert student? In H. J. Hartman (Ed.), Metacognition in learning and instruction. Dordrecht: Kluwer Academic Publishers.

Straka, G. A. (2000). Conditions promoting self-directed learning at the workplace. Human Resource Development International, 3(2), 241-251.

Straka, G. A. (2001). Lernen unter informellen Bedingungen (informelles Lernen). Begriffsbestimmung, Diskussion in Deutschland, Evaluation und Desiderate.

Straka, G. A. (2004). Informal learning: Genealogy, concepts, antagonisms and questions. Bremen: ITB.

Stuurgroep Evaluatie WEB (2001). De WEB: naar eenvoud en evenwicht: eindrapport van de Stuurgroep Evaluatie WEB. Zoetermeer: Stuurgroep Evaluatie WEB.

Svensson, L., \& Kjellberg, Y. (2001). Learning environments: What are they? In $\mathrm{C}$. Velde (Ed.), International perspectives on competence in the workplace: Research, policy and practice. Dordrecht: Kluwer Academic Publishers.

Swanborn, P. G. (1994). Methoden van sociaal-wetenschappelijk onderzoek: Nieuwe editie. Meppel/Amsterdam: Boom. 
't Hart, H., Van Dijk, J., De Goede, M., Jansen, W., \& Teunissen, J. (2001). Onderzoeksmethoden (5 ed.). Amsterdam: Boom.

Tannenbaum, S. I., Yukl, G., \&. (1992). Training and development in organizations. Annual Review of Psychology, 43, 399-441.

Ten Dam, G. \& Vermunt, J. (2003). De leerling. In N. Verloop \& J. Lowyck (Red): Onderwijskunde: Een kennisbasis voor professionals (pp. 150193). Groningen/Houten: Wolters-Noordhoff.

Teurlings, C., \& Van der Sanden, J. (1999). De werkplek als leeromgeving: Het leren in stages. In J. G. L. C. Lodewijks \& J. M. M. Van der Sanden (Red.), Op de student gericht: Een bundel opstellen over leren en studeren, opgedragen aan prof. dr. L.F.W. De Klerk. Tilburg: Tilburg University Press.

Thijssen, J. G. L. (1996). Leren, leeftijd en loopbaanperspectief. Opleidingsdeelname door oudere personeelsleden als component van human resource development. Deventer: Kluwer Bedrijfswetenschappen.

Toolsema, B. (2003). Werken met competenties: Naar een instrument voor de identificatie van competenties. Enschede: Twente University.

Van Bolhuis-Poortvliet, G.A. \& Snoek, J.P.A. (1996). Reflecteren op stageervaringen. Utrecht: Algemeen Pedagogisch Studiecentrum.

Van Brakel, R.L. (1996). De effectiviteit van bedrijfsopleidingen: meer dan de vier niveaus. De Lier: Academisch Boeken Centrum.

Van der Klink, M. R. (1999). Effectiviteit van werkplek-opleidingen. Enschede: Universiteit Twente.

Van der Sanden, M.M., Hornman, G.E.J.M. \& Teurlings, C.C.J. (Red.) (1996). Zelfstandig leren en de Leittextmethode. Tilburg: Vakgroep Psychologie Katholieke Universiteit Brabant.

Van der Vegt, R. (1978). Opgaven voor implementeren: Implementatieonderzoek als stiefkind? In W. J. Nijhof \& H. K. Oosthoek (Red.), Implementatie in het onderwijs. Bijdragen tot de Onderwijs Researchdagen 1978 (pp. 201-219). 's-Gravenhage: Staatsuitgeverij.

Van der Waals, J. K. (2001). Op eigen kracht. Van managergestuurd naar medewerkergestuurd opleiden en leren. Enschede: Universiteit Twente.

Van Kollenburg, T. (2003). Taakgroepen: Duurzaam verbeteren? Tien jaar praktijkervaring met sociotechnisch organiseren. Eindhoven: Technische Universiteit Eindhoven, Faculteit Technologie Management.

Van Merriënboer, J. J. G., Van der Klink, M. R., \& Hendriks, M. (2002). Competenties: Van complicaties tot compromis: Over schuifjes en begrenzers. Een studie in opdracht van de onderwijsraad. Den Haag: Onderwijsraad.

Van Merriënboer, J. J. G., \& Van Dijk, E. M. A. G. (1998). Use and misuse of taxonomies of learning: Integrated educational goals in computer 
science curricula. In F. Mulder \& T. Van Weet (Eds.), Informatics in higher education. London: Chapman \& Hall.

Van Muijen, J. J. (1994). Organisatiecultuur en organisatieklimaat: De ontwikkeling van een meetinstrument op basis van het 'competingvalues' model. Amsterdam: Vrije Universiteit.

Van Veldhoven, M., \& Meijman, T. (1994). Het meten van psychosociale arbeidsbelasting met een vragenlijst. De vragenlijst beleving en beoordeling van arbeid (vbba). Amsterdam: Nederlands Instituut voor Arbeidsomstandigheden.

Van Woerkom, M. (2003). Critical reflection at work: Bridging individual and organisational learning. Enschede: Twente University.

Vermunt, J. D. H. M. (1992). Leerstijlen en sturen van leerprocessen in het hoger onderwijs. Tilburg: Katholieke Universiteit Brabant.

Visscher-Voerman, J. I. A. (1999). Design approaches in training and education: A reconstructive study. Enschede: University of Twente.

Vygotsky, L. S. (1978). Mind and society: The development of higher mental processes. Cambridge, MA: Harvard University Press.

Weinert, F. E. (2001). Concept of competence: A conceptual clarification. In D. S. Rychen \& L. H. Salganik (Eds.), Defining and selecting key competencies (pp. 45-65). Göttingen: Hogrefe \& Huber.

Wenger, E. (1998). Communities of practice: Learning, meaning, and identity. Cambridge: Cambridge University Press.

Wognum, A.A.M. (1999). Strategische afstemming en effectiviteit van bedrijfsopleidingen. Enschede: Twente University Press.

Wubbels, Th., Van der Werf, G., Simons, R.J., Stevens, L., \& De Jong, T. (2006). Het nieuwe leren: Discussie. Pedagogische Studiën, 83, 74-99.

Yin, R. K. (1984). Case study research: Design and methods. London: Sage Publications Ltd. 


\section{Appendix 1}

\section{Overview of studies used for identifying variables that relate to effectiveness}

\begin{tabular}{|c|c|c|c|c|c|c|c|c|c|c|}
\hline \multirow{2}{*}{\multicolumn{2}{|c|}{ Study }} & \multicolumn{3}{|c|}{$\begin{array}{l}\text { Research } \\
\text { design }\end{array}$} & \multicolumn{3}{|c|}{ Kind of training } & \multicolumn{3}{|c|}{ Variables } \\
\hline & & 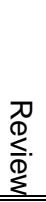 & 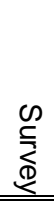 & 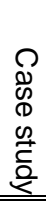 & 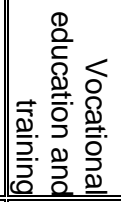 & 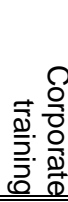 & 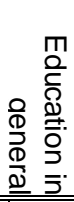 & $\begin{array}{l}\stackrel{0}{c} \\
\stackrel{2}{D} \\
\stackrel{D}{D}\end{array}$ & 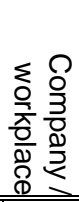 & 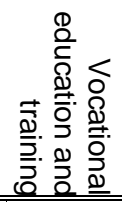 \\
\hline 1 & De Vries \& Meijer (1983) & & $\mathrm{X}$ & & $\bar{X}$ & & & $\mathrm{X}$ & $\bar{X}$ & $\overline{\mathrm{X}}$ \\
\hline 2 & Meijer \& Lucassen (1986) & & $\mathrm{X}$ & & $\mathrm{X}$ & & & $\mathrm{X}$ & $\mathrm{X}$ & $\mathrm{X}$ \\
\hline 3 & Baldwin \& Ford (1988) & $\mathrm{X}$ & & & & $\mathrm{X}$ & & $\mathrm{X}$ & $\mathrm{X}$ & $\mathrm{X}$ \\
\hline 4 & Kulik \& Kulik (1988) & $\mathrm{X}$ & & & & & $\mathrm{X}$ & & & $X$ \\
\hline 5 & De Vries (1988) & & & & $\mathrm{X}$ & & & $\mathrm{X}$ & $\mathrm{X}$ & $\mathrm{X}$ \\
\hline 6 & Collins et al (1989) & $\mathrm{X}$ & & & & & $\mathrm{X}$ & & & $\mathrm{X}$ \\
\hline 7 & Frietman (1990) & & $\mathrm{X}$ & & $\mathrm{X}$ & & & $\mathrm{X}$ & & $\mathrm{X}$ \\
\hline 8 & Onstenk et al (1990) & & & & $\mathrm{X}$ & & & $\mathrm{X}$ & $\mathrm{X}$ & $\mathrm{X}$ \\
\hline 9 & Creemers (1991) & $\mathrm{X}$ & & & & & $\mathrm{X}$ & & & $\mathrm{X}$ \\
\hline 10 & Nieuwenhuis (1991) & & $\mathrm{X}$ & & $\mathrm{X}$ & & & $\mathrm{X}$ & $\mathrm{X}$ & $\mathrm{X}$ \\
\hline 11 & Den Ouden (1992) & & $\mathrm{X}$ & & & $\mathrm{X}$ & & $\mathrm{X}$ & $\mathrm{X}$ & $\mathrm{X}$ \\
\hline 12 & Tannenbaum \& Yukl (1992) & & & & & $\mathrm{X}$ & & $\mathrm{X}$ & $\mathrm{X}$ & $\bar{X}$ \\
\hline 13 & Gielen (1995) & & & $\mathrm{X}$ & & $\mathrm{X}$ & & $\mathrm{X}$ & $\mathrm{X}$ & $X$ \\
\hline 14 & $\begin{array}{l}\text { Van Bolhuis-Poortvliet \& Snoek } \\
\text { (1996) }\end{array}$ & & $\mathrm{X}$ & & $\mathrm{X}$ & & & & & $\mathrm{X}$ \\
\hline 15 & Van Brakel (1996) & $\mathrm{X}$ & & & & $\mathrm{X}$ & & $\mathrm{X}$ & $\mathrm{X}$ & $\mathrm{X}$ \\
\hline 16 & Kessels (1996) & & & $\mathrm{X}$ & & $\mathrm{X}$ & & & $\mathrm{X}$ & $\mathrm{X}$ \\
\hline 17 & Van der Sanden et al (1996) & & & $\mathrm{X}$ & $\mathrm{X}$ & $\mathrm{X}$ & & $\mathrm{X}$ & & $\mathrm{X}$ \\
\hline 18 & Alliger et al (1997) & $\mathrm{X}$ & & & & & & & & \\
\hline 19 & Boekaerts (1997) & & $\mathrm{X}$ & & $\mathrm{X}$ & & & $\mathrm{X}$ & & $\mathrm{X}$ \\
\hline 20 & Glaudé (1997) & $\mathrm{X}$ & & $\mathrm{X}$ & & $\mathrm{X}$ & & & $\mathrm{X}$ & $\mathrm{X}$ \\
\hline 21 & Mulder (1997) & & $\mathrm{X}$ & & $\mathrm{X}$ & & & & $\mathrm{X}$ & $\mathrm{X}$ \\
\hline & Hoekstra (1998) & & & $\mathrm{X}$ & & & & $\mathrm{X}$ & $\mathrm{x}$ & $x$ \\
\hline
\end{tabular}




\begin{tabular}{ll|c|c|c||c|c|c|c|c|c}
\hline 23 & & & $\mathrm{X}$ & & $\mathrm{X}$ & & $\mathrm{X}$ & $\mathrm{X}$ & $\mathrm{X}$ \\
\hline 24 Van der Klink (1999) & $\mathrm{X}$ & & $\mathrm{X}$ & & $\mathrm{X}$ & & $\mathrm{X}$ & $\mathrm{X}$ & $\mathrm{X}$ \\
\hline 25 Slaats (1999) & & $\mathrm{X}$ & & $\mathrm{X}$ & & & $\mathrm{X}$ & & $\mathrm{X}$ \\
\hline 26 Wognum (1999) & & $\mathrm{X}$ & & & $\mathrm{X}$ & & & $\mathrm{X}$ & $\mathrm{X}$ \\
\hline 27 Bransford et al (2000) & $\mathrm{X}$ & & & & & $\mathrm{X}$ & $\mathrm{X}$ & & $\mathrm{X}$ \\
\hline 28 Hermanussen et al (2000) & & $\mathrm{X}$ & & $\mathrm{X}$ & & & $\mathrm{X}$ & & \\
\hline 29 Moerkamp (2000) & & & $\mathrm{X}$ & $\mathrm{X}$ & & & $\mathrm{X}$ & & $\mathrm{X}$ \\
\hline 30 Noss (2000) & & & $\mathrm{X}$ & $\mathrm{X}$ & & & $\mathrm{X}$ & $\mathrm{X}$ & $\mathrm{X}$ \\
\hline 31 Straka (2000) & & $\mathrm{X}$ & & & $\mathrm{X}$ & & $\mathrm{X}$ & $\mathrm{X}$ & \\
\hline 32 Cheetham \& Chivers (2001) & & $\mathrm{X}$ & & & $\mathrm{X}$ & & $\mathrm{X}$ & $\mathrm{X}$ & $\mathrm{X}$ \\
\hline 33 Colquitt et al (2001) & $\mathrm{X}$ & & & & $\mathrm{X}$ & & $\mathrm{X}$ & $\mathrm{X}$ & \\
\hline 34 Fitzpatrick (2001) & $\mathrm{X}$ & & & & $\mathrm{X}$ & & $\mathrm{X}$ & & $\mathrm{X}$ \\
\hline 35 Harris \& Simons (2001) & & $\mathrm{X}$ & & & $\mathrm{X}$ & & & $\mathrm{X}$ & \\
\hline 36 Van der Waals (2001) & & & $\mathrm{X}$ & & $\mathrm{X}$ & & $\mathrm{X}$ & $\mathrm{X}$ & $\mathrm{X}$ \\
\hline 37 Billett (2002) & & & $\mathrm{X}$ & & $\mathrm{X}$ & & & $\mathrm{X}$ & \\
\hline 38 Cullen et al (2002) & $\mathrm{X}$ & & & $\mathrm{X}$ & $\mathrm{X}$ & & $\mathrm{X}$ & $\mathrm{X}$ & $\mathrm{X}$ \\
\hline 39 Geertshuis et al (2002) & & $\mathrm{X}$ & & & $\mathrm{X}$ & & $\mathrm{X}$ & $\mathrm{X}$ & $\mathrm{X}$ \\
\hline 40 Lim \& Johnson (2002) & & $\mathrm{X}$ & & & $\mathrm{X}$ & & $\mathrm{X}$ & $\mathrm{X}$ & $\mathrm{X}$ \\
\hline 41 & Russ-Eft (2002) & $\mathrm{X}$ & & & & $\mathrm{X}$ & & $\mathrm{X}$ & $\mathrm{X}$ & $\mathrm{X}$ \\
\hline 42 Van Woerkom (2002) & $\mathrm{X}$ & $\mathrm{X}$ & & & $\mathrm{X}$ & & $\mathrm{X}$ & & \\
& & & & & & & & & & \\
\hline
\end{tabular}




\section{Appendix 2}

\section{Acquisition of competencies or constituent parts thereof}

\begin{tabular}{|c|c|c|}
\hline \begin{tabular}{|l|} 
Dependent \\
variable
\end{tabular} & Motivation to learn & Source \\
\hline \begin{tabular}{|l|} 
Independent \\
variables
\end{tabular} & $\begin{array}{l}\text { - Valence }(\text { beta }=.54), \text { self-efficacy }(\text { pretraining) } \\
\quad \text { (beta }=.29)(\mathrm{r} 2=.46) \\
\text { - locus of control }(\text { beta }=-.42), \text { anxiety }(\text { beta }=- \\
\quad .35), \text { climate }(\text { beta }=.24), \text { age }(\text { beta }=-.13),(\mathrm{r} 2 \\
\quad=.27) \\
p<.05\end{array}$ & $\begin{array}{l}\text { Colquitt et } \\
\text { al. (2000) }\end{array}$ \\
\hline
\end{tabular}

\begin{tabular}{|l|l|l|}
\hline $\begin{array}{l}\text { Dependent } \\
\text { variable }\end{array}$ & Reaction & Source \\
\hline $\begin{array}{l}\text { Independent } \\
\text { variables }\end{array}$ & $-\quad \begin{array}{l}\text { motivation to learn (beta }=.45)(\mathrm{r} 2=.20) \\
\text { locus of control (beta }=.52), \text { age }(\text { beta }=.23),\end{array}$ & $\begin{array}{l}\text { Colquitt et al. } \\
(2000)\end{array}$ \\
& $p<.05$ & \\
\hline
\end{tabular}

\begin{tabular}{|c|c|c|}
\hline $\begin{array}{l}\text { Dependent } \\
\text { variable }\end{array}$ & Knowledge & Source \\
\hline \multirow[t]{2}{*}{$\begin{array}{l}\text { Independent } \\
\text { variables }\end{array}$} & $\begin{array}{ll}- & \text { Cognitive ability }(\text { beta }=.76), \text { motivation to } \\
& \text { learn }(\text { beta }=.39)(\mathrm{r} 2=.63) \\
\text { - } & \text { Locus of control }(\text { beta }=.51), \text { climate }(\text { beta }= \\
& -.29), \text { anxiety }(\text { beta }=-.25) \text { conscientiousness } \\
& (\text { beta }=-.12), \text { age }(\text { beta }=.08)(\mathrm{r} 2=.24) \\
\mathrm{p}< & .05\end{array}$ & $\begin{array}{l}\text { Colquitt et al. } \\
(2000)\end{array}$ \\
\hline & $\begin{array}{ll}- & \text { Increasing contact with labour organisation } \\
& (\mathrm{r} 2=25 \%)(+) \\
- & \text { Increasing complexity of content }(\mathrm{r} 2=23 \%)(- \\
- & \text { Student characteristics }(\mathrm{r} 2=6-7 \%) \text { : } \\
- & \text { Ethnicity }(+), \text { prior knowledge }(+), \text { gender }(+), \\
& \text { prior education }(+), \text { experience }(-) \\
- & \text { Attitude of student }(\mathrm{r} 2=0 \%) \text { : motivation }(-)\end{array}$ & $\begin{array}{l}\text { Mulder } \\
\text { (1997) }\end{array}$ \\
\hline
\end{tabular}




\begin{tabular}{|c|c|c|}
\hline & $\begin{array}{ll}- & \text { Work experience (path coefficient varies from } \\
.12 \text { to .16) }\end{array}$ & $\begin{array}{l}\text { Nieuwenhuis } \\
\text { (1991) }\end{array}$ \\
\hline & \begin{tabular}{ll}
\multicolumn{2}{l}{ Correlations with Insight in field: } \\
$-\quad$ conversation with colleagues $(.34)$ \\
- & learning attitude $(.31)$ \\
- & variation in work $(.29)$ \\
- & Reality of work $(.30)$ \\
- & support $(.25)$
\end{tabular} & $\begin{array}{l}\text { Meijer \& } \\
\text { Lucassen } \\
(1986)\end{array}$ \\
\hline
\end{tabular}

\begin{tabular}{|c|c|c|}
\hline $\begin{array}{l}\text { Dependent } \\
\text { variable }\end{array}$ & Skills & Source \\
\hline \multirow[t]{3}{*}{$\begin{array}{l}\text { Independent } \\
\text { variables }\end{array}$} & $\begin{array}{ll}- & \text { Cognitive ability }(\text { beta }=.42), \text { motivation to } \\
& \text { learn }(\text { beta }=.22)(r 2=.20) \\
& \text { Anxiety }(\text { beta }=-.35), \text { conscientiousness (beta } \\
& =-.18), \text { age }(\text { beta }=.09)(r 2=.09) \\
\mathrm{p}< & 05\end{array}$ & $\begin{array}{l}\text { Colquitt et al } \\
(2000)\end{array}$ \\
\hline & 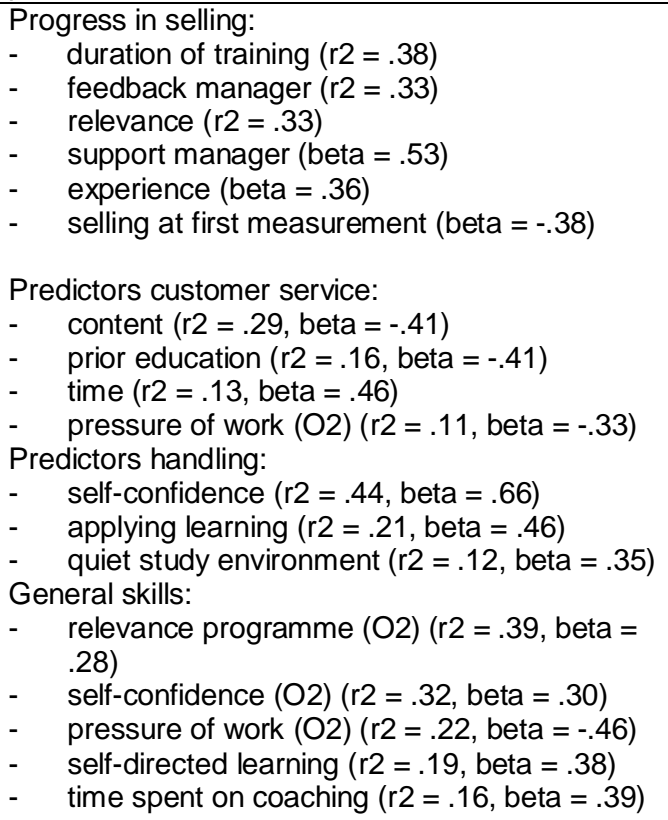 & $\begin{array}{l}\text { Van der } \\
\text { Klink (1999) }\end{array}$ \\
\hline & $\begin{array}{l}\text { Perceived effectiveness: } \\
-\quad \text { kinds of problems and type of programme (r2 } \\
=9 \%) \\
\text { - } \quad \text { form of programme }(\mathrm{r} 2=7 \%) \\
-\quad \text { type of programme }(\mathrm{r} 2=6 \%) \\
-\quad \text { quality of development and performance of } \\
\quad \text { the programme }(\mathrm{r} 2=6 \%) \\
\quad \text { position educational department }(\mathrm{r} 2=5 \%)\end{array}$ & $\begin{array}{l}\text { Wognum } \\
\text { (1999) }\end{array}$ \\
\hline
\end{tabular}




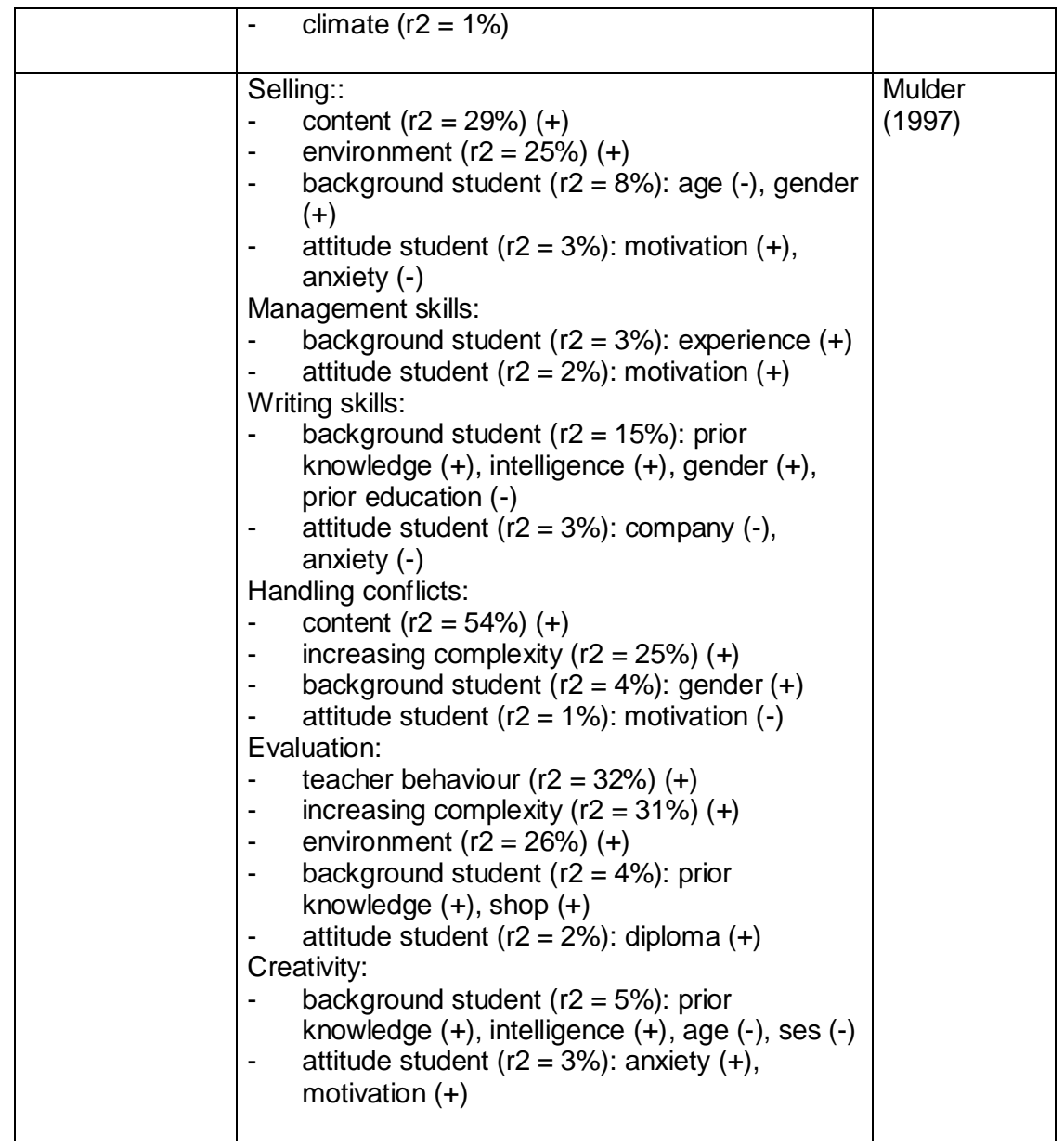

\begin{tabular}{|l|l|l|}
\hline $\begin{array}{l}\text { Dependent } \\
\text { variable }\end{array}$ & Learning results & Source \\
\hline $\begin{array}{l}\text { Independent } \\
\text { variables }\end{array}$ & $\begin{array}{l}\text { Correlations }{ }^{*} \text { alpha }<0.01 \text { or ** alpha < 0.001) } \\
\text { between global outcome scores and perceptions } \\
\text { of the learning process } \\
\text { Global score of learning: } \\
-\quad 0.534^{* *} \text { Was the programme pitched at the } \\
\text { right level? }\end{array}$ & $\begin{array}{l}\text { Geertshuis } \\
\text { et al. (2002) }\end{array}$ \\
& $\begin{array}{l}0.528^{* *} \text { Confidence in learning skills } \\
-0.483^{*} \text { Were you interested in the training? }\end{array}$ & \\
& $-\begin{array}{l}0.477^{* *} \text { Was the interaction with the trainer } \\
\text { good? }\end{array}$ & \\
& $-0.446^{* *}$ Level of motivation \\
& $0.424^{*}$ Did you learn in a way that suited & \\
\hline
\end{tabular}




\begin{tabular}{|c|c|c|}
\hline & $\begin{array}{l}\text { you? } \\
\text { Correlations }{ }^{*} \text { alpha }<0.01 \text { or } * * \text { alpha }<0.001 \text { ) } \\
\text { between global outcome scores and perceptions } \\
\text { of variables extrinsic to the learning process: } \\
\text { Total learning score: } \\
-\quad 0.570^{* *} \text { attitude of colleagues } \\
-\quad 0.476^{* *} \text { attitude of your boss } \\
-\quad 0.423^{* *} \text { attitude of helpers/teachers } \\
\text { Total impact of learning on work: } \\
-\quad 0.628^{* *} \text { attitude of colleagues } \\
-\quad 0.533^{* *} \text { attitude of your boss } \\
-\quad 0.390^{*} \text { attitude of family and friends }\end{array}$ & \\
\hline & $\begin{array}{l}\text { Variables that contribute to effectiveness } \\
\text { expressed as z-scores: } \\
-\quad>3 \text { motivation } \\
-\quad>2 \text { initiative } \\
-\quad>1 \text { priority, support, need } \\
-\quad>0 \text { skilled trainer, evaluating behavioural } \\
\text { change, learning organisation, vision, } \\
\text { feedback manager, systematic approach, } \\
\text { timing, self-confidence, challenging work }\end{array}$ & $\begin{array}{l}\text { Van der } \\
\text { Waals (2001) }\end{array}$ \\
\hline & 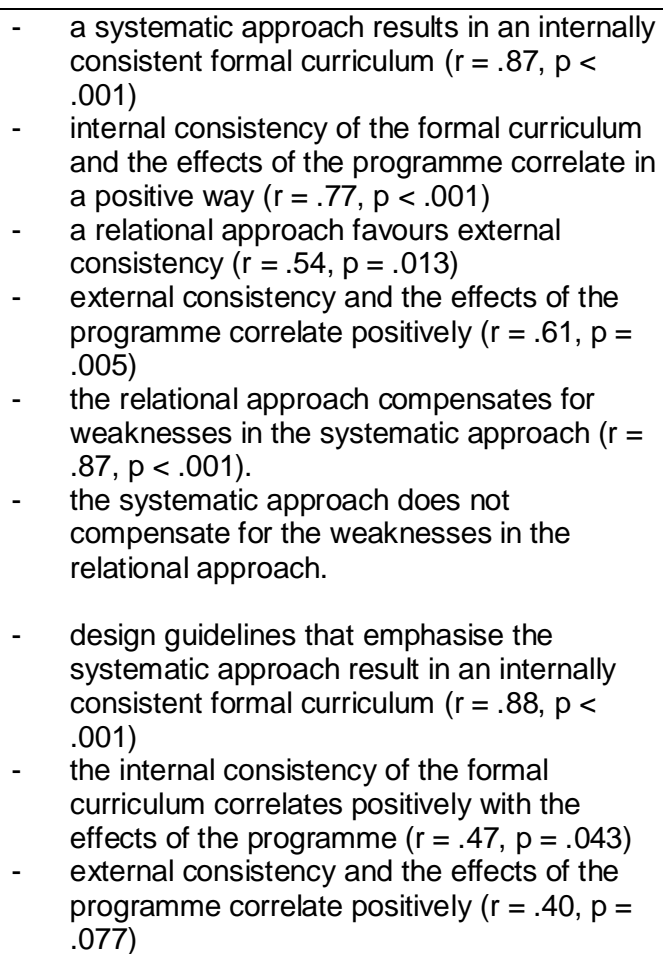 & $\begin{array}{l}\text { Kessels } \\
(1996)\end{array}$ \\
\hline
\end{tabular}




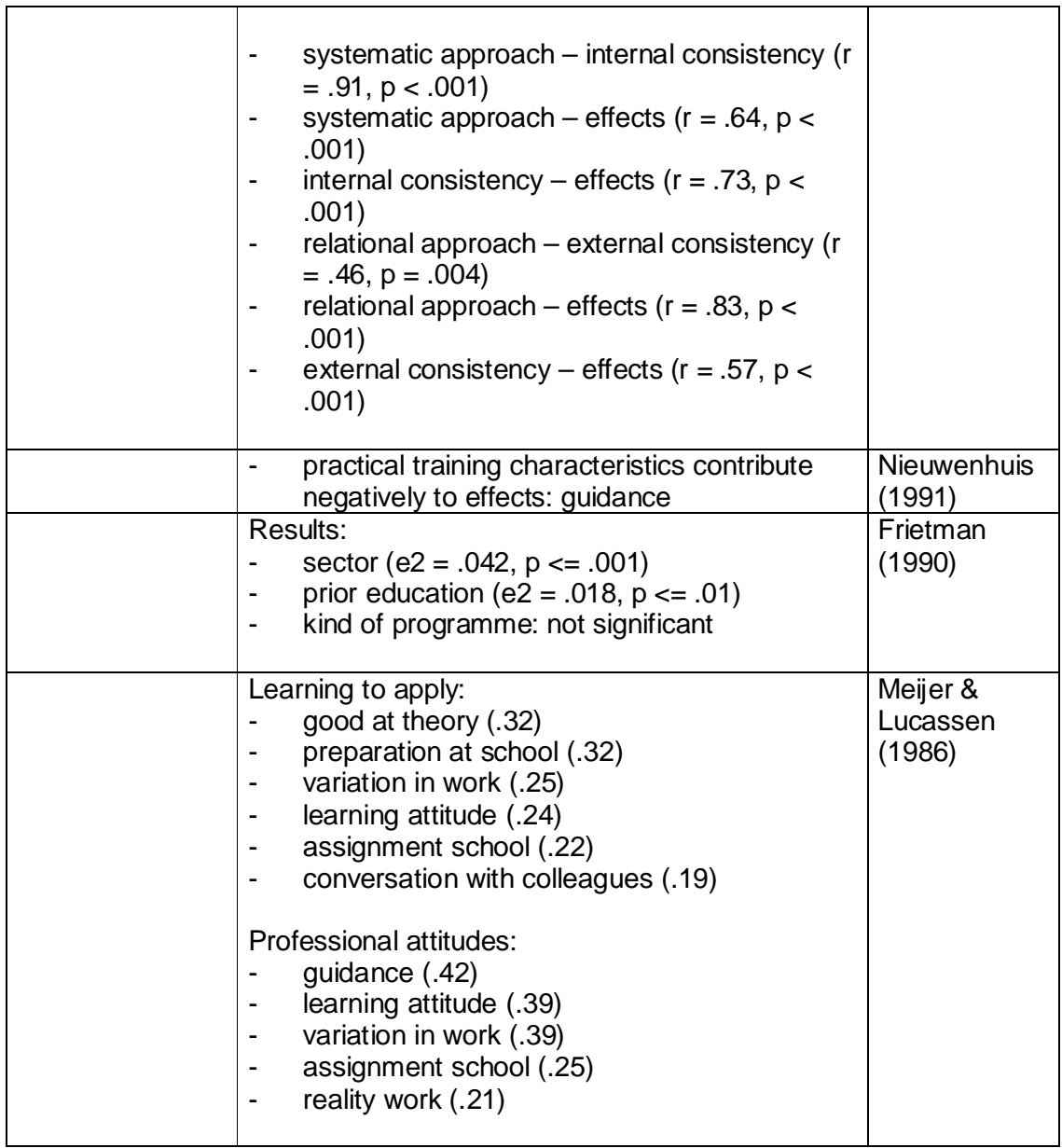

\begin{tabular}{|c|c|c|}
\hline $\begin{array}{l}\text { Dependent } \\
\text { variable }\end{array}$ & Self-efficacy & Source \\
\hline $\begin{array}{l}\text { Independent } \\
\text { variables }\end{array}$ & $\begin{array}{ll}- & \text { task obscurity (beta }=-.32) \\
- & \text { task variation (beta }=.17 \text { and } .30) \\
- & \text { participation (beta }=.18 \text { to } .28) \\
- & \text { task information }(\text { beta }=.24) \\
- & \text { gender (beta }=.17) \\
- & \text { confidence in management }(\text { beta }=.15) \\
- & \text { task autonomy (beta }=.13) \\
& \\
\text { Betas are significant at a } 95 \% \text { reliability interval } \\
\text { Adjusted R-square of predictors }=.28 \text { to } .34\end{array}$ & $\begin{array}{l}\text { Van } \\
\text { Woerkom } \\
\text { (2003) }\end{array}$ \\
\hline & $\begin{array}{ll}- & \text { Cognitive ability }(\text { beta }=.25), \text { motivation to } \\
& \text { learn }(\text { beta }=.22),(\mathrm{r} 2=.09) \\
\text { - } \quad \text { Climate }(\text { beta }=.99), \text { anxiety (beta }=-.75),\end{array}$ & $\begin{array}{l}\text { Colquitt et al. } \\
\text { (2001) }\end{array}$ \\
\hline
\end{tabular}




\begin{tabular}{|l|l|l|}
\hline \multicolumn{1}{|c|}{$\begin{array}{l}\text { locus of control (beta }=-.49), \text { age }(\text { beta }=- \\
\text { 35), conscientiousness }(\text { beta }=.14)(\mathrm{r} 2=.77) \\
\mathrm{p}<.05\end{array}$} & \\
\hline$-\quad \begin{array}{l}\text { Perception of relevance (beta }=.4) \\
-\quad \text { work experience (beta }=.3)\end{array}$ & Gielen (1995) \\
\hline
\end{tabular}

\section{Application of competencies or constituent parts thereof}

\begin{tabular}{|c|c|c|}
\hline $\begin{array}{l}\text { Dependent } \\
\text { variable }\end{array}$ & Transfer & Source \\
\hline \multirow[t]{2}{*}{$\begin{array}{l}\text { Independent } \\
\text { variables }\end{array}$} & $\begin{array}{ll}- & \text { skill acquisition }(\mathrm{beta}=.59,), \text { self-efficacy } \\
& (\text { beta }=.27)(\mathrm{r} 2=.53) \\
\text { - } & \text { conscientiousness }(\text { beta }=.52), \text { locus of } \\
& \text { control (beta }=.41) \text { anxiety }(\text { beta }=.21), \\
& \text { climate (beta }=.12), \text { age (beta }=.09),(\mathrm{r} 2= \\
& .28) \\
\mathrm{p}< & .05\end{array}$ & $\begin{array}{l}\text { Colquitt et al } \\
\text { (2001) }\end{array}$ \\
\hline & $\begin{array}{ll}- & \text { self-confidence }(\text { beta }=.38) \\
- & \text { prior scores on tests }(\mathrm{r} 2=.22 \text { to } .32, \text { beta }=- \\
& .47 \text { to }-.57) \\
- & \text { relevance of programme }(\mathrm{r} 2=.23) \\
- & \text { pressure of work }(\mathrm{r} 2=-.23) \\
- & \text { gender (t-test, } \mathrm{p}=.04)\end{array}$ & $\begin{array}{l}\text { Van der Klink } \\
\text { (1999) }\end{array}$ \\
\hline $\begin{array}{l}\text { Independent } \\
\text { variable }\end{array}$ & Opportunity to perform & Source \\
\hline \begin{tabular}{|l} 
Dependent \\
variables
\end{tabular} & $\begin{array}{ll}- & \text { self-efficacy }(\mathrm{r} 2=.2) \\
- & \text { supervisory support }(\text { beta }=.23)\end{array}$ & Gielen (1995) \\
\hline
\end{tabular}

\begin{tabular}{|c|c|c|}
\hline $\begin{array}{l}\text { Dependent } \\
\text { variable }\end{array}$ & Participation & Source \\
\hline $\begin{array}{l}\text { Independent } \\
\text { variables }\end{array}$ & $\begin{array}{ll}- & \text { Social integration colleagues }(\text { beta }=.81) \\
- & \text { Communication }(\text { beta }=.25) \\
- & \text { Task autonomy }(\text { beta }=.24) \\
- & \text { co-operation }(\text { beta }=.19) \\
- & \text { workplace and workload }(\text { beta }=.13) \\
- & \text { task variation }(\text { beta }=.12) \\
- & \text { confidence in management }(\text { beta }=.12)\end{array}$ & $\begin{array}{l}\text { Van } \\
\text { Woerkom } \\
(2003)\end{array}$ \\
\hline
\end{tabular}




\begin{tabular}{|c|c|c|}
\hline & $\begin{array}{l}\text { Betas are significant at a } 95 \% \text { reliability interval } \\
\text { Adjusted R-square of predictors }=.62 \text { to } .88\end{array}$ & \\
\hline $\begin{array}{l}\text { Dependent } \\
\text { variable }\end{array}$ & Job involvement & Source \\
\hline $\begin{array}{l}\text { Independent } \\
\text { variables }\end{array}$ & $\begin{array}{ll}- & \text { Opportunity to perform }(\text { beta }=.26) \\
- & \text { Learning result }(\text { beta }=.24) \\
- & \text { self-efficacy }(\text { beta }=.1)\end{array}$ & Gielen (1995) \\
\hline
\end{tabular}

\begin{tabular}{|c|c|c|}
\hline $\begin{array}{l}\text { Dependent } \\
\text { variable }\end{array}$ & Job performance / behaviour & Source \\
\hline \multirow[t]{5}{*}{$\begin{array}{l}\text { Independent } \\
\text { variables }\end{array}$} & $\begin{array}{l}\text { Global impact on performance: } \\
-\quad 0.483^{*} \text { Were you interested in the training? } \\
-\quad 0.461^{* *} \text { Confidence in learning skills } \\
-\quad 0.439^{*} \text { Was the programme pitched at the } \\
\text { right level? } \\
0.398^{*} \text { Did you learn in a way that suited } \\
\text { you? } \\
0.367^{*} \text { Was the interaction with the trainer } \\
\text { good? } \\
0.341^{*} \text { Level of motivation } \\
\left.\text { Correlations ( }{ }^{*} \text { alpha }<0.01 \text { or }{ }^{* *} \text { alpha }<0.001\right)\end{array}$ & $\begin{array}{l}\text { Geertshuis et } \\
\text { al. (2002) }\end{array}$ \\
\hline & $\begin{array}{ll}- & \text { Transfer (beta }=.59, \mathrm{r} 2=.35) \\
- & \text { Conscientiousness }(\text { beta }=.31), \text { locus of } \\
\text { control (beta }=.29), \text { anxiety }(\text { beta }=.26)(\mathrm{r} 2= \\
.12) \\
\mathrm{P}<.05\end{array}$ & $\begin{array}{l}\text { Colquitt et al. } \\
(2001)\end{array}$ \\
\hline & $\begin{array}{l}\text { handling: quiet study environment }(\mathrm{r} 2=.54, \\
\text { beta }=.28) \text { self-confidence }(\mathrm{r} 2=.46, \text { beta }= \\
.65) \\
\text { general skills: pressure of work at } \mathrm{O} 2(\mathrm{r} 2= \\
.38, \text { beta }=-.61) \\
\text { customer service: pressure of work at } \mathrm{O} 2(\mathrm{r} 2 \\
=.24, \text { beta }=-.48)\end{array}$ & $\begin{array}{l}\text { Van der Klink } \\
\text { (1999) }\end{array}$ \\
\hline & $\begin{array}{ll}- & \text { opportunity to use influences behaviour. } \\
\text { - } & \text { subjective norm influences behaviour. } \\
\text { - } & \text { self-efficacy influences behaviour indirectly } \\
\text { via social support. } \\
\text { - } \quad \text { self-efficacy influences behaviour indirectly } \\
\text { via opportunity. } \\
\text { - intention influences behaviour indirectly via } \\
\text { social support. } \\
\text { - social support influences behaviour indirectly } \\
\text { via opportunity. }\end{array}$ & \begin{tabular}{|l} 
Hoekstra \\
$(1998)$
\end{tabular} \\
\hline & $\begin{array}{ll}- & \text { opportunity to perform }(\mathrm{r} 2=.25) \\
- & \text { job involvement }(\mathrm{r} 2=.23) \\
- & \text { supervisory support }(\text { beta }=.2)\end{array}$ & Gielen (1995) \\
\hline
\end{tabular}




\begin{tabular}{|c|c|c|}
\hline & $\begin{array}{ll}- & \text { prior behaviour }(\mathrm{r} 2=.48) \\
- & \text { control and behavioural intentions }(\mathrm{r} 2=.05) \\
- & \text { social support and behavioural intentions }(\mathrm{r} 2 \\
& =.04) \\
- & \text { social norm }(\mathrm{r} 2=.02)\end{array}$ & \begin{tabular}{|l} 
Den Ouden \\
(1992)
\end{tabular} \\
\hline
\end{tabular}

\section{Improvement in competencies or constituent parts thereof}

\begin{tabular}{|c|c|c|}
\hline $\begin{array}{l}\text { Dependent } \\
\text { variable }\end{array}$ & Critically reflective work behaviour / reflection & Source \\
\hline \multirow[t]{2}{*}{$\begin{array}{l}\text { Independent } \\
\text { variables }\end{array}$} & $\begin{array}{ll}- & \text { self-efficacy (beta }=.30 \text { to } .41) \\
- & \text { task obscurity (beta }=.38 \text { ) } \\
- & \text { participation (beta }=.17 \text { to } .27) \\
- & \text { task variation (beta }=.12 \text { to } .21 \text { ) } \\
- & \text { variety of experience (beta }=.11 \text { to }-.20) \\
& \\
\text { Betas are significant at a } 95 \% \text { reliability interval } \\
\text { Adjusted R-square of predictors }=.30 \text { to } .31\end{array}$ & $\begin{array}{l}\text { Van } \\
\text { Woerkom } \\
\text { (2003) }\end{array}$ \\
\hline & $\begin{array}{l}\text { methods that are more focused on reflection } \\
\text { do not provide better results ( } F 9,1076=7.11, \\
p=0.000) \\
\text { schools that focus on reflection do not } \\
\text { provide better learning results ( } F 9,1076= \\
6.58, p=0.000) \\
\text { there are significant differences between the } \\
\text { four methods of reflection and their } \\
\text { contribution to realising practical learning } \\
\text { aims }(F 12,1226=11.4, p=0.000):\end{array}$ & $\begin{array}{l}\text { Van Bolhuis- } \\
\text { Poortvliet \& } \\
\text { Snoek (1996) }\end{array}$ \\
\hline
\end{tabular}




\section{Appendix 3}

\section{Guidelines for interaction}

Phase 1: Orienting to the task

Step 1: Select together a task the student wants to learn to execute.

1.1. Ask what task he wants to learn to execute.

1.2. Ask why he wants to learn to execute this particular task.

1.3. Determine together if and when the task can be executed.

Step 2: Talk through together the task the student wants to learn to execute.

2.1. Ask whether he has executed the task before.

2.2. Ask whether he has seen someone else executing the task.

2.3. Ask what he expects of executing the task.

2.4. Ask what he thinks the importance of the task is.

2.5. Ask what he thinks the result of the execution must be.

2.6. Ask what he thinks someone else should pay attention to if they were to executes the task.

2.7. Ask whether the task can be executed in different ways.

2.8. Tell him what is good about the answers. Provide additional information if this is necessary.

Step 3: Determine together what the student already knows and is capable of.

3.1. Ask what he thinks you must know to be able to execute the task.

3.2. Ask what he thinks you must be capable of to execute the task.

3.3. Ask what attitude he thinks you must have for the execution of the task.

3.4. Tell him what is good about the answers. Provide additional information if this is necessary.

3.5. Determine what he already knows and is capable of.

3.6. Ask him what he wants to learn from the task.

Step 4: Discuss together how the student wants to learn to execute the task. 4.1. Ask what he wants to do during working hours.

4.2. Ask what he wants to do before or after working hours and where.

4.3. Ask how he wants to be coached.

4.4. Ask how long and how often he wants to work on the task.

4.5. Ask how he wants to determine whether he has mastered the task.

4.6. Discuss what you feel should be done differently and why.

4.7. Formulate agreements. 
Step 5: Instruct the student to observe the performance of the task at least once.

5.1. Ask what he will pay special attention to.

5.2. Provide additional information if this is necessary.

Phase 2: Preparing for the execution of the task

Step 6: Discuss together the observation of the task.

6.1. Ask what he has noticed.

6.2. Ask whether the execution went as expected.

6.3. Ask what was new/unknown to him and what was familiar.

6.4. Ask what he would have done differently and why.

6.5. Tell him why the task was executed in that way.

Step 7: Prepare together for the execution of the task.

7.1. Choose a way of executing the task that has acceptable risks for him and for others.

7.2. Choose a way of executing the task that will bring a satisfying result.

7.3. Ask him to plan/prepare the execution.

7.4. Tell him what is good about the preparation and what should be done differently.

7.5. Ask whether he thinks he can execute the task correctly and why.

7.6. Tell him who he can rely on should this be necessary.

7.7. Tell him that he is allowed to make a mistake as long as he is willing to learn from it.

7.8. Express confidence in him.

Step 8: Make sure all the student needs to execute the task is available.

8.1. Make sure the necessary materials/tools/... are available.

8.2. Make sure the necessary information is available.

8.3. Make sure there is sufficient time to execute the task.

8.4. Make sure someone is on standby.

8.5. Make sure that the people involved know that the student is going to execute the task.

Phase 3: Supervising the execution of the task and discussing performance

Step 9: Supervise the execution of the task.

9.1. Allow him the initiative.

9.2. Allow him to execute the task as he wants to.

9.3. Let him determine the speed.

9.4. Pay attention to frustration or irritation.

The next guidelines should only be used as long as they do not disturb the execution of the task needlessly.

9.5. Ask him how it is going.

9.6. Express appreciation for what he is doing correctly.

9.7. Supply support if risky situations occur or if it seems he cannot continue the execution. 
Step 10: Discuss performance with the student immediately after execution.

10.1. Ask what he did while executing the task.

10.2. Ask whether the execution went as expected/planned and if not, why not.

10.3. Ask what went well and what did not. Ask about the reasons.

10.4. Ask what surprised him.

10.5. Ask what he thinks of the product/service he delivered.

10.6. Tell him what you saw during the execution.

10.7. Express your opinion about his execution of the task.

10.8. Express appreciation for the positive aspects of the execution.

10.9. Tell him what you would have done differently and why.

10.10. Ask what others could learn from him.

Step 11: Determine together the next steps necessary to learn to execute the task.

11.1. Determine what he has now mastered.

11.2. Determine what he has not yet mastered or what he wants to master better.

11.3. Ask what he wants to do differently from the last time.

11.4. Ask what he wants to do during working hours.

11.5. Ask what he wants to do before or after working hours and where.

11.6. Ask how he wants to be coached.

11.7. Ask how long and how often he wants to work on the task.

11.8. Ask how he wants to determine whether he has mastered the task.

11.9. Discuss what you feel should be done differently and why.

11.10. Formulate agreements.

Phase 4: Improving ability

Step 12: Instruct the student to execute the task a couple of times more.

12.1. Make sure there is variation in locations/people/materials/time/ ...

12.2. Ask him to execute the task in a different way.

12.3. Supervise the execution of the task.

12.4. Discuss performance with the student immediately after execution.

12.5. Determine together the next steps necessary to learn to execute the task.

12.6. Provide increasingly less support. 


\section{Curriculum Vitae}

Franck Blokhuis is a senior researcher at CINOP, the national Centre for the Innovation of Education and Training in the Netherlands. His work is focused on workplace learning and on questions with regard to harmonising labour and education. His interests also include the design and effectiveness of competence-based education. He has conducted numerous projects in the field of vocational education and higher professional education since 1990 and has written several books, chapters and articles on the above-mentioned subjects.

He attended pre-university education from 1975 to 1981 and in 1984 graduated as a primary school teacher. In 1990 he obtained his degree in Educational Science and Technology at the University of Twente and in the same year began work as an educational consultant at CINOP. In 2001 he started his $\mathrm{PhD}$ at the University of Twente, which was part of the research programme 'The learning potential of the workplace', subsidised by the Dutch Foundation for Scientific Research (NWO).

$\mathrm{He}$ is married and has two children.

For more information:

fblokhuis@ cinop.nl 